\title{
Task 3 - Bench-Scale Char Upgrading and Utilization Study
}

\author{
Topical Report
}

August 2, 1989

\author{
By \\ Mahesh C. Jha \\ Robert L. McCormick
}

RECEIVED

FFA 131998

OSTI

Work Performed Under Contract No.: DE-AC21-87MC24268

For

U.S. Department of Energy

Office of Fossil Energy

Federal Energy Technology Center

Morgantown Site

P.O. Box 880

Morgantown, West Virginia 26507-0880

DISTRIBUTION OF THIS DOCUMENT IS UNLIMTTED hh

\author{
By \\ Western Research Institute \\ 365 No. 9th Street \\ Laramie, Wyoming 82071




\section{Disclaimer}

This report was prepared as an account of work sponsored by an agency of the United States Government. Neither the United States Government nor any agency thereof, nor any of their employees, makes any warranty, express or implied, or assumes any legal liability or responsibility for the accuracy, completeness, or usefulness of any information, apparatus, product, or process disclosed, or represents that its use would not infringe privately owned rights. Reference herein to any specific commercial product, process, or service by trade name, trademark, manufacturer, or otherwise does not necessarily constitute or imply its endorsement, recommendation, or favoring by the United States Government or any agency thereof. The views and opinions of authors expressed herein do not necessarily state or reflect those of the United States Government or any agency thereof. 


\section{ABSTRACT}

This report describes the results of the bench-scale char upgrading study conducted as Task 3 of "Development of an Advanced, Continuous Mild Gasification Process for the Production of Coproducts", Contract No. DE-AC21-87MC24268. A process where the char is gasified to produce methane in a first stage reactor was investigated. This methane is then decomposed to produce carbon and hydrogen for recycle in a second stage. The results indicate that both reaction steps are feasible using mild gasification char as the starting feedstock. Conditions for methanation are 700 to $800^{\circ} \mathrm{C}$ and 200 to $400 \mathrm{psig}$. Carbon formation conditions are 1,200 to $1,400^{\circ} \mathrm{C}$ at atmospheric pressure. The carbon produced has properties similar to those of carbons which are commercially marketed as carbon black. 


\section{ACKNOWLEDGEMENTS}

The authors would like to thank the United states Department of Energy's Morgantown Energy Technology Center for funding this work under contract No. DE-AC21-87MC24268. 
1.0. INTRODUCTION . . . . . . . . . . . . . . I 1

2.0. PROCESS BACKGROUND . . . . . . . . . . . . 2

2.1. CHEMISTRY . . . . . . . . . . . . . 2

2.2. THERMODYNAMICS .............. 2

2.3. PROCESS ENGINEERING ........... 4

3.0. DESCRIPTION OF TEST EQUIPMENT . . . . . . . . 6

3.1. CHAR CHARACTERIZATION . . . . . . . . . 6

3.2. ATMOSPHERIC PRESSURE TGA . . . . . . . . . 6

3.3. HIGH PRESSURE TGA . . . . . . . . . . . 6

3.4. MICRO-FIXED-BED REACTOR .......... . 8

3.5. BENCH-SCALE FIXED-BED REACTOR . . . . . . 10

3.6. MULLITE CARBON PRODUCTION REACTOR . . . . 13

3.7. CARBON PRODUCT CHARACTERIZATION ..... 13

4.0. MILD GASIFICATION CHAR CHARACTERIZATION . . . . 16

4.1. VOLATILE MATTER CONTENT . . . . . . . 16

4.2. HEATING VALUE .............. 18

4.3. ELEMENTAL COMPOSITION ........... 18

4.4. SURFACE AREA, PORE STRUCTURE, AND BULK

PROPERTIES ................ . 24

4.5. CHARACTERIZATION BY XRD AND SEM ...... 26

4.6. SUMMARY OF CHAR CHARACTERIZATION RESULTS . • 31

5.0. METHANATION TEST RESUltS . . . . . . . . . . 32

5.1. TECHNICAL BACKGROUND . . . . . . . . . 32

5.1.1. Reaction Kinetics ........ 33

5.1.2. Mechanism ........... 34

5.1.3. Catalytic Gasification...... 34

5.1.4. Hydrogasification Processes . . . 35

5.2. ATMOSPHERIC PRESSURE TGA TESTS ....... 36

5.2.1. Non-Catalytic Gasification.... 36

5.2.2. Catalytic Gasification ...... 37

5.2.3. Char Reactivity Tests ...... 39

5.3. HIGH PRESSURE TGA TESTS . . . . . . . . . 40

5.4. MICRO-FIXED-BED REACTOR TESTS ...... . 40

5.4.1. Data Analysis .......... . 42

5.4.2. Effect of Pressure . . . . . . . 43

5.4.3. Effect of Temperature ....... 43

5.4.4. Effect of Steam .......... 46

5.4.5. Effect of Catalysts ........ 50

5.4.6. Summary ........... 55 
TABLE OF CONTENTS

(Continued)

Page

5.5. BENCH-SCALE FIXED-BED REACTOR TESTS . . . . 60

5.5.1. Preliminary Runs ... . . . . . . 60

5.5.2. Process Variable study with MGT-12

Char . . . . . . . . . . 65

5.5.3. Process Variable study with MGT-9

5.5.4. Results of Catalytic Gasification

Runs . . . . ......... . 80

5.5.5. Bench-scale Char Reactivity study: 83

5.5.6. Analysis of spent Chars ...... 89

5.5.7. Summary .............. . 94

5.6. OVERALL SUMMARY OF METHANATION TEST
RESULTS . . . . . . . . . . . . . . . 94

6.0. CARBON FORMATION TEST RESULTS . . . . . . . . . . 95

6.1. TECHNICAL BACKGROUND . . . . . . . . . . 95

6.1.1. Mechanism of Carbon Formation . . . 95

6.1.2. Properties and structure of Carbon

6.1.3. Blacks : •. . . . • . . . 96

6.2. MULIITE CARBON PRODUCTION REACTOR TESTS * . 97

6.3. PROPERTIES OF CARBON PRODUCT . . . . . . . . . 99

6.3.1. Particle Size and Distribution. . . 99

6.3.2. Elemental Analysis......... 100

6.3.3. Surface Area ............ 100

6.3.4. Carbon Particle and Agglomerate

6.4. SUMMARY OF CARBON With Commercial Carbons - 105

7.0. SIGNIFICANCE OF RESULTS . . . . . . . . . . . 106

7.1. PROCESS FEASIBILITY . . . . . . . . . 106

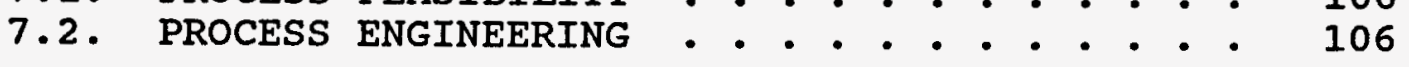

8.0. CONCLUSIONS . . . . . . . . . . . 108

9.0. REFERENCES ....................... . . 109

APPENDIX A
THERMAL GRAVIMETRIC ANALYSIS OF MILD GASIFICATION

CHAR . . . . . . . .

APPENDIX B

PORE SIZE DISTRIBUTIONS FOR MILD GASIFICATION

CHARS. 
TABLE OF CONTENTS

(Continued)

Page

APPENDIX C

RESULTS OF MICRO-FIXED-BED GASIFICATION TESTS • • 128

APPENDIX D

RESULTS OF BENCH-SCALE CHAR GASIFICATION TESTS • • 149

APPENDIX $\mathbf{E}$

PORE SIZE DISTRIBUTIONS FOR SPENT CHARS • • • • . 177 


\section{LIST OF TABLES}

Page

Table 1. Conditions for Mild Gasification Runs . • . 7

Table 2. Proximate Analyses and Heating Values of Mild Gasification Chars ... . . . . . . 16

Table 3. Ultimate Analyses of Mild Gasification Chars..... . . . . . . . . . . 21

Table 4. Proximate and Ultimate Analyses of Eagle Butte Coal ................. 22

Table 5. Sulfur and Nitrogen-to-Ash Ratios for Coal and Chars... . . . . . . . . . . . 22

Table 6. Metals Analyses of Mild Gasification Chars . 23

Table 7. Miscellaneous Properties of Mild Gasification Chars.................. . 24

Table 8. X-ray Powder Diffraction Results for Mild Gasification Chars .. . . . . . . . 27

Table 9. Results of Non-Catalytic, Atmospheric Pressure TGA Gasification Tests . . . . . . . . . 37

Table 10. Results of Catalyzed, Atmospheric Pressure TGA Gasification Tests ............ . 38

Table 11. Char Reactivities Observed in Atmospheric Pressure TGA Tests .. . . . . . . . . 39

Table 12. Results of High Pressure TGA Gasification Tests . . . . . . . . . . . . . .

Table 13. Results of Micro-Fixed-Bed Non-Catalytic Gasification Tests . . . . . . . . . .

Table 14. Results of Micro-Fixed-Bed Catalytic Gasification Tests . . . . . . . . . .

Table 15. Results of Preliminary Char Gasification Runs with MGT-12 Char . . . . . . . .

Table 16. Results of Char Gasification Process Variable study with MGT-12 Char . . . . . . . .

Table 17. Results of Char Gasification Process Variable study with MGT-9 Char . . . . . . . . 


\section{LIST OF TABLES}

(Continued)

Page

Table 18. Results of Bench-Scale Catalytic Gasification Study . . . . . . . . . . . . . . .

Table 19. Results of Bench-scale Char Reactivity study . . . . . . . . . . . . . . . .

Table 20. Ultimate Analyses of Spent Chars Produced from MGT-12 Char

Table 21. Ultimate Analyses of Spent Chars Produced from MGT-9 Char . . . . . . . . . . . 90

Table 22. Ultimate Analyses of Various Spent Chars . . 90

Table 23. Heteroatom-to-Ash Ratios for Spent Chars . . 92

Table 24. Characterization Results for Various spent Chars . . . . . . . . . . . . . . 92

Table 25. Carbon Formation Experiments Performed in the Mullite Carbon Formation Reactor . . . . 98

Table 26. Properties of Mullite Carbon Formation Reactor Product . . . . . . . . . . . . 


\section{LIST OF FIGURES}

Page

Figure 1. Heat of reaction as a function of

temperature. ...............

Figure 2. Equilibrium gas composition as a function of temperature and pressure. . . . . . . .

Figure 3. Block flow diagram of the char upgrading process. . . . . . . . . . . . . 5

Figure 4. Photograph of the micro-fixed-bed reactor. .

Figure 5. Block flow diagram of the bench-scale, fixedbed gasification reactor system. . . . . .

Figure 6. Photograph of the Haynes alloy tube

Figure 7. Block flow diagram of the mullite carbon production reactor. . . . . . . . . .

Figure 8. Temperature profiles in the mullite carbon production reactor.

Figure 9. Char volatile matter as a function of average bed temperature. . . . . . . .

Figure 10. Char hydrogen and carbon content as a function of average bed temperature. . . . .

Figure 11. H/O mass ratio as a function of average bed temperature and volatile matter content. . .

Figure 12. $\mathrm{S} / \mathrm{ash}$ and $\mathrm{N} / \mathrm{ash}$ ratios as a function of volatile matter content for mild gasification chars. . . . . . . . . . .

Figure 13. Surface area as a function of average bed temperature and volatile matter content. . .

Figure 14. Scanning electron micrographs of MGT-9

char.

Figure 15. Scanning electron micrographs of MGT-12 char.

Figure 16. Energy dispersive X-ray analysis for chars MGT-9 and MGT-12. 


\section{LIST OF FIGURES}

(Continued)

Page

Figure 17. Effect of hydrogen partial pressure on methane formation rates in micro-fixed-bed tests. formation rates in micromixed-bed

Figure 18. Effect of temperature on methane formation rates in micro-fixed-bed tests. . . . . .

Figure 19. Effect of steam on methane formation rates in micro-fixed-bed tests at $700^{\circ} \mathrm{C} . . . . .$.

Figure 20. Effect of steam on methane formation rates in micro-fixed-bed tests at $800^{\circ} \mathrm{C} . . . .$.

Figure 21. Effect of steam on the selectivity to methane. . . . . . . . . . . . . .

Figure 22. Effect of impregnated iron catalyst at

Figure 23. Effect of impregnated iron catalyst at $800^{\circ} \mathrm{C}$

Figure 24. Effect of impregnated iron catalyst and steam on selectivity to methane. . . . . . . .

Figure 25. Effect of physically mixed magnetite catalyst.

Figure 26. Effect of impregnated potassium catalyst at

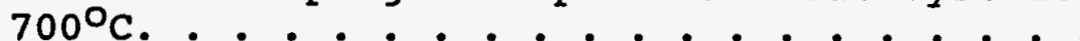

Figure 27. Effect of impregnated potassium catalyst at $800^{\circ} \mathrm{C}$. . . . . . . . . . . . . . .

Figure 28. Effect of impregnated potassium catalyst and steam on selectivity to methane. . . . . . .

Figure 29. Effect of physically mixed potassium carbonate catalyst.

Figure 30. Percent conversion as a function of time on stream for preliminary bench-scale char gasification runs conducted at $900^{\circ} \mathrm{C}$. . . .

Figure 31. Gasification rate as a function of time on stream for preliminary bench-scale char gasification runs conducted at $900^{\circ} \mathrm{C}$. 


\section{LIST OF FIGURES}

(Continued)

Page

Figure 32. Percent conversion as a function of time on stream for preliminary bench-scale char gasification runs conducted at $800^{\circ} \mathrm{C}$. . .

Figure 33. Conversion versus time plots for gasification runs made with MGT-12 char. .

Figure 34. Final conversion as a function of

temperature for gasification runs made with MGT-12 char. . . . . . . . . . . . .

Figure 35. Effect of temperature on gasification rate for runs made at 385 psig with MGT-12 char.

Figure 36. Effect of pressure on conversion for runs made at $750^{\circ} \mathrm{C}$ with MGT-12 char. . . . . 70

Figure 37. Effect of pressure on gasification rate for runs made at $750^{\circ} \mathrm{C}$ with MGT-12 char. . . . 71

Figure 38. Effect of methane partial pressure on conversion.

Figure 39. Effect of methane partial pressure on gasification rate. . . . . . . . . . .

Figure 40. Conversion versus time plots for gasification runs made with MGT-9 char. . . . . . .

Figure 41. Final conversion as a function of temperature for gasification runs made with MGT-9 char.

Figure 42. Effect of temperature on gasification rate for runs made at 385 psig with MGT-9 char. .

Figure 43. Effect of pressure on conversion for runs made at $750^{\circ} \mathrm{C}$ with MGT-9 char. . . . . .

Figure 44. Effect of pressure on gasification rate for runs made at $750^{\circ} \mathrm{C}$ with MGT-9 char. . . .

Figure 45. Effect of potassium carbonate catalyst on conversion at $750^{\circ} \mathrm{C}$ and $285 \mathrm{psig.} \mathrm{.} \mathrm{.} \mathrm{.} \mathrm{.}$

Figure 46. Effect of potassium carbonate catalyst on gasification rate at $750^{\circ} \mathrm{C}$ and $285 \mathrm{psig.} \mathrm{.}$ 


\section{LIST OF FIGURES}

(Continued)

Page

Figure 47. Effect of increased temperature on conversion in potassium carbonate catalyzed gasification. . . . . . . . . . . . .

Figure 48. Effect of sodium carbonate catalyst on conversion at $800^{\circ} \mathrm{C}$ and $285 \mathrm{psig.} \mathrm{.} \mathrm{.} \mathrm{.} \mathrm{.} \mathrm{.}$

Figure 49. Effect of sodium carbonate catalyst on gasification rate at $800^{\circ} \mathrm{C}$ and $285 \mathrm{psig.} \mathrm{.}$

Figure 50. Percent conversion as a function of char volatile matter content for bench-scale gasification tests. . . . . . . . . . .

Figure 51. Percent conversion as a function of char oxygen content for bench-scale gasification tests. . . . . . . . . . . . . . .

Figure 52. Sulfur and nitrogen-to-ash ratios as a function of temperature for spent chars. . .

Figure 53. Surface area and pore volume as a function of conversion for spent chars. . . . . .

Figure 54. Particle size distributions for several carbon black samples. . . . . . . . .

Figure 55. Scanning electron micrograph of carbon produced in Run 7. . . . . . . . . . . 103

Figure 56. Scanning electron micrograph of carbon produced in Run 10. . . . . . . . . . . 103

Figure 57. Scanning electron micrograph of carbon produced in Run 12. . . . . . . . . . .

Figure 58. Scanning electron micrograph of carbon produced in Run 13. ... . . . . . . . 104

Figure 59. Scanning electron micrograph of carbon produced in Run 17. 


\subsection{INTRODUCTION}

Under Contract No. DE-AC21-87MC24268 from DOE/METC, Western Research Institute (WRI) of Laramie, Wyoming, is working with AMAX Research \& Development Center, Golden, Colorado, and Riley Stoker Corporation (RSC), Worcester, Massachusetts, on "Development of an Advanced, Continuous Mild Gasification Process for the Production of coproducts". The project is divided into four tasks:

Task 1. Literature Survey and Market Assessment Task 2. Bench-Scale Mild Gasification study

Task 3. Bench-Scale Char Upgrading/Utilization study

Task 4. System Integration studies

Task 1 was completed in January 1988. The results have been presented in a topical report. 1 The studies performed under Task 1 indicated that the economic viability of the mild gasification process depends mainly on the value of the char, the major product in tonnage. It is crucial that the char be marketed at a premium (higher in value in $\$ / M M$ Btu or equivalent than the parent coal). Several energy and nonenergy applications were investigated in detail.

It was concluded that the most attractive approach is to convert char to carbon. This solid, relatively pure product can be easily marketed in several different industries. Three specific markets have been targeted, based on the market size and the price that the product carbon may command in these markets. These markets are:

- Carbon black for the rubber industry.

- Carbon anodes for aluminum production.

- Carbon as a premium fuel for power production.

WRI has the primary responsibility for performing Task 2, while AMAX has the primary responsibility for performing Task 3, the bench-scale char upgrading study. AMAX has been developing a process to convert char to high purity carbon at the bench-scale. This topical report describes the results obtained in Task 3 and discusses the significance of these results with respect to scale-up and commercialization. 


\subsection{PROCESS BACKGROUND}

Based on an extensive evaluation of char upgrading methods and on potential markets for upgraded char, 1 a char upgrading process was selected. This process involves the formation and decomposition of methane. Technical details are given below.

\subsection{CHEMISTRY}

In the process under development, mild gasification char is first gasified to produce methane:

$$
\mathrm{C}+2 \mathrm{H}_{2} \rightarrow \mathrm{CH}_{4}
$$

Ash and any unreacted carbon is discharged as spent char, a low-grade fuel. Any fine particulates carried over with the gas will be separated using cyclones or filters.

The purified gas is heated to a higher temperature in a second reactor where it decomposes to produce carbon:

$$
\mathrm{CH}_{4} \rightarrow \mathrm{C}+2 \mathrm{H}_{2}
$$

This reaction is the basis for the production of thermal blacks from natural gas in well known processes. 2 The hydrogen will be recycled back to the first reactor where it will react with more char. In actual practice, both the methane-rich and hydrogen-rich gas streams will contain small quantities of impurities such as steam, $\mathrm{H}_{2} \mathrm{~S}$, and other gases.

\subsection{THERMODYNAMICS}

The methane formation reaction is exothermic (about 20 to $25 \mathrm{kcal} / \mathrm{mole}$ ) and the carbon formation reaction is endothermic (about 20 to $25 \mathrm{kcal} / \mathrm{mole}$ ). This heat of reaction varies with temperature, as shown in Figure 1. Figure 2 presents a plot of equilibrium gas composition as a function of temperature and pressure. The thermodynamic data were taken from Smith and Van Ness. 3 The char gasification reaction is favored below about $525^{\circ} \mathrm{C}$ at $1 \mathrm{~atm}$. Carbon deposition from methane is favored at higher temperatures. For the methane formation reaction, there is a change from 2 to 1 mole in the gas phase, indicating that high pressures also favor this reaction. As Figure 2 indicates, the effect of pressure is small relative to the temperature effect. However, high pressure will allow gasification at higher temperatures which will enhance the reaction rate. 

The scientific basis of this process has been described by researchers at Brookhaven National Laboratory. 4 A thermodynamic analysis conducted by Brookhaven indicates that the presence of oxygen-containing gases $\left(\mathrm{H}_{2} \mathrm{O}, \mathrm{CO}_{2}\right.$, or $\left.\mathrm{CO}\right)$ can limit the extent to which temperature and pressure can be used to control methane concentrations. This is particularly true in the methane decomposition stage because at high temperature, carbon monoxide is the thermodynamically favored oxygencontaining species. If oxygen levels are too high in this stage, much of the carbon will be converted to co rather than to elemental carbon.

\subsection{PROCESS ENGINEERING}

A block flow diagram of the process is shown in Figure 3. Mild gasification char is fed via lock hoppers to a pressurized reactor where it is gasified to produce methane. Spent char and fines blow-over are removed and utilized as a low-grade fuel. The heat of reaction is removed by heating a heat transfer fluid in heating coils.

The methane rich product gas is then reduced in pressure and preheated to about $900^{\circ} \mathrm{C}$. At this temperature, methane decomposition is minimal because of slow kinetics. The preheated methane rich gas is then fed to a two-stage indirectly heated reactor system. The two stages cycle between heating and methane decomposition. The process is similar to conventional thermal black technology. ${ }^{2}$ During the heating phase, mild gasification product gas and a purge gas are burned in the reactor. During the methane decomposition phase, the methane rich gas is fed to the heated reactor where it decomposes to carbon and hydrogen. The reactors are cycled rapidly to reduce the temperature variation during methane decomposition.

The carbon formed during methane decomposition consists of very small particles which leave the reactor entrained in the gas phase. The gas is then cooled by a water spray before removal of the carbon particles in bag filters. A bleed stream is taken from the hydrogen rich gas to maintain a constant volume in the loop and avoid the buildup of impurities. This bleed gas is used to heat the methane decomposition reactors. The majority of the hydrogen rich gas is dried and compressed before being recycled to the char gasification reactor to produce more methane. 


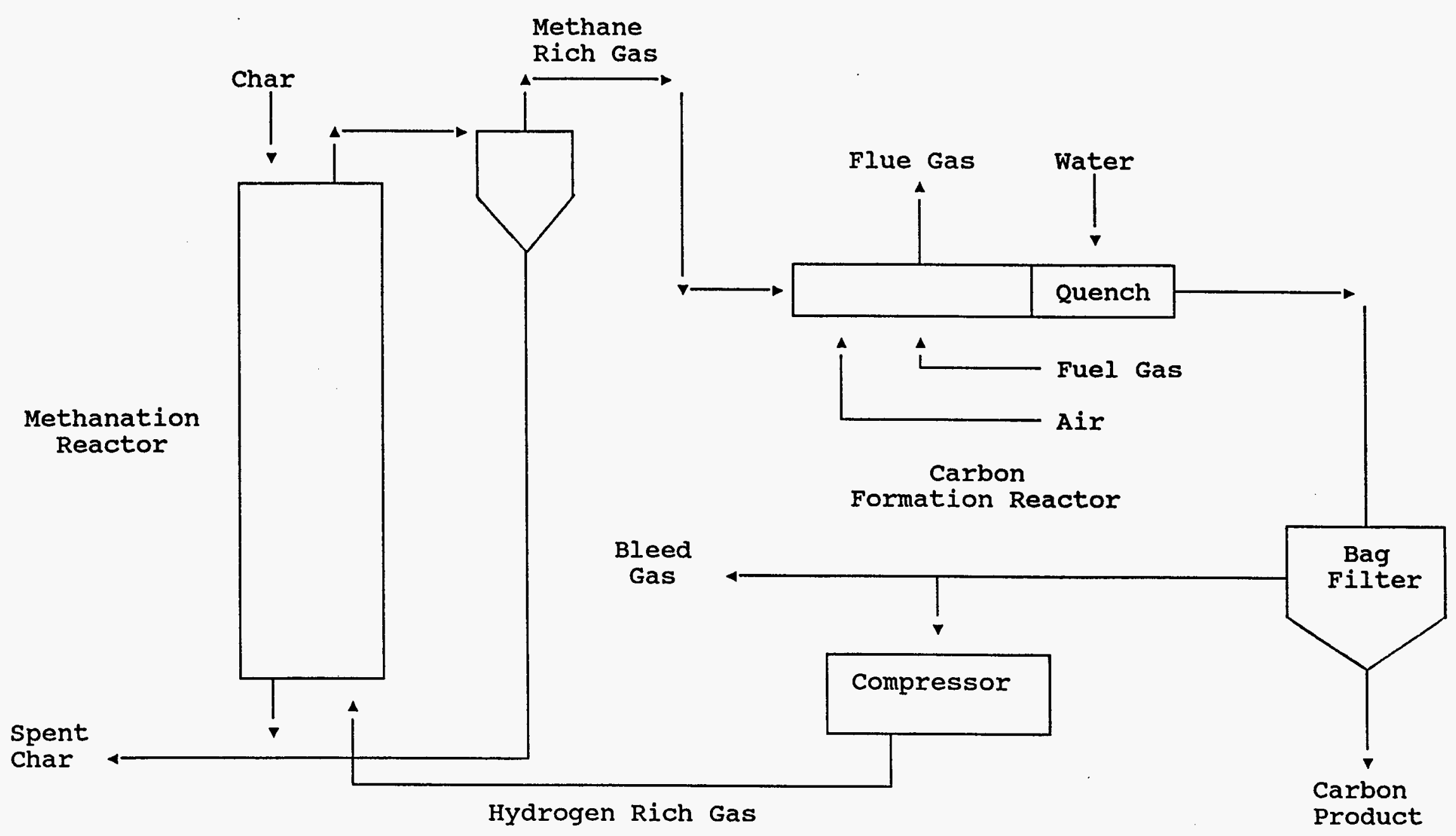

Figure 3. Block flow diagram of char upgrading process. 


\subsection{DESCRIPTION OF TEST EQUIPMENT}

\subsection{CHAR CHARACTERIZATION}

All chars were produced during mild gasification runs conducted under Task 2 in the inclined fluid-bed dryer/mild gasification reactor system at WRI. Run conditions for the 15 chars studied are listed in Table 1. The chars were analyzed to determine chemical composition and physical properties. Proximate and ultimate analyses were conducted by standard methods. Heating values were determined at WRI as gross calorific value in an adiabatic oxygen bomb calorimeter (ASTM D-2015). Combustion properties were also studied thermogravimetrically by Riley stoker. Average particle sizes were determined via a screen analysis and calculated as the surface mean particle diameter. BET surface areas were measured with $\mathrm{N}_{2}$ or $\mathrm{CO}_{2}$ as the adsorbing gas. True density, porosity, and pore size distributions were determined by mercury porosimetry (ASTM C-699). This technique does not measure pores smaller than about $60 \AA$ diameter. Bulk densities were measured using simple pycnometers. Analyses for several metals were performed using atomic absorption spectrometry. $x$-ray powder diffraction (XRD) patterns were obtained on a standard instrument using $\mathrm{Cu}$ $\mathrm{K}_{\alpha}$ radiation. Some chars were observed in the scanning electron microscope (SEM) and analyzed for inorganic content by energy dispersive $\mathrm{X}$-ray analysis.

Spent chars from the bench-scale gasification reactor were also analyzed. Ultimate analyses, $\mathrm{N}_{2}$ BET surface areas, and Xray powder diffraction patterns were obtained for several of these chars.

\subsection{ATMOSPHERIC PRESSURE TGA}

The apparatus used in these gasification experiments was a Setaram Model TGC-85/B-85 TGA with computer data acquisition. The sample hangs in a quartz bucket inside of an approximately 3/4-inch diameter quartz tube. Gas flows were controlled by mass flow controllers $\left(\mathrm{CH}_{4}\right)$ and rotameters $\left(\mathrm{H}_{2}\right.$ and $\left.\mathrm{N}_{2}\right)$. In some experiments, the hydrogen was bubbled through water at $25^{\circ} \mathrm{C}$ to introduce about 3 mole percent steam into the feed gas. In a typical experiment, the sample was loaded into the bucket and weighed under a nitrogen flow of $100 \mathrm{ml} / \mathrm{min}$. The sample was then heated to the reaction temperature as fast as possible (usually about 20 minutes). When the reaction temperature had been achieved, the gas flow was switched to the reactive gases, also flowing at a rate of $100 \mathrm{ml} / \mathrm{min}$. Experiments were continued until it was apparent that no reaction was occurring or until at least 50 percent weight loss.

\subsection{HIGH PRESSURE TGA}

The apparatus used was a Cahn Instruments Model 1000 recording electrobalance equipped with a high pressure reaction 
Table 1. Conditions for Mild Gasification Runs

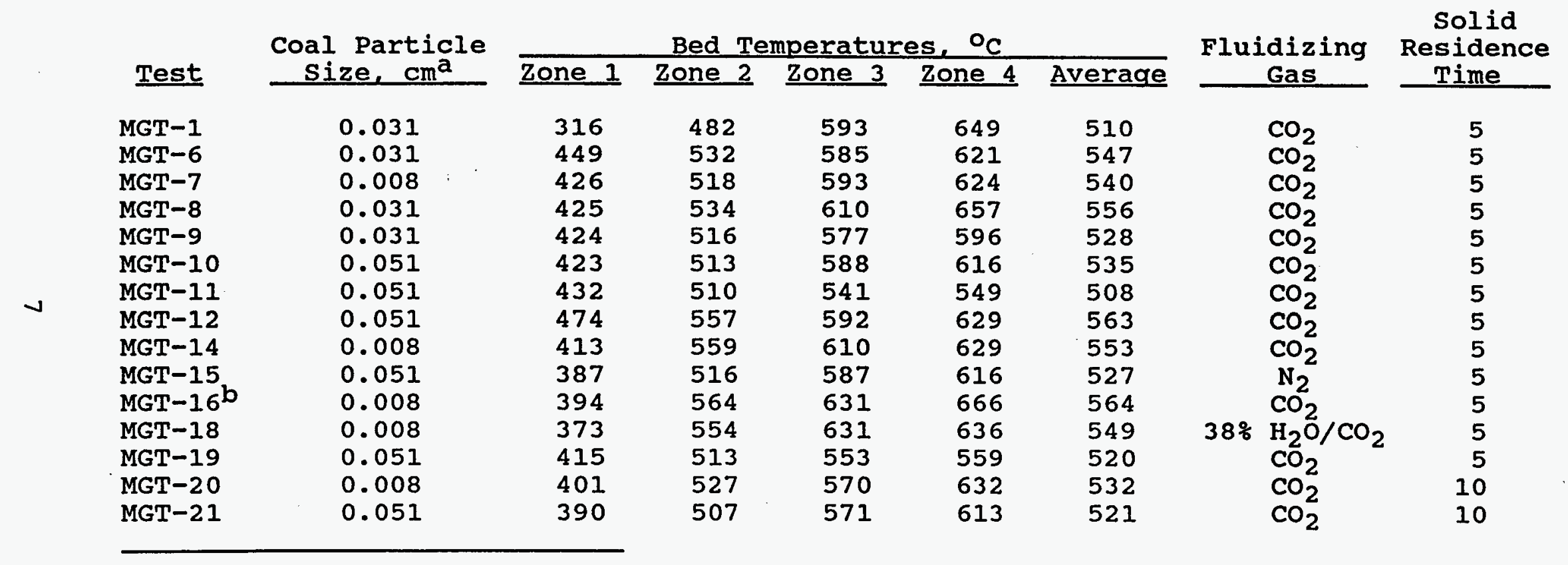

a surface mean particle diameter.

b 2 weight percent $\mathrm{Na}_{2} \mathrm{CO}_{3}-\mathrm{NaHCO}_{3}-2 \mathrm{H}_{2} \mathrm{O}$ mixed with coal feed.

All tests were run using Eagle Butte coal. 
tube. Both gasification and carbon formation experiments were performed. Gases were metered using high pressure mass flow controllers, and steam was injected using a high pressure water pump. Char was weighed on an analytical balance and then loaded into the TGA. A flow of $\mathrm{N}_{2}$ was started, the system was pressurized, and the furnace was turned on. The sample was heated to the reaction temperature at $25^{\circ} \mathrm{C} /$ minute. Reactive gas flows were begun upon reaching the desired reaction temperature.

\subsection{MICRO-FIXED-BED REACTOR}

These gasification experiments were conducted using a 1/2inch diameter tubular reactor which was part of a chemical Data systems micro-pilot plant. A photograph of the reactor vessel is shown in Figure 4. Approximately 5 grams of char in a 4inch long bed was gasified. Feed gases were metered using mass flow controllers. Steam was introduced into the reactant gases by bubbling through water in a heated pressure vessel. In a typical experiment, the reactive gas flow was begun at ambient conditions. After this flow was established, the reactor was pressurized and then rapidly heated to the desired temperature. The product gas flow rate was measured approximately every 5 minutes using a soap bubble flow meter. Product gases were analyzed using gas chromatography and gas composition was used to calculate reaction rates. Runs were continued for several hours with gas analyses every 3 to 10 minutes, depending upon the rapidity of the reaction being studied. Data were analyzed under the assumption of a differential reactor. Because this assumption is only approximately valid for this system, kinetic data must be regarded as qualitative.

Shakedown runs were conducted at different gas flow rates to examine the influence of external diffusion limitations. It was determined there was no advantage to operating at feed gas rates higher than $100 \mathrm{ml} / \mathrm{min}$. The influence of mass transport resistances in individual particles was examined theoretically employing the Thiele modulus and effectiveness factor. 5

The effectiveness factor, $\eta$, is defined as the observed reaction rate divided by the rate which would be observed in the absence of any transport limitations. The effectiveness factor is given by Thiele in correlation charts as a function of the Thiele modulus, $\phi$, which is defined as:

$$
\phi=\frac{\mathrm{R}_{\mathrm{h}}}{3}\left[\frac{\mathrm{k}}{\mathrm{D}_{\mathrm{e}}}\right]^{1 / 2}
$$

for first order, heterogeneous reactions. $R_{h}$ is the hydraulic radius of the particle (equal to $D / 2$ for a sphere), $k$ is the 
reaction rate constant, and $\mathrm{D}_{e}$ is the effective diffusivity. For a $0.03 \mathrm{~cm}$ diameter sphere, the hydraulic radius is 0.015 $\mathrm{cm}$. The assumption of first order for hydrogasification is well supported in the literature. 6 A commonly used rate expression for hydrogasification is:

$$
R=k C_{\mathrm{H} 2}
$$

where $\mathrm{C}_{\mathrm{H} 2}$ is the molar concentration of hydrogen and $\mathrm{R}$ is the reaction rate. Under typical conditions of $750^{\circ} \mathrm{C}$ and $300 \mathrm{psig}$, the methane production rate was around 20 standard $\mathrm{cm}^{3}$ per minute (sccm) in the micro-fixed-bed system. This translates to $4.5 \times 10^{-4}$ moles of $\mathrm{H}_{2} / \mathrm{min}-\mathrm{g}$ carbon. Characterization data (presented in Chapter 4) indicate a typical true density of $1.39 \mathrm{~g} / \mathrm{cm}^{3}$ or $1.11 \mathrm{~g}$ carbon $/ \mathrm{cm}^{3}$ at 80 weight percent carbon. Thus, the reaction rate reaches a value of $8.33 \times 10^{-6}$ moles of $\mathrm{H}_{2} / \mathrm{sec}-\mathrm{cm}^{3}$. At $750^{\circ} \mathrm{C}$ and $300 \mathrm{psig}$, the concentration of hydrogen is $2.43 \times 10^{-4}$ mole $/ \mathrm{cm}^{3}$. 'Substitution of these values into Equation 3.2 produces a rate constant, $k$, of $0.0343 \mathrm{sec}^{-1}$, which is used in Equation 3.1 .

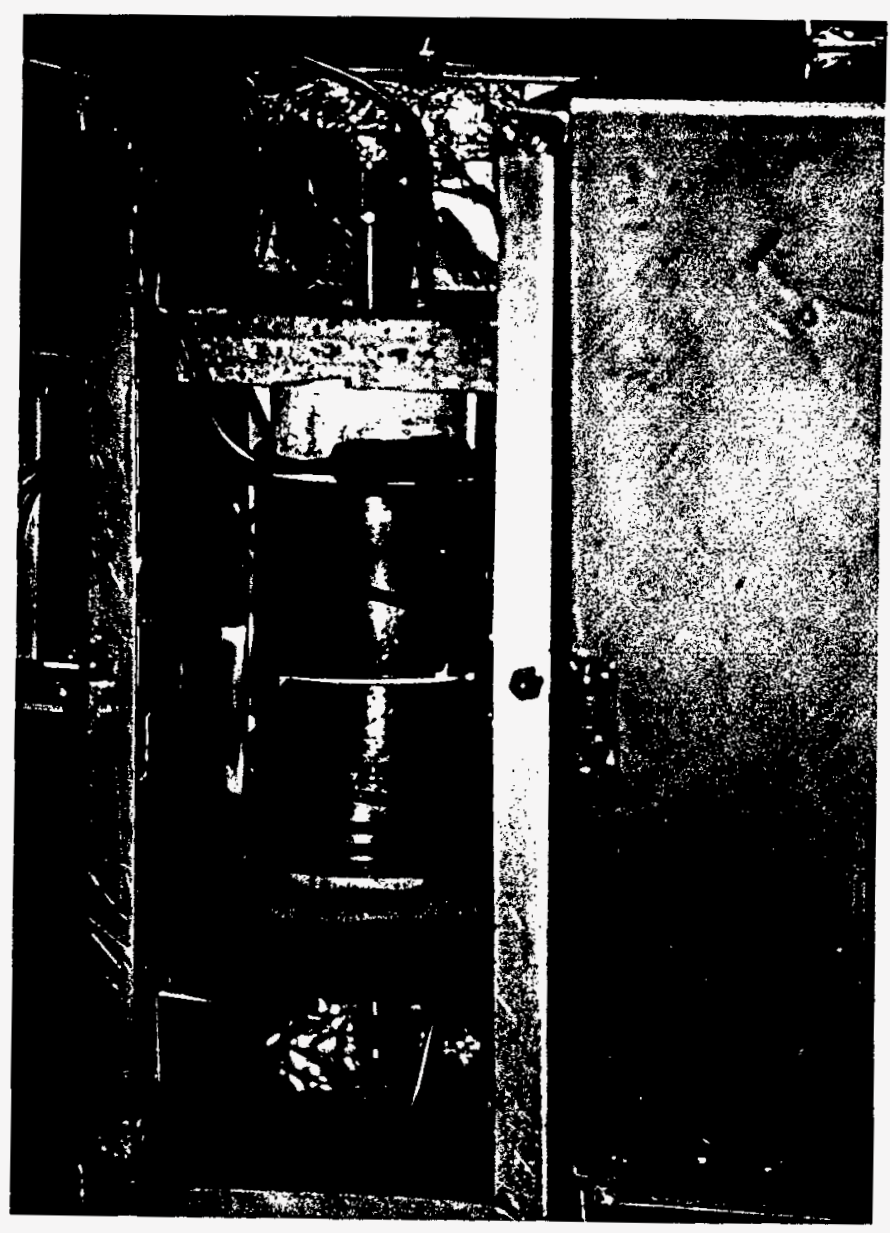

Figure 4. Photograph of the micro-fixed-bed reactor. 
Char characterization data presented in chapter 4 indicate that these chars initially have a very open pore structure dominated by large pores. In this type of system, bulk diffusion occurs rather than Knudsen diffusion. The diffusion coefficient, $\mathrm{D}_{\mathrm{ab}}$, for the binary system $\mathrm{H}_{2}-\mathrm{CH}_{4}$ may be estimated from published correlations. ${ }^{7}$ At $750^{\circ} \mathrm{C}$ and $300 \mathrm{psig}$, $\mathrm{D}_{\mathrm{ab}}$ has a value of $0.222 \mathrm{~cm}^{2} /$ second. The effective diffusivity is related to $\mathrm{D}_{\mathrm{ab}}$ by Equation 3.3:

$$
\mathrm{D}_{\mathrm{e}}=\frac{\epsilon_{\mathrm{p}}}{\tau} \mathrm{D}_{\mathrm{ab}}
$$

where $\epsilon_{\mathrm{p}}$ is the porosity and $\tau$ is the tortuosity factor. 8 The results in chapter 4 indicate that a porosity of 0.21 is typical. Values of the tortuosity ${ }^{8}$ are less than 10, so a value of 10 can be used as a conservative estimate. This yields a value of the effective diffusivity, $D_{e}$, of 0.0047 $\mathrm{cm}^{2} /$ second.

Substitution of these values into Equation 3.1 yields a value of 0.014 for the Thiele modulus. Referring to correlation charts in Reference 5, this corresponds to an effectiveness factor of 1.0 , indicating that diffusion inside the char particles is not a limiting factor at the beginning of a run. During a gasification run, the char pore structure changes as carbon is gasified. This may involve the introduction of smaller pores in which Knudsen diffusion is dominant. If this occurs, diffusion might become a rate limiting factor in the reaction.

\subsection{BENCH-SCALE FIXED-BED REACTOR}

A block flow diagram of this bench-scale gasification system is shown in Figure 5. It consists of a 2-inch diameter fixed-bed reactor that is heated by an electric tube furnace. The reactor vessel itself is a 2 -inch diameter Haynes alloy 25 tube welded to steel flanges at both ends. A photograph of the reactor vessel is shown in Figure 6 . Gases are fed through electronic mass flow controllers. Reactor pressure is regulated with a back pressure regulator. Product gases are sampled with a sampling valve and analyzed by gas

chromatography. Product gases are also continuously monitored for methane via a continuous gas analyzer. Data are logged on a micro-computer.

A run is started by putting a weighed amount of char onto a porous metal plate which supports the char bed. The reactor is then sealed and pressure tested in nitrogen. After the pressure test, a low flow of nitrogen is started, 0.2 standard liter per minute (SLM), and the reactor temperature is raised 


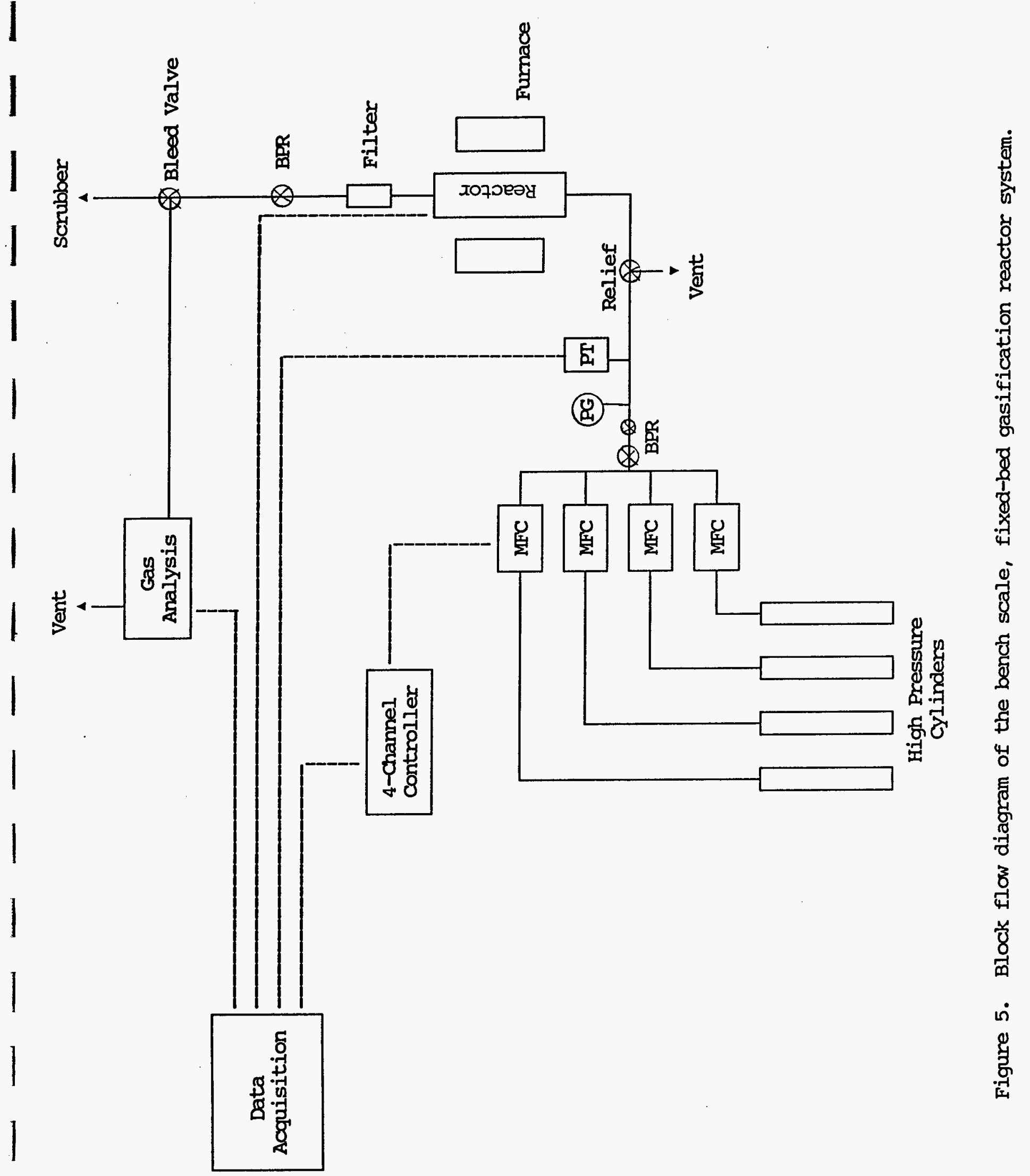

I

. 
to the reaction temperature over the course of about $I$ hour. When the desired temperature is attained, the gas flow is switched to the reactive gases and the run clock is started. Some runs were started with specific char pretreatments which are described in the results section. Product gases are analyzed about every 10 minutes. Runs are usually continued for 4 hours, although longer runs have been conducted. At the end of a run, the unit is flushed with nitrogen and depressurized as it cools to room temperature.

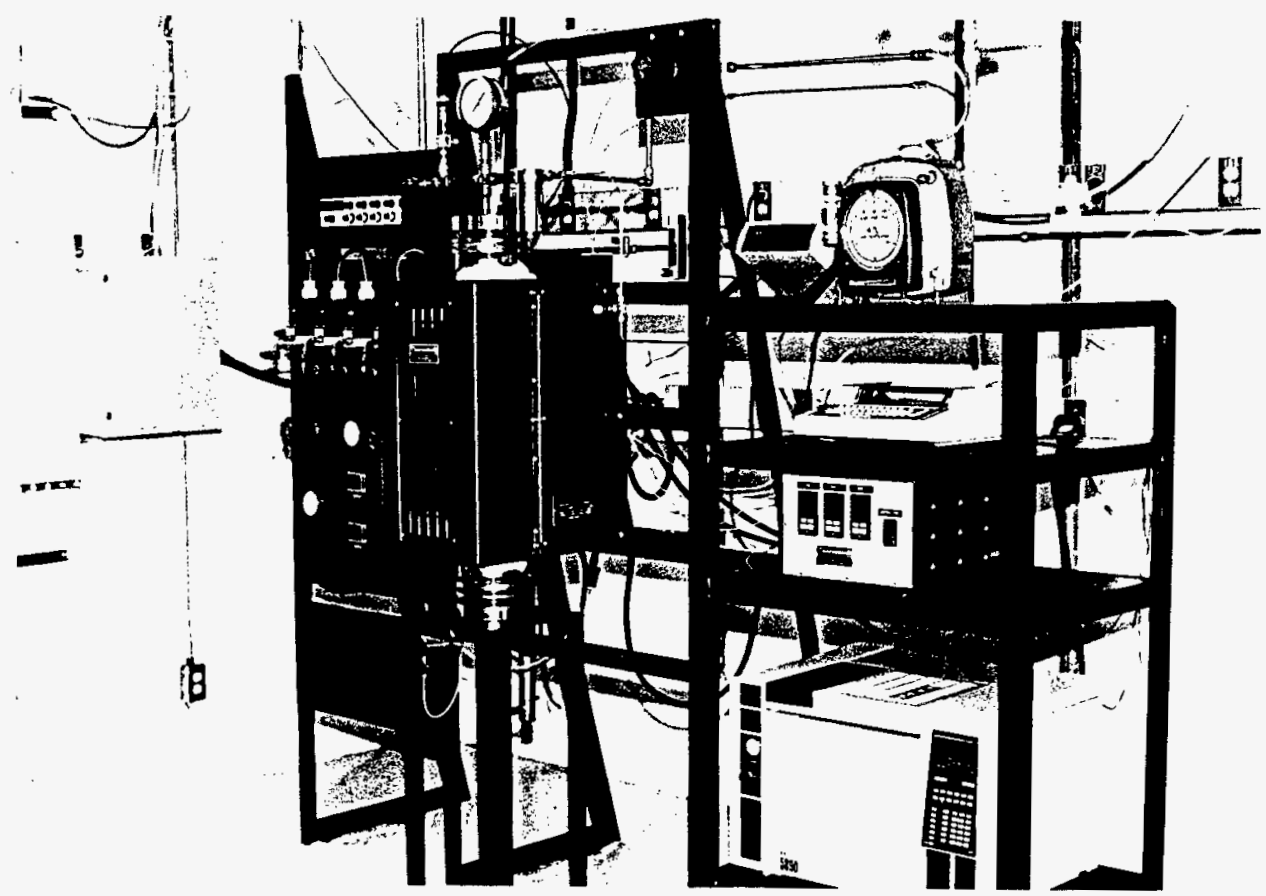

Figure 6. Photograph of the Haynes alloy tube reactor.

Based on preliminary experiments, it was decided that a flow rate of 4.0 SLM was sufficient to avoid external diffusion limitations. A theoretical analysis indicated that under these conditions, pore diffusion inside the individual char particles is not a rate limiting factor at the start of a run. However, in relatively large laboratory scale fixed beds such as the one used here, heat and mass transport effects cannot be ruled out.

Results are reported in terms conversion, $\mathrm{x}$, and $\mathrm{a}$ gasification rate, $\mathrm{dx} / \mathrm{dt}$. The quantity $\mathrm{x}$ is the fractional conversion of the char and is defined as the mass of carbon gasified per initial mass of char (maf). The gasification rate, $d x / d t$, is computed from the exit gas analysis on a per gram of carbon basis. These data are then integrated numerically using the trapezoid rule to produce the conversion 
as a function of time on stream. The results will be discussed in terms of conversion and rate.

\subsection{MULLITE CARBON PRODUCTION REACTOR}

This bench-scale system was used to study carbon production by methane decomposition at high temperatures $(1,200$ to $\left.1,400^{\circ} \mathrm{C}\right)$. A schematic drawing of the system is shown in Figure 7. Feed gases are metered via rotameters. These gases then enter a 1-inch nominal diameter mullite tube which is heated in a high temperature tube furnace. The heated zone is about 6 inches $(15 \mathrm{~cm})$ long. Temperature profiles for this system at various temperatures are shown in Figure 8 . The carbon-containing product gas passes through a double pipe heat exchanger (cooling jacket) and is cooled to below $200^{\circ} \mathrm{C}$ before entering the bag filter where the carbon product is collected. The exit gas flow rate is measured in a soap bubble flow meter. Conversion is calculated from the change in gas volume with reaction. There is some error in this calculation because the temperature of the gas in the soap bubble flow meter is unknown.

\subsection{CARBON PRODUCT CHARACTERIZATION}

The carbon product was analyzed for carbon and hydrogen. One sample was produced in the presence of hydrogen sulfide and analyzed for sulfur. The carbons were also analyzed for particle size and distribution at a commercial laboratory using transmission electron microscopy. Scanning electron micrographs were obtained to evaluate carbon particle morphology. Surface areas were measured by the BET method using nitrogen. 
1

I

I

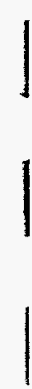

I

I

I

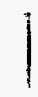

1

I

1
1
1

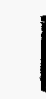

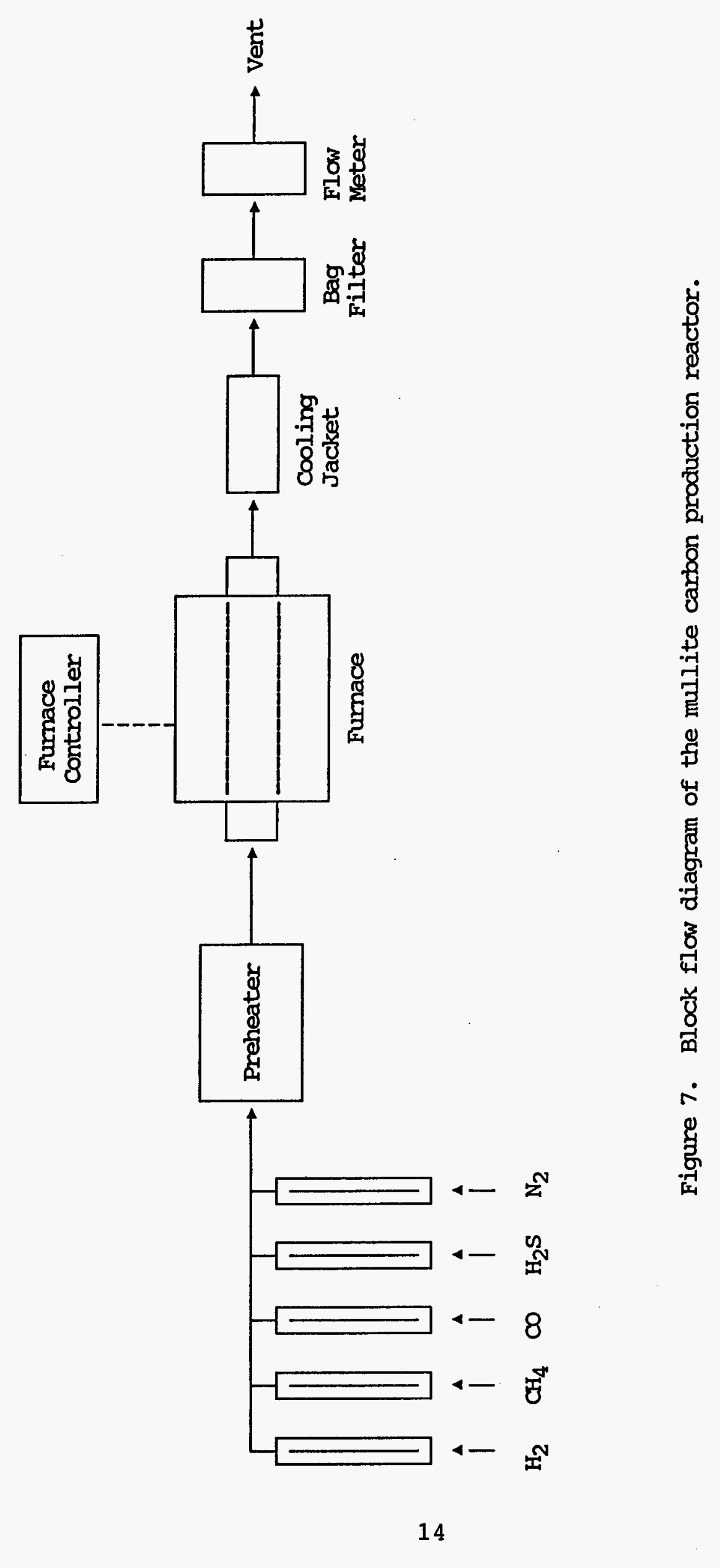


1

।

1

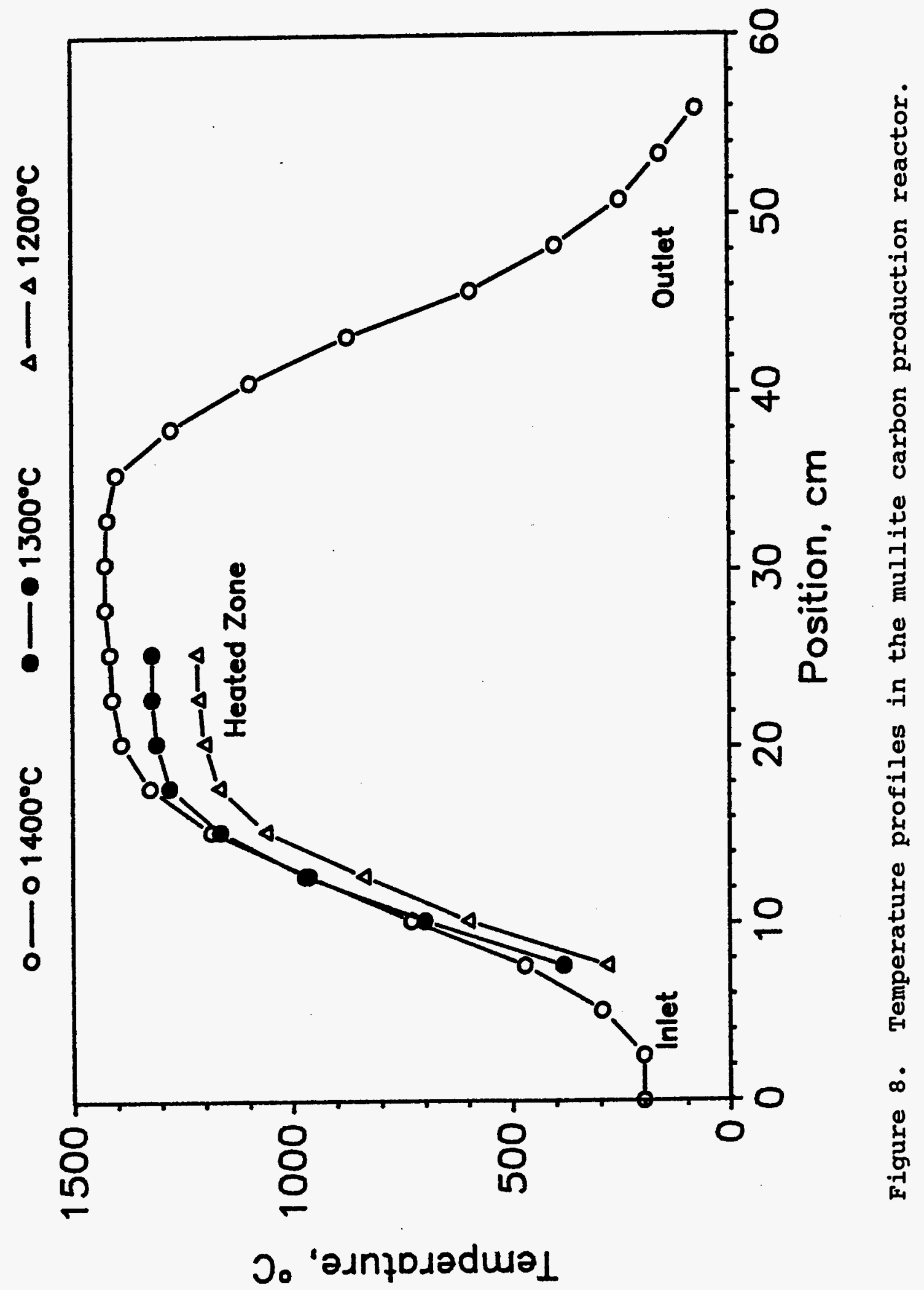




\subsection{MILD GASIFICATION CHAR CHARACTERIZATION}

Chars produced at WRI under Task 2 were characterized to determine the effect of mild gasification processing on char reactivity and conversion. The important processing variables in mild gasification are coal particle size, bed temperature, fluidizing gas, and solids residence time. The data in Table 1 indicate that most runs were conducted using $\mathrm{CO}_{2}$ as the fluidizing gas and with a 5 -minute solids residence time.

\subsection{VOLATILE MATTER CONTENT}

Figure 9 reports the effect of average bed temperature on char volatile matter content. Proximate analyses are reported in Table 2. For a coal particle size of $0.031 \mathrm{~cm}$, increasing the bed temperature reduces the volatile content, as might be expected. This trend is also observed for coal particle size equal to $0.008 \mathrm{~cm}$ (not plotted). However, for a larger coal particle size of $0.051 \mathrm{~cm}$, no apparent trend is observed (Figure 9, right side). It is possible that data for the larger particle size are incorrect because of problems in the run or because the char sample is not representative of char actually produced. The most reasonable conclusion to make at this time is that increasing temperature leads to reduced char volatile matter content.

Table 2. Proximate Analyses and Heating Values of Mild Gasification Chars

\begin{tabular}{|c|c|c|c|}
\hline Test & $\begin{array}{c}\text { Weight \% } \\
\text { Fixed Carbon }\end{array}$ & $\begin{array}{l}\text { Weight } \% \\
\text { Volatile }\end{array}$ & $\begin{array}{l}\text { Heating } \\
\text { Value, } \\
\text { Btu/Ib* }\end{array}$ \\
\hline MGT-1 & 71.7 & 17.7 & -- \\
\hline$M G T-6$ & 74.6 & 16.4 & 12,388 \\
\hline MGT-7 & 75.5 & 15.6 & 12,333 \\
\hline MGT-8 & 76.6 & 13.3 & 12,531 \\
\hline MGT-9 & 74.9 & 16.3 & 12,418 \\
\hline MGT-10 & 71.9 & 19.5 & 12,693 \\
\hline MGT-11 & 73.7 & 17.4 & 12,665 \\
\hline MGT-12 & 75.5 & 15.5 & 12,851 \\
\hline MGT-14 & 77.4 & 13.6 & 12,905 \\
\hline MGT-15 & 75.5 & 15.3 & -- \\
\hline MGT-16 & 72.0 & 16.0 & -- \\
\hline MGT-18 & 77.9 & 11.9 & -- \\
\hline MGT-19 & 76.5 & 13.6 & -- \\
\hline MGT-20 & 78.2 & 11.7 & -- \\
\hline MGT-21 & 79.1 & 11.1 & -- \\
\hline
\end{tabular}

* Gross calorific (heating) value via adiabatic oxygen bomb calorimeter (ASTM D2015). 


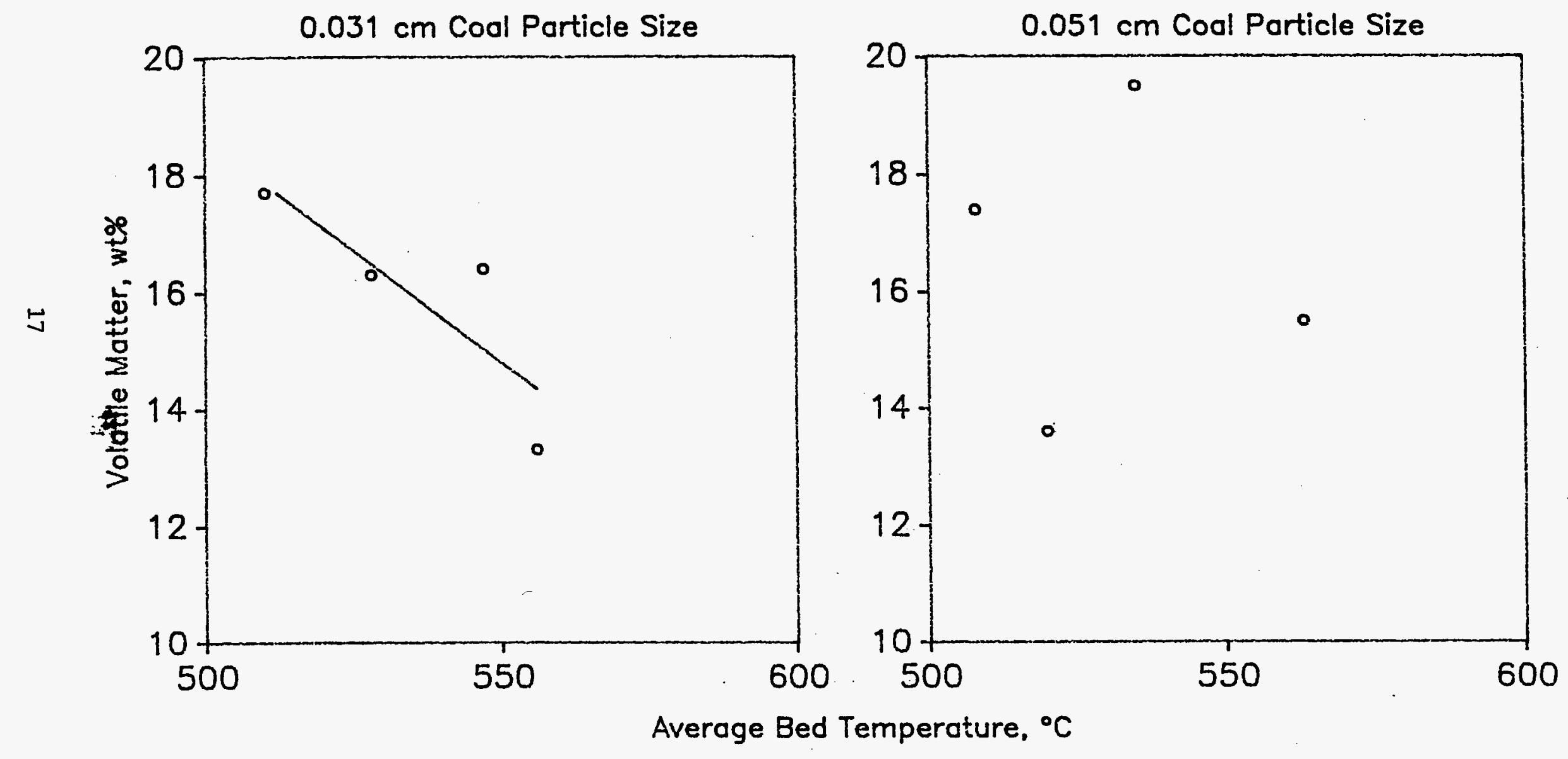

Figure 9. Char volatile matter as a function of average bed temperature. 
Runs 20 and 21 were conducted at a 10-minute residence time. The low volatile matter contents measured for chars from these runs indicate that the volatile content can be reduced by increasing residence time. Run 18 was conducted with 38 percent steam in the fluidizing gas. Runs 7 and 14 were made using the same coal particle size but without steam. Data in Table 2 indicate that the volatile content of the char from Run 18 is significantly lower than observed for Run 7 and 14 chars. This suggests that the use of steam also reduces char volatiles.

\subsection{HEATING VALUE}

Heating values for several chars are also reported in Table 2. They are all in the range of 12,000 to 13,000 Btu/lb. This value seems high enough to give the char significant value for blending with lower Btu coals. The char heating values did not appear to correlate with any other char properties or processing conditions. Char combustion rates were measured by thermal gravimetric analysis and the results are presented in Appendix A. Mild gasification chars were very reactive when compared to other coal chars.

\subsection{ELEMENTAL COMPOSITION}

The effect of bed temperature on char hydrogen and carbon content is shown in Figure 10. Ultimate analyses are reported in Table 3. Increasing temperature serves to reduce hydrogen content. This is consistent with the reduction of volatile matter content with increasing temperature, as the volatiles are relatively rich in hydrogen. There is a great deal of scatter in these data which is not easily explained by particle size effects.

The effect of residence time and fluidizing gas on char hydrogen and carbon content is consistent with the effect on volatile matter content. At higher residence times, volatile matter content and hydrogen content is reduced while carbon content correspondingly increases. The use of steam in the fluidizing gas also reduces volatiles and hydrogen content. The use of nitrogen appears to produce no more devolatilization than using $\mathrm{CO}_{2}$.

The $\mathrm{H} / \mathrm{O}$ ratio is expected to be an important parameter for char upgrading. This is because the oxygen in the char will react with and consume hydrogen in the methanation reactor. The relationship of bed temperature and volatile matter content with the $H / O$ mass ratio is shown in Figure 11 . The $H / O$ ratios are based on direct oxygen analysis and reported in Table 3 . The data suggest that increasing bed temperature reduces the H/O ratio by reducing the hydrogen content, leaving the oxygen with the char. This conclusion is supported by the increase in the $\mathrm{H} / \mathrm{O}$ ratio with the volatile matter content, also shown in Figure 11. The effect of residence time and fluidizing gas on 


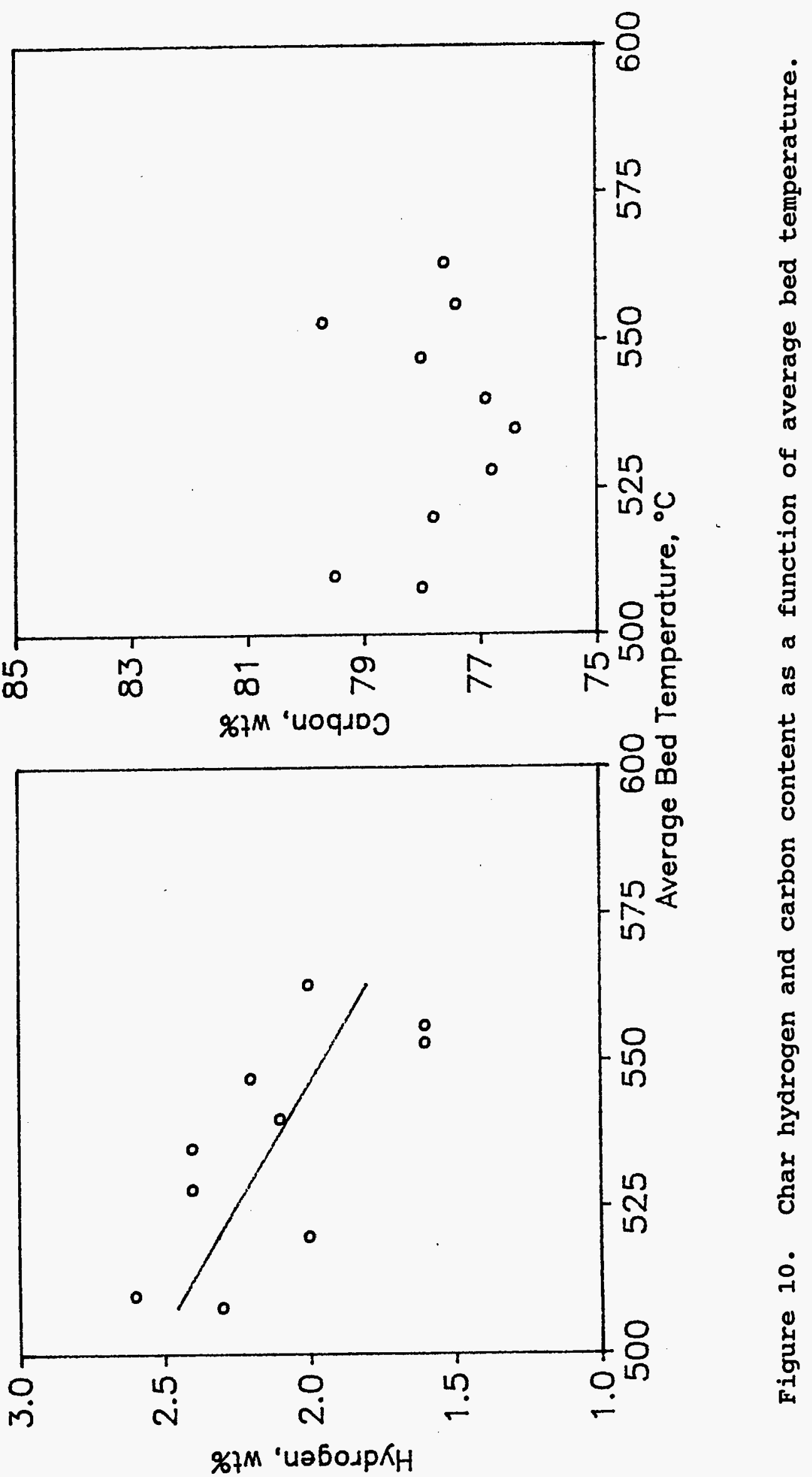




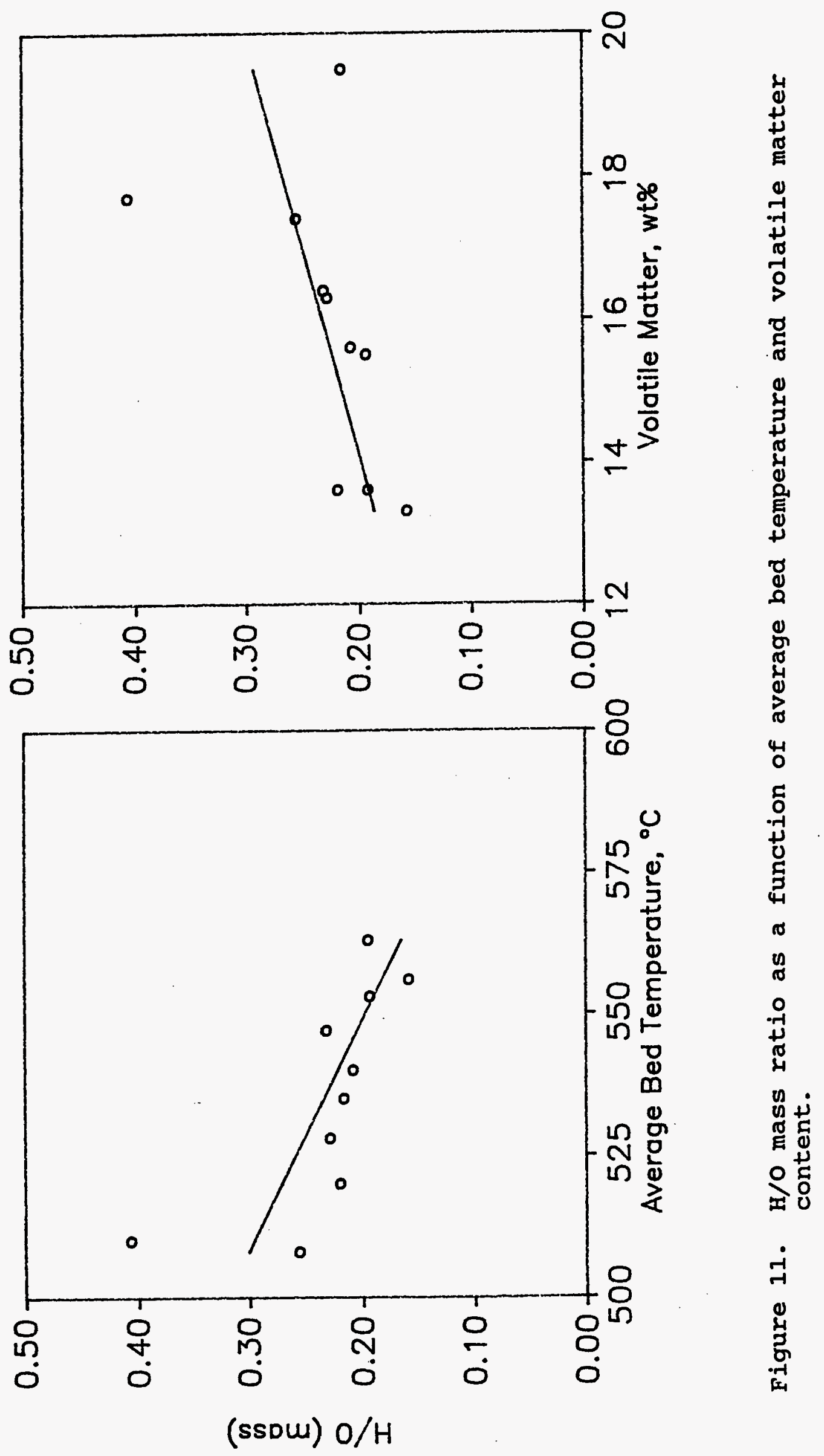


the $\mathrm{H} / \mathrm{O}$ ratio is consistent with the effect of these variables on hydrogen content.

\section{Table 3. Ultimate* Analyses of Mild Gasification Chars}

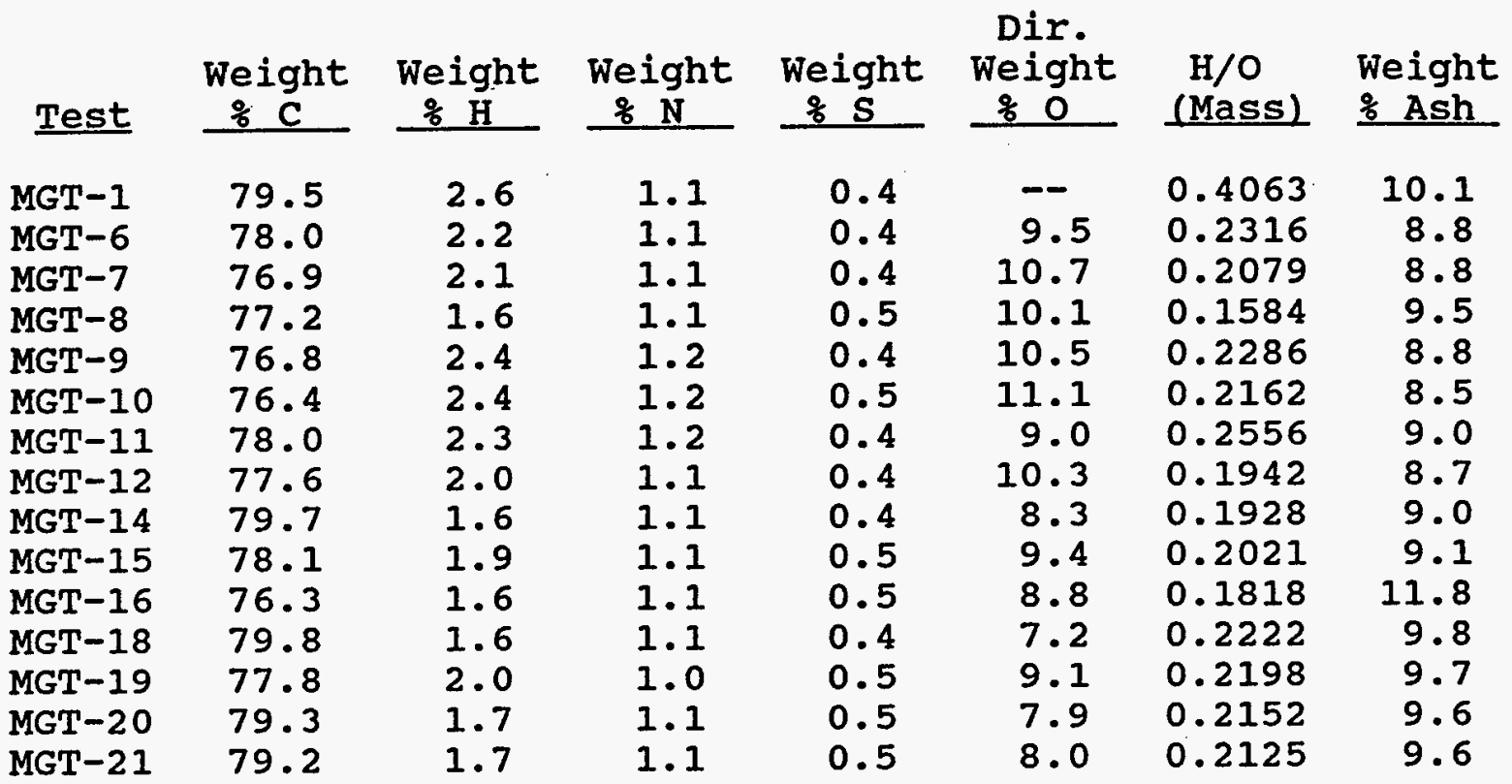

*

Normalized.

Independently of having a high $\mathrm{H} / \mathrm{O}$ ratio, it is important for the chars to have a low oxygen content. This is because any oxygen which is gasified to $\mathrm{CO}, \mathrm{CO}_{2}$, or $\mathrm{H}_{2} \mathrm{O}$ and is fed to the carbon formation reactor will tie up carbon as $C O$. A high oxygen content in the carbon formation reactor feed will severely limit overall carbon yield from the process. Inspection of Table 3 indicates that the char produced in Run MGT-18 has the lowest oxygen content. This char was produced using 38 percent steam in $\mathrm{CO}_{2}$ as the fluidizing gas. Others have reported that steam treatment of coal can reduce oxygen content. 32 It is likely that the use of steam in Run MGT-18 is responsible for the lower oxygen content of this char. The results reported in Table 3 for runs MGT-20 and 21 indicate that longer mild gasification residence times can produce relatively low oxygen chars.

In Table 4 are listed proximate and ultimate analyses for the Eagle Butte coal from which these chars were made. If we assume that the ash in the coal is not changed by mild gasification, it is possible to estimate what fraction of the sulfur and nitrogen is leaving with the liquid and gaseous products. Table 5 lists $\mathrm{S} / \mathrm{ash}$ and $\mathrm{N} / \mathrm{ash}$ ratios for the Eagle Butte coal and all of the mild gasification chars. Both s/ash and $\mathrm{N} / \mathrm{ash}$ ratios are reduced in the chars relative to the 
starting coal. These ratios are plotted for the chars in Figure 12 as a function of volatile matter content. volatile matter content was related to bed temperature, residence time, and fluidizing gas as discussed above. The results in Figure 12 indicate that the char $\mathrm{S} / \mathrm{ash}$ ratio is relatively unaffected by mild gasification conditions. The $\mathrm{N} / \mathrm{ash}$ ratio correlates weakly with volatile matter content and, therefore, with bed temperature, residence time, and fluidizing gas. This suggests that most or all of the sulfur left in the char is inorganic and cannot be volatilized while a large fraction of the nitrogen is in the organic form and can be removed with the volatile matter.

\section{Table 4. Proximate and Ultimate Analyses of Eagle Butte Coal}

\section{Weight $\%$}

Proximate (Dry Basis)

\begin{tabular}{lr} 
Fixed Carbon & 50.0 \\
Volatiles & 43.6 \\
Ultimate (Dry Basis)* & \\
\hline Carbon & 71.5 \\
Hydrogen & 4.2 \\
Sulfur & 0.5 \\
Nitrogen & 0.9 \\
Oxygen & 17.3 \\
Ash & 6.5
\end{tabular}

* Normalized

Table 5. Sulfur and Nitrogen-to-Ash Ratios for Coal and Chars

\begin{tabular}{lll}
\multicolumn{1}{c}{ Sample } & $\underline{\text { S/Ash }}$ & $\underline{\mathrm{N} / \text { Ash }}$ \\
Eagle Butte Coal & 0.077 & 0.139 \\
MGT-1 & 0.040 & 0.109 \\
MGT-6 & 0.046 & 0.125 \\
MGT-7 & 0.046 & 0.125 \\
MGT-8 & 0.053 & 0.116 \\
MGT-9 & 0.046 & 0.136 \\
MGT-10 & 0.059 & 0.141 \\
MGT-11 & 0.044 & 0.133 \\
MGT-12 & 0.046 & 0.126 \\
MGT-14 & 0.044 & 0.122 \\
MGT-15 & 0.055 & 0.121 \\
MGT-16 & 0.051 & 0.112 \\
MGT-18 & 0.041 & 0.112 \\
MGT-19 & 0.052 & 0.103 \\
MGT-20 & 0.052 & 0.115 \\
MGT-21 & 0.052 & 0.115
\end{tabular}




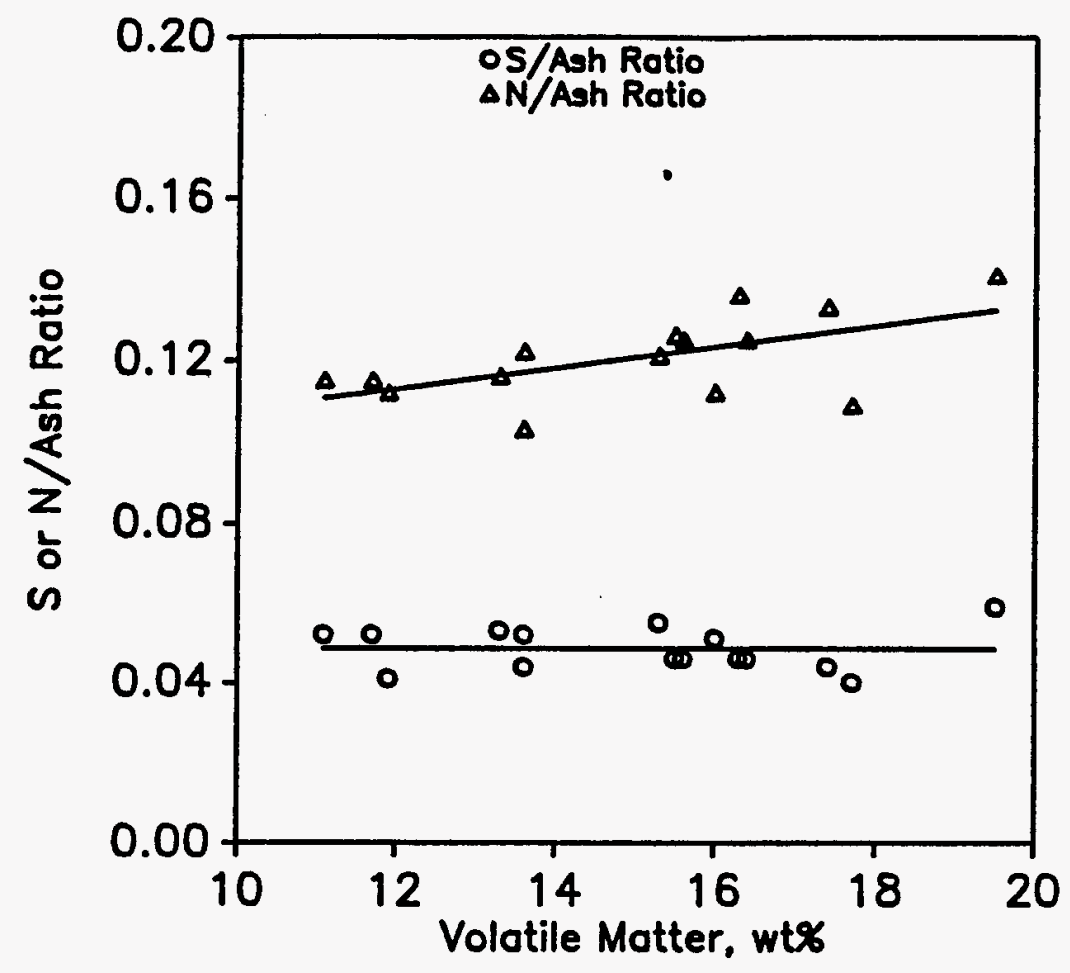

Figure 12. $\mathrm{S} / \mathrm{ash}$ and $\mathrm{N} / \mathrm{ash}$ ratios as a function of volatile matter content for mild gasification chars.

Sodium, potassium, magnesium, calcium, and iron are present in coal and coal chars and can catalyze gasification reactions.15 Accordingly, several chars were analyzed for these elements and results are reported in Table 6 . There is not a great deal of variation in these samples, except for the sodium analysis for char MGT-16. This char was produced from coal containing 2 weight percent sodium sesquicarbonate and is expected to have a very high sodium content. It is possible that this sodium, added before mild gasification, can serve as a methanation catalyst. Also, the chars are relatively calcium rich, having around 2 weight percent calcium.

Table 6. Metals Analyses of Mild Gasification Chars

$\mathrm{Ca}$,

Char $\mathrm{Na}$, ppm $\mathrm{K}$, ppm $\mathrm{Mg}$, ppm Weight $\%$ Fe, ppm

$\begin{array}{lrrccc}\text { MGT-1 } & 1,005 & 352 & -- & -- & -- \\ \text { MGT-9 } & 1,187 & 171 & 3,420 & 1.95 & 3,790 \\ \text { MGT-12 } & 1,108 & 169 & 3,590 & 2.03 & 3,710 \\ \text { MGT-16 } & 11,525 & 305 & -- & -- & -- \\ \text { MGT-18 } & 1,245 & 347 & 3,950 & 2.13 & --\end{array}$




\subsection{SURFACE AREA, PORE STRUCTURE, AND BULK PROPERTIES}

Another parameter which may be important in char reactivity is surface area. BET surface areas were measured using both nitrogen (at liquid nitrogen temperature) and carbon dioxide (at ice water temperature) as the adsorbate. Carbon dioxide is thought to be a more appropriate adsorbate for microporous materials than nitrogen because diffusion of nitrogen into these small pores is very slow at low temperatures.21 If the carbon dioxide surface area is substantially higher than the nitrogen surface area, then the samples can be assumed to be microporous.

Both nitrogen and carbon dioxide BET surface areas and other char properties are reported in Table 7. A comparison of the values for both adsorbates indicates that the char samples are not microporous. The term "surface area" will henceforth mean the nitrogen BET surface area.

Table 7. Miscellaneous Properties of Mild Gasification Chars

\begin{tabular}{|c|c|c|c|c|c|c|}
\hline & $\begin{array}{c}\text { Average } \\
\text { Particle }\end{array}$ & $\begin{array}{r}\text { Suj } \\
\text { Areas } \\
\text { a }\end{array}$ & $\frac{m^{2} / g}{c o n}$ & $\begin{array}{c}\text { True } \\
\text { Density, } \\
\text { cc/q }\end{array}$ & $\begin{array}{l}\text { Pore } \\
\text { Volume, } \\
\mathrm{cc} / \mathrm{g}\end{array}$ & $\begin{array}{c}\text { Bulk } \\
\text { Density, } \\
\text { cc/a }\end{array}$ \\
\hline Test & Size, Inches* & $\mathrm{N}_{2-}$ & $\mathrm{CO}_{2}-$ & $\mathrm{cc} / \mathrm{g}$ & & \\
\hline MGT-1 & -- & 38.8 & 43.3 & 1.39 & 0.194 & -- \\
\hline MGT- 6 & 0.010 & 51.7 & 53.0 & 1.35 & 0.189 & 0.65 \\
\hline MGT-7 & 0.007 & 54.5 & 52.3 & 1.36 & 0.202 & 0.62 \\
\hline MGT-8 & 0.011 & 66.9 & 54.1 & 1.35 & 0.206 & 0.66 \\
\hline MGT-9 & 0.012 & 34.1 & 48.3 & 1.34 & 0.178 & 0.64 \\
\hline MGT-10 & 0.012 & 30.8 & 40.4 & 1.33 & 0.166 & 0.61 \\
\hline MGT-11 & 0.013 & 22.3 & 23.1 & 1.32 & 0.200 & 0.59 \\
\hline MGT-12 & 0.012 & 51.8 & 51.9 & 1.33 & 0.220 & 0.58 \\
\hline MGT-14 & 0.008 & 71.0 & 52.0 & 1.37 & 0.140 & 0.61 \\
\hline MGT-15 & 0.012 & 38.7 & 52.5 & 1.33 & 0.162 & 0.59 \\
\hline MGT-16 & 0.007 & 37.6 & 47.8 & 1.41 & 0.184 & 0.59 \\
\hline MGT-18 & 0.007 & 62.8 & -- & 1.34 & 0.172 & 0.62 \\
\hline MGT-19 & 014 & 56.0 & -- & 1.28 & 0.206 & 0.58 \\
\hline $\mathrm{GT}-20$ & & 70.3 & -- & 1.33 & 0.158 & 0.64 \\
\hline MGT-21 & 0.012 & 58.0 & -- & 1.31 & 0.128 & 0.64 \\
\hline
\end{tabular}

* Surface mean particle diameter.

The relationship between surface area and average bed temperature and volatile matter content is shown in Figure 13. The results indicate an increase in surface area with bed temperature and a decrease in surface area with increasing volatile matter content. This suggests that devolatilization can be thought of as a removal of the volatile matter from the 

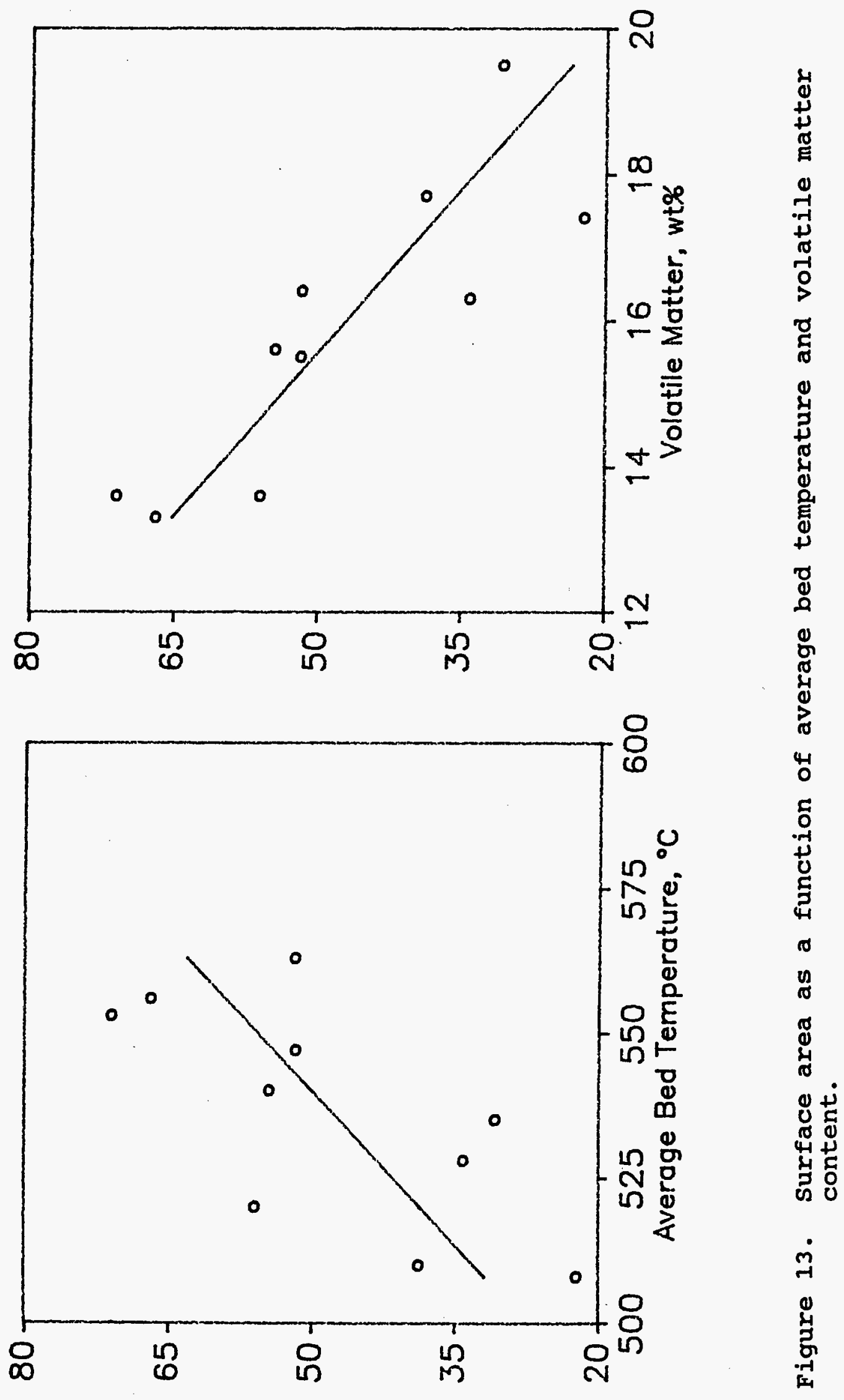

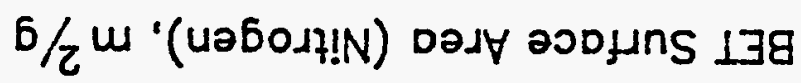


pores of a porous solid rather than as a thermally induced chemical reaction. Residence time and fluidizing gas appear to have the same effects noted above for reducing volatile matter content, leading to an increase in surface area.

Pore volumes measured by mercury intrusion are also reported in Table 7 . These values are widely scattered and do not correlate with volatile matter content or with surface area. Pore size distributions for each char are shown in Appendix B. There is very little difference between the chars, with all exhibiting pores broadly distributed between about 0.02 and 5 microns pore diameter. This is consistent with the good agreement obtained between nitrogen and carbon dioxide surface areas and supports the idea that these chars are nonmicroporous.

Average particle size, true density, and bulk density are also reported in Table 7. A comparison of average particle sizes for the fresh coal in Table 1 with the values in Table 7 indicates some differences between the particle size of the starting coal and the char. In some cases, particle size decreases and in some cases, particle size increases. It is likely that these differences are caused by experimental error. Possibly this error is related to the different equipment and operators used to measure the particle size distributions. In fact, particle size distributions for the coal were done at WRI, while those for the chars were done at AMAX.

\subsection{CHARACTERIZATION BY XRD AND SEM}

$X$-ray powder diffraction was used in an attempt to identify any major mineral components of the chars and to observe differences in the crystallinity of the carbon. Wertz 22 has reported the formation of an amorphous scattering peak at $d=2.05 \AA$ in partially combusted coals. He attributes this peak to the formation of a carbon black-like structure. The carbon black structure does not present a high number of edge sites on the surface relative to a highly disordered char and might be expected to be relatively unreactive.

The diffraction peak corresponding to this structure was observed, to some extent, in all of the mild gasification chars examined. Qualitative results are tabulated in Table 8 . A comparison of these results with the mild gasification conditions listed in Table 1 indicates that the samples with the largest carbon black-like structural peak were produced at high average bed temperatures or from the largest coal particle size. This may indicate that high temperatures can cause a structural rearrangement of the carbon in the char. Also, the particle size effect suggests that if volatiles are not rapidly removed from the coal particle, they can undergo retrogressive reactions to produce this structure. Because of the very 
qualitative nature of these results, these conclusions must be regarded as speculative.

\section{Table 8. X-ray Powder Diffraction Results for Mild Gasification Chars}

$\begin{array}{lcccc}\text { Char } & \text { Quartz } & \text { Feldspar } & & \text { "Carbon Black" Structure } \\ \text { MGT-1 } & \text { Yes } & \text { Yes } & \text { Weak and Broad } \\ \text { MGT-6 } & \text { Yes } & \text { No } & \text { Weak and Broad } \\ \text { MGT-7 } & \text { Yes } & \text { No } & \text { Very Weak and Broad } \\ \text { MGT-9 } & \text { Yes } & \text { No } & \text { Very Weak and Broad } \\ \text { MGT-10 } & \text { Yes } & \text { No } & \text { Medium and Broad } \\ \text { MGT-11 } & \text { Yes } & \text { No } & \text { Medium and Broad } \\ \text { MGT-12 } & \text { Yes } & \text { No } & \text { Medium and Sharp } \\ \text { MGT-14 } & \text { Yes } & \text { No } & \text { Very Weak and Very Broad } \\ \text { MGT-16 } & \text { Yes } & \text { No } & \text { Medium and Broad } \\ \text { MGT-18 } & \text { Yes } & \text { No } & \text { Very Weak and VerY Broad } \\ \text { MGT-20 } & \text { Yes } & \text { No } & \text { VerY Weak and Broad }\end{array}$

Scanning electron microscopy (SEM) can provide high quality photographs (micrographs) of char morphology and structure. The X-ray microanalysis option allows a qualitative or semi-quantitative elemental analysis and under favorable conditions can produce elemental maps. SEM was used to examine two char samples for structure and qualitative elemental analysis. The chars studied were MGT-9 and MGT-12. Electron micrographs for these samples are shown in Figures 14 and 15, respectively. The fields of view shown were selected because they exhibited interesting structural features and may not be completely representative of the particular char under consideration. The micrographs show large, slit shaped pores, as well as platelet and granular structures. Some very interesting twisted platelet structures were observed for MGT9.

Figure 16 shows $X$-ray analysis scans for the two chars. The scan for MGT-9 was done with a thin window which allows $x-$ rays from carbon and oxygen to reach the detector. The scan for MGT-12 was made with a beryllium window which only allows $x$-rays from elements heavier than fluorine to reach the detector. Results for both chars are quite similar. The thin window allows very low intensity $x$-rays from titanium to reach the detector from MGT-9, while these X-rays were not detected from MGT-12. Si, Al, Ca, and Mg are present in both chars. The last two elements have been shown to have a catalytic effect in steam gasification but not in hydrogasification. 14, 15 

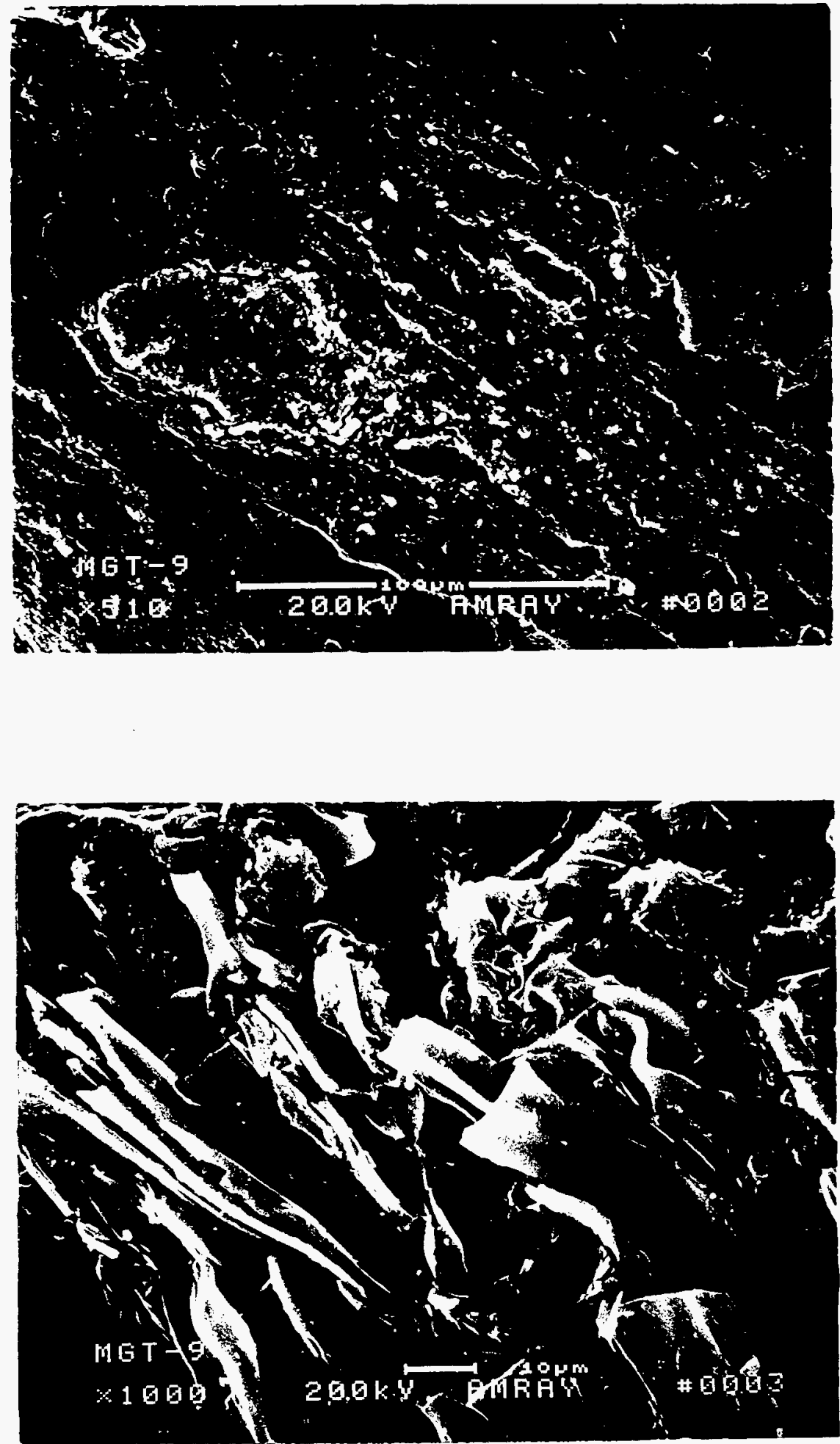

Figure 14. Scanning electron micrographs for MGT-9 char. 

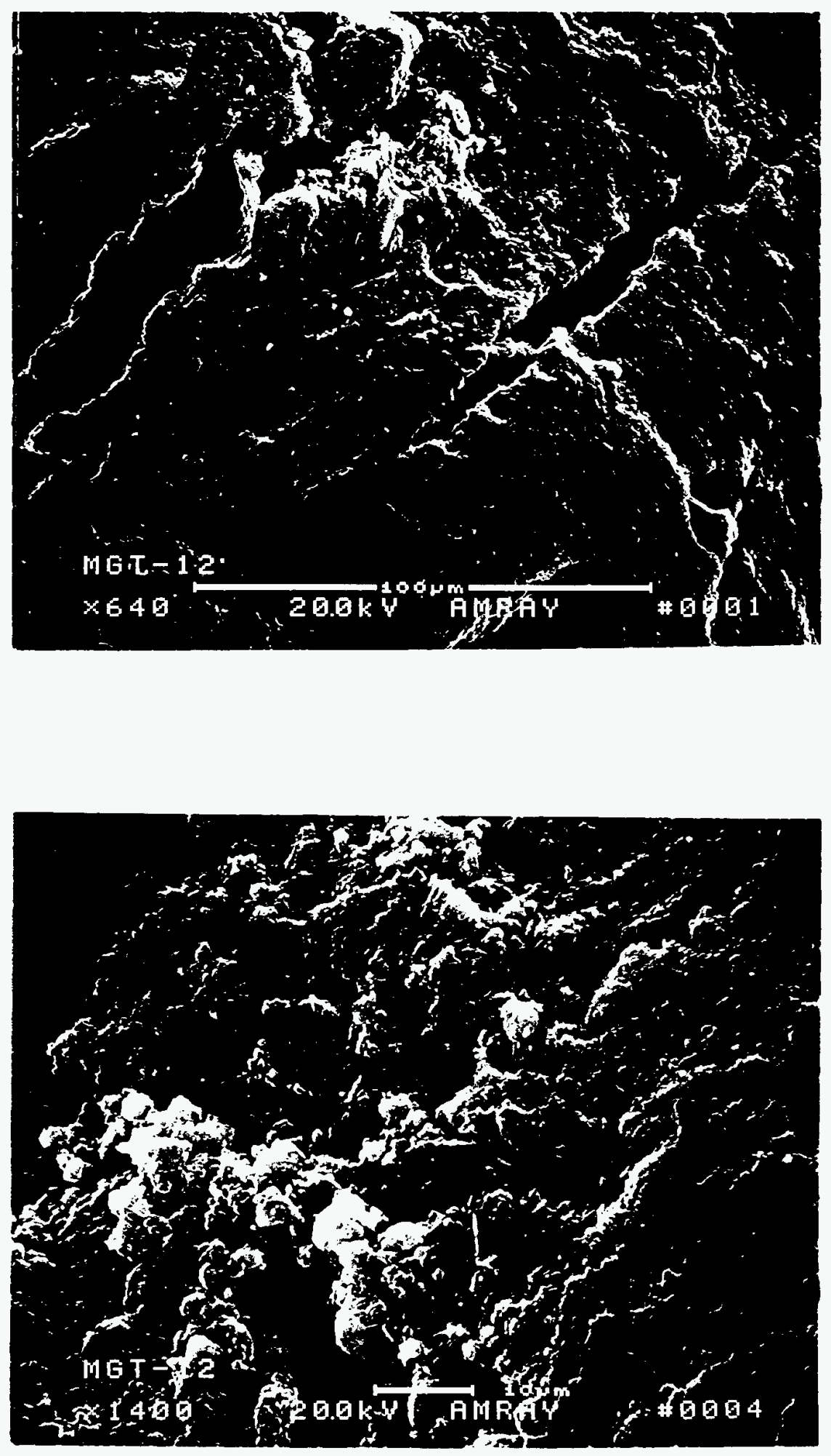

Figure 15. Scanning electron micrographs for MGT-12 char. 

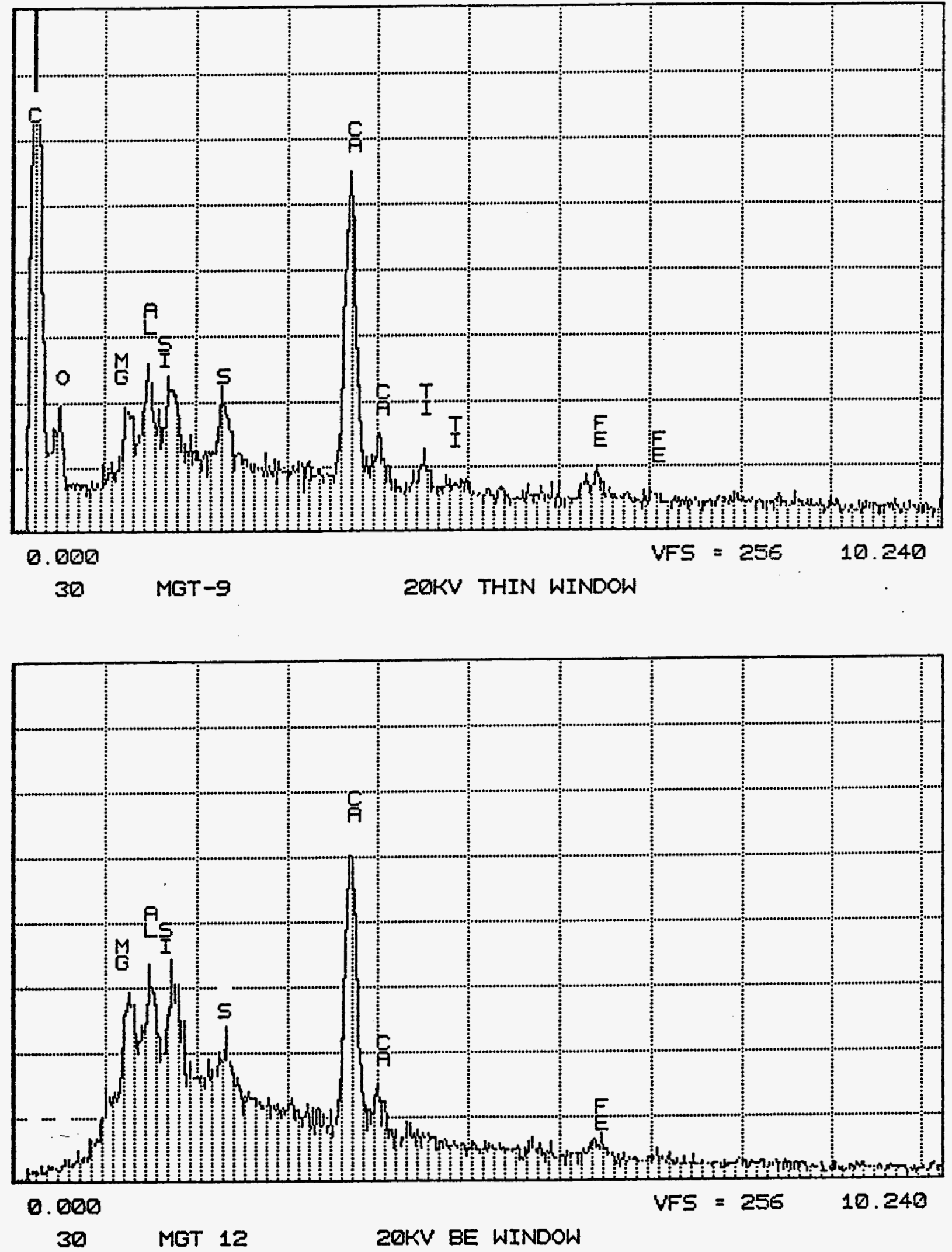

Figure 16. Energy dispersive X-ray analysis for chars MGT-9 and MGT-12. 


\subsection{SUMMARY OF CHAR CHARACTERIZATION RESULTS}

Volatile matter content was correlated with average mild gasification bed temperature, residence time, and starting coal particle size for most samples. Higher average bed temperatures lead to lower hydrogen content and lower $\mathrm{H} / \mathrm{O}$ ratios in the chars. These data are consistent with the higher hydrogen content of the mild gasification liquids relative to the starting coal. The amount of sulfur in the final char is not affected by mild gasification conditions. The amount of nitrogen is lower for chars with a lower volatile matter content (chars processed at higher temperatures). The use of steam in mild gasification produces a low volatile, relatively low oxygen char. BET surface areas for the chars also correlated with average bed temperature and inversely with volatile matter content. All of the chars exhibited a very open pore structure with most of the surface area in relatively large macropores.

$\mathrm{X}$-ray diffraction analysis suggested the possibility that processing at high temperatures can produce a carbon black-like structure which is thought to be unreactive. Energy dispersive $\mathrm{X}$-ray analysis in the SEM indicated the presence of $\mathrm{Si}, \mathrm{Al}, \mathrm{Ca}$, and $\mathrm{Mg}$, with Fe present at a lower level. SEM micrographs were obtained for two chars, but an interpretation of these images in terms of mild gasification conditions was not possible. 


\subsection{METHANATION TEST RESULTS}

Methanation is defined in this work as the reaction of solid carbon with hydrogen to produce gaseous methane. In this chapter, the literature on the kinetics and mechanism of this reaction is reviewed. Experimental work on the methanation of mild gasification chars is then described. The reaction was initially studied in atmospheric and high-pressure thermogravimetric systems. These experiments were followed by a series of tests in a micro-fixed-bed reactor. Based on the data obtained in these systems, a bench-scale reactor was fabricated and used to obtain the data to be utilized in the process demonstration unit design.

\subsection{TECHNICAL BACKGROUND}

The reaction of hydrogen with solid carbon to form gaseous hydrocarbon products (predominantly methane) is an extremely complicated process. It involves the diffusion of hydrogen from the bulk to the char surface, followed by adsorption of hydrogen on the surface. Then reaction of hydrogen with carbon at the surface (possibly a multi-step process) occurs. The final steps are desorption of the methane product and diffusion of methane into the bulk gas phase. As the carbon in the char reacts, the surface and pore structure change, making this an inherently unsteady state process.

Also, the reaction is highly exothermic and limited by thermodynamic equilibrium. That is, the reaction generates heat which raises the temperature of the system and makes the reaction less thermodynamically favorable. As the reaction stoichiometry indicates:

$$
2 \mathrm{H}_{2}+\mathrm{C} \rightarrow \mathrm{CH}_{4}
$$

There is a change in the number of moles in the gas phase from two to one, indicating that the reaction is favored at high pressure. The basic thermodynamics of this reaction were outlined in Chapter 2 .

Some fundamental work has been reported in the literature on the kinetics and mechanism of hydrogasification of carbon and coal, which in many aspects should be similar to methanation of char. In this section, that work will be reviewed, along with work on catalytic gasification of char in general. Also, hydrogasification processes have been tested on a fairly large scale and the results of this development work will be briefly described. 


\subsubsection{Reaction Kinetics}

Many authors have proposed the empirical first order kinetic expression: 6

$$
\mathrm{R}=\mathrm{kP}_{\mathrm{H} 2}
$$

This expression is considered reliable for low methane partial pressures and conditions far from thermodynamic equilibrium. A true rate expression should predict the equilibrium gas composition and show how the system approaches equilibrium. Such a rate expression has been proposed by Blackwood and Shaw (as described in Reference 6 ) and is of the form:

$$
R=\frac{k_{1} P^{2}{ }_{H 2}-k_{2} P_{C H 4}}{1+k_{3} P_{H 2}+k_{4} P_{C H}}
$$

Where $\mathrm{k}_{1}, \mathrm{k}_{2}, \mathrm{k}_{3}$, and $\mathrm{k}_{4}$ are constants related to the rate constants of specific steps in a proposed mechanism. At low methane concentrations and high hydrogen partial pressures, this expression reduces to the first order expression given in Equation 5.1.

Another approach has been reported by Huttinger and Schleicher ${ }^{9}$ using a semi-empirical rate expression. They assumed a rate expression of the form:

$$
R=\text { (kinetic term) (potential term)/(adsorption term) }^{n}
$$

Their analysis produced the following rate expression:

$$
R=\frac{k_{1}\left(P_{H 2}-P_{H 2}^{e_{H}}\right)}{\left(1+k_{2} P_{H 2}\right)^{2}}
$$

Where $\mathrm{P}^{\mathrm{e}} \mathrm{H} 2$ is the hydrogen partial pressure at equilibrium, $\mathrm{k}_{1}$ is the kinetic term (a constant), and $k_{2}$ is an equilibrium constant for hydrogen adsorption. This rate expression adequately fits Huttinger and Schleicher's data. However, it has not been widely employed in studies of hydrogasification possibly because it was originally developed for transition metal catalyzed gasification.

Several authors have reported that the inhibiting effect of methane is not significant under a wide range of 
conditions. 6 Because of this, Equation 5.1 is frequently employed, unless equilibrium is approached.

\subsubsection{Mechanism}

The exact chemical mechanism of hydrogasification is not well understood. Zielke and Gorin 10 have proposed a mechanism based on the hydrogenation of graphitic edge sites in the char. The mechanism involves successive hydrogenation of edge carbon atoms until they are hydrogenated to methane. Unfortunately, this mechanism does little to explain the variation in the reactivities of chars or graphites which are thought to have the same number of exposed edge sites. It fails because of a simplistic view of the surface active sites.

A more detailed picture was suggested by the work of Cao and $B^{A c k}{ }^{11}$ and expanded upon by Zoheidi and Miller.12,13 These researchers have reported that the presence of oxygencontaining groups on the surface of carbons enhances the hydrogasification rate. It has been proposed that these oxygen groups are located on the edge sites, as proposed by zielke and Gorin. 10 Upon heating, these sites decompose to form $\mathrm{CO}, \mathrm{CO}_{2}$, and a highly reactive surface site. A detailed picture of how these oxygen groups or highly reactive surface sites actually interact with hydrogen to produce methane at a high rate has yet to emerge.

While some progress has been made in recent years, the details of the mechanism of hydrogasification remain vague. A better understanding of this phenomenon will allow the optimization of mild gasification processes for production of highly reactive char. This may also point the way to highly active gasification catalysts.

\subsubsection{Catalytic Gasification}

A great deal of experimental work has been reported using transition metal and alkali metal catalysts which have been impregnated onto the char. Because impregnation of the char is not currently an economically viable alternative, this review will deal mostly with physically mixed alkali metal catalysts. Alkali metal carbonates are known to be highly active steam and hydrogasification catalysts, 6,12 and there is evidence that the loading method has little effect on the activity of potassium carbonate in steam gasification. 14,15

The overall gasification process with a physically mixed catalyst involves the following steps:

1. Migration of the catalyst to the surface of the char. 
2. Wetting of the char surface by the catalyst and reaction of the catalytic material with this surface to form the active catalyst (active sites).

3. Catalysis of the gasification reaction.

4. Continued migration of the catalytic material to maintain contact with the reacting char.

5. Reaction of the catalyst with mineral matter leading to deactivation and loss of contact between the catalyst and the char.

Migration of the potassium catalyst has been shown to be independent of reactive gas composition and to occur in the range of 400 to $650^{\circ} \mathrm{C}$. $16^{9}$ The potassium migration is thought to be accompanied by melting of the catalyst phase. 17 The liquid phase formed upon melting must wet the char surface to be a highly active catalyst. 17,18 The reactive gas environment can affect the wettability of the char surface, and it is not known how hydrogen might affect this relative to steam. Also, little or no information is available on how a hydrogen atmosphere can affect the reaction of the catalyst with mineral matter.

So, while there have been a few fundamental studies of catalytic hydrogasification, there is little information available of a practical nature. Gasification catalysts were investigated as a part of this study.

\subsubsection{Hydrogasification Processes}

Several hydrogasification processes have been proposed for the production of synthetic natural gas (SNG) from coal. AIl of these processes involve the production of hydrogen as an integral part of the overall process. Because hydrogen production is not a problem in the integrated process under development, it will not be described in any detail here. This section will discuss several of the gasification reactor designs which have been proposed and piloted. This section is largely based on information in Reference 19 and, therefore, does not include developments occurring after 1981.

\subsubsection{British Gas Coal Hydrogasification Process}

In this process, coal is devolatilized under hydrogen in a first-stage fluidized bed at $750 \mathrm{psi}$ and 800 to $850^{\circ} \mathrm{C}$. The volatile matter is hydrogenated and cracked to methane. The methane yield in this first stage is not limited by thermodynamic equilibrium. The remaining char is gasified by a slow reaction in a second-stage fluidized bed at 700 psi and 900 to $950^{\circ} \mathrm{C}$. This slower reaction is conducted under a high hydrogen partial pressure to enhance the reaction rate. Gas 
and coal are fed to the two-stage system countercurrently. Internal recirculation of solids is used to aid in temperature control and avoid agglomeration at solids injection points. The residual char is gasified with steam to produce the necessary hydrogen.

Development work consisted of a 34 by 3 foot i.d. reactor operating at $300 \mathrm{psi}$ and $200^{\circ} \mathrm{C}$, which was used to define recycle rates within the recirculating fluidized beds. A 3,360 pound/hour char pilot plant to operate at $450 \mathrm{psi}$ and $1,050^{\circ} \mathrm{C}$ was designed and constructed but was never operated because of the discovery of natural gas in the North Sea in 1965.

\subsubsection{HYGAS Process}

This process is designed around the IGT multi-stage fluidized-bed gasifier. It involves countercurrent gas and solid flow. A 75 TPD pilot plant was constructed in 1971 and designed to operate at $1,100 \mathrm{psi}$ and $930^{\circ} \mathrm{C}$. The plant was successfully operated until at least 1976.

\subsubsection{HYDRANE Process}

This process was developed by the U. S. Bureau of Mines. It is a two-stage system consisting of a free fall dilute phase first stage operating at 760 to $900^{\circ} \mathrm{C}$ and a fluidized second stage operating at 900 to $980^{\circ} \mathrm{C}$. The nominal operating pressure is $1,000 \mathrm{psi}$. The individual stages of this system have been tested independently on the bench scale but have not been operated in an integrated manner. More recently, the HYDRANE process has been changed to a single-stage system and development work has continued.

Serious technical difficulties have been encountered in many of the hydrogasification processes which have been piloted. 20 Also, with the drop in natural gas prices which occurred in the 1980s, the short term economic incentive for these projects no longer exists.

\subsection{ATMOSPHERIC PRESSURE TGA TESTS}

Atmospheric pressure TGA was used as an initial screening. This simple experiment allowed the testing of a variety of catalysts and conditions at relatively low cost.

\subsubsection{Non-Catalytic Gasification}

Results of non-catalytic gasification tests performed using atmospheric pressure TGA are summarized in Table 9. TGA work was conducted using 0.1 gram of MGT-1 char. The different runs are compared on the basis of average and maximum gasification rates (weight loss). The maximum rate occurs very near the beginning of the run. The average rate is taken over 
the duration of the experiment (usually at least 100 minutes). This rate is an indicator of the rate to be expected under lined out, non-optimum conditions. Atmospheric pressure is 12 psia in Golden, Colorado. Some gasification rates at atmospheric pressure are approximate because they were too low to measure accurately.

Table 9. Results of Non-Catalytic, Atmospheric Pressure TGA Gasification Tests

Gas Composition

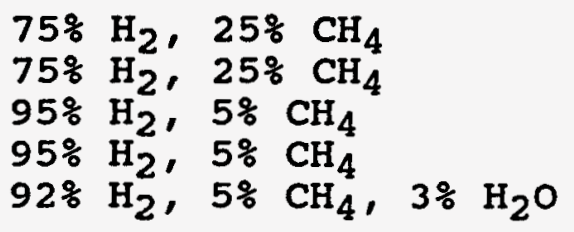

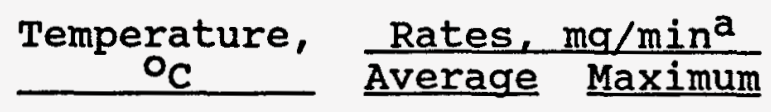

600

700

800

900

900
$(0.01)$

$(0.02)$

$(0.02)$

$(0.01)$

0.35
$(0.01)$

$(0.02)$

$(0.02)$

0.05

0.45

a Values in parentheses are approximate.

As the numbers in Table 9 indicate, gasification rates at atmospheric pressure are quite low. The rate can be increased slightly by raising the temperature, but if the temperature is increased too much, the thermodynamic driving force switches to the reverse reaction. Adding 3 percent steam to the gas had a dramatic effect on the gasification rate, increasing by more than a factor of 10 .

\subsubsection{Catalytic Gasification}

The alkali metal carbonates have been shown to catalyze the hydrogen-carbon reaction 12 and are active in a physically mixed form.14,15 Iron and nickel are more commonly employed, however. 23,24 Alkaline earths are thought to promote hydrogasification catalysis by iron group metals. 25 Each of these potential catalyst systems was investigated.

The results of 20 catalytic gasification tests are listed in Table 10. In dry hydrogen gasification, the physically mixed alkali metal carbonate catalysts produced a significant enhancement in initial (maximum) rates but did not increase the average rates. This indicates that the catalyst is either deactivated or loses contact rapidly. When $\mathrm{K}_{2} \mathrm{CO}_{3}$ was impregnated onto the char, a higher average rate was obtained. (This sample was tested in 100 percent $\mathrm{H}_{2}$, so these results are not completely comparable.) This observation suggests that the low average activity for the physically mixed samples is caused by loss of contact rather than deactivation. 
Table 10. Results of Catalyzed, Atmospheric Pressure TGA Gasification Tests

\section{Gas Composition}

$75 \% \mathrm{H}_{2}, 25 \% \mathrm{CH}_{4}$
$92 \% \mathrm{H}_{2}, 5 \% \mathrm{CH}_{4}, 3 \% \mathrm{H}_{2} \mathrm{O}$
$75 \% \mathrm{H}_{2}, 25 \% \mathrm{CH}_{4}$
$75 \% \mathrm{H}_{2}, 25 \% \mathrm{CH}_{4}$
$100 \% \mathrm{H}_{2}, 5 \% \mathrm{CH}_{4}, 3 \% \mathrm{H}_{2} \mathrm{O}$
$92 \% \mathrm{H}_{2}, 5 \% \mathrm{H}_{2} \mathrm{O}$
$92 \% \mathrm{H}_{2}, 5 \% \mathrm{CH}_{4}, 3 \%$
$100 \% \mathrm{H}_{2}$
$100 \% \mathrm{H}_{2}$
$100 \% \mathrm{H}_{2}$
$95 \% \mathrm{H}_{2}, 5 \% \mathrm{CH}_{4}$
$97 \% \mathrm{H}_{2}, 3 \% \mathrm{H}_{2} \mathrm{O}$
$97 \% \mathrm{H}_{2}, 3 \% \mathrm{H}_{2} \mathrm{O}$
$95 \% \mathrm{H}_{2}, 5 \% \mathrm{CH}_{4}$
$92 \% \mathrm{H}_{2}, 5 \% \mathrm{CH}_{4}, 3 \% \mathrm{H}_{2} \mathrm{O}$
$100 \% \mathrm{H}_{2}, 3 \% \mathrm{H}_{2} \mathrm{O}$
$97 \% \mathrm{H}_{2}, 3 \%$
$97 \% \mathrm{H}_{2}, 3 \% \mathrm{H}_{2} \mathrm{O}$
$92 \% \mathrm{H}_{2}, 5 \% \mathrm{CH}_{4}, 3 \% \mathrm{H}_{2} \mathrm{O}$
$92 \% \mathrm{H}_{2}, 5 \% \mathrm{CH}_{4}, 3 \% \mathrm{H}_{2} \mathrm{O}$
9

Temperature,

Catalyst Average Maximum

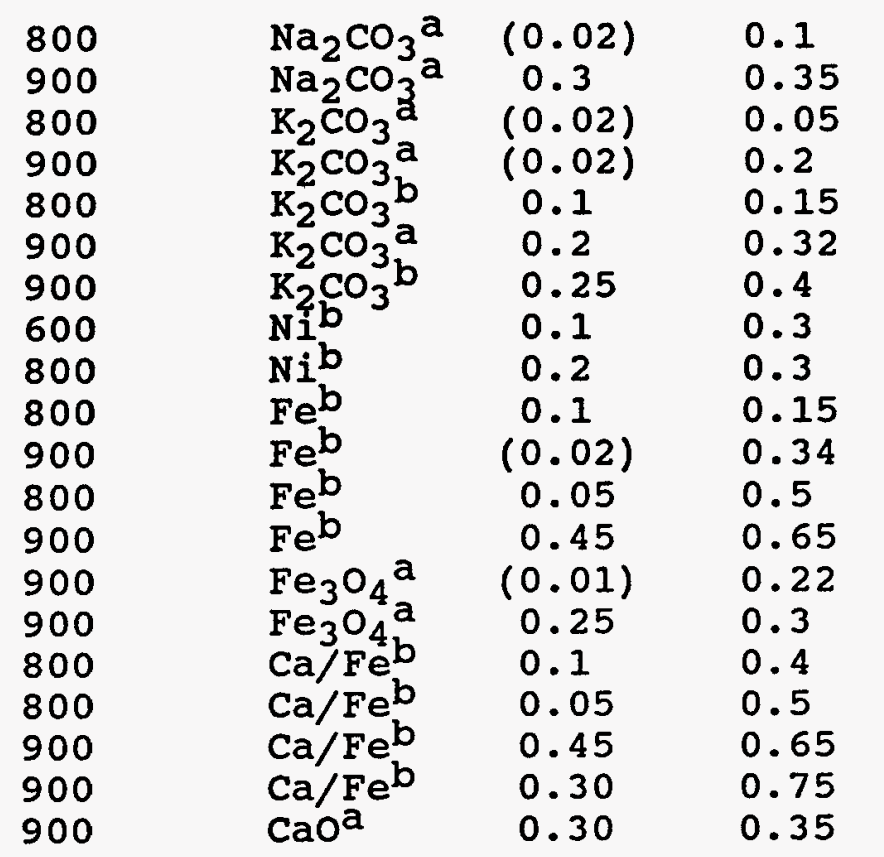

a Physically mixed.

b Impregnated.

All catalysts used at 5 weight \% loading unless indicated otherwise in the text. Starting weight of char sample was 0.1 gram.

The transition metal catalysts also exhibited a catalytic effect of about the same magnitude as impregnated $\mathrm{K}_{2} \mathrm{CO}_{3}$. Nickel was a slightly more active catalyst than iron, as has been reported by others. 23 Iron promoted with calcium was easily as active as nickel, however. Huttinger has reported that the optimum loading of $\mathrm{Ni}$ and $\mathrm{Fe}$ for catalysis of hydrogasification is about 2 weight percent, so the loadings employed here may have been high. 23

In gasification with feed gas containing 3 percent steam, only impregnated iron and calcium/iron produced rates which were higher than those obtained in the non-catalyzed case. The results suggest that there may be some advantage to using catalysts for gasification without steam at atmospheric pressure. However, in the presence of steam, catalysts may not be necessary. 


\subsubsection{Char Reactivity Tests}

A simple reactivity test was used to screen the chars for atmospheric pressure reactivity with wet hydrogen. The char samples were heated to $900^{\circ} \mathrm{C}$ at $40^{\circ} \mathrm{C} /$ minute in nitrogen flowing at $120 \mathrm{cc} /$ minute. After this temperature had been reached and the sample mass had equilibrated (usually within 5 minutes), the gas was switched to hydrogen containing 3 percent $\mathrm{H}_{2} \mathrm{O}$. The reactivity values reported are the percent weight loss (ash free basis) occurring in 20 minutes after switching to the reactive gas. These values should be regarded as an indication of initial reactivity at atmospheric pressure.

Char reactivity values are listed in Table 11 . It was attempted to correlate char reactivity with surface area, particle size, porosity, H/O ratio, volatile content, hydrogen content, oxygen content, and oxygen-to-carbon ratio without success. The reactivity factor for MGT-9 is the average of three replications whose reactivity values were $14.4,13.2$, and 11.8. The standard deviation is 1.30. Based on these replications, it can be stated that the chars produced in MGT1, MGT-6, MGT-9, and MGT-16 are more reactive than the others. MGT-16 was produced in a run in which sodium carbonate was added to the coal before processing. It is possible that the high reactivity of this material can be attributed to the catalytic effect of sodium. However, in the catalytic TGA work reported above, sodium carbonate was not active at a 5 percent loading under similar conditions to those used in these reactivity tests.

Table 11. Char Reactivities observed in Atmospheric Pressure TGA Tests

$\begin{array}{lr}\text { Char } & \text { Reactivity } \\ \text { MGT-1 } & 12.9 \\ \text { MGT-6 } & 11.8 \\ \text { MGT-7 } & 7.9 \\ \text { MGT-8 } & 7.2 \\ \text { MGT-9 } & 13.1 \\ \text { MGT-10 } & 7.7 \\ \text { MGT-11 } & 9.8 \\ \text { MGT-12 } & 6.5 \\ \text { MGT-14 } & 8.0 \\ \text { MGT-15 } & 8.3 \\ \text { MGT-16 } & 12.3 \\ \text { MGT-18 } & 8.0 \\ \text { MGT-19 } & 9.1 \\ \text { MGT-20 } & 8.6 \\ \text { MGT-21 } & 8.7\end{array}$


The chars from runs MGT-1, MGT-6, and MGT-9 have two things in common. First, they were all produced from coal with a surface mean particle diameter of $0.031 \mathrm{~cm}$. Three coal particle sizes were investigated and this was the intermediate size. These three chars also have relatively high $\mathrm{H} / \mathrm{O}$ ratios, although some of the other chars also have relatively high $\mathrm{H} / \mathrm{O}$ ratios. A correlation between volatile matter content and $\mathrm{H} / \mathrm{O}$ ratio was reported above, so these chars have correspondingly high volatile matter contents. Other chars, notably MGT-10 and MGT-11, also have high $\mathrm{H} / 0$ ratios and volatile matter contents but do not exhibit high reactivity. These chars were produced from coal of the largest particle size $(0.051 \mathrm{~cm})$.

$X$-ray powder diffraction has been applied to several of the chars, as discussed earlier. The results are listed in Table 8. The carbon black structural peak is the sharpest in the least reactive char, MGT-12, processed from coal at the highest temperature. The most reactive chars, MGT-1 and MGT-9, exhibit this peak very weakly. The structure of carbon black does not expose highly reactive edge sites relative to highly disordered carbon. It is possible that formation of this structure in a char is one reason for low reactivity. High processing temperature may be responsible for this. Because some low reactivity chars do not exhibit this structure, its presence may not be the only reason for low reactivity.

\subsection{HIGH PRESSURE TGA TESTS}

High pressure TGA tests were conducted using 0.1 gram of MGT-1 char, and the results are reported in Table 12. These results should be compared with the atmospheric pressure TGA results reported in Table 9. This comparison indicates that higher rates in dry hydrogen at 600,700 , and $800^{\circ} \mathrm{C}$ were obtained under pressure. This is consistent with the reaction kinetics discussed above. The high pressure runs made with steam were made at a lower temperature than the run at atmospheric pressure and used a much higher steam feed rate of 20 percent. A rate slightly less than that obtained at $900^{\circ} \mathrm{C}$ and atmospheric pressure was obtained at $800^{\circ} \mathrm{C}$ and $300 \mathrm{psia}$ in the high pressure TGA. At this high steam partial pressure, it is likely that steam gasification to $\mathrm{CO}, \mathrm{CO}_{2}$, and $\mathrm{H}_{2}$

predominates, and this reaction is thermodynamically favored at low pressure.

\subsection{MICRO-FIXED-BED REACTOR TESTS}

Run conditions, durations, and char total weight loss data for these runs are Iisted in Tables 13 and 14 . Plots of gas production rates for methane and carbon oxides may be found in Appendix C. The temperatures ranged from 600 to $800^{\circ} \mathrm{C}$, pressures from 300 to $1,200 \mathrm{psig}$, and run durations from 4 to nearly 7 hours. Potassium carbonate and iron catalysts were tested in both impregnated and physically mixed forms. 
Table 12. Results of High Pressure TGA Gasification Tests

Gas Composition

Temperature, Pressure, Rates, mg/min

$\begin{array}{llll}75 \% \mathrm{H}_{2}, & 25 \% \mathrm{CH}_{4} & \\ 82 \% \mathrm{H}_{2}, & 18 \% \mathrm{CH}_{4} & \\ 95 \% \mathrm{H}_{2}, 5 \% \mathrm{CH}_{4} & \\ 60 \% \mathrm{H}_{2}, & 20 \% \mathrm{CH}_{4}, 20 \% \mathrm{H}_{2} \mathrm{O} \\ 60 \% \mathrm{H}_{2}, 20 \% \mathrm{CH}_{4}, 20 \% \mathrm{H}_{2} \mathrm{O} \\ 60 \% \mathrm{H}_{2}, 20 \% \mathrm{CH}_{4}, 20 \% \mathrm{H}_{2} \mathrm{O}\end{array}$

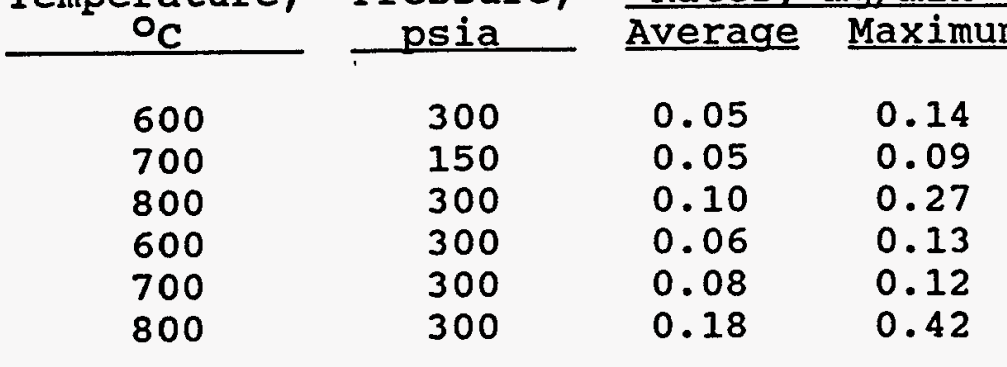

Table 13. Results of Micro-Fixed-Bed Non-Catalytic Gasification Tests

\begin{tabular}{|c|c|c|c|c|c|c|c|}
\hline \multirow[b]{2}{*}{ Run } & \multirow{2}{*}{$\begin{array}{c}\text { Temperature, } \\
{ }^{\circ} \mathrm{C} \\
\end{array}$} & \multirow{2}{*}{$\begin{array}{c}\text { Pressure, } \\
\text { psig }\end{array}$} & \multicolumn{3}{|c|}{$\begin{array}{c}\text { Inlet Flows, } \\
\text { SCCM }\end{array}$} & \multirow{2}{*}{$\begin{array}{l}\text { Run } \\
\text { Time, } \\
\text { Hours }\end{array}$} & \multirow{2}{*}{$\begin{array}{l}\text { Percent } \\
\text { Weight } \\
\text { Loss } \\
\end{array}$} \\
\hline & & & $\underline{\mathrm{H}}_{2}$ & $\mathrm{CH}_{4}$ & $\underline{\mathrm{H}}_{2} \underline{\mathrm{O}}$ & & \\
\hline 10 & 600 & 300 & 75 & 25 & 0 & 5.00 & 23.7 \\
\hline 11 & 700 & 300 & 95 & 5 & 0 & 6.25 & 36.8 \\
\hline 12 & 700 & 300 & 95 & 0 & 5 & 5.50 & 34.8 \\
\hline 13 & 700 & 500 & 95 & 0 & 5 & 4.00 & 36.4 \\
\hline 14 & 700 & 500 & 90 & 0 & 10 & 6.50 & 42.9 \\
\hline 15 & 700 & 750 & 75 & 25 & 0 & 6.75 & 40.5 \\
\hline 17 & 700 & 1,200 & 75 & 25 & 0 & 4.50 & 41.4 \\
\hline 27 & 800 & 150 & 75 & 10 & 15 & 6.25 & 55.2 \\
\hline 30 & 800 & 150 & 75 & 25 & 0 & 5.00 & 35.8 \\
\hline
\end{tabular}

Table 14. Results of Micro-Fixed-Bed Catalytic Gasification Tests

\begin{tabular}{|c|c|c|c|c|c|c|c|c|}
\hline \multirow[b]{2}{*}{$\underline{\text { Run }}$} & \multirow{2}{*}{$\begin{array}{c}\text { Temperature, } \\
{ }^{\circ} \mathrm{C} \\
\end{array}$} & \multirow{2}{*}{$\begin{array}{c}\text { Pressure, } \\
\text { psig } \\
\end{array}$} & \multicolumn{3}{|c|}{$\begin{array}{c}\text { Inlet Flows, } \\
\text { SCCM }\end{array}$} & \multirow[b]{2}{*}{ Catalyst } & \multirow{2}{*}{$\begin{array}{l}\text { Run } \\
\text { Time, } \\
\text { Hours }\end{array}$} & \multirow{2}{*}{$\begin{array}{l}\text { Percent } \\
\text { Weight } \\
\text { Loss } \\
\end{array}$} \\
\hline & & & $\underline{\mathrm{H}}_{2}$ & $\mathrm{CH}_{4}$ & $\underline{\mathrm{H}}_{2} \underline{\mathrm{O}}$ & & & \\
\hline 16 & 700 & 500 & 75 & 0 & 25 & $\mathrm{~K}_{2} \mathrm{CO}_{3}{ }^{\mathrm{a}}$ & 5.75 & 58.7 \\
\hline 19 & 700 & 300 & 75 & 25 & 0 & & 5.25 & 44.2 \\
\hline 22 & 700 & 300 & 75 & 10 & 15 & $\mathrm{~K}_{2} \mathrm{C}$ & 6.50 & 60.8 \\
\hline 23 & 700 & 300 & 75 & 10 & 15 & $\mathrm{Fe}^{\mathrm{b}}$ & 6.00 & 47.1 \\
\hline 24 & 700 & 300 & 75 & 25 & 0 & $\mathrm{~K}_{2} \mathrm{CO}$ & 5.50 & 54.6 \\
\hline 28 & 800 & 150 & 75 & 10 & 15 & $F e^{b}$ & 6.00 & 61.9 \\
\hline 29 & 800 & 150 & 75 & 10 & 15 & $\mathrm{~K}_{2} \mathrm{CO}_{3} \mathrm{~b}$ & 5.00 & 76.6 \\
\hline 31 & 800 & 150 & 75 & 25 & 0 & $\mathrm{Fe}^{\mathrm{b} b}$ & 6.00 & 49.8 \\
\hline 32 & 800 & 150 & 75 & 25 & 0 & $\mathrm{~K}_{2} \mathrm{CO}_{3}^{\mathrm{b}}$ & 5.50 & 45.8 \\
\hline 33 & 800 & 150 & 75 & 25 & 0 & $\mathrm{Fe}_{3} \mathrm{O}_{4} \mathrm{a}$ & 5.00 & 30.7 \\
\hline 34 & 800 & 150 & 75 & 15 & 10 & & 6.00 & 37.0 \\
\hline
\end{tabular}

a Physically mixed.
b Impregnated. 
Total char weight losses were as high as 76.6 percent. Complete conversion of carbon would have resulted in a 79.5 percent weight loss, assuming only carbon gasification. High weight losses required the use of a catalyst or high temperature and steam. For runs at high temperature $\left(800^{\circ} \mathrm{C}\right)$ and using steam, the plots in Appendix $C$ indicate significant formation of carbon oxides, as well as methane. In comparing char weight losses, the effect of differing run times must be taken into account.

The gasification of coal chars can be divided into two stages. 26 The first stage is a transient, rapid-rate gasification which lasts for 10 to 15 minutes at moderate temperatures but may require only seconds at higher temperatures. The methane formation rates achieved in this stage can be affected by the use of a catalyst. This first stage is followed by a steady state gasification which occurs at a much lower rate. Johnson has proposed an interpretation of this phenomenon in which rapid-rate active sites are formed by the evolution of char hydrogen in a thermal reaction which is independent of gas phase composition. These active sites can then react further in competing reactions to form unreactive char or to produce methane by reaction with gas phase hydrogen. 27

The phenomenon of initial rapid-rate gasification was observed, to some extent, in all runs. However, the effect was small at $600^{\circ} \mathrm{C}$. Catalysts and steam had some effect on the maximum rate obtained and the rate of activity loss at the end of the rapid-rate stage. Some carbon oxide formation was observed during the initial stage in all runs and can be attributed to decarboxylation of the char rather than to gasification.

\subsubsection{Data Analysis}

An analysis of the results was performed by assuming that the reactor was a differential reactor. This assumption implies that conditions do not change significantly with position in the char bed. To insure that this assumption was reasonable, the main reaction product, methane, was included in the feed. Also, gas phase conversions were kept relatively low by operating at a high feed flow rate of $100 \mathrm{SCCM}$ (standard cubic centimeters per minute). Methane formation rates were sufficiently high in most runs that this assumption is not strictly valid. Therefore, conclusions based on kinetic analysis must be regarded as qualitative.

The data were analyzed using the commonly employed 8 rate expression for hydrogasification: 


$$
\mathrm{R}_{\mathrm{CH} 4}=\mathrm{kP}_{\mathrm{H} 2}
$$

where: $\mathrm{R}_{\mathrm{CH} 4}=$ Rate of methane formation in units of SCCM. $\mathrm{k}=$ First order reaction rate constant in units of $\mathrm{SCCM} / \mathrm{psig}$.

$\mathrm{P}_{\mathrm{H} 2}=$ Hydrogen partial pressure in units of psig.

The rate of methane formation, $\mathrm{R}_{\mathrm{CH} 4}$, is calculated as the difference between the methane flow rate out of the reactor and that into the reactor. Then, this rate and the hydrogen partial pressure are used to calculate the rate constant, $k$.

Another important calculated parameter is the selectivity to methane, $\mathrm{S}_{\mathrm{CH} 4}$. This can be defined as the fraction of carbon gasified as methane or:

$$
\mathrm{S}_{\mathrm{CH} 4}=\mathrm{R}_{\mathrm{CH} 4} /\left(\mathrm{R}_{\mathrm{CO}}+\mathrm{R}_{\mathrm{CO} 2}+\mathrm{R}_{\mathrm{CH} 4}\right)
$$

Where $R_{\mathrm{CO}}$ and $\mathrm{R}_{\mathrm{CO} 2}$ are the rates of carbon oxide formation. This equation assume that the only gasification products are methane, carbon monoxide, and carbon dioxide. The selectivity is 1 if none of the char is converted to carbon oxides.

\subsubsection{Effect of Pressure}

Figure 17 reports methane formation rates at $700^{\circ} \mathrm{C}$ for different hydrogen partial pressures. These runs all exhibited rapid-rate gasification, followed by a sharp decline in rate to zero or to some low steady state value. Pressure does not have a dramatic effect on the rate of activity loss after the rapidrate stage. Carbon oxide formation in these runs was negligible (see Appendix C), so methane selectivities approached 1. The important conclusion to be drawn from Figure 17 is that increasing hydrogen pressure above 285 psig has little or no effect on methane production rate at this temperature. The effect on total weight loss is also small.

The kinetic expression which was discussed above indicates that the methane formation rate should increase in proportion to hydrogen partial pressure. The results reported in Figure 17 are not consistent with this kinetic expression in that reaction rates do not increase in direct proportion to pressure. This result may indicate the presence of product inhibition at higher pressures or the onset of mass or heat transport limitations.

\subsubsection{Effect of Temperature}

Figure 18 shows the effect of temperature on methane formation rate constants. The rate constants were calculated 


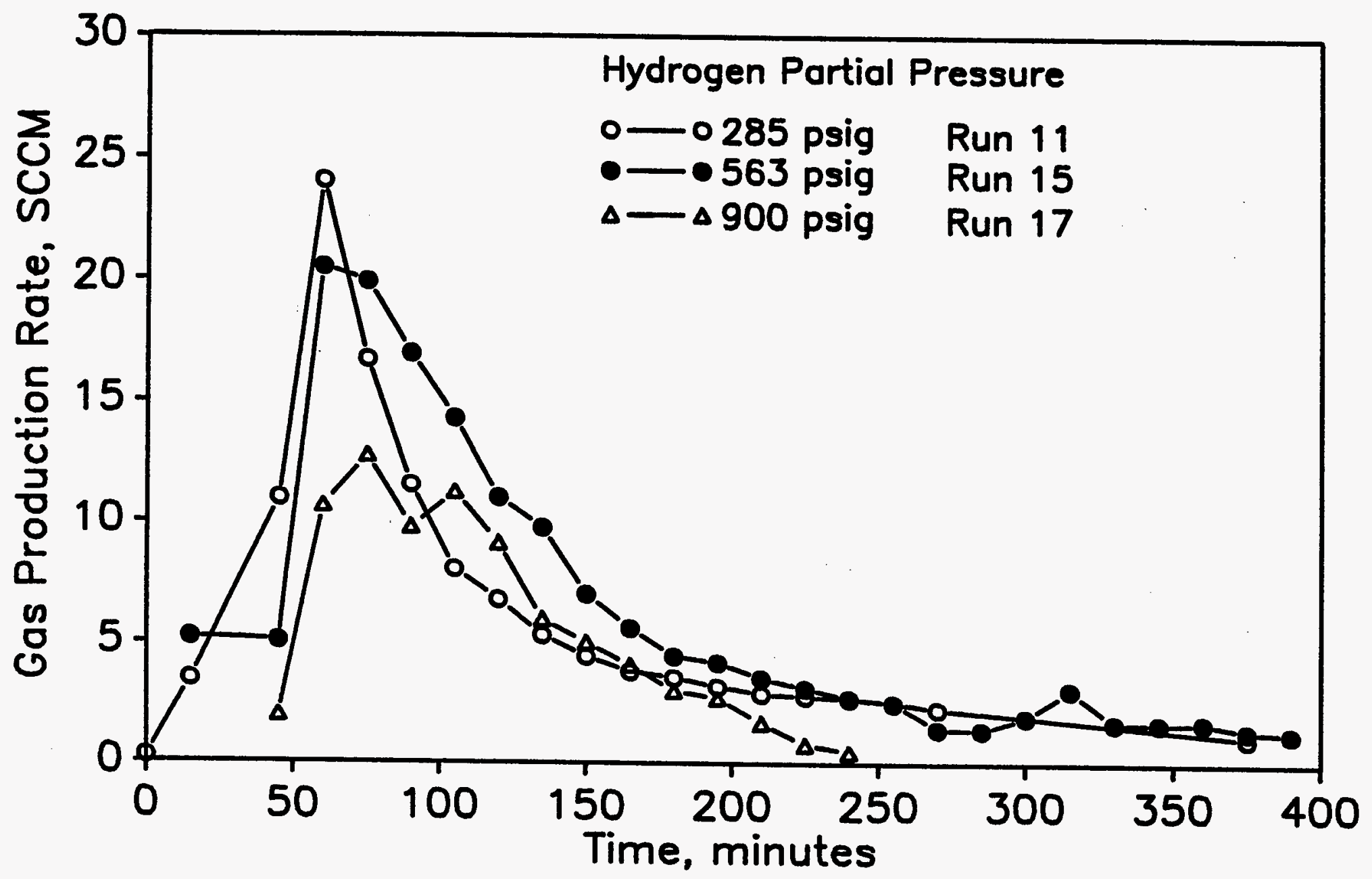

Figure 17. Effect of hydrogen partial pressure on methane formation rates in microfixed-bed tests. 


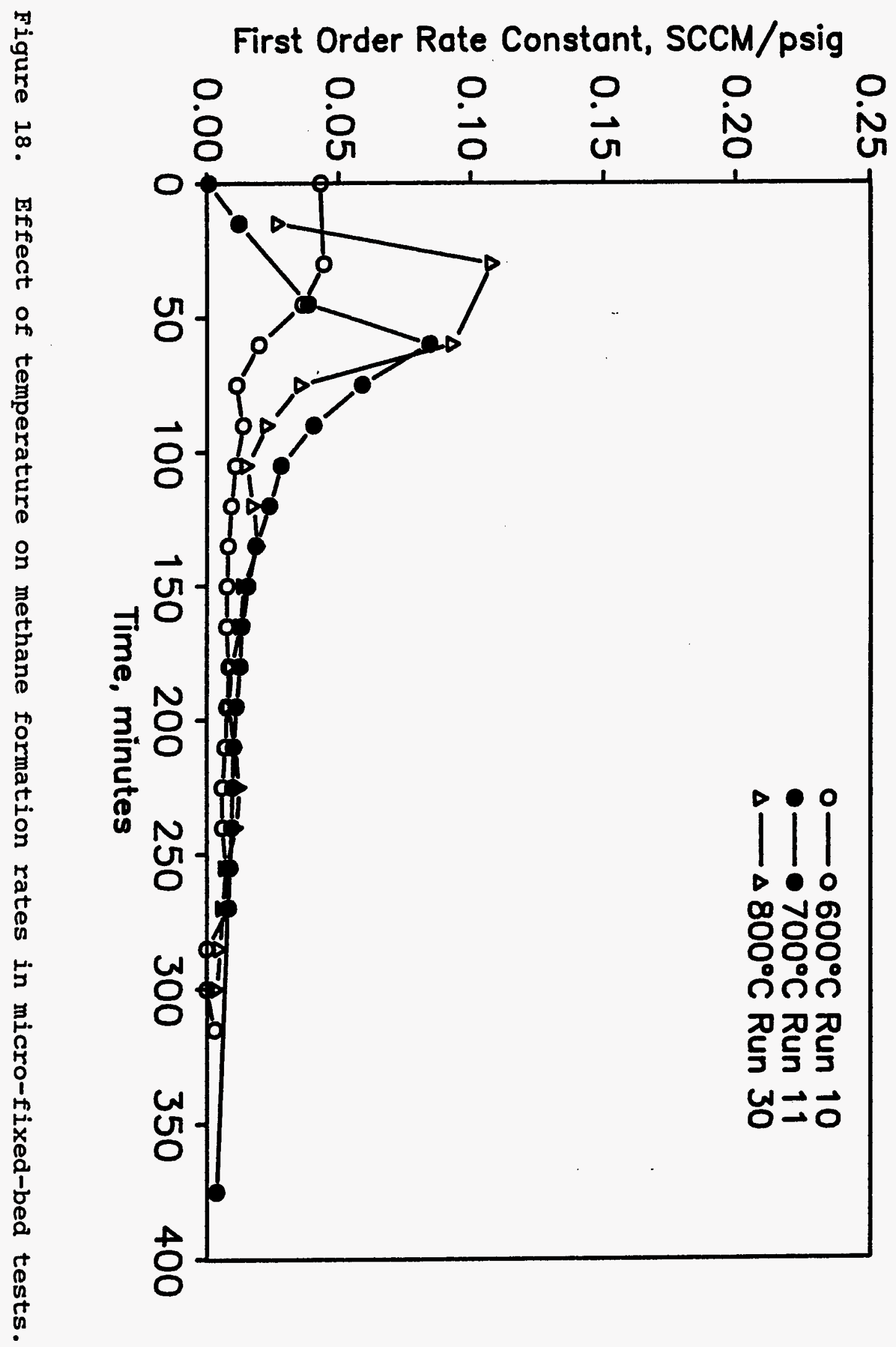


from Equation 5.4. This parameter is a function of temperature only and, therefore, removes the effect of pressure from the evaluation. The data in Figure 18 indicate very little influence of temperature on the reaction rate for the conditions tested, except during the initial stages of the run. Total weight loss data for Runs 10, 11, and 30 also suggest only a small temperature influence. Carbon oxide formation was negligible in these runs, so methane selectivity is approximately 1 .

The disappearance of the temperature effect after the first few minutes of the run could be caused by several factors. It is possible that as char conversion proceeds, micropores are formed and the reaction becomes pore diffusion limited, or the char temperature may rise because of the heat of reaction and the reaction might become thermodynamically limited. Also, the char may become unreactive at some conversion level or at high temperatures.

\subsubsection{Effect of Steam}

Runs 12, 13, 14, and 27 investigated the effect of adding steam to the feed gas. Figure 19 shows the methane production rate as a function of time for runs conducted at $700^{\circ} \mathrm{C}$, including Run 11 which was made without steam. Run 12 exhibits a lower maximum methane rate than the other runs. This is most likely an error in that the product gas was not sampled at the time of the maximum rate. The most important point to be made by Figure 19 is that at $700^{\circ} \mathrm{C}$, the use of steam does not enhance methane formation rates and may, in fact, inhibit methane formation.

Figure 20 shows the effect of steam addition at $800^{\circ} \mathrm{C}$. At $700^{\circ} \mathrm{C}$ (Runs 11 and 12 , Figure 19), steam has virtually no effect. Raising the temperature without steam also does not increase the methane formation rate constant (Run 30, Figure 18). However, at $800^{\circ} \mathrm{C}$, steam does increase the methane formation rate slightly. This increase in methane rate with steam at $800^{\circ} \mathrm{C}$ is accompanied by undesirable side reactions to form carbon oxides. This is illustrated in Figure 21 where the selectivity to methane is plotted for runs made with and without steam at $800^{\circ} \mathrm{C}$. Figure 21 indicates that including steam in the feed gas at $800^{\circ} \mathrm{C}$ results in methane selectivities that average below 0.5 . One is the maximum possible methane selectivity. Selectivities approaching this value were observed in runs made with steam at lower temperatures and in all other non-catalytic runs made without steam at any temperature. The high total weight loss of 55 percent reported for Run 27 in Table 13 is the result of steam gasification of much of the carbon to carbon oxides. 


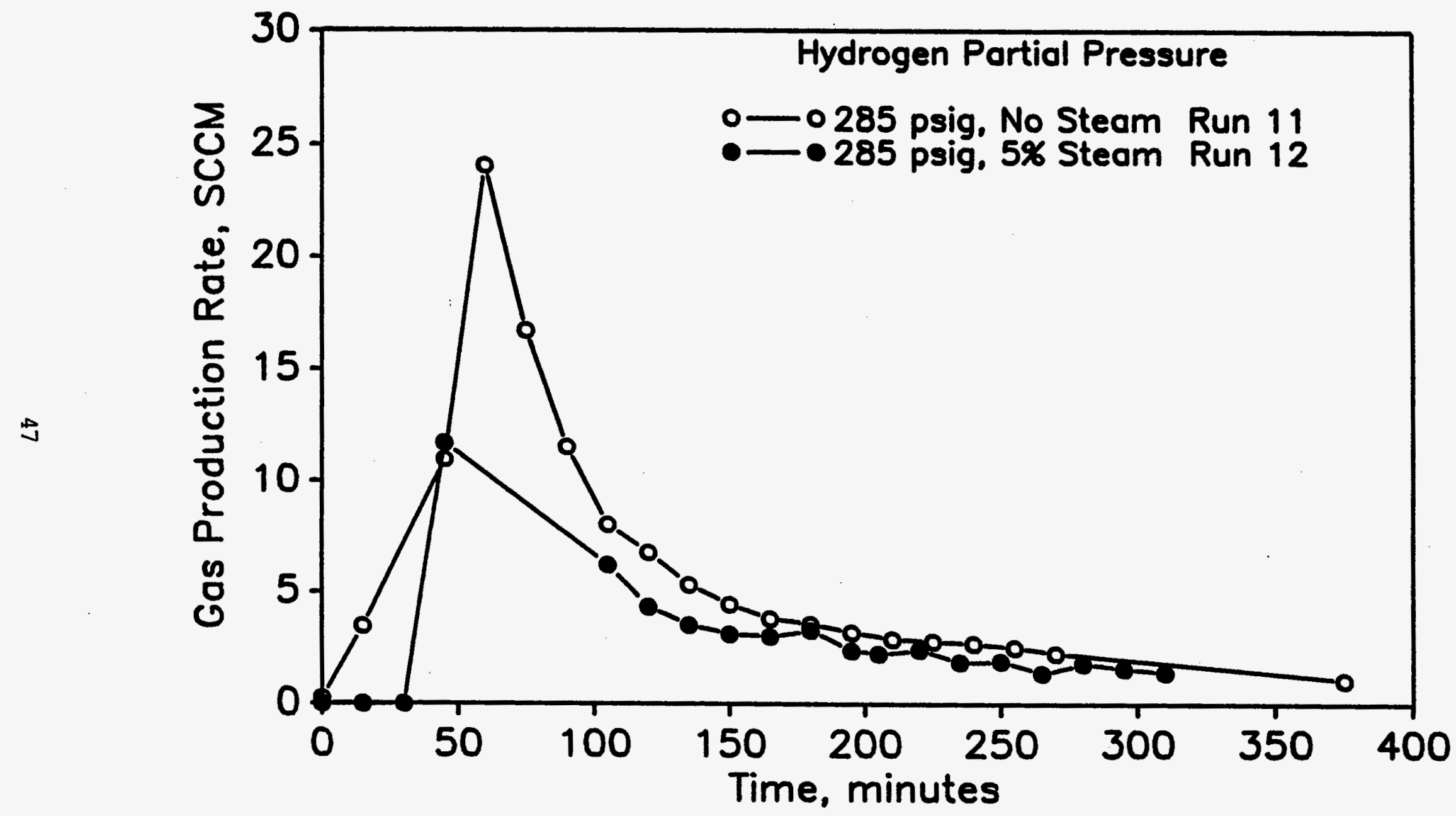

Figure 19. Effect of steam on methane formation rates in micro-fixed-bed tests at $700^{\circ} \mathrm{C}$. 


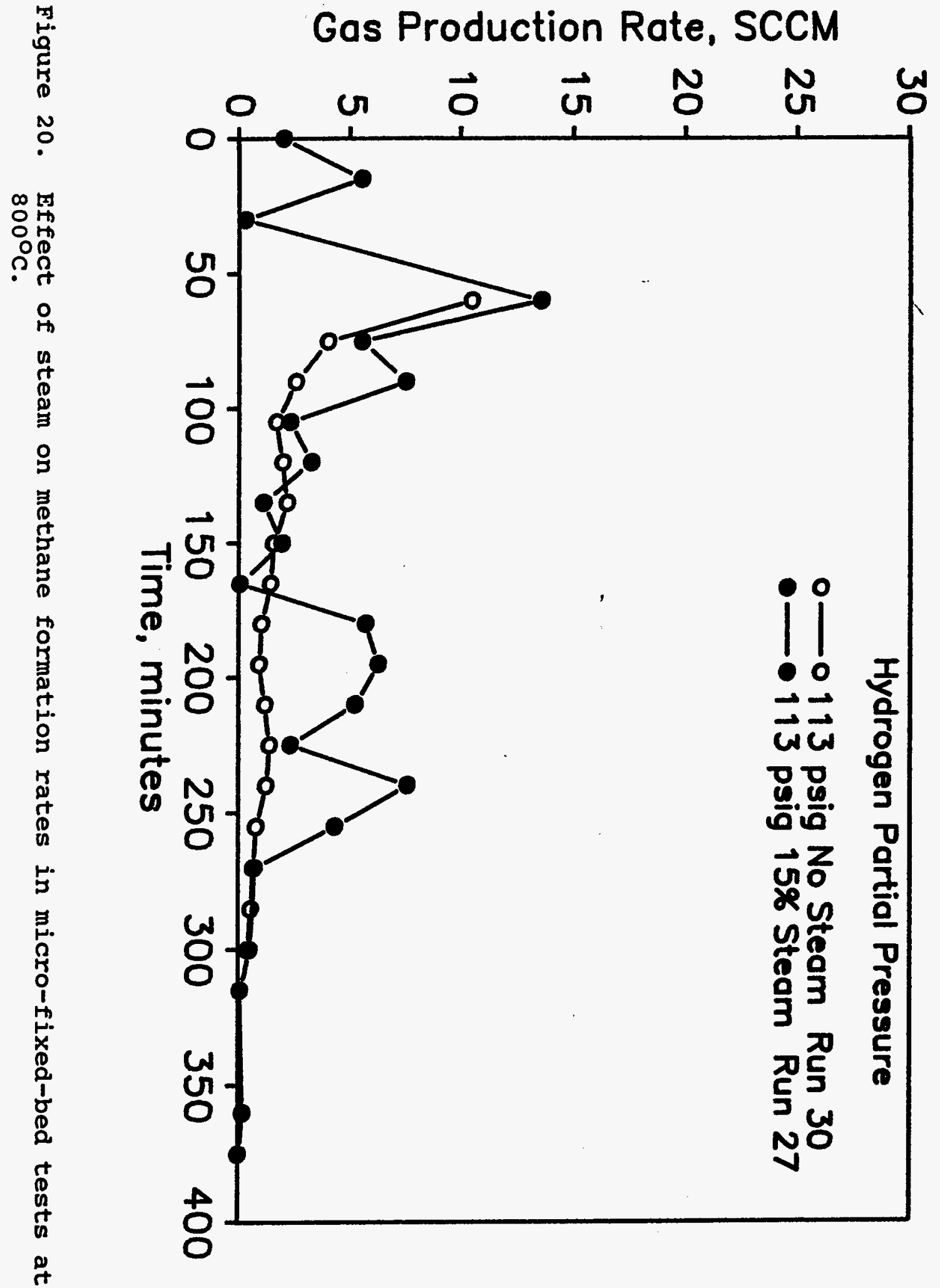




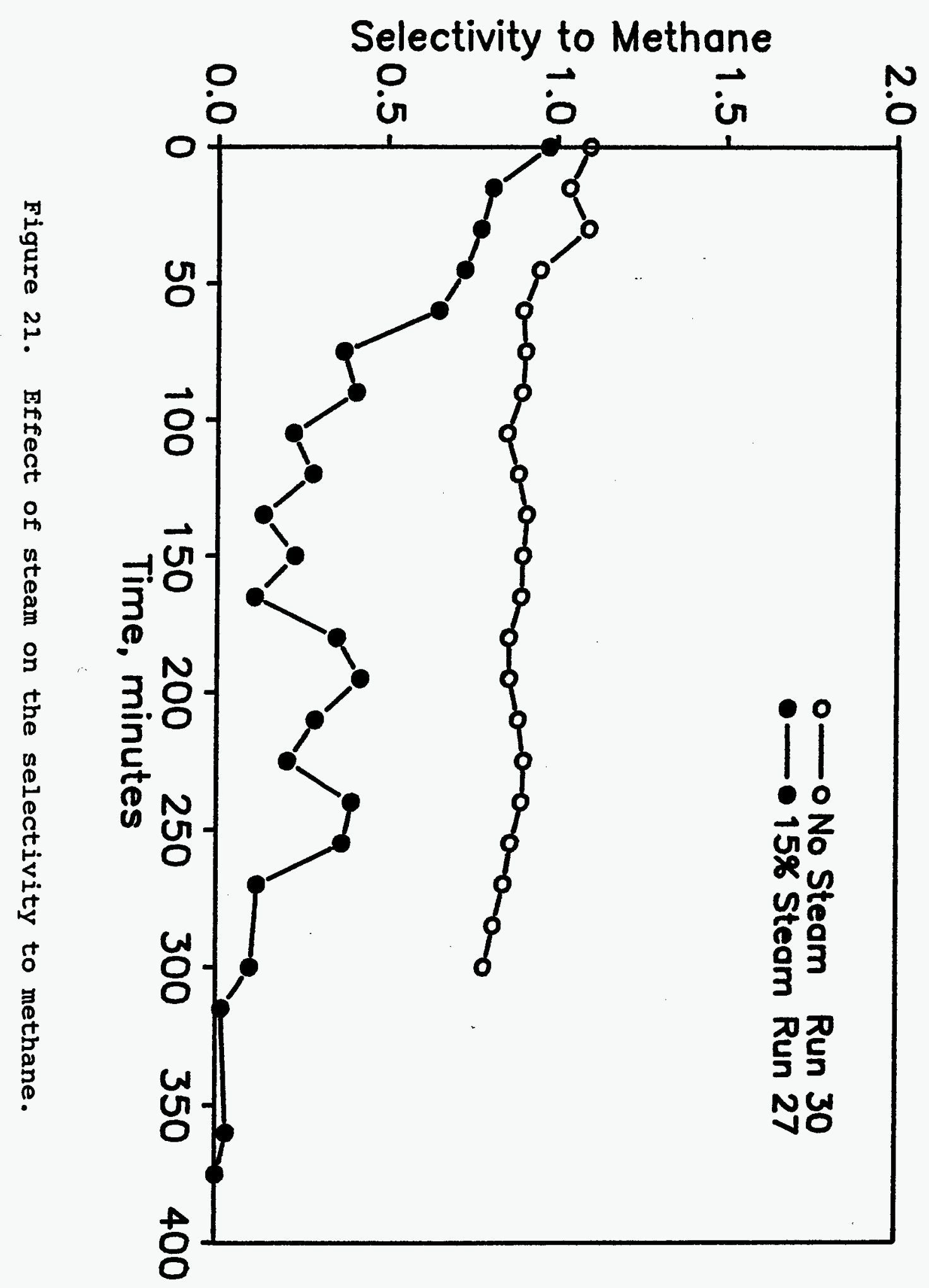




\subsubsection{Effect of Catalysts}

\subsubsection{Iron Catalysts}

The catalytic influence of iron was investigated using 5 percent impregnated iron nitrate and 5 percent physically mixed magnetite. The results of these runs (Runs $19,23,28,31$, 33, and 34) are presented in Appendix $C$ and in Table 14. Iron has been reported to be a highly active hydrogasification catalyst in both wet and dry atmospheres. 23

Figure 22 shows the effect of impregnated iron at $700^{\circ} \mathrm{C}$ on methane formation rates. The data indicate essentially no catalytic effect of iron at this temperature without steam. However, there is a small catalytic effect of about a factor of 1.5 to 2 in the presence of steam. Figure 23 shows the effect of this catalyst at $800^{\circ} \mathrm{C}$. At this temperature, there does seem to be a catalytic effect during the initial stage. However, methane formation rates are not enhanced during the steady-state stage of the run.

The results also indicate that impregnated iron has little effect on selectivity. Runs conducted with dry feed gas show almost no carbon oxide formation (see Appendix $c$ ). When steam was included in the feed gas, the results are almost identical to what was observed without a catalyst. This is illustrated in Figure 24 where at $700^{\circ} \mathrm{C}$, methane selectivity is near 1 ; while at $800^{\circ} \mathrm{C}$, selectivities are much less than 0.50 . So under the conditions studied, impregnated iron has little catalytic effect on the gasification rate and no effect on selectivity.

Magnetite was mixed with the char in Runs 33 and 34 to investigate the effect of physically mixed iron. A comparison of rates for these runs with those for uncatalyzed runs is shown in Figure 25. It is apparent that physically mixed iron has very little catalytic effect after the first few minutes of the run.

Total weight losses for runs made with iron are all quite low except for Run $28\left(800^{\circ} \mathrm{C}\right.$, steam). In this case, the high weight loss can be attributed to the formation of carbon oxides.

\subsubsection{Potassium Catalysts}

The catalytic effect of 5 percent impregnated potassium carbonate and 15 percent physically mixed potassium carbonate was investigated in Runs $16,22,24,29$, and 32 . Plots for each run are listed in Appendix $C$. The data in Table 14 indicate that the highest char weight losses were achieved in the runs using potassium. 


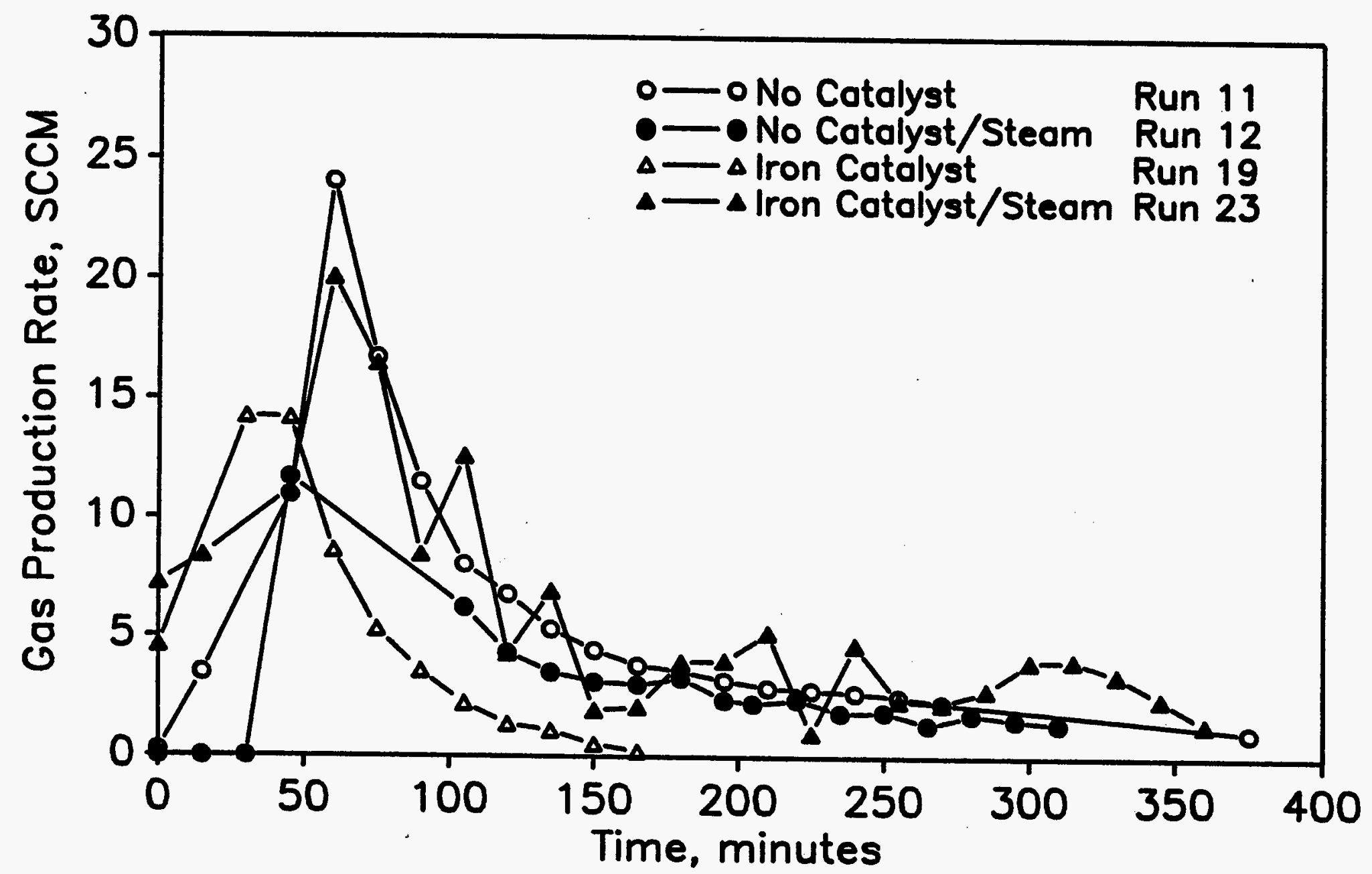

Figure 22. Effect of impregnated iron catalyst at $700^{\circ} \mathrm{C}$. 


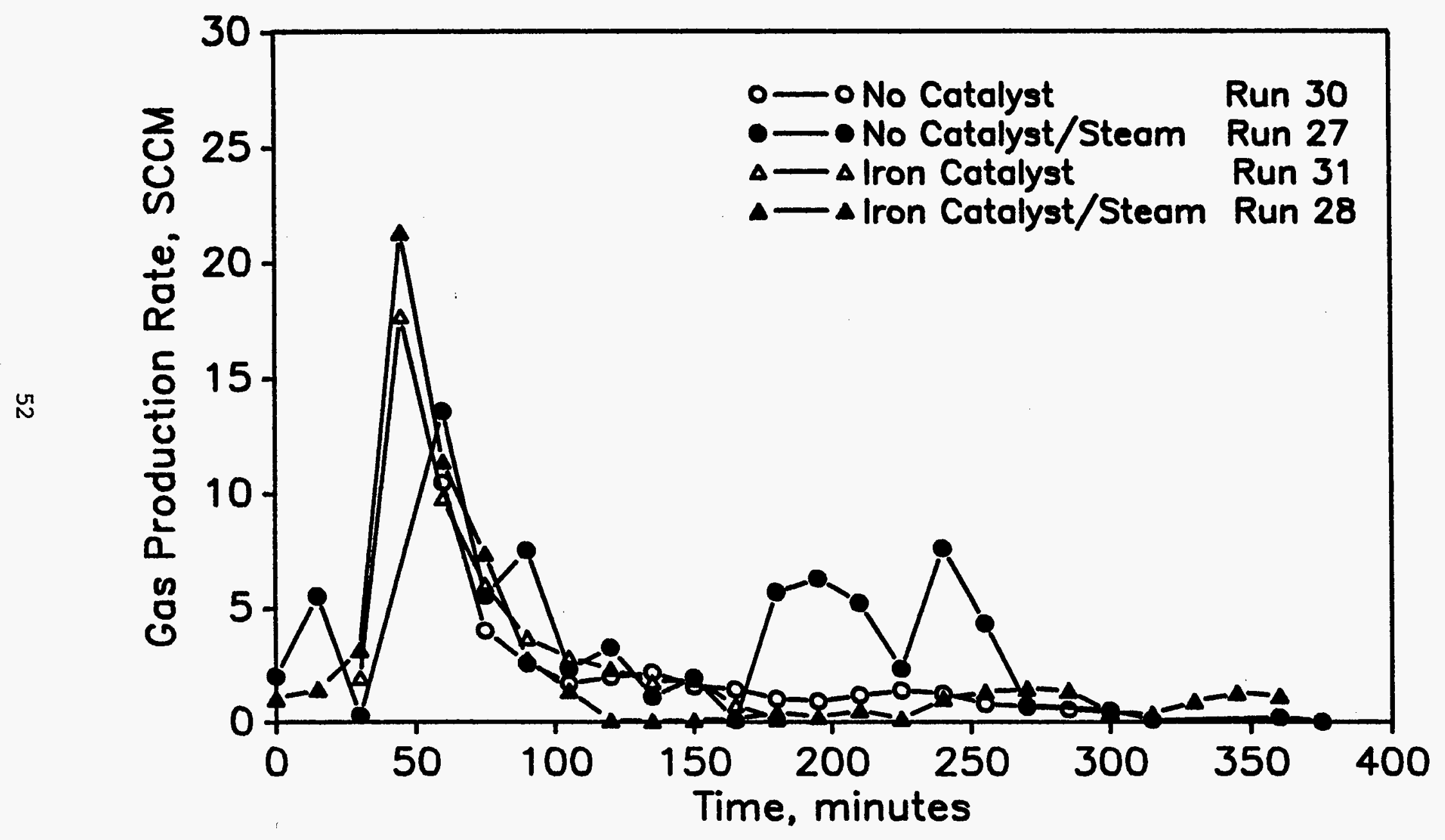

Figure 23. Effect of impregnated iron catalyst at $800^{\circ} \mathrm{C}$. 


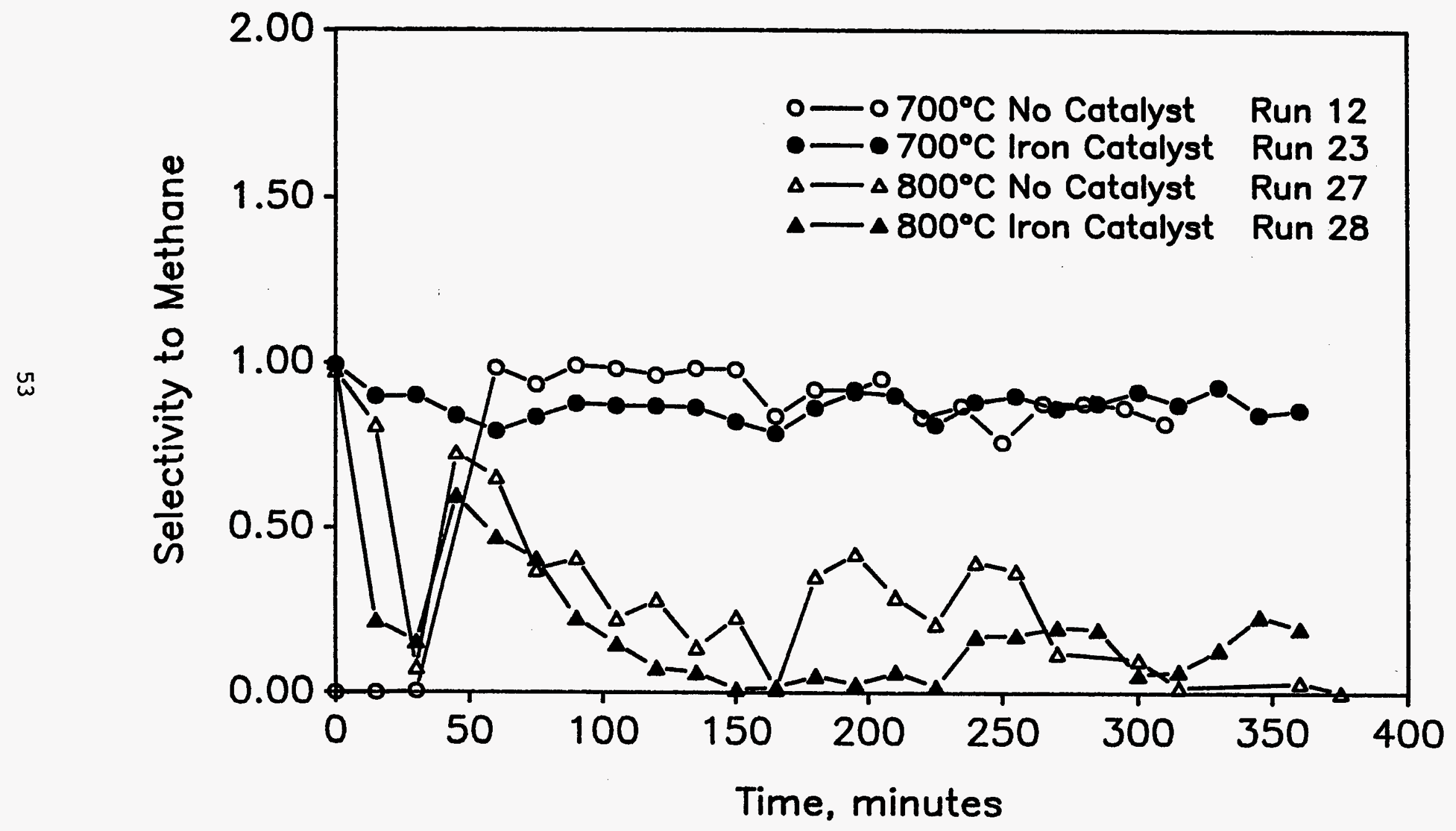

Figure 24. Effect of impregnated iron catalyst and steam on selectivity to methane. 


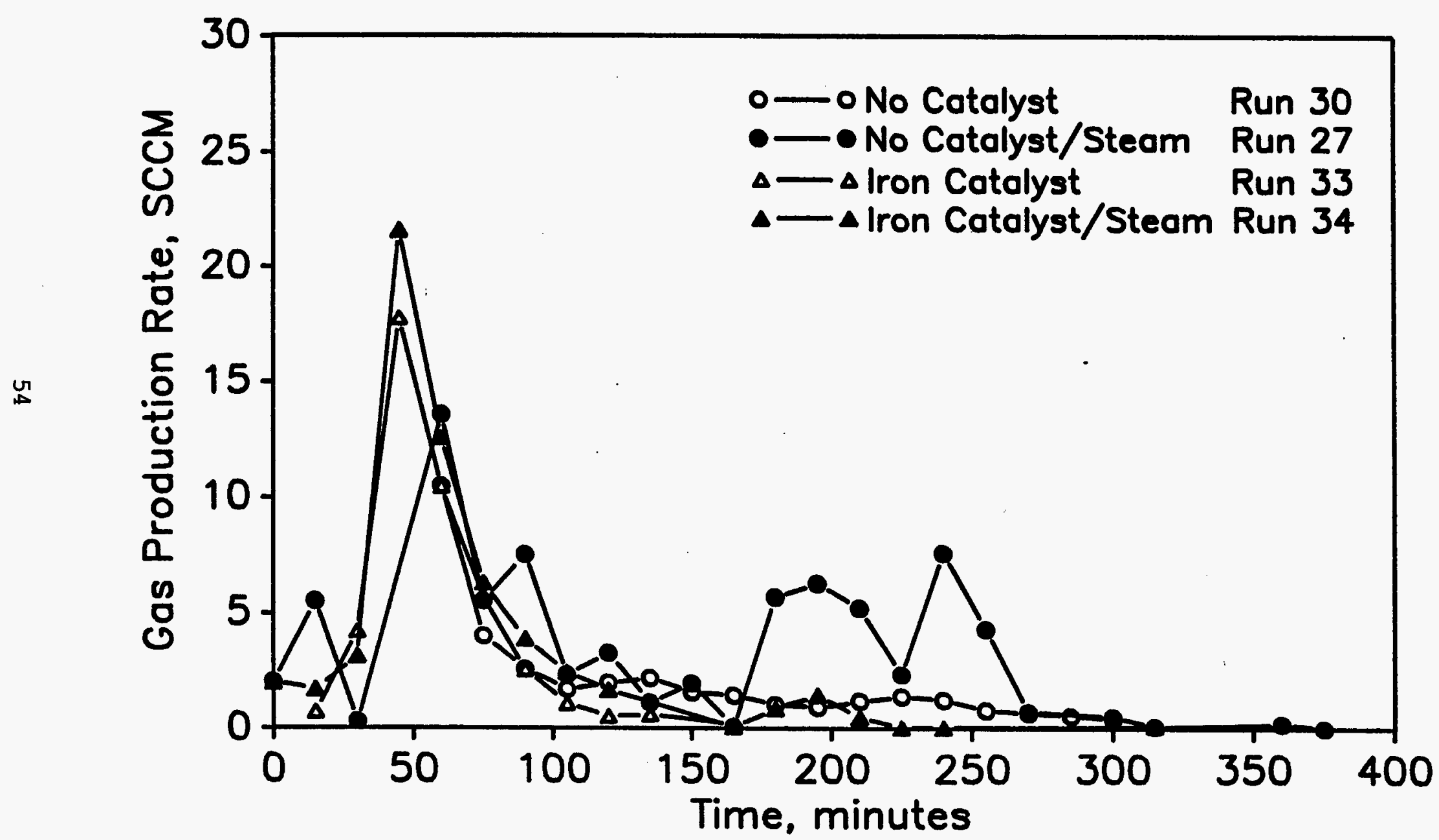

Figure 25. Effect of physically mixed magnetite catalyst. 
Figure 26 shows the effect of impregnated potassium on methane formation rates at $700^{\circ} \mathrm{C}$. The data indicate a catalytic effect on both rapid-rate and steady-state gasification. In the rapid-rate stage, the catalyst accelerates the rate by a factor of about 1.5 . In the steadystate stage, the catalytic enhancement is almost a factor of 3 . The use of steam has no effect on the methane formation rate in the presence of potassium at this temperature.

Figure 27 shows the effect of potassium on methane formation rates at $800^{\circ} \mathrm{C}$. Without steam, no catalytic effect is observed. There is some catalytic effect in the presence of steam, but catalytic activity declines much faster than was observed at $700^{\circ} \mathrm{C}$.

In runs made without steam, the selectivity to methane was near 1. The effect of potassium catalyst and steam on selectivity is illustrated in Figure 28. The results indicate no effect of potassium on selectivity. As was observed in uncatalyzed runs, the use of steam at $800^{\circ} \mathrm{C}$ results in very low selectivities to methane.

Run 16 was conducted using 15 percent physically mixed potassium carbonate. The results of this run are compared with the results of uncatalyzed and impregnated potassium catalyzed runs made at similar conditions in Figure 29. Rate constants are plotted because the runs were not all made at the same pressure. The physically mixed catalyst produces a steadystate rate enhancement of about a factor of 2 compared to almost a factor of 3 for the impregnated catalyst. The mixed catalyst had almost no effect of the rapid-rate stage, however.

These results indicate a pronounced catalytic effect of potassium carbonate and indicate that this material is active in the physically mixed form. The use of physically mixed catalysts is highly desirable in a gasification process because this eliminates a process step (impregnation).

\subsubsection{Summary}

are:

The significant results from the micro-fixed-bed study

- The use of steam can enhance methane formation rates at $800^{\circ} \mathrm{C}$ (but not at $700^{\circ} \mathrm{C}$ ), but only at the expense of steam gasifying a large fraction of the carbon to carbon oxides.

- Iron catalysts do not exhibit sufficient rate enhancement to merit further attention.

- Potassium and possibly other alkali metal catalysts are promising because of their high activity and activity in the physically mixed form. 


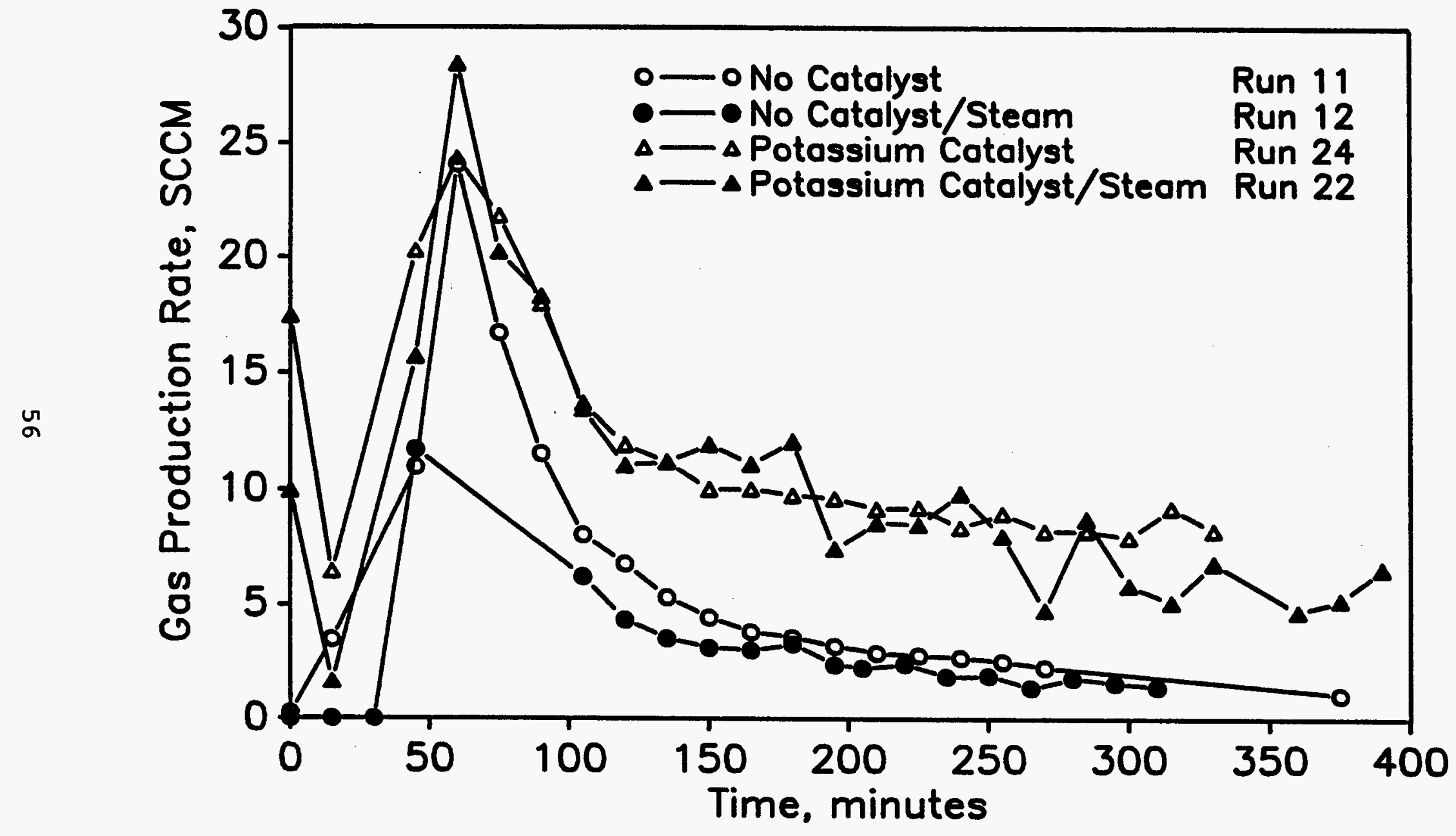

Figure 26. Effect of impregnated potassium catalyst at $700^{\circ} \mathrm{C}$. 


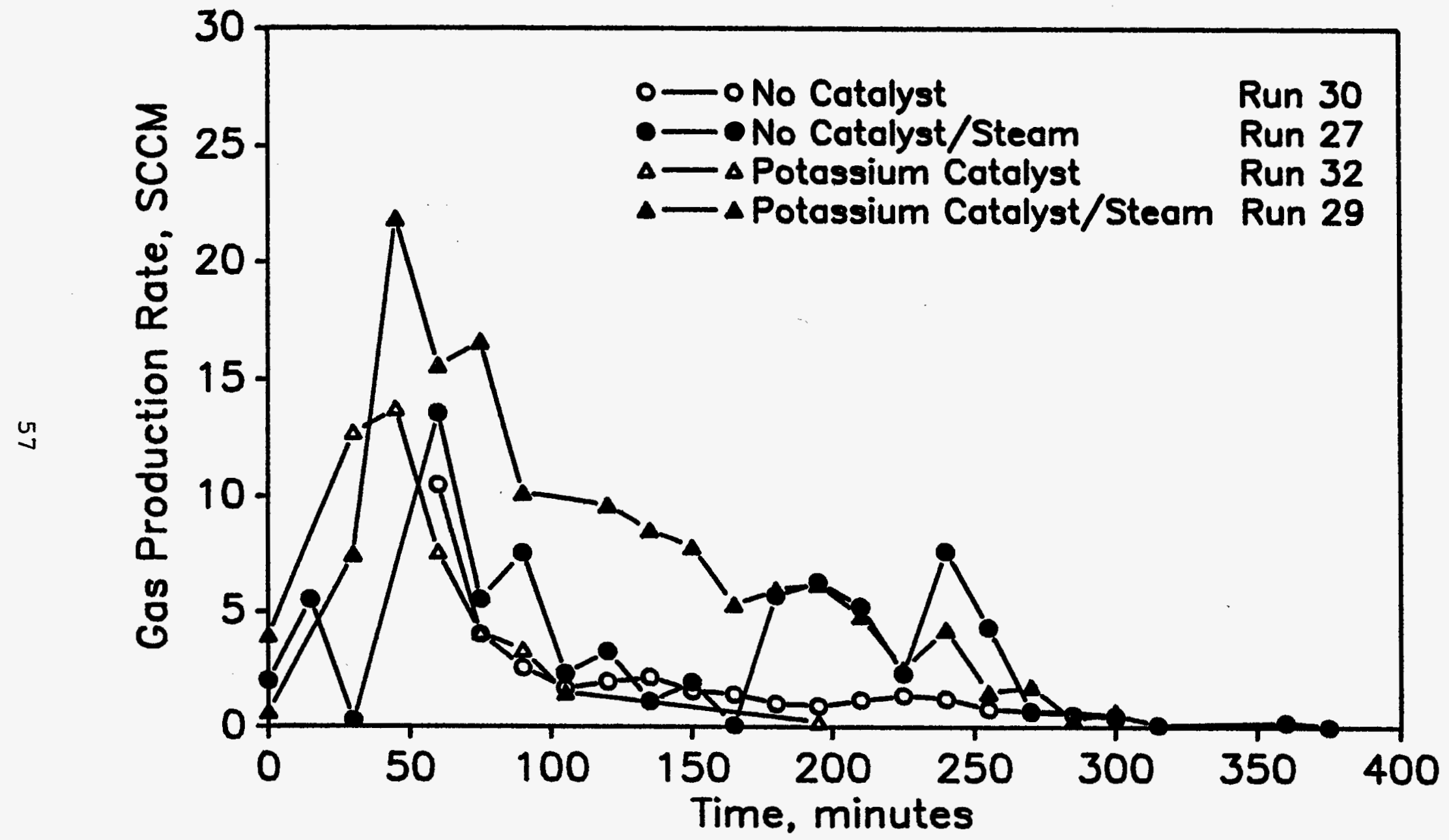

Figure 27. Effect of impregnated potassium catalyst at $800^{\circ} \mathrm{C}$. 


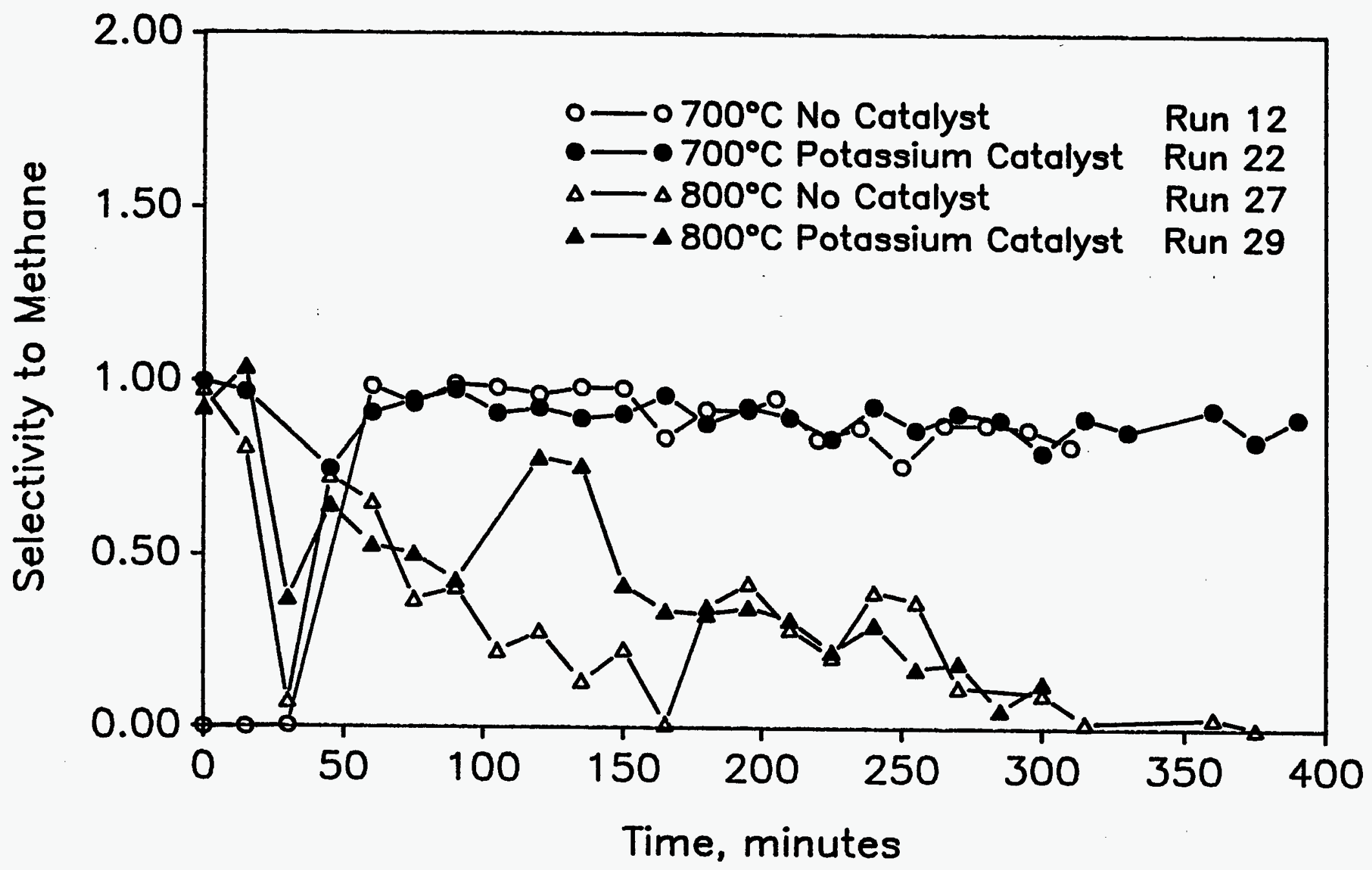
Figure 28. Effect of impregnated potassium catalyst and steam on selectivity to
methane. 


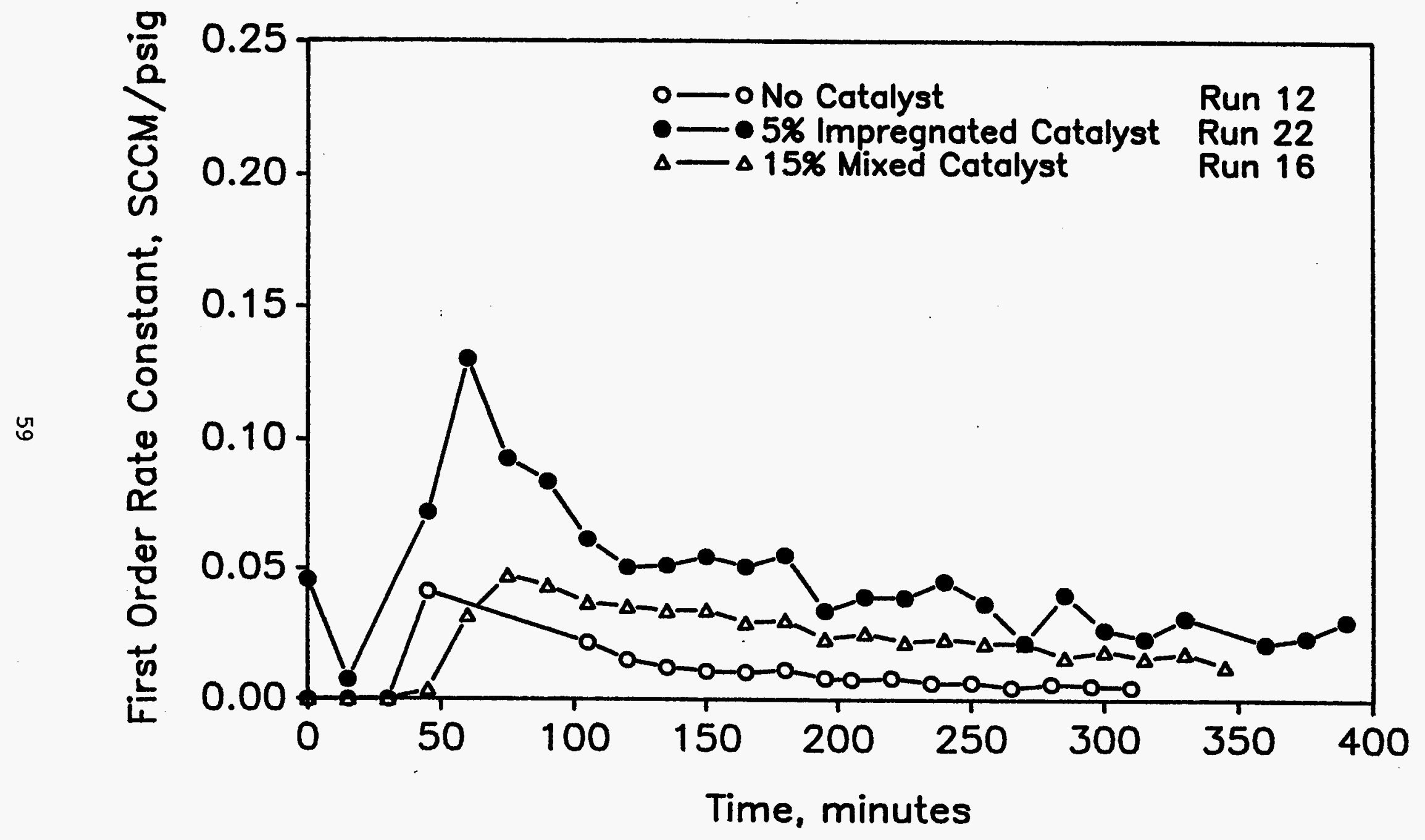

Figure 29. Effect of physically mixed potassium carbonate catalyst. 
- The effects of pressure and temperature could not be adequately examined in the micro-fixed-bed system probably because of heat and mass transport limitations.

\subsection{BENCH-SCALE FIXED-BED REACTOR TESTS}

Bench-scale tests involved process variable studies on two chars (MGT-9 and MGT-12), a study of rate inhibition by methane, a study of potassium carbonate and sodium carbonate as catalysts, and a study of the reactivity of all mild gasification chars. More than 50 runs were conducted, well in excess of the number specified in the test plan.28 plots of percent conversion (maf) and bed temperature as a function of time on stream can be found in Appendix $D$ for all bench-scale char gasification runs. There are two measurements of conversion reported for these runs. The first, which is reported in the tables, is based on the char weight loss converted to an ash-free basis. The second, which is reported in the figures, is calculated from the methane production rate. Final conversions from both methods usually agree within 2 or 3 percent when the loss of volatile matter during heat-up is taken into account.

Because steam was shown to have no benefit in the microfixed-bed tests, the use of steam was not investigated on the bench scale. Also, chars produced from caking coal were not tested because the mild gasification of caking coals did not prove to be feasible in the inclined fluid-bed mild gasification system at WRI.

\subsubsection{Preliminary Runs}

Eight preliminary runs were conducted. All were conducted at $400 \mathrm{psig}$ at temperatures ranging from 700 to $900^{\circ} \mathrm{C}$. A summary of run conditions is shown in Table 15. The only significant gaseous product of these runs was methane. Weight loss data reported in this table indicate that a much higher fraction of the char was gasified at $700^{\circ} \mathrm{C}$ than at 800 or $900^{\circ} \mathrm{C}$. This is consistent with the results obtained in the micro-fixed-bed reactor.

Runs 03, 04, 08, 10, 11, and 12 were performed primarily to determine if the flow rate was high enough to avoid external diffusion limitations. However, in the runs made at $900^{\circ} \mathrm{C}(03$, 04,08 , and 10), problems were encountered with the methane mass flow controller, so these runs must be regarded as shakedown runs. Also, exit methane concentrations approached thermodynamic equilibrium. Temperature profiles were not obtained, so they are not shown in Appendix D. Conversion versus time plots are shown for these runs in Figure 30 . As this figure indicates, conversions were very low in all cases. Agreement between calculated conversions, as shown in the 


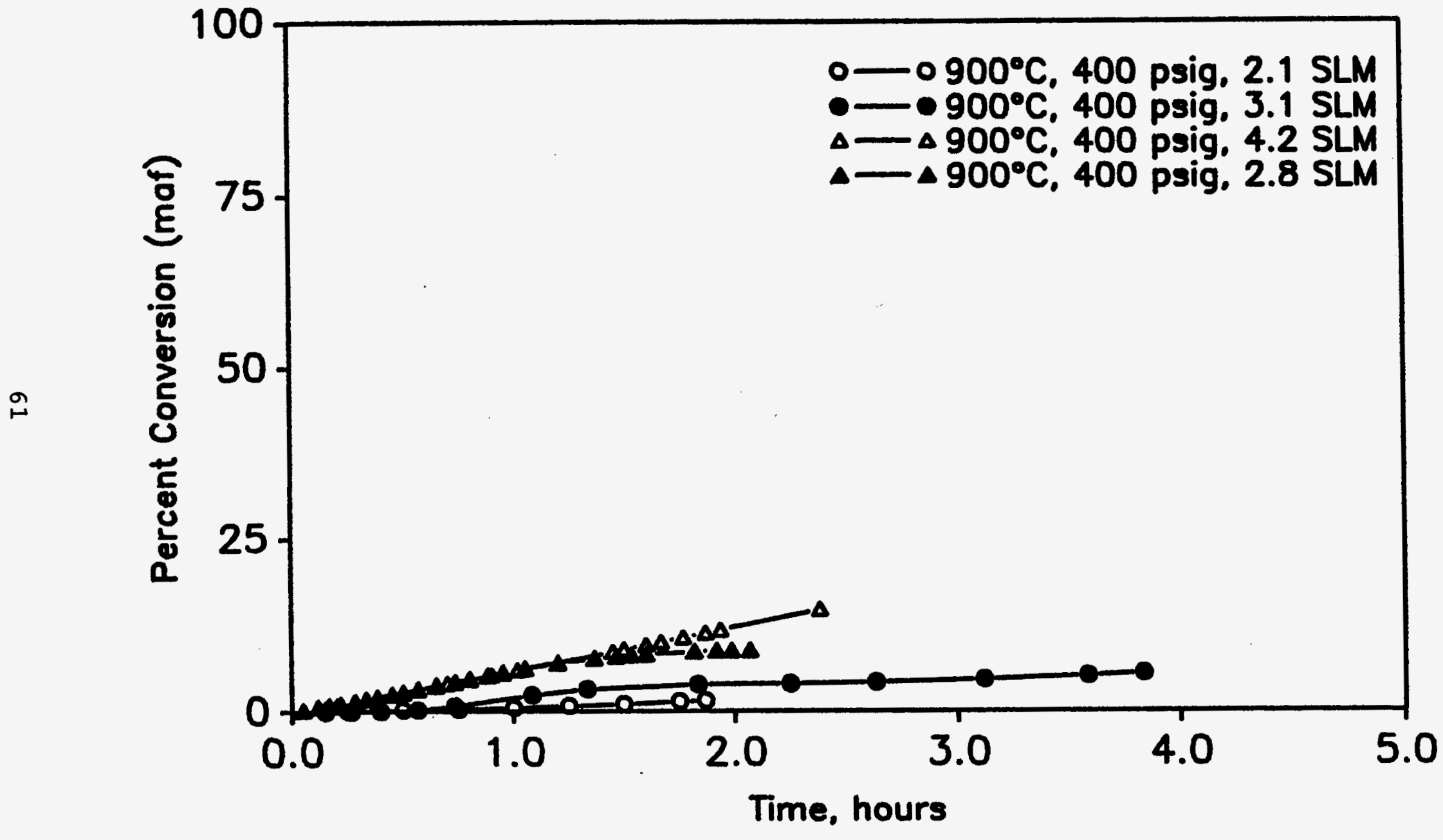

Figure 30. Percent conversion as a function of time on stream for preliminary benchscale char gasification runs conducted at $900^{\circ} \mathrm{C}$. 
figure, and actual measured weight losses; as reported in

Table 15, is quite good.

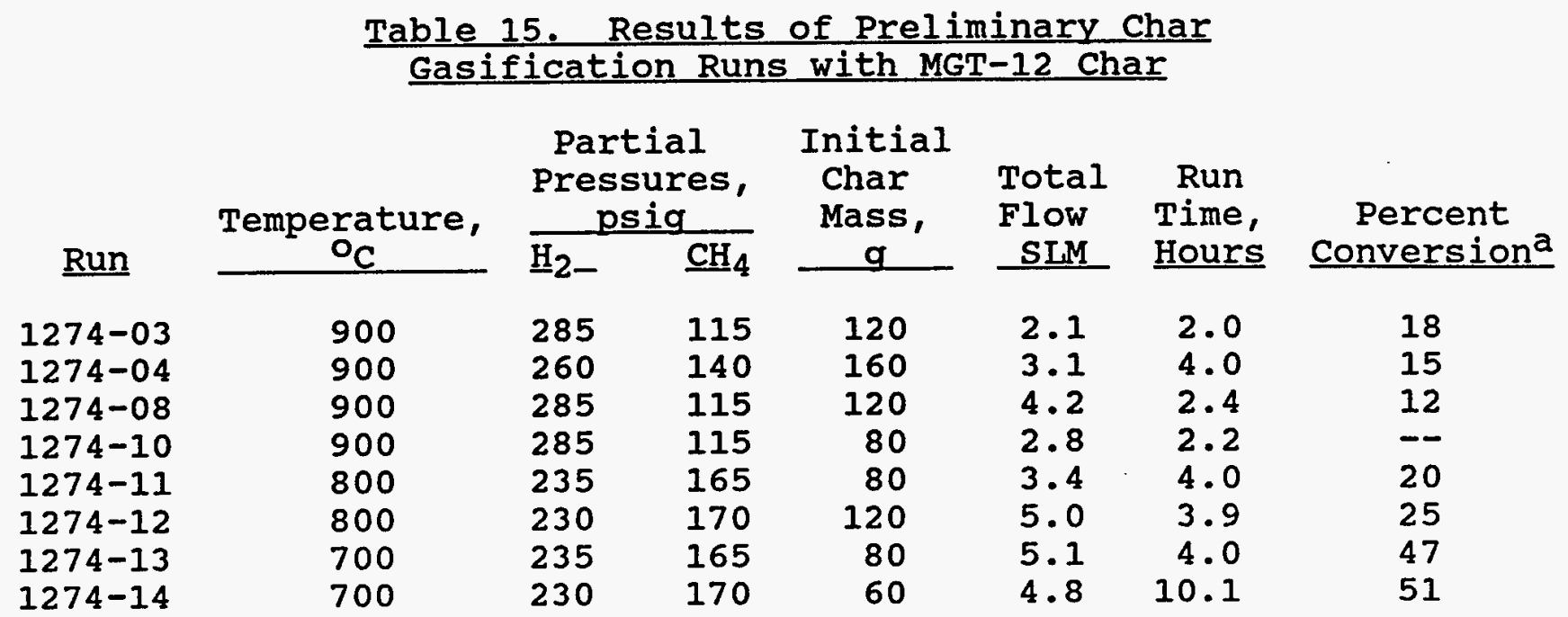

a Ash-free basis.

Runs 11 and 12 were conducted at $800^{\circ} \mathrm{C}$ and at different flow rates (with constant initial space velocity) to investigate the effect of external transport limitations. Gasification rate data are shown in Figure 31 . The gasification rate is significantly higher at $800^{\circ} \mathrm{C}$ than at $900^{\circ} \mathrm{C}$, but exit gas concentrations do not approach the thermodynamic limit (about 50 percent) as closely as at $900^{\circ} \mathrm{C}$. Reaction rates are almost identical in these two runs. This indicates that external diffusion limitations are probably not important under these conditions. Percent conversion as a function of time is shown in Figure 32. The calculated conversions of about 20 to 25 percent agree reasonably well with the total weight loss reported in Table 15.

Run 13 was conducted at $700^{\circ} \mathrm{C}$ and percent conversion data are reported in Appendix D. As before, lowering the temperature produced an increase in the observed gasification rate. Again, there is reasonable agreement between calculated conversion and measured weight loss. An extended run at the same conditions as Run 13 (Run 14) was conducted over the course of two days. The conversion in this run was only slightly higher than the conversion obtained in the 4-hour run. Inspection of the conversion versus time plot for Run 13 in Appendix $D$ indicates that most of the reaction occurs within the first 2 hours of the run.

Based on these preliminary experiments, it was decided that a flow rate of 4.0 SIM was sufficient for later 


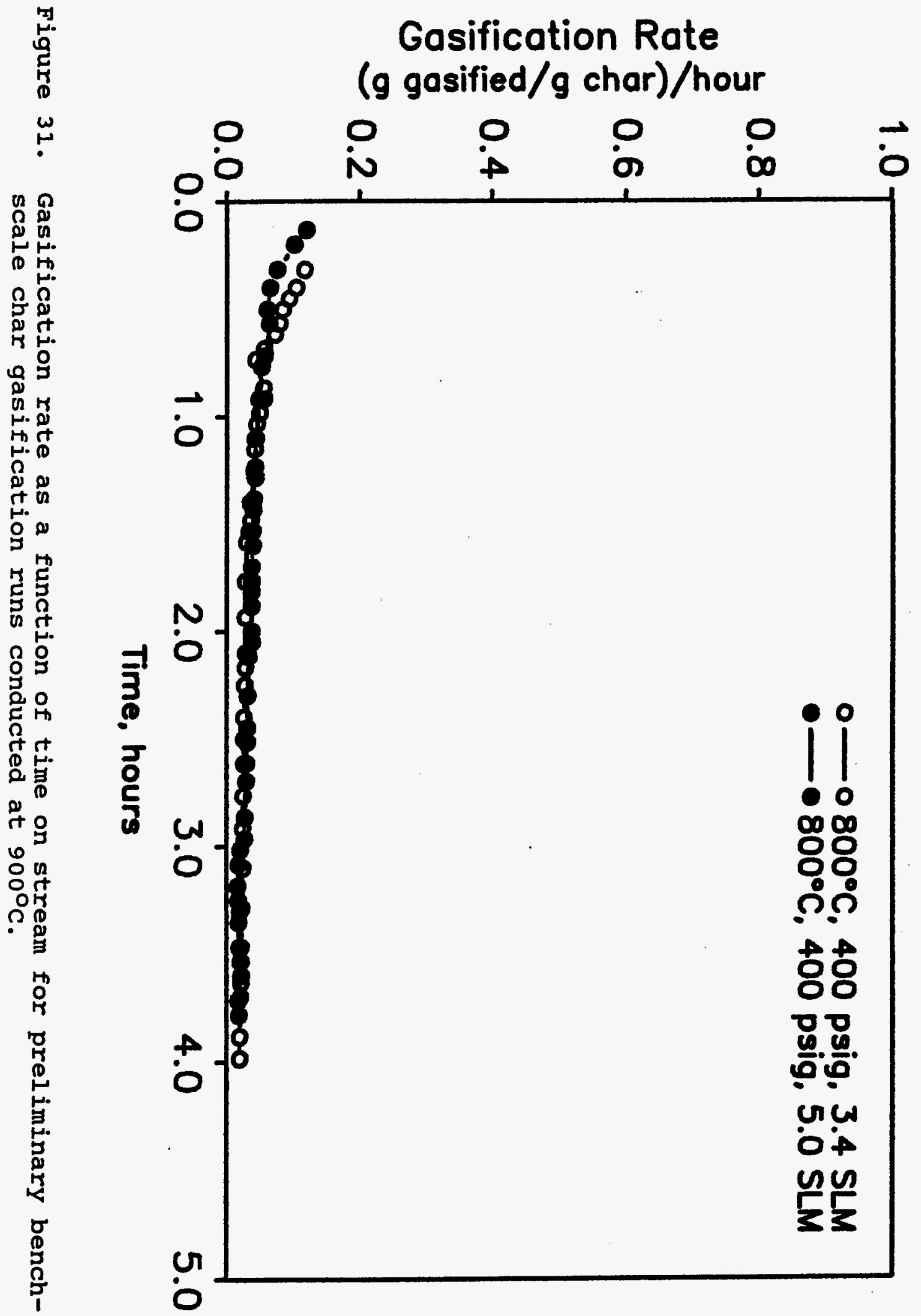




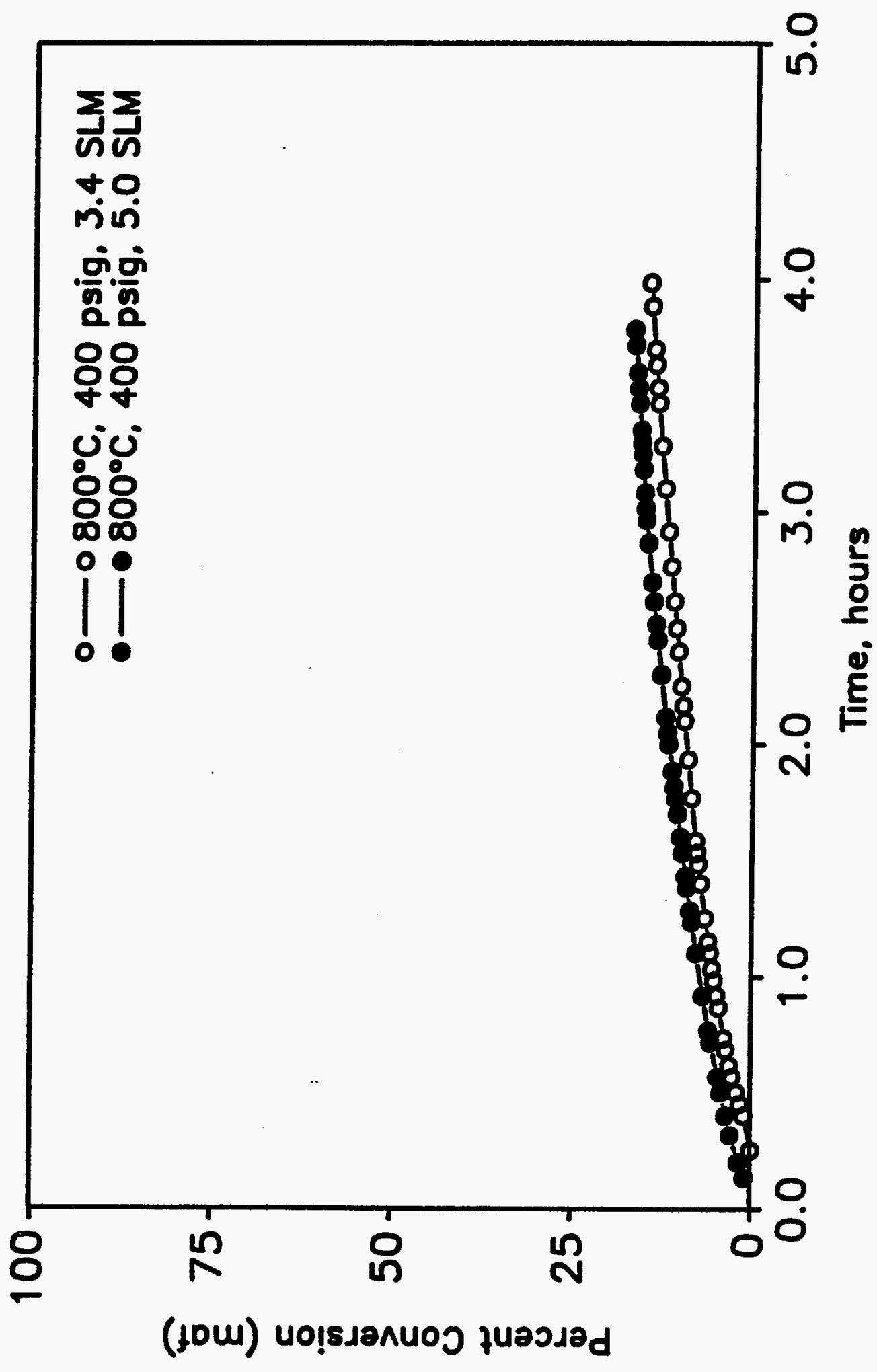

롱

\&

मे

$\stackrel{8}{\circ}$

E

or

수

芩

్ำ

U

म4.

is

द

崩

E

$+8$

40

$0 \stackrel{5}{7}$

ธ

.

$\forall$ 叫

马્

त 5

ט

ơ

동 U

운

क्

ब

o

엉

$+\frac{5}{0}$

동

0

प्र

¿

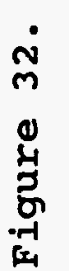


experiments. Also, temperatures in the range of 650 to $850^{\circ} \mathrm{C}$ were selected. There was no advantage to run times of more than a few hours, so runs were normally limited to 4 hours.

\subsubsection{Process Variable Study with MGT-12 Char}

The results of a process variable study using MGT-12 char are listed in Table 16. The variables investigated were temperature, pressure, and methane inhibition. Results of replicated runs (runs 21 and 29) indicate some experimental error, but the conversion values are relatively close. Figure 33 shows conversion versus time plots for runs made with pure hydrogen as the feed gas and in the range of 650 to $750^{\circ} \mathrm{C}$ and 185 to $385 \mathrm{psig}$. It is apparent from this plot that higher temperatures produce higher conversions. The highest conversion obtained was 74 percent. An important feature of the data is that under all conditions studied, the gasification reaction is very nearly complete after $1-1 / 2$ hours on stream.

Table 16. Results of Char Gasification Process Variable study with MGT-12 Char

\begin{tabular}{|c|c|c|c|c|c|c|}
\hline \multirow[b]{2}{*}{ Run } & \multirow{2}{*}{$\begin{array}{c}\text { Temperature, } \\
{ }^{\circ} \mathrm{C} \\
\end{array}$} & \multicolumn{2}{|c|}{$\begin{array}{c}\text { Partial } \\
\text { Pressures, } \\
\text { psig } \\
\end{array}$} & \multirow{2}{*}{$\begin{array}{c}\text { Initial } \\
\text { Char } \\
\text { Mass, } \\
\text { g } \\
\end{array}$} & \multirow{2}{*}{$\begin{array}{l}\text { Run } \\
\text { Time, } \\
\text { Hours }\end{array}$} & \multirow{2}{*}{$\begin{array}{c}\text { Percent } \\
\text { Conversion a }\end{array}$} \\
\hline & & $\underline{\mathrm{H}}_{2-}$ & $\underline{\mathrm{CH}}_{4}$ & & & \\
\hline $1274-20$ & 650 & 305 & 95 & 80 & 4.0 & 33 \\
\hline $1274-21$ & 700 & 285 & 0 & 80 & 4.0 & 66 \\
\hline $1274-22$ & 650 & 185 & 0 & 80 & 4.0 & 30 \\
\hline $1274-23$ & 750 & 185 & 0 & 80 & 4.0 & 68 \\
\hline $1274-24$ & 650 & 385 & 0 & 80 & 4.0 & 31 \\
\hline $1274-25$ & 750 & 385 & 0 & 80 & 4.0 & 74 \\
\hline $1274-29$ & 700 & 285 & 0 & 80 & 4.1 & 54 \\
\hline $1274-51$ & 750 & 205 & 95 & 80 & 4.0 & 65 \\
\hline $1274-52$ & 750 & 200 & 135 & 80 & 4.0 & 53 \\
\hline $1274-54$ & 750 & 180 & 120 & 80 & 4.0 & 67 \\
\hline $1274-62$ & 750 & 285 & 0 & 80 & 4.0 & 68 \\
\hline $1274-65$ & 750 & 285 & 15 & 80 & 4.0 & 70 \\
\hline
\end{tabular}

a Ash-free basis.

Final conversion as a function of temperature for all runs made with pure hydrogen as the feed is shown in Figure 34 . The trend of higher conversion with increasing temperature is evident. The effect of temperature on gasification rate at 385 psig is shown in Figure 35. The maximum rates obtained at the beginning of the run are independent of temperature. Raising the temperature appears to increase the length of time at which relatively fast gasification occurs. 


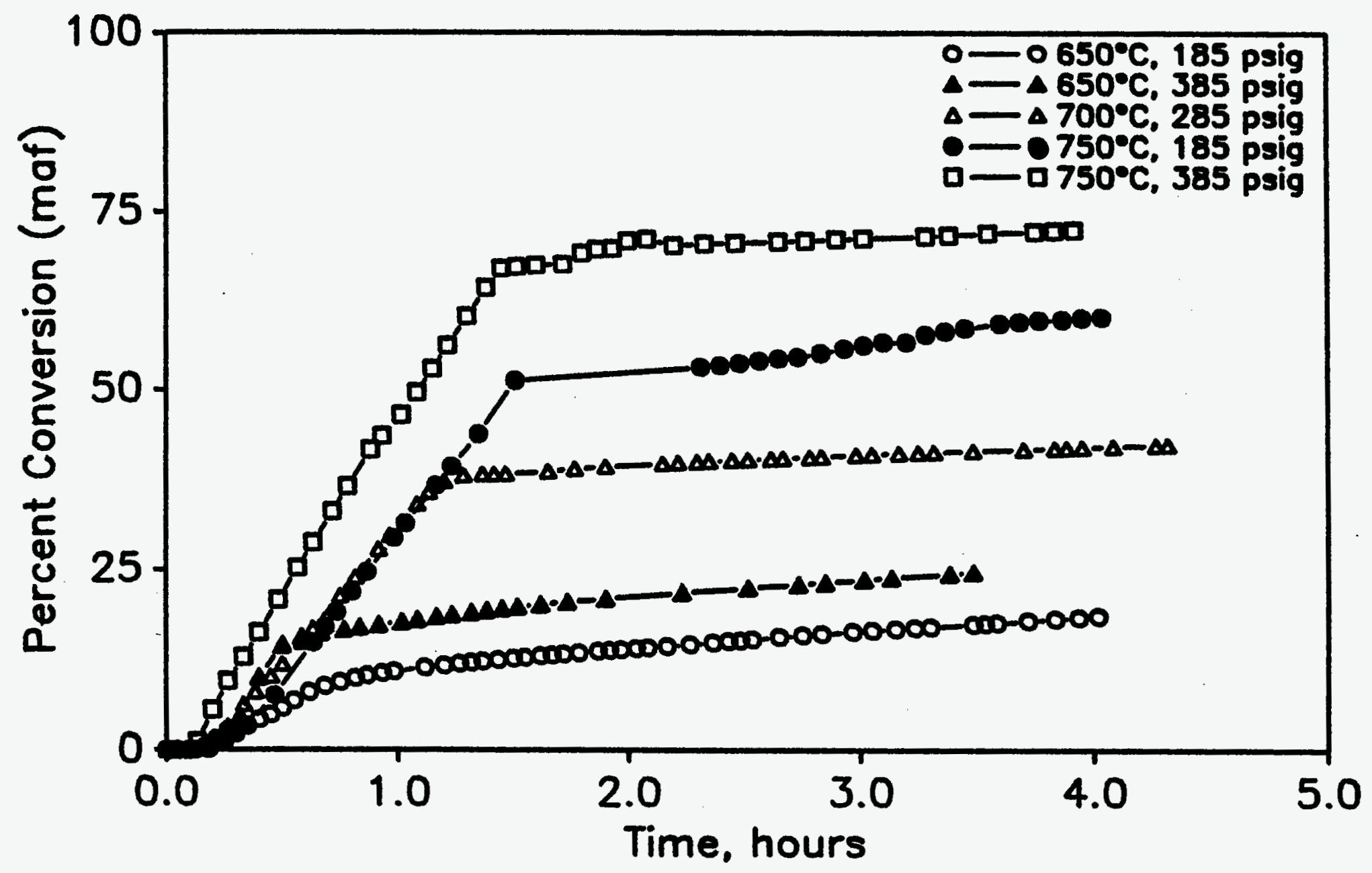

Figure 33. Conversion versus time plots for gasification runs made with MGT-12 char. 


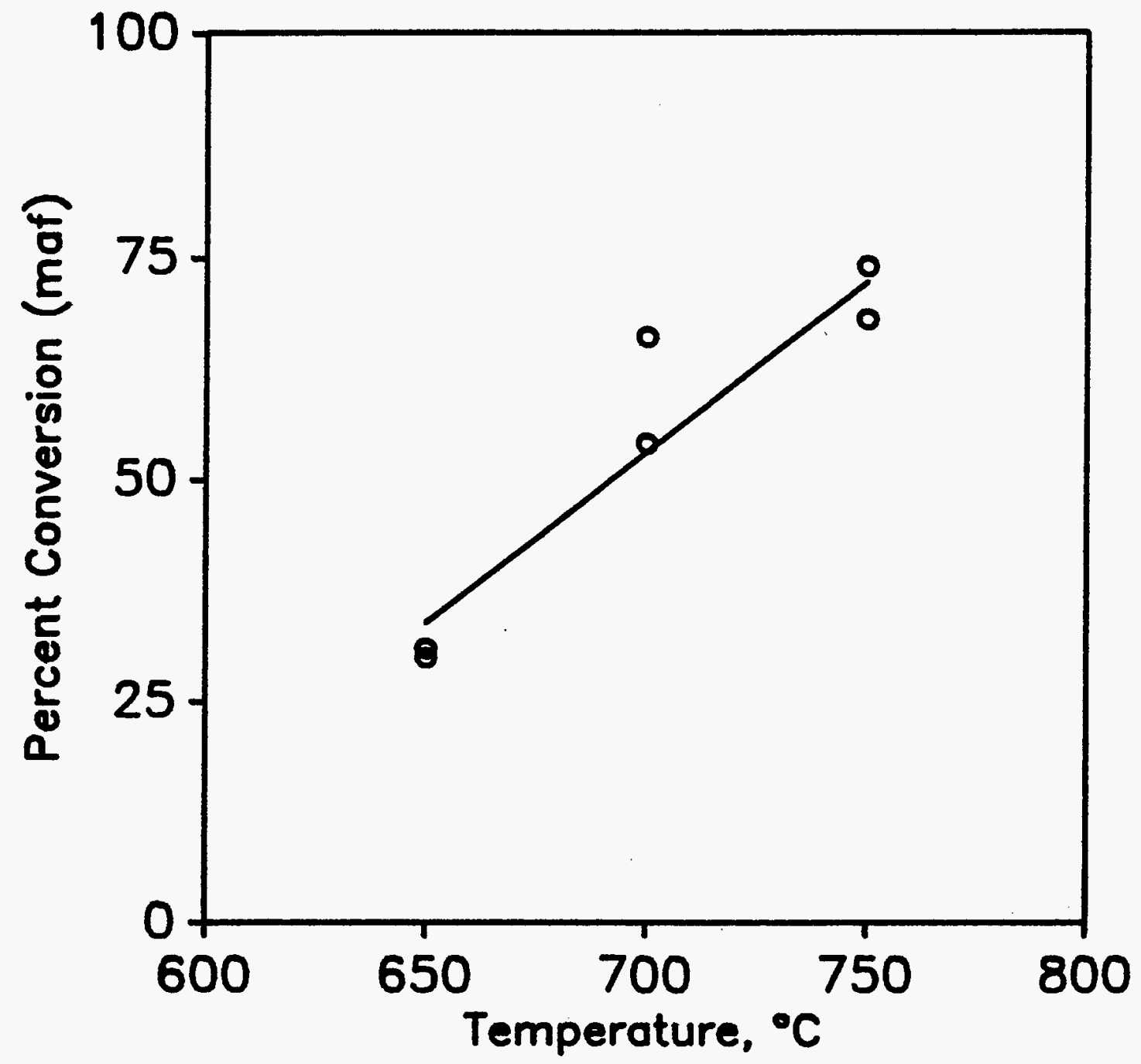

Figure 34. Final conversion as a function of temperature for gasification runs made with MGT-12 char. 


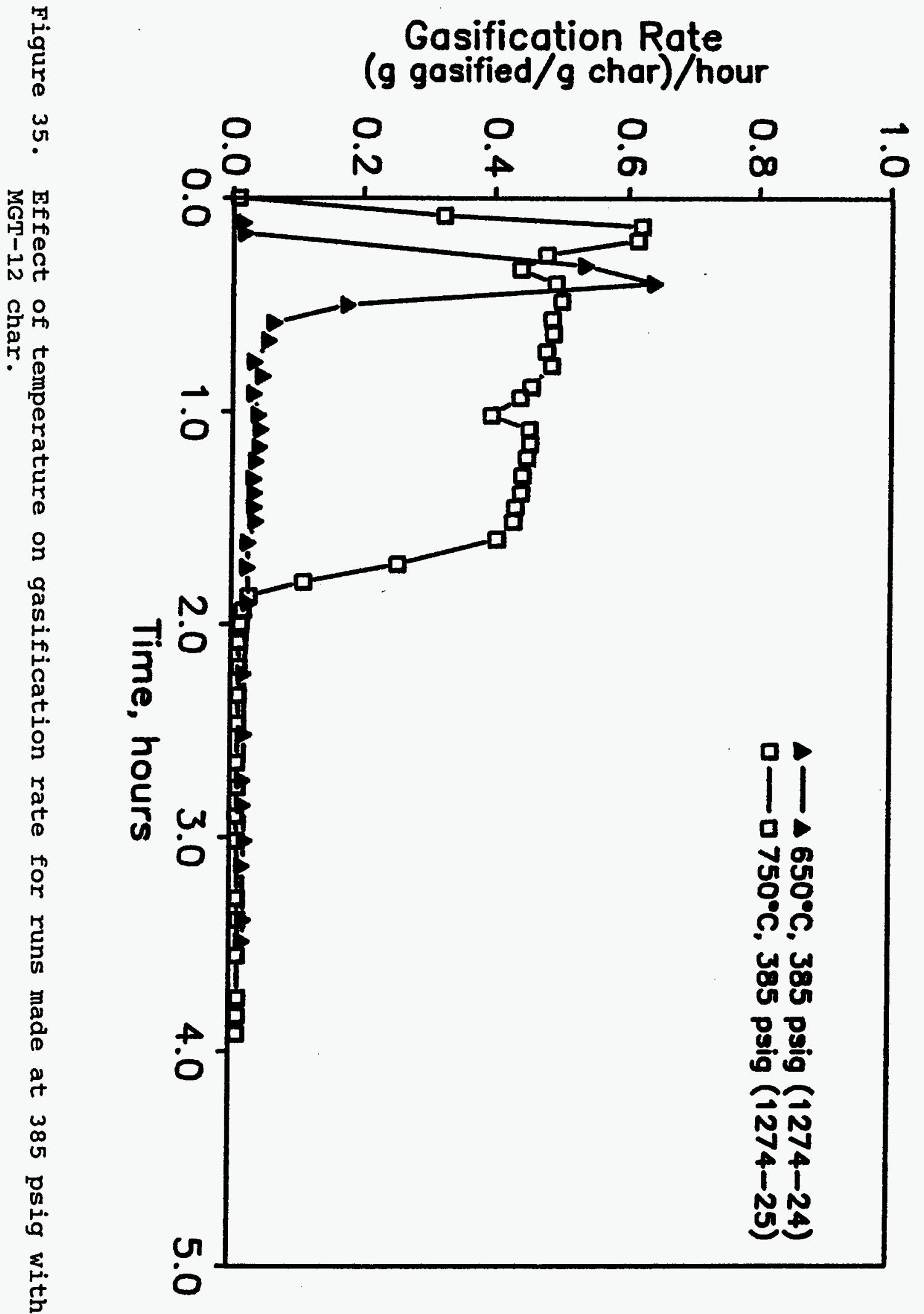


Figure 36 illustrates the effect of pressure on conversion for runs made at $750^{\circ} \mathrm{C}$. Increasing the pressure produces a slightly higher final conversion in each case. Also, the slope of the conversion versus time curve appears to increase slightly with pressure. This impression is only partially confirmed in Figure 37 where the gasification rate is plotted as a function of time on stream for these runs. There is little difference in the rates at 185 and $285 \mathrm{psig}$, but the rate at $385 \mathrm{psig}$ is somewhat higher. Increasing the pressure to $385 \mathrm{psig}$ did increase the duration of the gasification reaction.

The effect of having a high methane partial pressure on conversion is shown in Figure 38 for runs made at $750^{\circ} \mathrm{C}$ and about 200 psig hydrogen partial pressure. These results suggest that high methane partial pressures do not limit the conversion but slightly decrease the reaction rate. This is confirmed by the data plotted in Figure 39 where gasification rates are shown for the same runs. High methane partial pressures decrease the gasification rate, but the duration of the gasification reaction was longer, leading to nearly the same final conversion. Runs conducted at $650^{\circ} \mathrm{C}$ and at $750^{\circ} \mathrm{C}$ and 285 psig are consistent with this conclusion. These results suggest that under the conditions employed in this study, product inhibition is not significant in the gasification reaction.

\subsubsection{Process Variable study with MGT-9 Char}

The results of these runs are listed in Table 17. For this series of runs, experimental error is quite low, as shown by a comparison of conversions achieved in replicated runs (runs 41, 43, 53, and 60). Conversion versus time plots for a series of runs made with MGT-9 char are shown in Figure 40 . Temperature ranged from 750 to $850^{\circ} \mathrm{C}$ and pressures ranged from 100 to $385 \mathrm{psig}$. Again, conversion increases somewhat with increasing temperature. This trend is not as strong as was observed with MGT-12, however, as illustrated in Figure 41. If this figure is compared with Figure 34 , the corresponding figure for MGT-12, the slope of the trend is greater for MGT12. Possibly this is because of the different temperature ranges employed in the two process variable studies. The curve may begin to level off at $800^{\circ} \mathrm{C}$, producing the reduced slope seen in Figure 41. If this is true, then there is no benefit to be derived from operating at temperatures higher than 750 to $800^{\circ} \mathrm{C}$. 


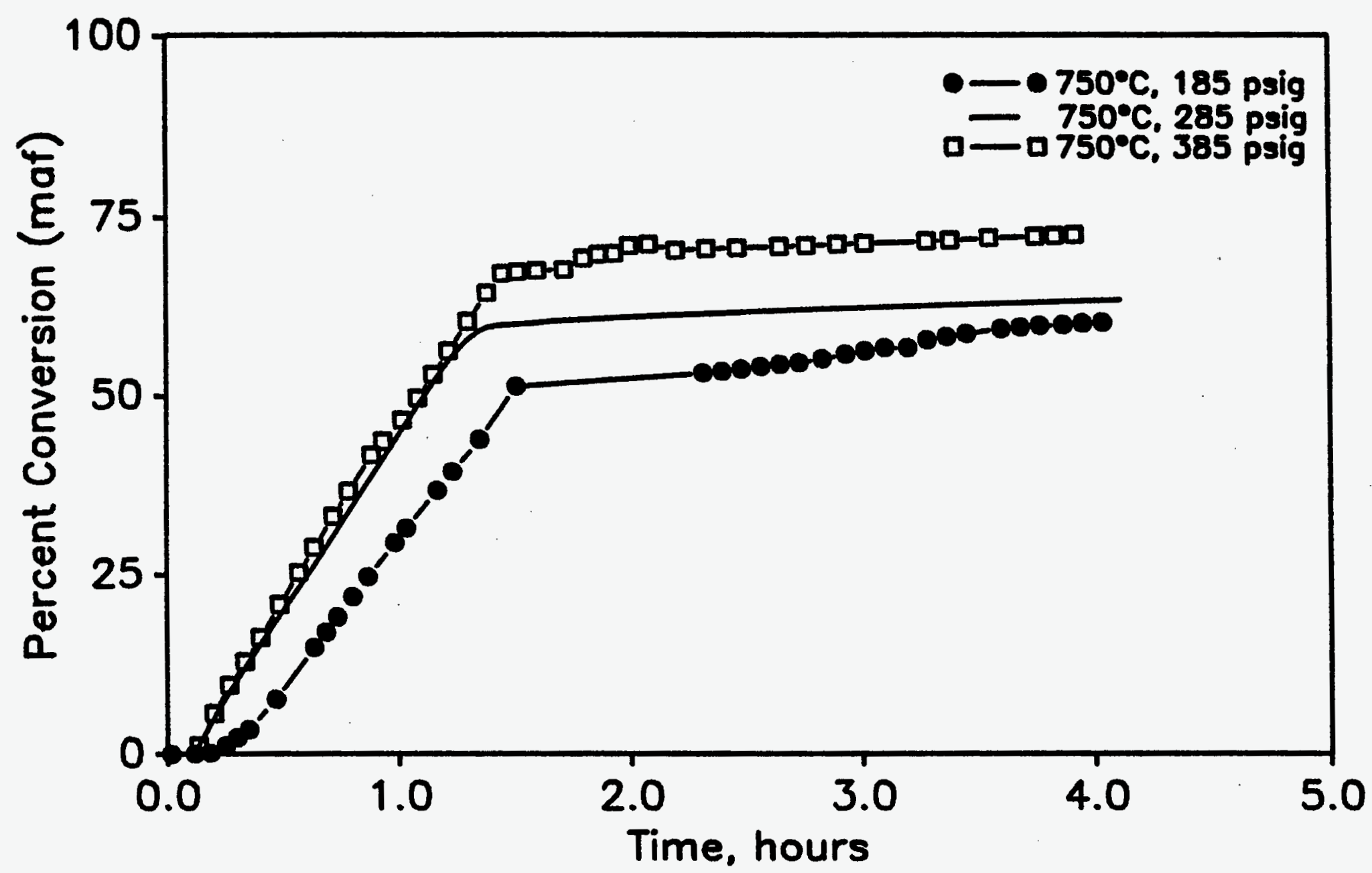

Figure 36. Effect of pressure on conversion for runs made at $750^{\circ} \mathrm{C}$ with MGT-12 char. 


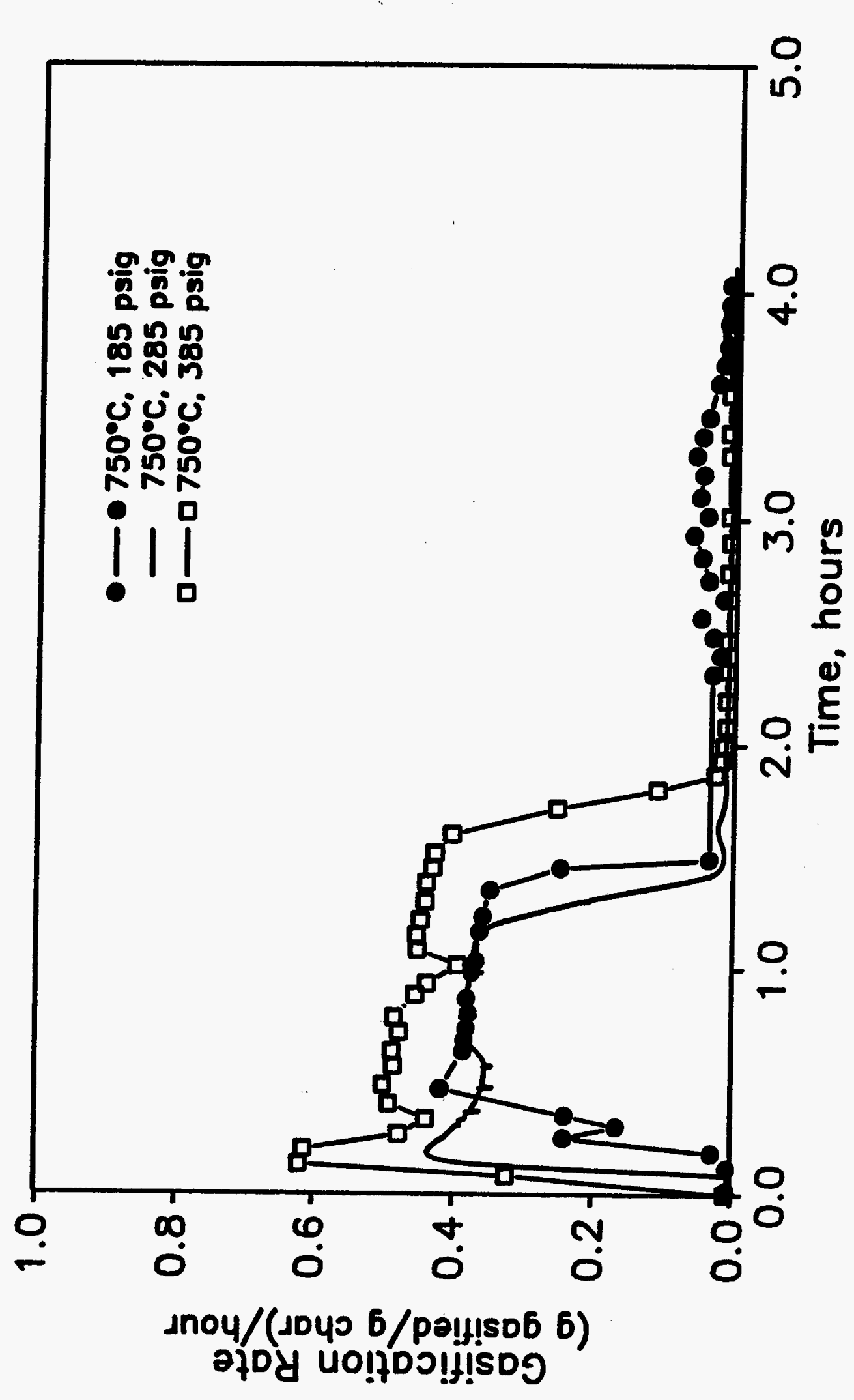

告

o

N

$+$

ชั

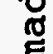

号

मू

I)

范

.

0
0
-11
0
0
01
-1
-1
-1
0
0
0

5

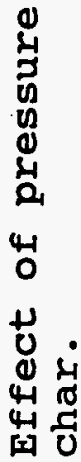

ñ

点 


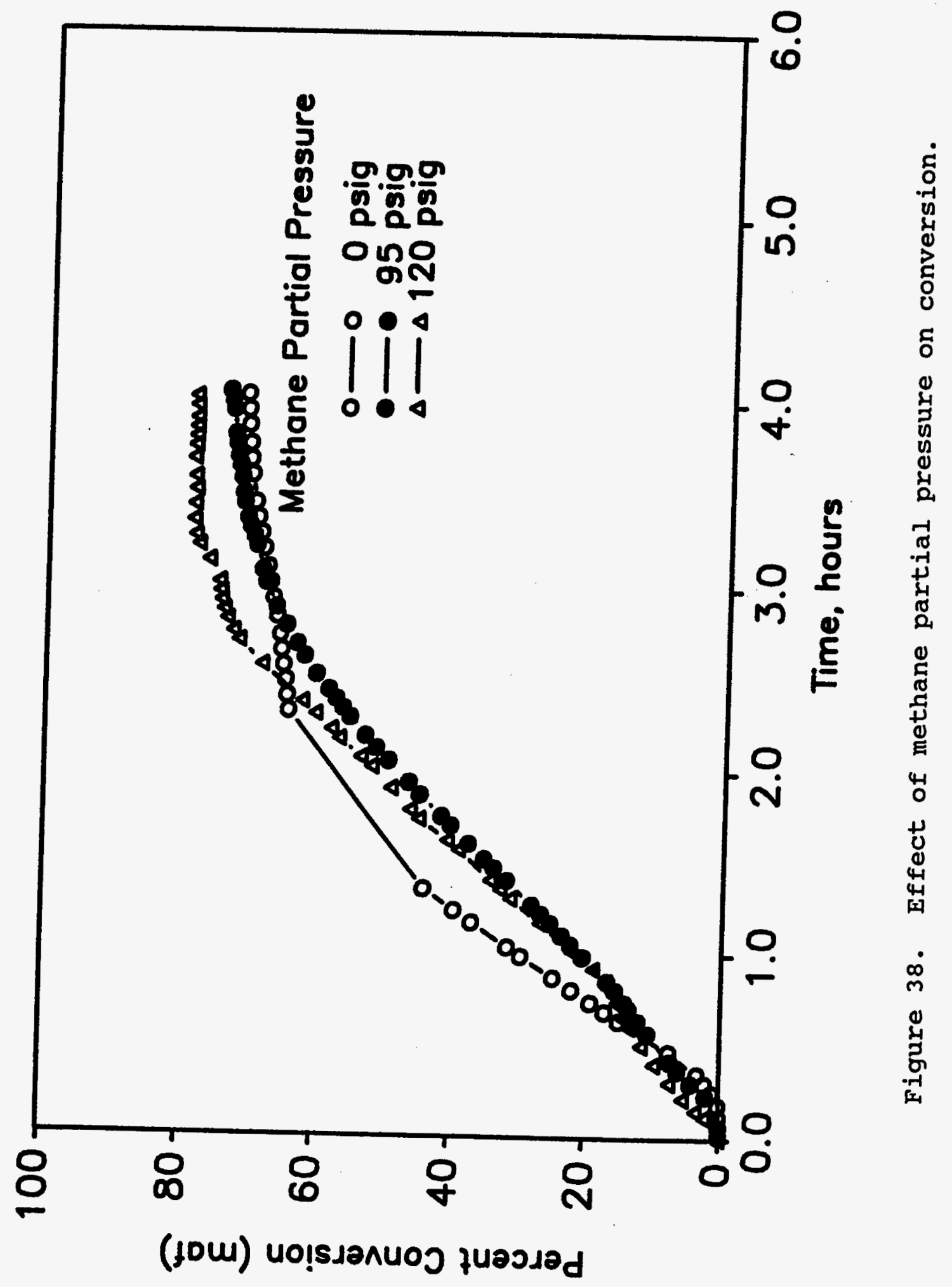




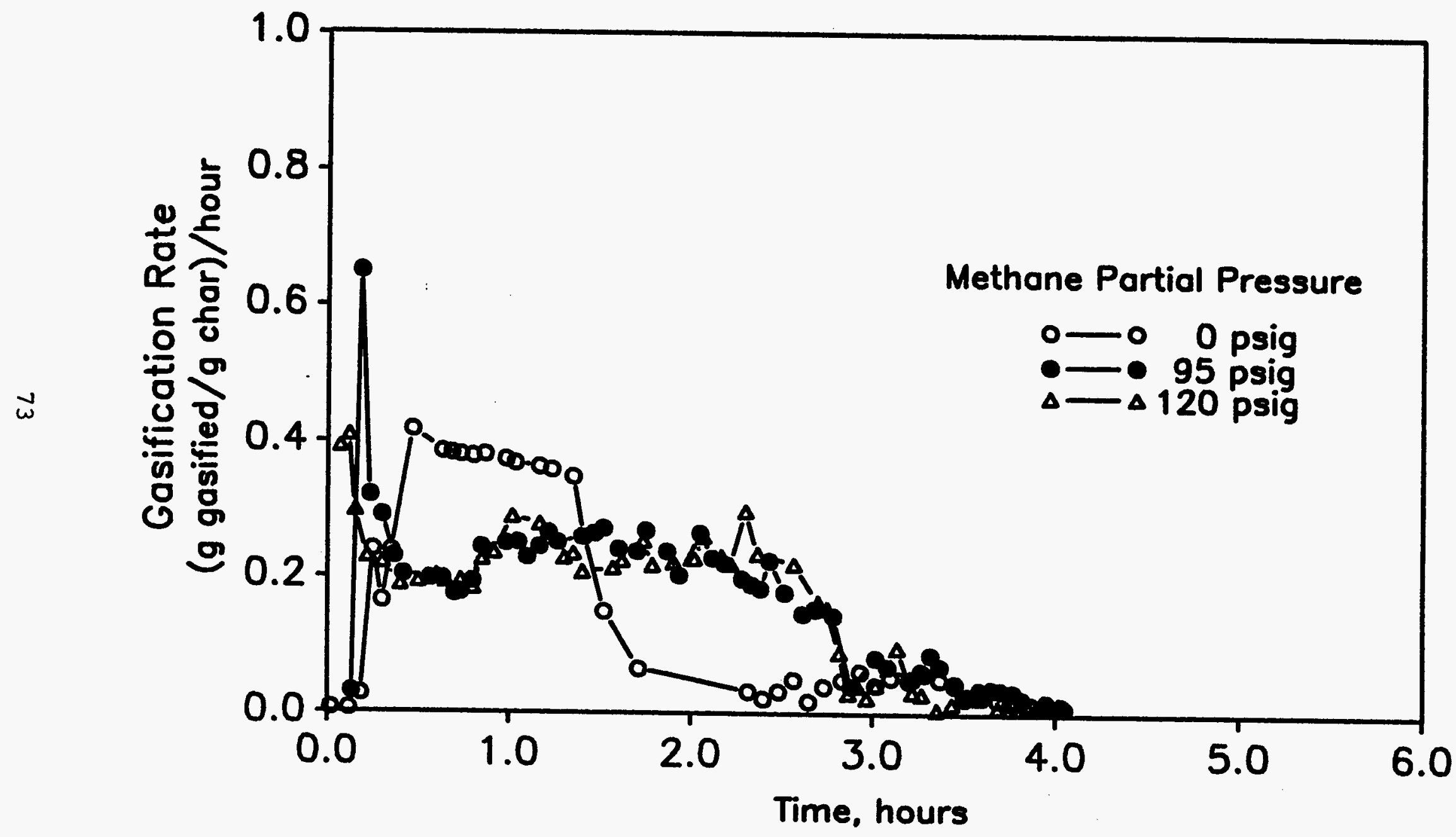

Figure 39. Effect of methane partial pressure on gasification rate. 


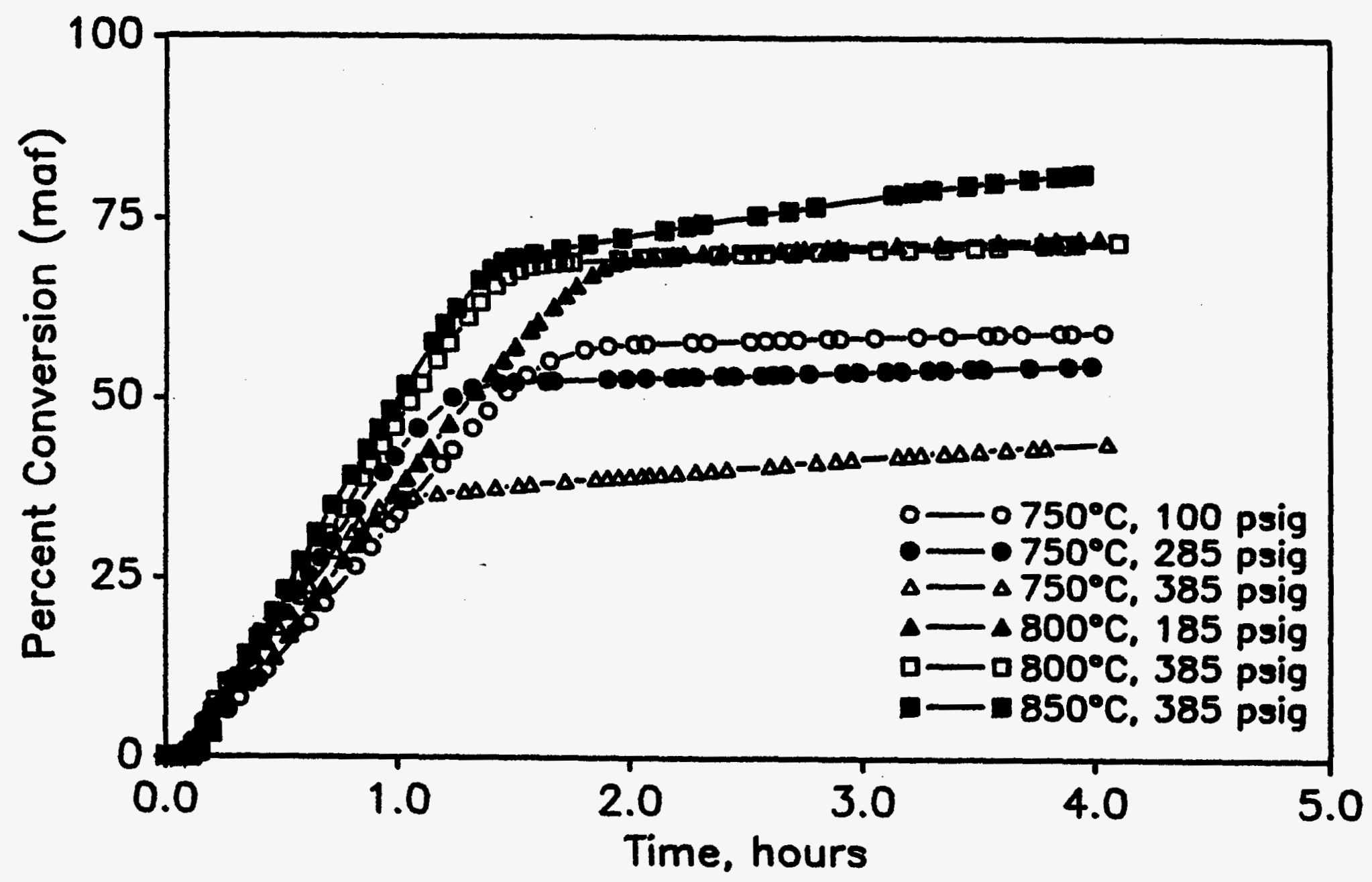

Figure 40. Conversion versus time plots for gasification runs made with MGT-12 char. 


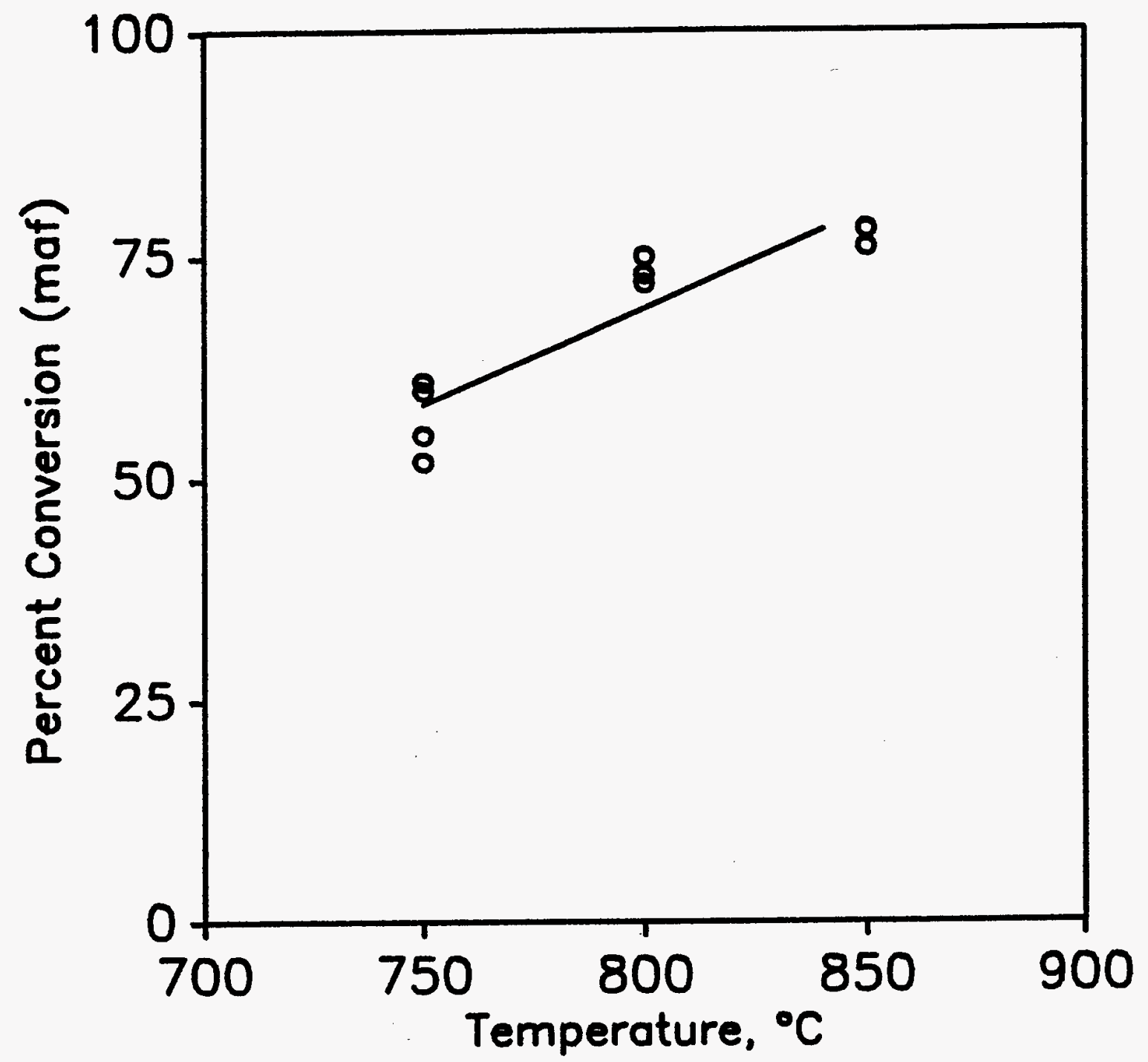

Figure 41. Final conversion as a function of temperature for gasification runs made with MGT-9 char. 
Table 17. Results of Char Gasification Process Variable study with MGT-9 Char

\begin{tabular}{|c|c|c|c|c|c|c|}
\hline \multirow[b]{2}{*}{ Run } & \multirow{2}{*}{$\begin{array}{c}\text { Temperature, } \\
{ }^{\circ} \mathrm{C}\end{array}$} & \multicolumn{2}{|c|}{$\begin{array}{c}\text { Partial } \\
\text { Pressures, } \\
\text { psig } \\
\end{array}$} & \multirow{2}{*}{$\begin{array}{c}\text { Initial } \\
\text { Char } \\
\text { Mass, } \\
g \\
\end{array}$} & \multirow{2}{*}{$\begin{array}{l}\text { Run } \\
\text { Time, } \\
\text { Hours }\end{array}$} & \multirow{2}{*}{$\begin{array}{c}\text { Percent } \\
\text { Conversion } \\
\end{array}$} \\
\hline & & $\underline{H}_{2-}$ & $\mathrm{CH}_{4}$ & & & \\
\hline $\begin{array}{l}1274-27 \\
1274-32 \\
1274-37 \\
1274-38 \\
1274-40 \\
1274-41 \\
1274-43 \\
1274-45 b \\
1274-53 \\
1274-60\end{array}$ & $\begin{array}{l}700 \\
750 \\
750 \\
800 \\
750 \\
800 \\
800 \\
750 \\
850 \\
850\end{array}$ & $\begin{array}{l}285 \\
285 \\
385 \\
385 \\
100 \\
185 \\
185 \\
185 \\
385 \\
385\end{array}$ & $\begin{array}{l}0 \\
0 \\
0 \\
0 \\
0 \\
0 \\
0 \\
0 \\
0 \\
0\end{array}$ & $\begin{array}{l}80 \\
80 \\
80 \\
80 \\
80 \\
80 \\
80 \\
80 \\
80 \\
80\end{array}$ & $\begin{array}{r}11.2 \\
4.0 \\
4.0 \\
4.0 \\
4.0 \\
4.0 \\
4.0 \\
4.0 \\
4.0 \\
4.0\end{array}$ & $\begin{array}{l}74 \\
61 \\
52 \\
75 \\
60 \\
73 \\
72 \\
55 \\
76 \\
78\end{array}$ \\
\hline $\begin{array}{l}\text { Ash-f: } \\
\text { Pretr } \\
\text { hydro }\end{array}$ & $\begin{array}{l}\text { basis. } \\
\text { in } 1 \text { atm or } \\
\text { ification. }\end{array}$ & & $900^{\circ} \mathrm{C}$ & for 154 & minutes & prior to \\
\hline
\end{tabular}

The effect of temperature on the gasification rate at 385 psig is shown in Figure 42. As was observed in runs made with MGT-12, increasing the temperature from 750 to $800^{\circ} \mathrm{C}$ increases the duration of the gasification reaction. However, increasing the temperature from 800 to $850^{\circ} \mathrm{C}$ has little effect. This is consistent with the leveling off of the conversion versus temperature plot suggested by Figure 41 .

The effect of pressure on conversion versus time plots at $750^{\circ} \mathrm{C}$ is shown in Figure 43 . Increasing the pressure from 100 to $285 \mathrm{psig}$ increases the final conversion, consistent with the results reported for MGT-12. Increasing the pressure from 285 to 385 psig resulted in a decrease in the conversion. This result is inconsistent with all of the other data reported, and it is likely that some operator error occurred during this run. The gasification rate at $750^{\circ} \mathrm{C}$ with various pressures is shown in Figure 44. A small increase in rate is apparent upon going from 100 to 285 psig; however, no increase is observed when the pressure is increased from 285 to $385 \mathrm{psig}$. For this series of runs, increasing pressure appears to shorten the duration of the gasification reaction.

Run 1274-61 was conducted with MGT-9 char in an attempt to determine if methanation proceeds as a reaction front through the bed. The run was made at $800^{\circ} \mathrm{C}$ and $285 \mathrm{psig}$ with 275 grams of char. A weight loss conversion of 73 percent (maf) was obtained. Samples were taken for analysis from the top, middle, and bottom of the bed. The results indicated 


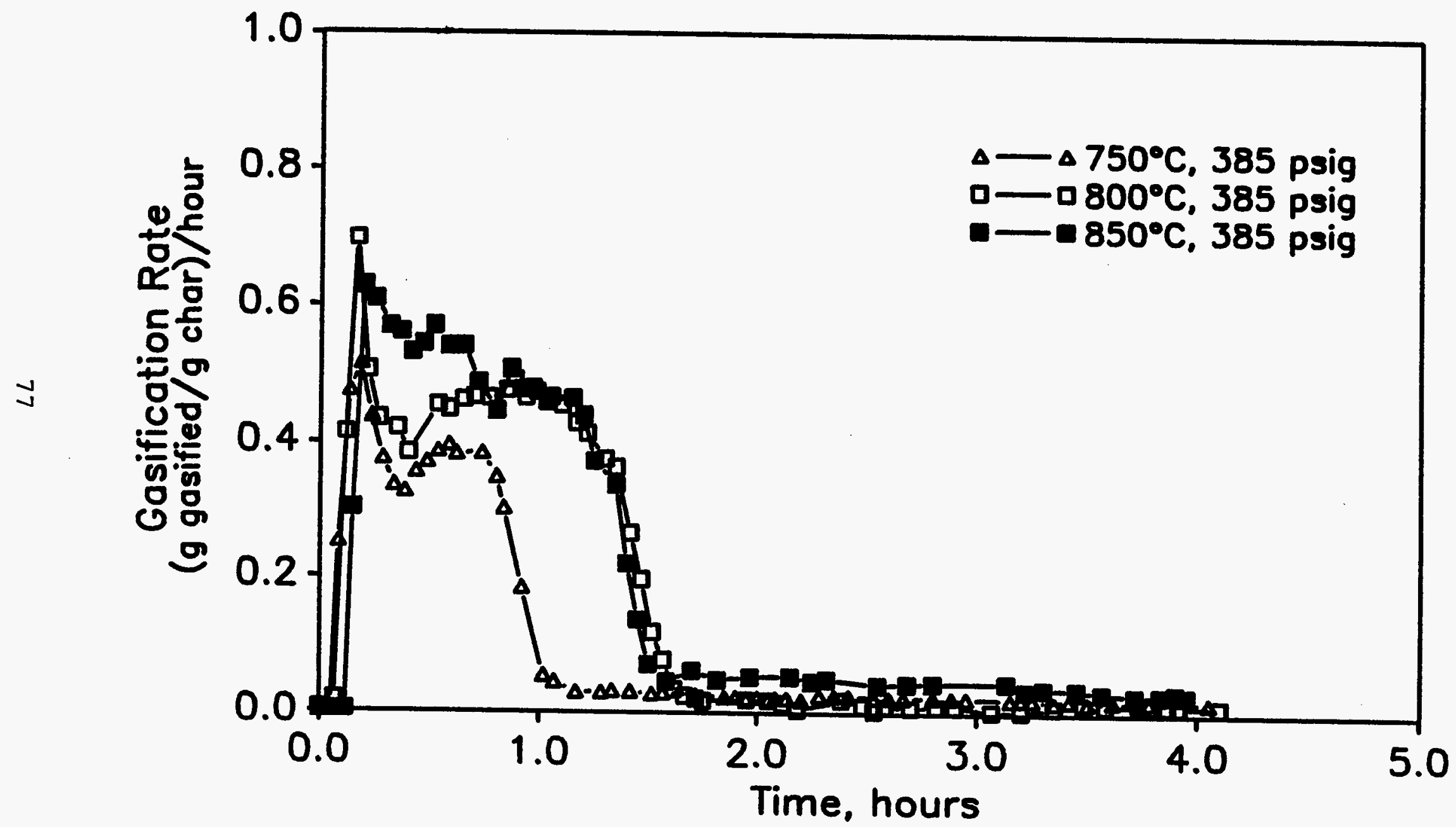

Figure 42. Effect of temperature on gasification rate for runs made at 385 psig with MGT-9 char. 


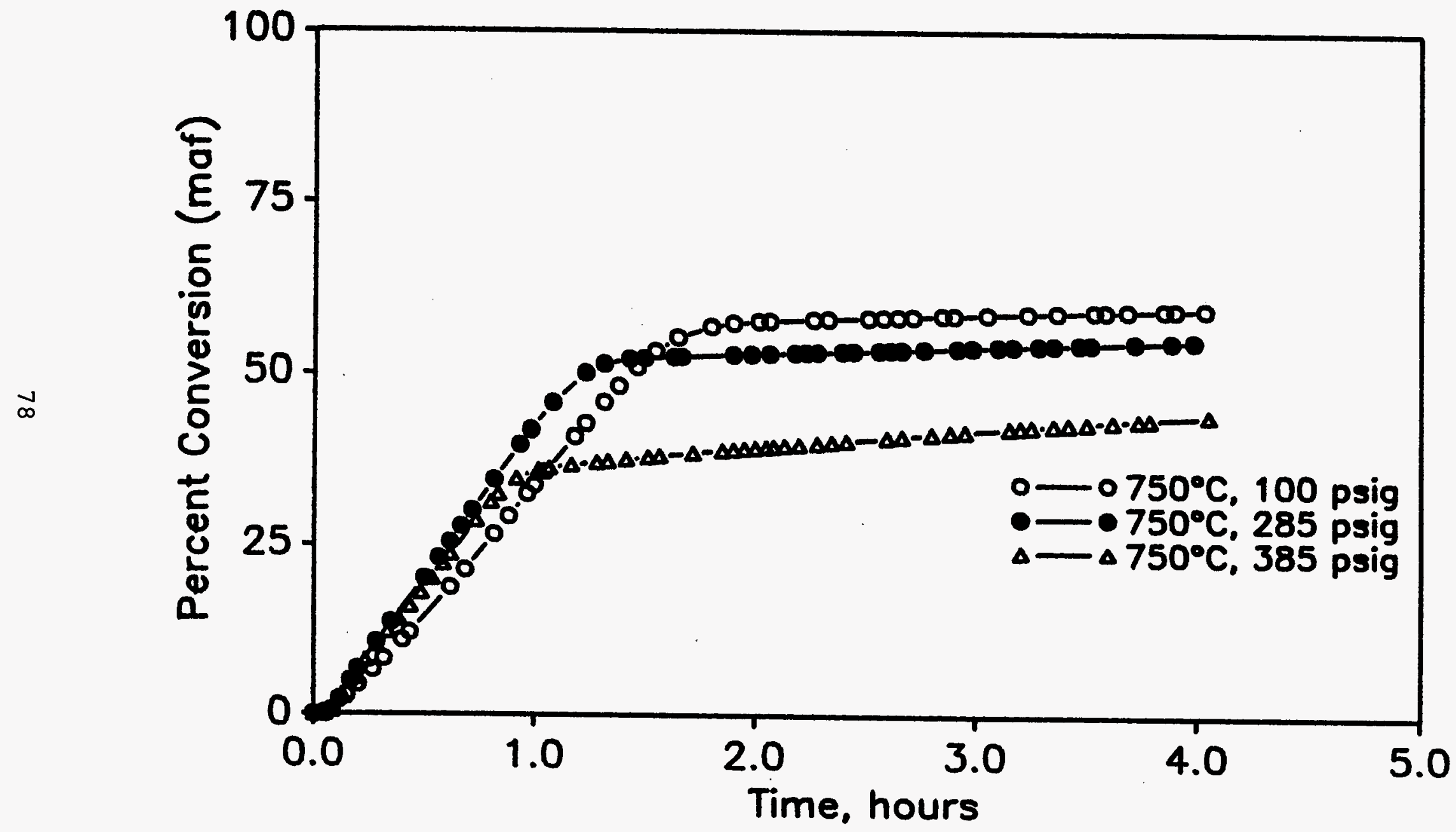

Figure 43. Effect of pressure on conversion for runs made at $750^{\circ} \mathrm{C}$ with MGT-9 char. 


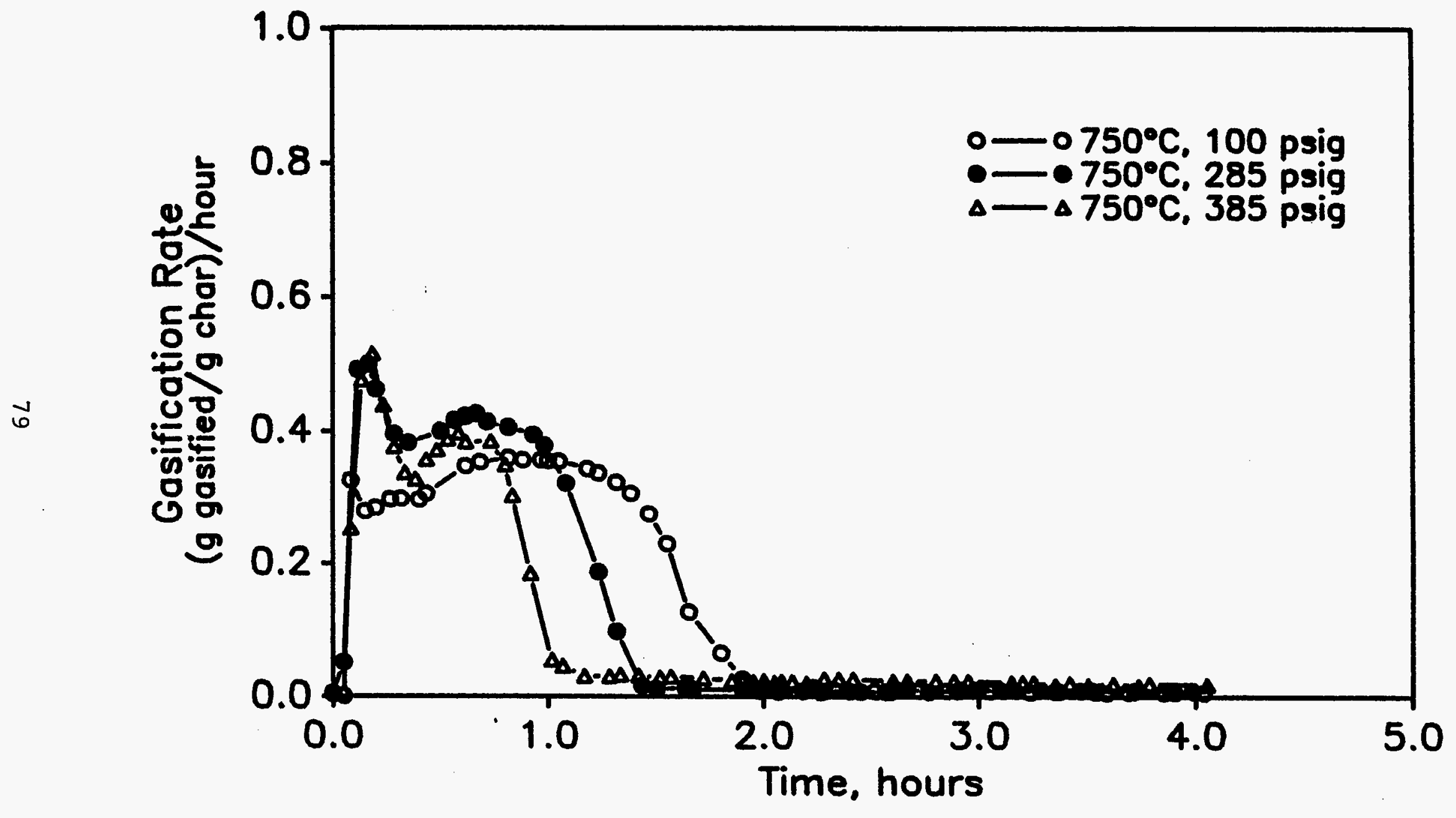

Figure 44. Effect of pressure on gasification rate for runs made at $750^{\circ} \mathrm{C}$ with $\mathrm{MGT}-9$ char. 
increasing ash content in going from the top to the bottom $(21.6,25.0$, and 25.9 percent ash, respectively). This indicates that the reaction is proceeding as a front through the bed and that the reactor is far from a differential reactor.

\subsubsection{Results of Catalytic Gasification Runs}

Two catalysts were studied in physically mixed form. These were $\mathrm{K}_{2} \mathrm{CO}_{3}$ and $\mathrm{Na}_{2} \mathrm{CO}_{3}$. Loadings of 5 and 10 weight percent were examined. Results are reported in Table 18 . An examination of these results indicates that catalysts were not very active at the 5 percent loading and, in fact, inhibited conversion. At the 10 percent loading, catalysts produced an increase in conversion relative to the uncatalyzed case.

Table 18. Results of Bench-Scale Catalytic Gasification Studya

$\underline{\text { Run }}$

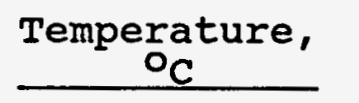

Partial

Pressure, $\frac{\text { psig }}{\underline{\mathrm{H}}_{2}-\underline{\mathrm{CH}}_{4}}$

Initial

\begin{tabular}{ccc} 
Temperature, & $\begin{array}{c}\text { Partial } \\
\text { Pressure, } \\
\text { osig }\end{array}$ & $\begin{array}{c}\text { Initial } \\
\text { Char } \\
\text { Mass, }\end{array}$ \\
\hline
\end{tabular}

Run

Time, Hours

Catalyst,

Percent

$1274-26$

700

$1274-28$

700

285

285

80

285

80

Weight \% Conversion $\mathrm{C}$

1274-30

750

285

80

750

385

80

1274-39

800

285

80

285

80

800

285

80

80

800

285

80

4.0

5.5

5.4

$5 \% \mathrm{~K}_{2} \mathrm{CO}_{3}$

39

5.6

4.1

4.0

4.0

4.1

4.0

$5 \% \mathrm{~K}_{2} \mathrm{CO}_{3}$

$10 \% \mathrm{~K}_{2} \mathrm{CO}_{3}$

$5 \% \mathrm{~K}_{2} \mathrm{CO}_{3}$

$10 \% \mathrm{~K}_{2} \mathrm{CO}_{3}$

$10 \% \mathrm{~K}_{2} \mathrm{CO}_{3}$

$5 \% \mathrm{~K}_{2} \mathrm{CO}_{3}$

$5 \% \mathrm{Na}_{2} \mathrm{CO}_{3}$

$10 \% \mathrm{Na}_{2} \mathrm{CO}_{3}$

41

85

50

54

104

58

48

98

a All runs were made with MGT-12 char, except 1274-46 and 1274-47 which were made with MGT-9 char.

b Including weight of catalyst.

c Ash and catalyst-free basis, extremely high conversions may be caused by evaporation of the catalyst or loss of carbonate as $\mathrm{CO}_{2}$.

For example, results obtained using no catalyst and 5 and 10 weight percent potassium carbonate are reported in Figures 45 and 46 for runs made at $750^{\circ} \mathrm{C}$ and $285 \mathrm{psig}$. Figure 45 shows conversion versus time. At 5 weight percent, the catalyst. severely limits conversion. While at 10 weight percent, conversion is slow, but a much higher conversion is eventually obtained. Figure 46 shows the gasification rate as a function of time for the same runs. In the uncatalyzed run, the rate is fairly high for the first 1.5 hours and then drops to near zero. For both catalyzed runs, the rate never drops to zero, 


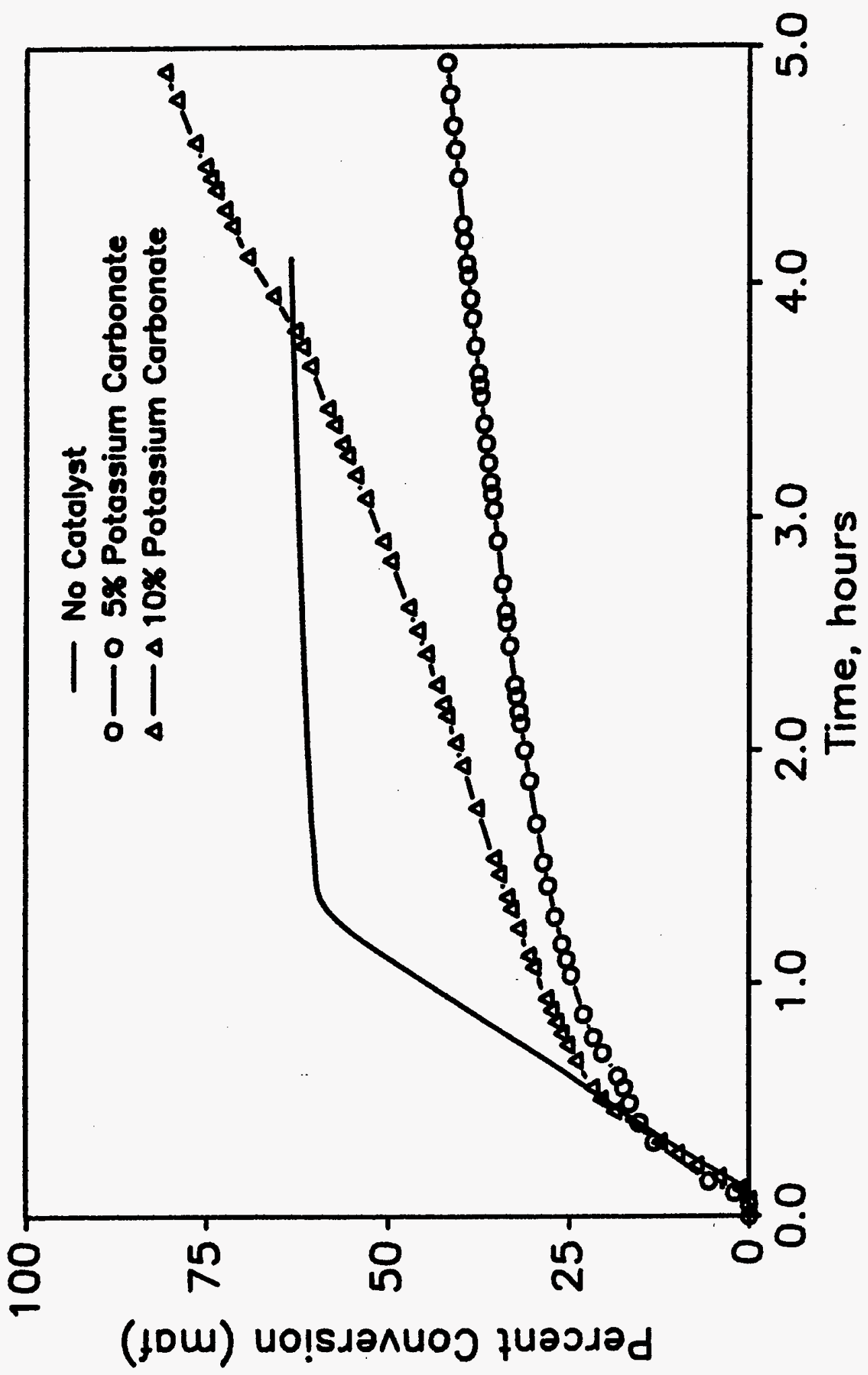

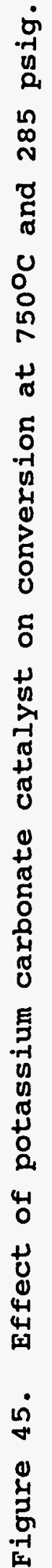




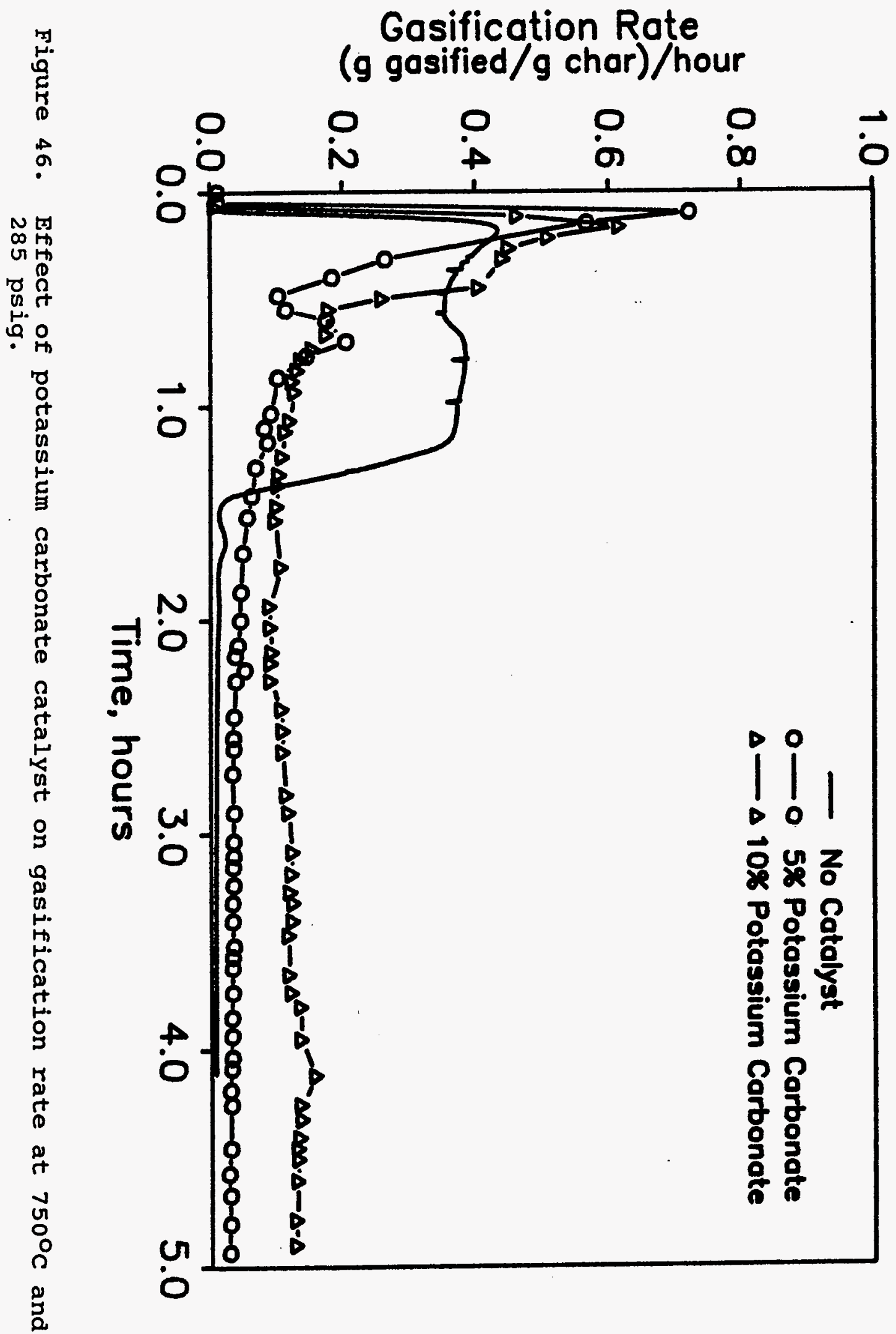


and for the 10 percent loaded sample, the lined out rate is approximately 10 times that of the uncatalyzed run. The rate inhibition observed in the initial stages of the catalyzed runs may be caused by intraparticle (pore) diffusion limitations. The presence of the presumably molten catalyst may block the pores and hinder the access of reactants to or the removal of products from the surface.

The effect of increasing the temperature at $285 \mathrm{psig}$ in potassium carbonate catalyzed gasification is shown in Figure 47. Raising the temperature from 750 to $800^{\circ} \mathrm{C}$ results in higher rates of gasification and a very high final conversion of 104 percent (maf). A conversion more than 100 percent is probably caused by two factors, both related to the assumption that the catalyst does not change and can be considered as part of the ash. At these temperatures, the alkali metal carbonates can be reduçed by carbon, liberating $\mathrm{CO}_{2}$, which may later be methanated.29 Also, the loss of potassium by vaporization under gasification conditions has been documented.12,13 while these factors can account for the conversion being more than 100 percent, an extremely high carbon conversion was achieved in the run made at $800^{\circ} \mathrm{C}$.

Similar results were observed using sodium carbonate. Conversion versus time plots are shown in Figure 48 for runs made at $800^{\circ} \mathrm{C}$ and $285 \mathrm{psig}$. (The uncatalyzed run was made at $800^{\circ} \mathrm{C}$ and $385 \mathrm{psi.)}$ As was observed for potassium carbonate, at 5 percent, conversion is inhibited. While at 10 percent, the reaction rate is slowed, but the duration of the reaction is much longer. These conclusions, based on the reaction rate, are shown more clearly in Figure 49 where the gasification rate as a function of time is plotted. In catalyzed runs, the rate is less than in the uncatalyzed run, but for the 10 percent loaded sample, the reaction continues to very high conversion.

While high conversions can be obtained using catalysts, the extra cost incurred cannot be justified based on benefits derived. The catalyst does not actually increase the reaction rate, which would result in decreased reactor size. Instead, the catalyst allows higher conversions and yields to be achieved but at the cost of longer residence times, and hence larger reactors.

\subsubsection{Bench-Scale Char Reactivity Study}

Each of the mild gasification chars whose characterization was described in chapter 3 was tested in the bench-scale fixedbed gasifier. The conditions employed were $750^{\circ} \mathrm{C}$ and $285 \mathrm{psig}$ with pure hydrogen as the feed gas. Results are reported in Table 19. The run with the MGT-6 char was replicated, and there was a large discrepancy in conversions obtained in these runs. Run 63 is thought to be more reliable than Run 33 


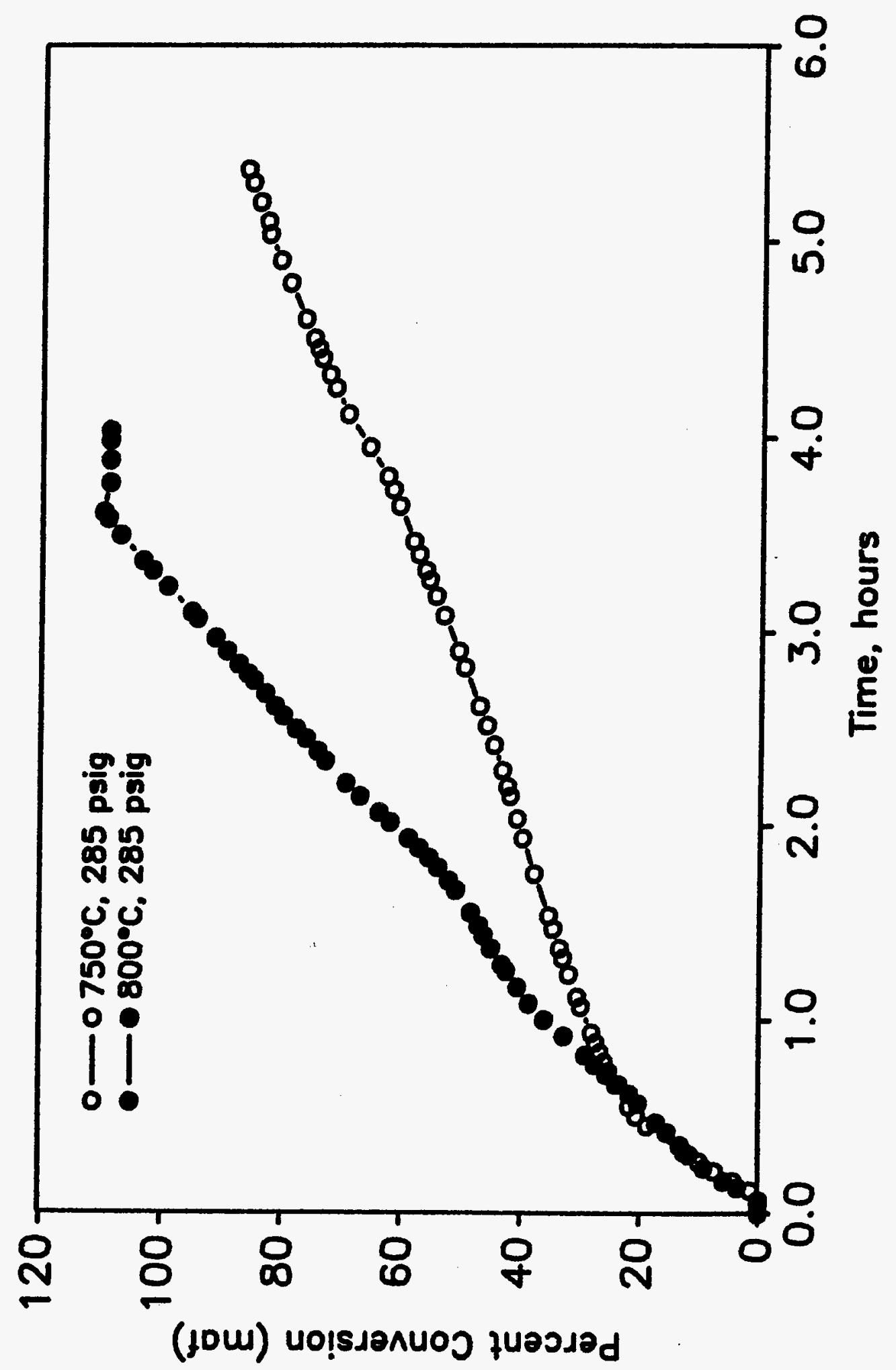

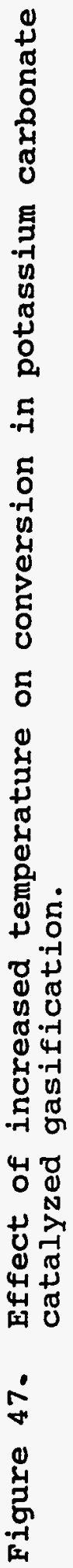




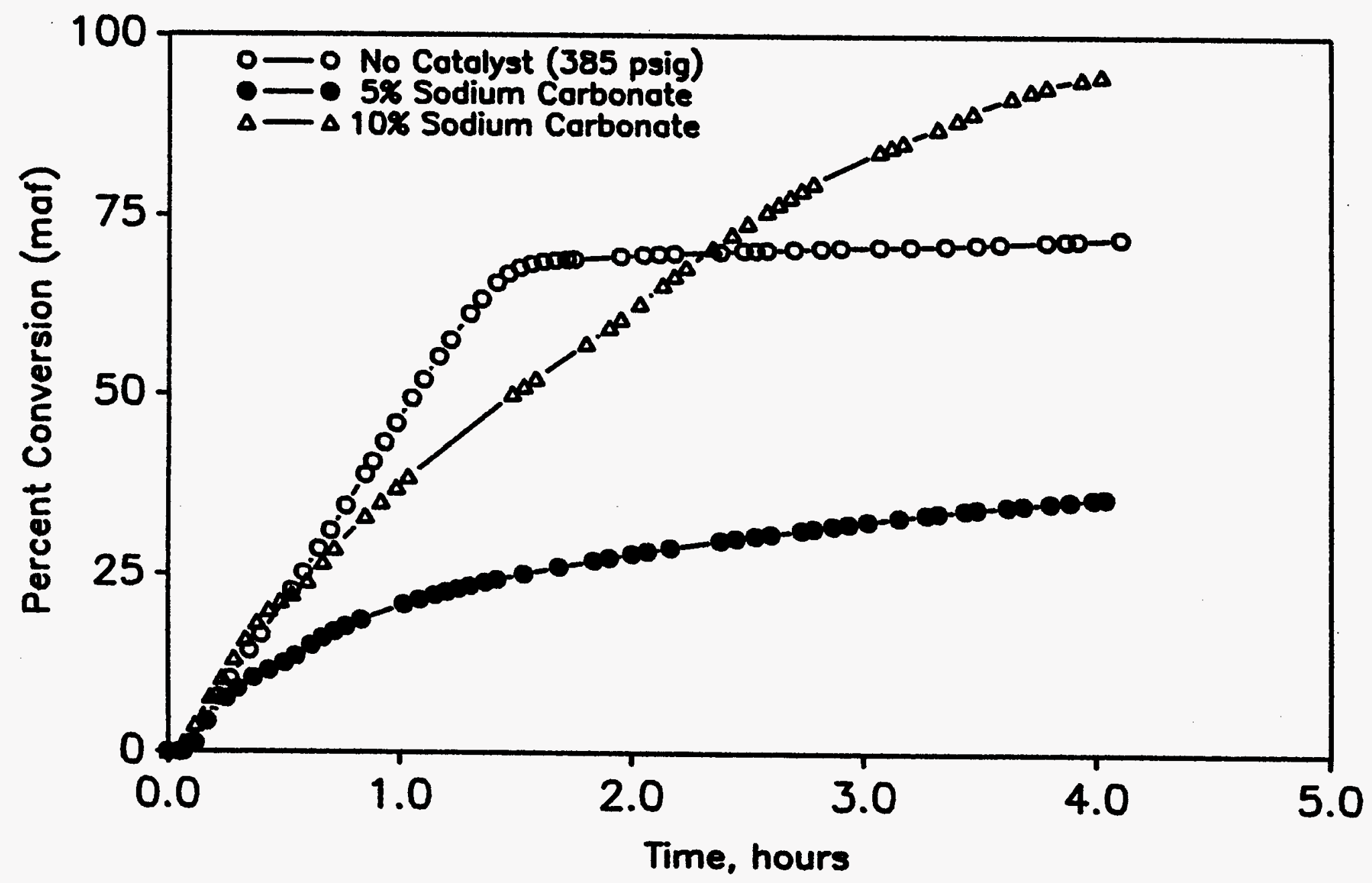

Figure 48. Effect of sodium carbonate catalyst on conversion at $800^{\circ} \mathrm{C}$ and 285 psig. 


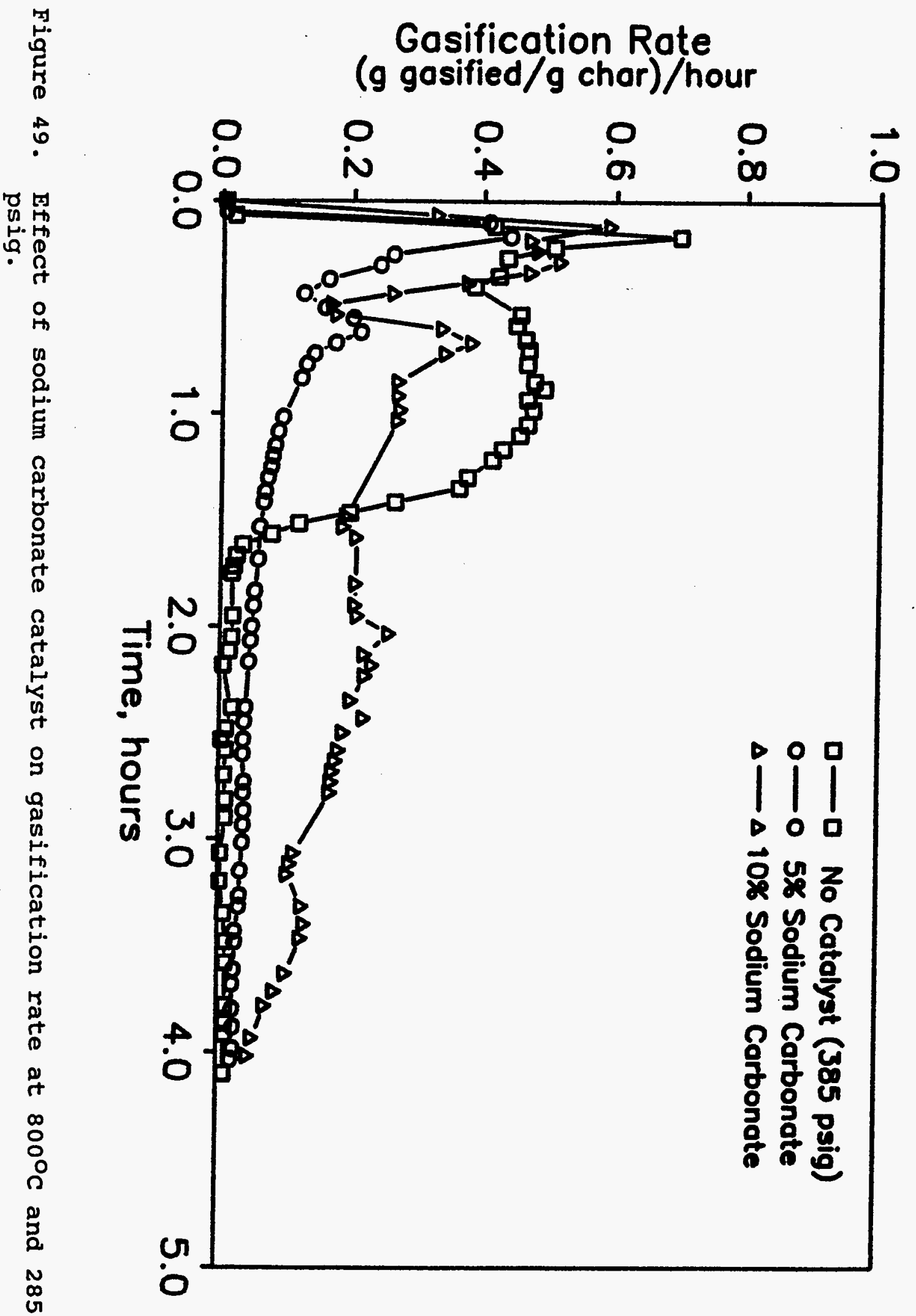


because the operator had more experience and runs were being made in a more reproducible manner.

\section{Table 19. Results of Bench-Scale Char Reactivity Study}

\begin{tabular}{lccc} 
Char & Run & $\begin{array}{c}\text { Run } \\
\text { Hours }\end{array}$ & $\begin{array}{c}\text { Percent } \\
\text { Conversiona }\end{array}$ \\
MGT-6 & $1274-33$ & 4.0 & 39 \\
MGT-6 & $1274-63$ & 4.0 & 68 \\
MGT-7 & $1274-50$ & 4.0 & 77 \\
MGT-8 & $1274-56$ & 4.0 & 69 \\
MGT-9 & $1274-32$ & 4.0 & 61 \\
MGT-10 & $1274-55$ & 4.1 & 70 \\
MGT-11 & $1274-49$ & 4.0 & 75 \\
MGT-12 & $1274-62$ & 4.0 & 68 \\
MGT-14 & $1274-35$ & 4.0 & 58 \\
MGT-15 & $1274-57$ & 4.0 & 67 \\
MGT-16 & $1274-34$ & 4.0 & 39 \\
MGT-18 & $1274-48$ & 4.1 & 36 \\
MGT-19 & $1274-58$ & 4.0 & 69 \\
MGT-20 & $1274-36$ & 3.9 & 36 \\
MGT-21 & $1274-59$ & 4.0 & \\
\hline \\
a Ash- (and additive) free basis. \\
All runs conducted at $750^{\circ} \mathrm{C}, 285$ psig, \\
with pure H2 feed.
\end{tabular}

There is some variability in the conversions obtained for the various chars. It was attempted to correlate final char conversion with char properties, including ash content, $\mathrm{H} / \mathrm{O}$ ratio, volatile matter content, and oxygen content. No correlation was observed with ash content and $\mathrm{H} / \mathrm{O}$ ratio. A plot of conversion versus volatile matter content is shown in Figure 50. It is apparent from this plot that no relationship exists. Figure 51 shows a plot of conversion versus oxygen content. There is a very weak correlation between oxygen content and conversion. It is difficult to place much faith in this correlation because of the difficulty in obtaining reliable oxygen analyses for fossil fuel samples and the dependence of oxygen content on sample history. An examination of the char properties reported in chapter 3 suggests that low conversions were obtained with chars having a low volatile matter content. However, this condition is not sufficient for low conversion. 


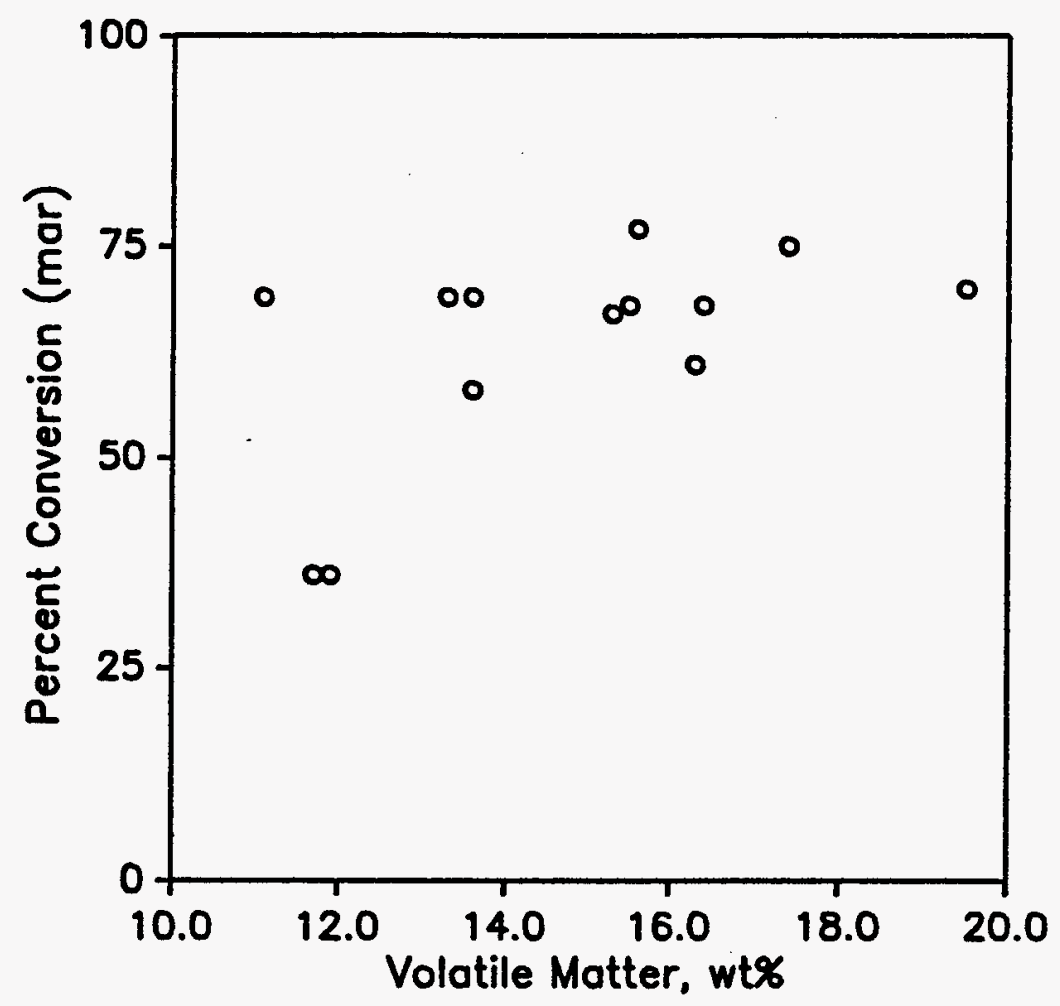

Figure 50. Percent conversion as a function of char volatile matter content for bench-scale gasification tests.

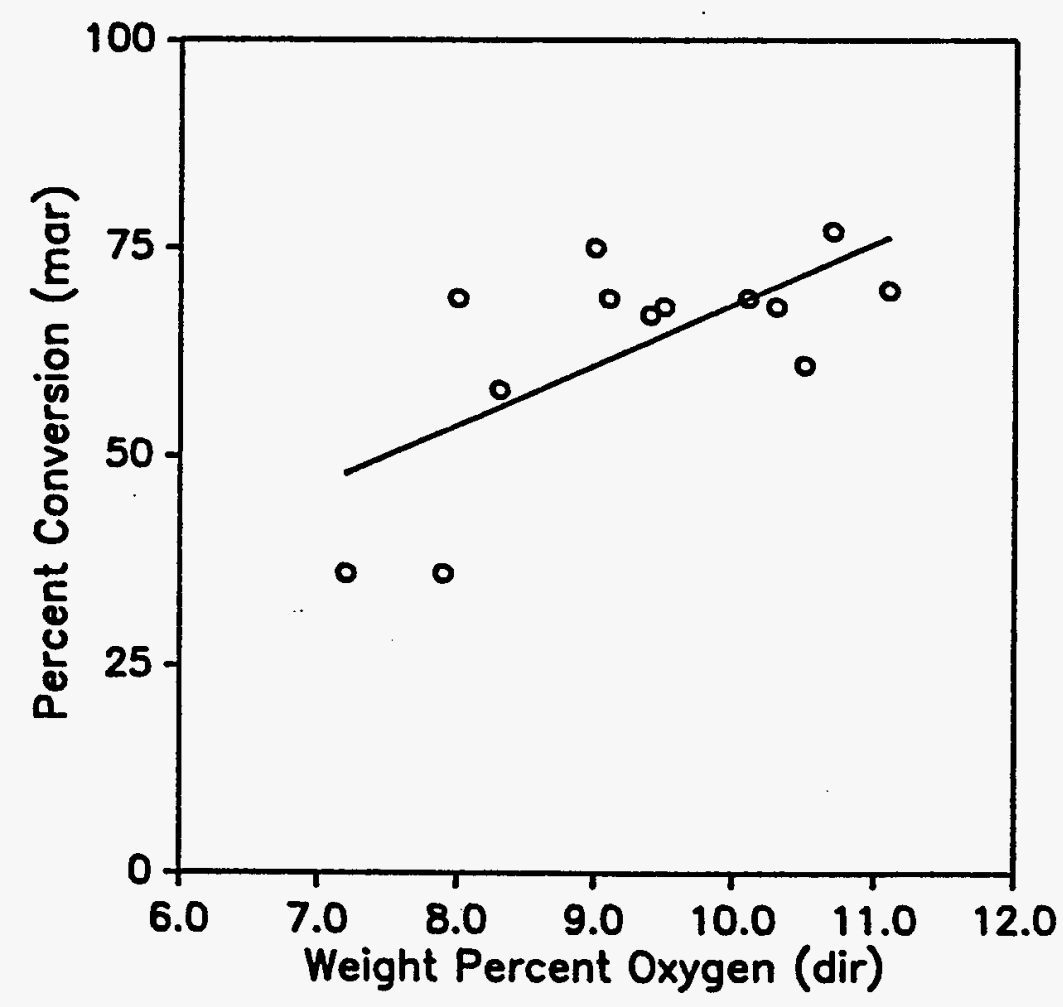

Figure 51. Percent conversion as a function of char oxygen content for bench-scale gasification tests. 


\subsubsection{Analysis of Spent Chars}

Several spent char samples were analyzed for elemental composition, surface area, and pore structure after methanation in the bench-scale fixed-bed system. Elemental analyses for chars produced from MGT-12, MGT-9, and various other mild gasification chars are shown in Tables 20, 21, and 22. These data allow a determination of the fate of heteroatoms during methanation. Sulfur and nitrogen-to-ash ratios are shown in Table 23. Sulfur-to-ash ratios are all around 0.04 , only slightly less than the S/ash ratio observed for the chars before methanation. This suggests that most of the sulfur is remaining in the char, rather than being gasified to $\mathrm{H}_{2} \mathrm{~S}$ in the gasifier. Figure 52 shows the effect of char gasification temperature and pressure on the $\mathrm{S} / \mathrm{ash}$ ratio. There is a very weak trend towards higher $\mathrm{s} / \mathrm{ash}$ ratios for samples produced at higher temperatures. For the most part, char gasification conditions had little effect on the spent char s/ash ratio.

Also reported in Table 23 are $\mathrm{N} /$ ash ratios. These values exhibit significant variability and are all less than the values observed for the chars before methanation. The effect of temperature and pressure in the methanation reactor on the $\mathrm{N} /$ ash ratio is shown in Figure 52. Here there is a definite trend towards lower nitrogen content for chars gasified at higher temperature. Chars produced at 800 and $850^{\circ} \mathrm{C}$ have essentially zero nitrogen content. The effect of pressure is minor.

Analyses of chars from catalyzed gasification runs are reported in Table 22. For these runs (Runs 30 and 44), we observe a much higher ash content than for uncatalyzed chars because of the presence of the catalyst. oxygen content is also higher. Nitrogen and sulfur analyses are not significantly different from those reported for uncatalyzed chars.

Several spent chars were also characterized for surface area and pore structure. The results are reported in Table 24 . The surface areas of these materials are more than one order of magnitude larger than the surface areas of the starting chars. Apparently methanation produces many micropores leading to these very high surface area values. In microporous samples such as these, it is possible that mass transport, in particular Knudsen diffusion, is rate limiting. 
Table 20. Ultimate Analyses of Spent Chars Produced from MGT-12 Char

\begin{tabular}{|c|c|c|c|c|c|c|c|c|c|}
\hline Test & 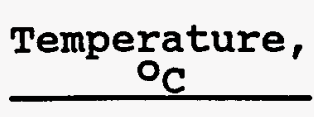 & $\begin{array}{c}\text { Pressure, } \\
\text { psig } \\
\end{array}$ & $\begin{array}{l}\text { Conversion, } \\
\text { Weight } 8 \\
\end{array}$ & $\begin{array}{l}\text { Weight } \\
\frac{\circ \mathrm{C}}{}\end{array}$ & $\begin{array}{l}\text { Weight } \\
\% \mathrm{H} \\
\end{array}$ & $\begin{array}{l}\text { Weight } \\
\frac{\mathrm{g} N \mathrm{~N}}{}\end{array}$ & $\begin{array}{l}\text { Weight } \\
8 \mathrm{~s} \\
\end{array}$ & $\begin{array}{l}\text { Weight } \\
80 \\
\end{array}$ & $\begin{array}{l}\text { Weight } \\
\text { \% Ash }\end{array}$ \\
\hline $\begin{array}{l}274-21 \\
1274-22 \\
274-23 \\
274-24 \\
274-25\end{array}$ & $\begin{array}{l}700 \\
650 \\
750 \\
650 \\
750\end{array}$ & $\begin{array}{l}285 \\
185 \\
185 \\
385 \\
385\end{array}$ & $\begin{array}{l}66 \\
30 \\
68 \\
31 \\
74\end{array}$ & $\begin{array}{l}75.3 \\
80.9 \\
74.8 \\
84.1 \\
67.7\end{array}$ & $\begin{array}{l}1.0 \\
1.8 \\
0.8 \\
1.6 \\
1.2\end{array}$ & $\begin{array}{l}0.3 \\
0.6 \\
0.4 \\
0.4 \\
0.2\end{array}$ & $\begin{array}{l}0.9 \\
0.4 \\
0.9 \\
0.5 \\
1.0\end{array}$ & $\begin{array}{l}0.1 \\
3.5 \\
0.1 \\
1.0 \\
3.5\end{array}$ & $\begin{array}{l}22.3 \\
12.8 \\
23.0 \\
12.4 \\
26.4\end{array}$ \\
\hline
\end{tabular}

Table 21. Ultimate Analyses of Spent Chars Produced from MGT-9 Char

Temperature, Pressure, Conversion, Weight Weight Weight Weight Weight Weight

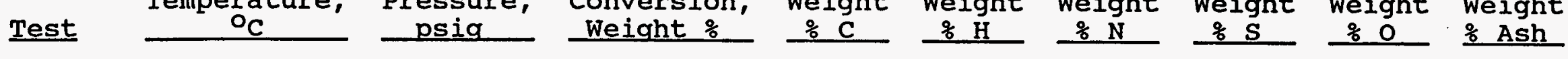

1274-27

1274-32

6 1274-37

700

285

750

\section{4}

285

750

385

385

750

100

800

185

$1274-41$

1274-53

850

385

70.8
74.6
79.4
68.6
75.7
70.6
67.2

1.1

0.6

0.1

0.2

1.3

0.9

1.0

1.0

0.2

0

26.4

$0.9 \quad 3.5$

$0.7 \quad 3.2$

19.8

15.3

$1.2 \quad 2.3$

27.0

18.9

1.23 .0

24.2

$76 \quad 67.2$

Table 22. Ultimate Analyses of Various spent chars $\left(750^{\circ} \mathrm{C}\right.$ and 285 psig unless specified otherwise)

\begin{tabular}{|c|c|c|c|c|c|c|c|c|}
\hline Test & Char & $\begin{array}{l}\text { Conversion } \\
\text { Weight } \% \\
\end{array}$ & $\begin{array}{l}\text { Weight } \\
\% \mathrm{C} \\
\end{array}$ & $\begin{array}{l}\text { Weight } \\
\% \mathrm{H} \\
\end{array}$ & $\begin{array}{l}\text { Weight } \\
\frac{\mathrm{N}}{\circ} \\
\end{array}$ & $\begin{array}{l}\text { Weight } \\
\% \mathrm{~S} \\
\end{array}$ & $\begin{array}{l}\text { Diff. } \\
\text { Weight } \\
\circ 0 \\
\end{array}$ & $\begin{array}{l}\text { Weight } \\
\div \text { Ash }\end{array}$ \\
\hline $\begin{array}{l}1274-30 \\
1274-33 \\
1274-35 \\
1274-44\end{array}$ & $\begin{array}{l}\text { MGT-12a } \\
\text { MGT-6 } \\
\text { MGT-14 } \\
\text { MGT- } 12 b\end{array}$ & $\begin{array}{l}85 \\
39 \\
58 \\
58\end{array}$ & $\begin{array}{l}46.0 \\
81.1 \\
76.7 \\
69.2\end{array}$ & $\begin{array}{l}0.7 \\
1.4 \\
1.2 \\
1.0\end{array}$ & $\begin{array}{l}0.7 \\
0.3 \\
0.2 \\
0.3\end{array}$ & $\begin{array}{l}1.0 \\
0.6 \\
0.8 \\
0.6\end{array}$ & $\begin{array}{r}10.7 \\
3.2 \\
3.0 \\
5.8\end{array}$ & $\begin{array}{l}40.9 \\
13.4 \\
18.1 \\
23.1\end{array}$ \\
\hline
\end{tabular}

a with $10 \% \mathrm{~K}_{2} \mathrm{CO}_{3}$.

b $800^{\circ} \mathrm{C}, 285^{\circ} \mathrm{psig}$ with $5 \% \mathrm{~K}_{2} \mathrm{CO}_{3}$. 


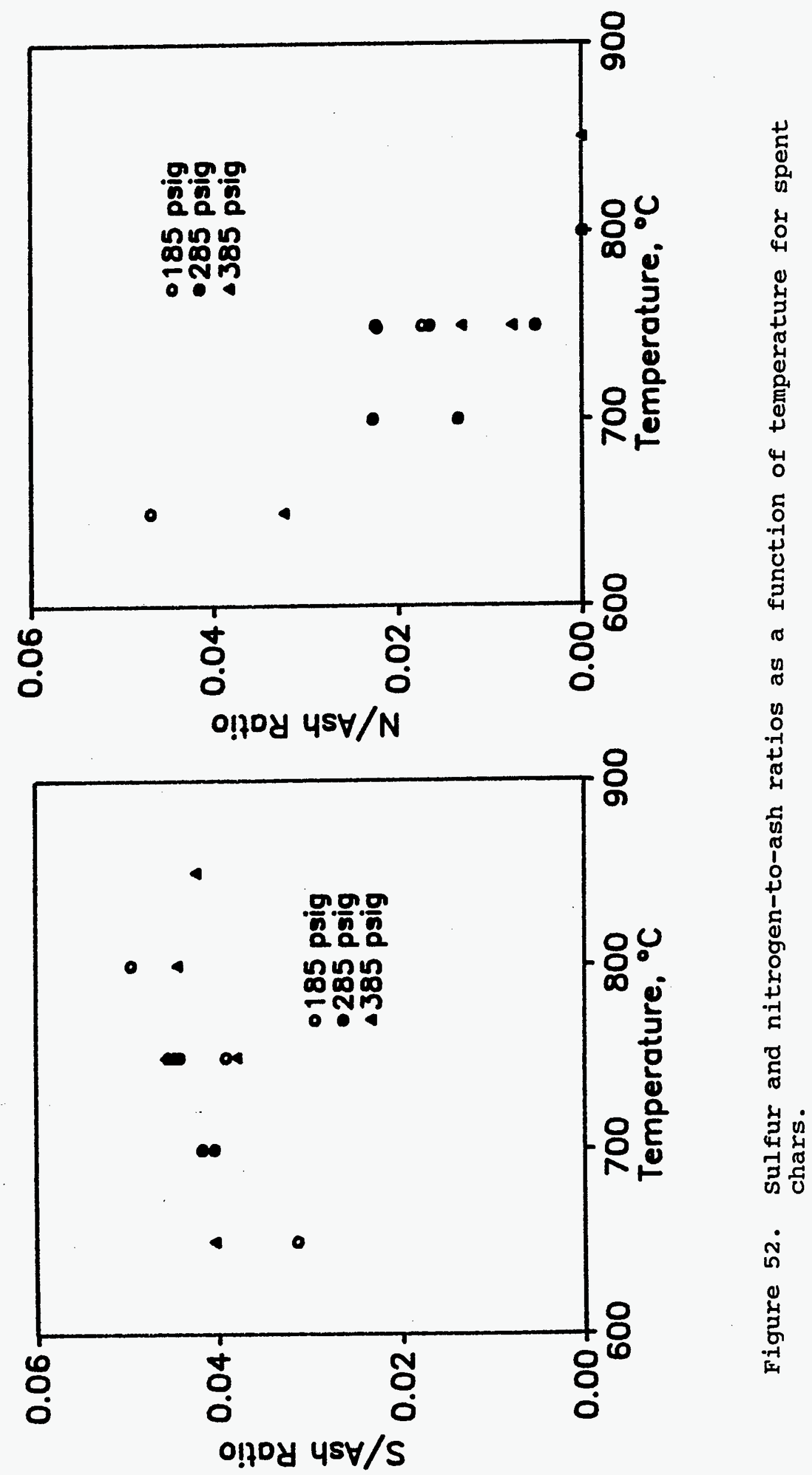


Table 23. Heteroatom-to-Ash Ratios for Spent Chars

Test $\quad \underline{S} / \mathrm{Ash} \quad \mathrm{N} / \mathrm{Ash}$

$\begin{array}{lll}1274-21 & 0.0404 & 0.0135 \\ 1274-22 & 0.0313 & 0.0469 \\ 1274-23 & 0.0391 & 0.0174 \\ 1274-24 & 0.0403 & 0.0323 \\ 1274-25 & 0.0379 & 0.0076 \\ 1274-27 & 0.0417 & 0.0227 \\ 1274-32 & 0.0455 & 0.0051 \\ 1274-33 & 0.0448 & 0.0224 \\ 1274-35 & 0.0442 & 0.0166 \\ 1274-37 & 0.0458 & 0.0131 \\ 1274-38 & 0.0444 & 0 \\ 1274-40 & 0.0423 & 0.0106 \\ 1274-41 & 0.0496 & 0 \\ 1274-53 & 0.0423 & 0\end{array}$

Table 24. Characterization Results for Various spent Chars

\begin{tabular}{|c|c|c|c|c|c|}
\hline Test & Char & $\begin{array}{l}\text { Conversion, } \\
\text { Weight } \%\end{array}$ & $\begin{array}{c}\text { Surface } \\
\text { Area, } \\
\mathrm{m}^{2} / \mathrm{g} \\
\end{array}$ & $\begin{array}{c}\text { True } \\
\text { Density, } \\
\text { cc/g } \\
\end{array}$ & $\begin{array}{l}\text { Pore } \\
\text { Volume, } \\
\text { cc/a } \\
\end{array}$ \\
\hline $1274-21$ & MGT-12 & 66 & 735 & 1.01 & 0.62 \\
\hline $1274-22$ & MGT-12 & 30 & 309 & 1.48 & 0.22 \\
\hline $1274-23$ & MGT-12 & 68 & 700 & 0.99 & 0.61 \\
\hline $1274-24$ & $\mathrm{MGT}-12$ & 31 & 379 & 1.43 & 0.21 \\
\hline $1274-25$ & $\mathrm{MGT}-12$ & 74 & 776 & 1.02 & 0.78 \\
\hline $1274-32$ & $\mathrm{MGT}-9$ & 61 & 702 & - & -- \\
\hline $1274-33$ & MGT- 6 & 39 & 558 & -- & -- \\
\hline $1274-35$ & MGT-14 & 58 & 671 & -- & -- \\
\hline $1274-49$ & MGT-11 & 75 & 688 & -- & -- \\
\hline $1274-50$ & MGT-7 & 77 & 667 & -- & -- \\
\hline
\end{tabular}

The results of mercury porosimetry are also reported in Table 24 for several samples. For high conversion samples, pore volumes have increased by a factor of 2 or 3, while true densities have declined. Pore size distributions are shown in Appendix $\mathbf{E}$ for the spent char samples. A comparison of these results with those for the fresh chars (Appendix B) indicates the formation of a large volume in small pores. The pore size distributions are nearly identical down to 0.1 micron pore diameter, but for smaller pores, the spent char samples show an increased pore volume.

Surface area and pore volume are plotted as a function of conversion in Figure 53. Both surface area and pore volume increase sharply with conversion. This is because of the formation of many very small pores, as carbon is gasified. 

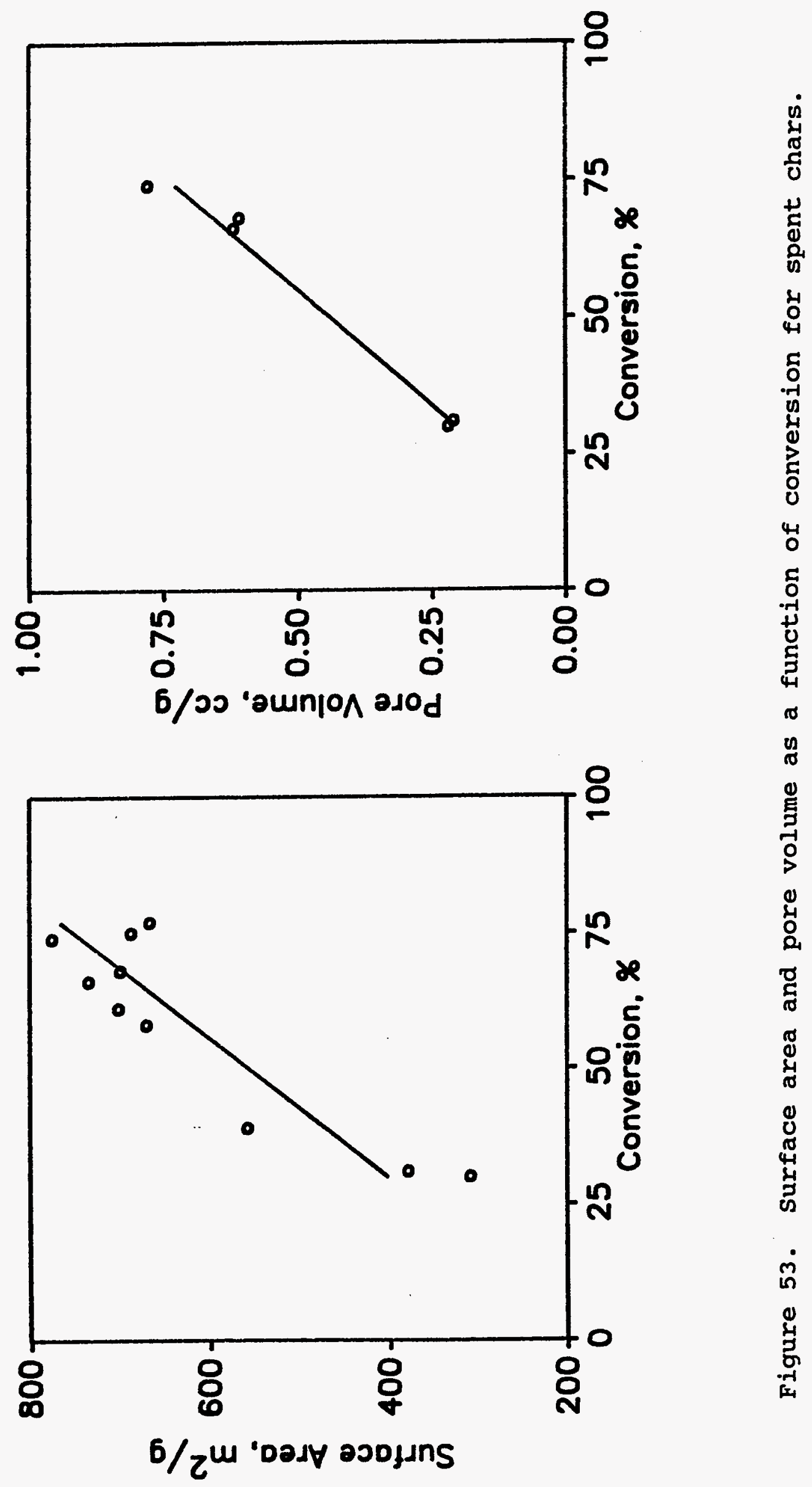


\subsubsection{Summary}

Bench-scale char gasification studies indicate that conversions up to 70 percent can be obtained in less than 2 hours at relatively moderate conditions of temperature and pressure. Temperatures in the range of 700 to $850^{\circ} \mathrm{C}$ and pressures of about 200 to 400 psig are adequate.

The use of gasification catalysts appeared to offer no advantage in runs conducted in the bench-scale system, in contrast to results obtained in the micro-fixed bed. Catalysts did not increase the gasification rate; however, they did increase the final conversion obtainable with a given char.

The results of a char reactivity test indicated that there were some significant differences in the chars produced in mild gasification at different conditions. These differences in reactivity could not be conclusively correlated with char properties or with mild gasification conditions. It did appear, however, that chars with a low volatile matter content were less reactive.

\subsection{OVERALL SUMMARY OF METHANATION TEST RESULTS}

The important results from this study are:

- Methanation to 70 percent conversion is possible in less than 2 hours at temperatures in the range of 700 to $850^{\circ} \mathrm{C}$ and at pressures ranging from 200 to $400 \mathrm{psig}$. These conditions are relatively moderate, and gasification at these conditions is possible because of the specific properties of mild gasification char. These properties include pore structure and the chemical nature of both surface and bulk.

- The use of steam does not have a beneficial effect on the methane formation rate and can result in gasification of a large portion of the carbon to carbon oxides.

- The effect of catalyst addition was inconclusive. 


\subsection{CARBON FORMATION TEST RESULTS}

This chapter reviews the literature on carbon formation from hydrocarbons and describes the results of the carbon formation studies. These studies were conducted using a synthetic gas mixture designed to simulate the methanation reactor product gas.

\subsection{TECHNICAL BACKGROUND}

Methane has been used in the production of carbon for many years. 2 In early processes, the methane was burned in an oxygen deficient flame, producing soot. The flame impinged upon iron channels where the soot was deposited. This type of carbon was originally used as a pigment, but in the twentieth century, carbon has found other uses. These include anodes for electrochemical processes and as a reinforcing and strengthening agent for elastomers. This section will review the mechanism of carbon formation from methane and the properties of this type of carbon which are thought to be important in commercial applications. Finally, commercial processes for the production of carbon from methane will be described.

\subsubsection{Mechanism of Carbon Formation}

Carbon can be produced from methane in two types of processes, partial combustion and pyrolysis. Also, two types of carbon are formed. These are pyrocarbon, which forms on the reactor walls and internals, and a carbon made up of nearly spherical particles, which is referred to as soot or carbon black. This review will concentrate on the mechanism of carbon black formation in partial combustion and pyrolysis processes.

There are two phases in the formation reaction of carbon black. 30 These phases are nucleation and particle growth, which have very different mechanisms. Particle growth can be followed by particle agglomeration, which has a significant effect on the properties of the final carbon product.

Before nucleation, the hydrocarbon (methane) is thought to be thermally decomposed to acetylene or similar species by complex reactions. 31 The acetylene then polymerizes to produce reactive macromolecules in the vapor phase known as saturated platelets. The platelets consist of several condensed sixmembered carbon rings which are not aromatic. 31 The platelets can then polymerize further to form macromolecules.

The vapor pressure of the platelets and macromolecules increases with residence time in the reactor until supersaturation. At some vapor pressure above saturation (nucleation vapor pressure), the vapor condenses into small droplets. When this occurs, the vapor pressure is reduced 
below saturation and no further droplet formation occurs. The formation of platelets and macromolecules continues, and these condense on the nuclei which have already formed. 30 'These liquid droplets then pyrolyze to form solid carbon by dehydrogenation, condensation, and molecular rearrangements. The idea of a liquid intermediate is supported by the continuity of planar carbon structures observed in carbon black aggregates.

Some information is also available on particle growth. The temperatures required for particle growth are much lower than those required for nucleation. Also, particle growth can occur at hydrocarbon concentrations below those required for formation of nucleates and isolated particles. 30

There has been controversy surrounding the question of whether coalescence of nucleates is a significant phenomenon. The data appear to indicate that at low hydrocarbon concentrations, no coalescence occurs. This conclusion is based on the observation of a normal particle size distribution for carbon black produced under these conditions. As hydrocarbon concentration is raised, the size distribution shifts to log normal, as expected for nucleate coalescence. These results are supported by transmission electron microscope studies of thermal black particles showing multiple nuclei. 30 However, in furnace blacks, multiple nuclei are not observed, even though the particle size distribution is log normal. Furnace blacks are produced using residence times which are shorter by a factor of 100 to 1,000 than those used for thermal blacks. In this situation, nucleate coalescence would not be expected to occur. The log normal distribution of particle sizes arises from the log normal distribution of residence times in the highly turbulent furnace reactor. 30

\subsubsection{Properties and Structure of Carbon Blacks}

Particle size and size distribution are important properties of carbon blacks. Also important are the presence and structure of aggregates and agglomerates. Thermal blacks consist of individual particles, while furnace blacks are made up of agglomerates. Carbon surface area is important because the carbon will interact with other substances (elastomers, anode binders, etc.) at the surface. Porosity, density, and electrical conductivity are also of practical interest.

Elemental composition and the chemistry of surface functional groups can have a marked effect on carbon black properties. 30 In particular, the type of surface groups which are present determines the reactivity of the carbon black surface. These groups are predominantly surface oxides, although sulfur-containing groups may also form if sulfur is present. 
Carbon blacks are considered to be polycrystalline solids; however, the building block of a carbon black particle is not a crystaliite but a graphite plane. These graphite planes are wrapped in concentric layers around the original nucleate, or nucleates if multiple nuclei are present.

\subsubsection{Production of Carbon Blacks from Methane}

Three processes have been used to produce carbon blacks from methane. These are the channel black, thermal black, and gas-furnace black processes. The channel black process is the early process described above where soot is collected on iron channels.

In the thermal black process, two refractory lined furnaces alternate on about a 5-minute cycle between heating and carbon production. The overall production is continuous from the two reactors. These refractory lined furnaces are filled with an open checkerwork of silica brick. 2 During operation, one reactor is heated with a stoichiometric mixture of fuel and air, while the other reactor, heated in the previous cycle, is fed with methane. The methane decomposes to produce a product stream-containing carbon particles, hydrogen, methane, and other hydrocarbons. This stream is cooled with water spray and the carbon is removed in filters. Carbon recovery is about 30 to 45 percent, including any methane used as fuel. The hydrogen rich product gas is cooled and used to heat the reactors or is used to dilute the methane if smaller particle size fine thermal black is to be produced.

In the gas-furnace process, natural gas (methane) is partially combusted in a refractory lined furnace. Different grades of black are made by changing reactor temperature and residence time. The carbon is cooled in a water spray and separated from the combustion gases with electrostatic precipitators, cyclones, and filters. Since the 1960s, this process has been replaced by the oil furnace process where a petroleum based oil is partially combusted to produce the carbon black.

\subsection{MULLITE CARBON PRODUCTION REACTOR TESTS}

Fourteen tests were run in the mullite tube carbon production reactor and the results are shown in Table 25. Temperature, residence time, and gas composition were varied in the ranges of 1,200 to $1,400^{\circ} \mathrm{C}, 0.07$ to 7.7 seconds, and from 33 to 66 percent hydrogen, respectively. Most runs were made using a feed of 50 percent hydrogen and 50 percent methane. In Run $13,0.1$ percent $\mathrm{H}_{2} \mathrm{~S}$ was included in the feed gas to determine if the sulfur would become incorporated into the carbon. 
Table 25. Carbon Formation Experiments Performed in the Mullite Carbon Formation Reactor

Gas

Feed Flow Rates Residence

\begin{tabular}{lll}
$\mathrm{H}_{2}$ & $\mathrm{CH}_{4}$ & $\mathrm{H}_{2} \mathrm{~S}$ \\
\hline
\end{tabular}

Time, Test

Temperature,

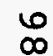

7.7

7.7 ${ }^{\circ} \mathrm{C}$

1,400
1,400
1,400
1,400
1,200
1,300
1,400
1,400
1,400
1,400
1,300
1,200
1,300
1,300

1,400 $\underline{\text { SIM SLM }}$

\subsection{4}

0.04

0.04

0.04

0.50

0.50

0.50

0.50

0.25

0.50

4.5

0.50

0.60

0.40

0.50

0.20

0.40
0.20

0.50

4.5

0.50

0.60

0.45

0.50

0.20

0.20

0.40

0.6

0.6

0.7

1.3

0.07

0.6

0.5

0.7

0.7

1.8

1.1

1.1

\begin{tabular}{c}
$\begin{array}{c}\text { Run } \\
\text { Time, } \\
\text { Minute }\end{array}$ \\
\hline 223 \\
360 \\
106 \\
113 \\
225 \\
191 \\
31 \\
94 \\
56 \\
82 \\
89 \\
360 \\
306 \\
120
\end{tabular}

outlet Flow Rate, $\mathrm{ccm}$

--
--
1,530
1,530
1,270
820
12,500
1,460
1,550
1,145
1,380
460
720
950

Carbon Produced,

0.42
0.46
1.9
3.3
2.3
1.5
3.9
1.3
5.0
6.1
8.6
1.8
5.4
6.8


Outlet flow rates were measured in most runs to give an indication of methane conversion. There is a change from 1 mole of methane to 2 moles of hydrogen with this reaction, so at complete conversion, the product gas flow rate should be equal to the inlet hydrogen flow rate plus two times the inlet methane flow rate. As the data in Table 25 indicate, flow rates for many runs are more than expected for complete conversion. Apparently the outlet gas had not cooled to ambient temperature when the measurement was made. In any case, very high conversions were obtained at 1,300 and $1,400^{\circ} \mathrm{C}$, but at $1,200^{\circ} \mathrm{C}$, conversion was relatively low.

Plugging of the reactor tube with pyrolytic carbon was observed in all runs. In most runs, the run duration was determined by the formation of this plug. It is reasonable to assume at this stage that reactor plugging will not be a problem in a larger reactor with a smaller surface-to-volume ratio and higher gas velocities.

\subsection{PROPERTIES OF CARBON PRODUCT}

The results of carbon product characterization are shown in Table 26. Because of the limited quantities of carbon produced, not all characterization techniques could be applied to all samples. Even with this limitation, it is possible to draw several important conclusions from the data presented in Table 26.

\section{Table 26. Properties of Mullite Carbon} Formation Reactor Product

\begin{tabular}{|c|c|c|c|c|c|}
\hline Test & $\begin{array}{l}\text { Weight } \\
\% \mathrm{C} \\
\end{array}$ & $\begin{array}{l}\text { Weight } \\
\frac{\%}{} \mathrm{H} \\
\end{array}$ & $\begin{array}{c}\text { Weight } \\
\% \mathrm{~S} \\
\end{array}$ & $\begin{array}{l}\text { Average } \\
\text { Particle } \\
\text { Size, nm }\end{array}$ & $\begin{array}{c}\text { Surface } \\
\text { Area, } \\
\mathrm{m}^{2} / \mathrm{q} \\
\end{array}$ \\
\hline 9 & 99.4 & 0.4 & -- & -- & 40.5 \\
\hline $\begin{array}{l}11 \\
12\end{array}$ & $\begin{array}{c}99.3 \\
--\end{array}$ & $\begin{array}{l}0.8 \\
--\end{array}$ & -- & $\begin{array}{l}64.19 \\
68.90\end{array}$ & $\begin{array}{c}36.1 \\
--\end{array}$ \\
\hline 13 & 98.3 & 0.6 & 0.06 & -- & 43.0 \\
\hline 14 & 99.6 & 0.4 & -- & -- & 23.9 \\
\hline 16 & -- & -- & -- & 97.57 & - \\
\hline 17 & 99.4 & 0.6 & - & 115.38 & 20.9 \\
\hline 18 & 97.9 & 1.2 & -- & 116.20 & 15.4 \\
\hline 19 & -- & -- & -- & 102.69 & 23.8 \\
\hline 20 & 99.5 & 0.6 & -- & 143.08 & 15.7 \\
\hline
\end{tabular}

\subsubsection{Particle size and Distribution}

Runs 12 and 16 were conducted at the same temperature $\left(1,400^{\circ} \mathrm{C}\right)$ and feed gas composition $\left(50\right.$ percent $\left.\mathrm{H}_{2}\right)$ but at 
residence times which differ by a factor of 10 . The data indicate that the average particle diameter is 30 to 40 percent smaller at the shorter residence time. Particle size distributions for several runs are shown in Figure 54. The data for runs 12 and 16 suggest a slightly broader distribution of particle sizes for Run 16, which was made at the longer residence time. All of these particle size distributions are approximately log normal.

Runs 16 and 17 can be compared to evaluate the effect of temperature on particle size. Run 16 was conducted at $1,400^{\circ} \mathrm{C}$, while Run 17 was conducted at $1,300^{\circ} \mathrm{C}$. Gas compositions and residence times were the same in both runs. The results indicate that lower temperatures favor the formation of larger particles. Also, particle size distributions suggest a slight broadening of the size distribution at the lower temperature.

The effect of gas composition was investigated in runs 19 and 20. Run 19 was conducted with a hydrogen rich feed gas and resulted in a reduced particle size relative to Run 20 . The carbon from Run 19 also exhibits a significantly narrower particle size distribution than the run conducted with a methane rich feed gas (Run 20).

\subsubsection{Elemental Analysis}

Analytical results were obtained for seven of the carbons. There is very little variation in the carbon and hydrogen analyses with one exception. The carbon produced at $1,200^{\circ} \mathrm{C}$ contained about twice as much hydrogen as those produced at higher temperatures. Also, in Run 13 where 0.1 percent $\mathrm{H}_{2} \mathrm{~S}$ was present in the feed gas, some of this sulfur was retained in the carbon product. The carbon produced in this run contained 0.06 weight percent sulfur. However, a simple calculation (sulfur material balance) indicates that only 10 percent of the sulfur fed to the system exits in the char. This high level of sulfur rejection indicates that a low sulfur carbon can be obtained even when sulfur is present in the reactor.

\subsubsection{Surface Area}

Surface areas were measured for five samples. The data allow some conclusions to be draw about the effect of temperature, residence time, and gas composition on carbon surface area. Carbons from runs 9 and 14 were produced at $1,400^{\circ} \mathrm{C}$ and with a feed gas containing 50 percent hydrogen but at very different residence times. The results indicate that longer residence times lead to high surface area carbon. A comparison of runs 14 and 18 indicates that lowering the temperature can reduce surface area. A comparison of runs 19 and 20 indicates that increasing the hydrogen content of the feed can lead to increased surface area. The results indicate 

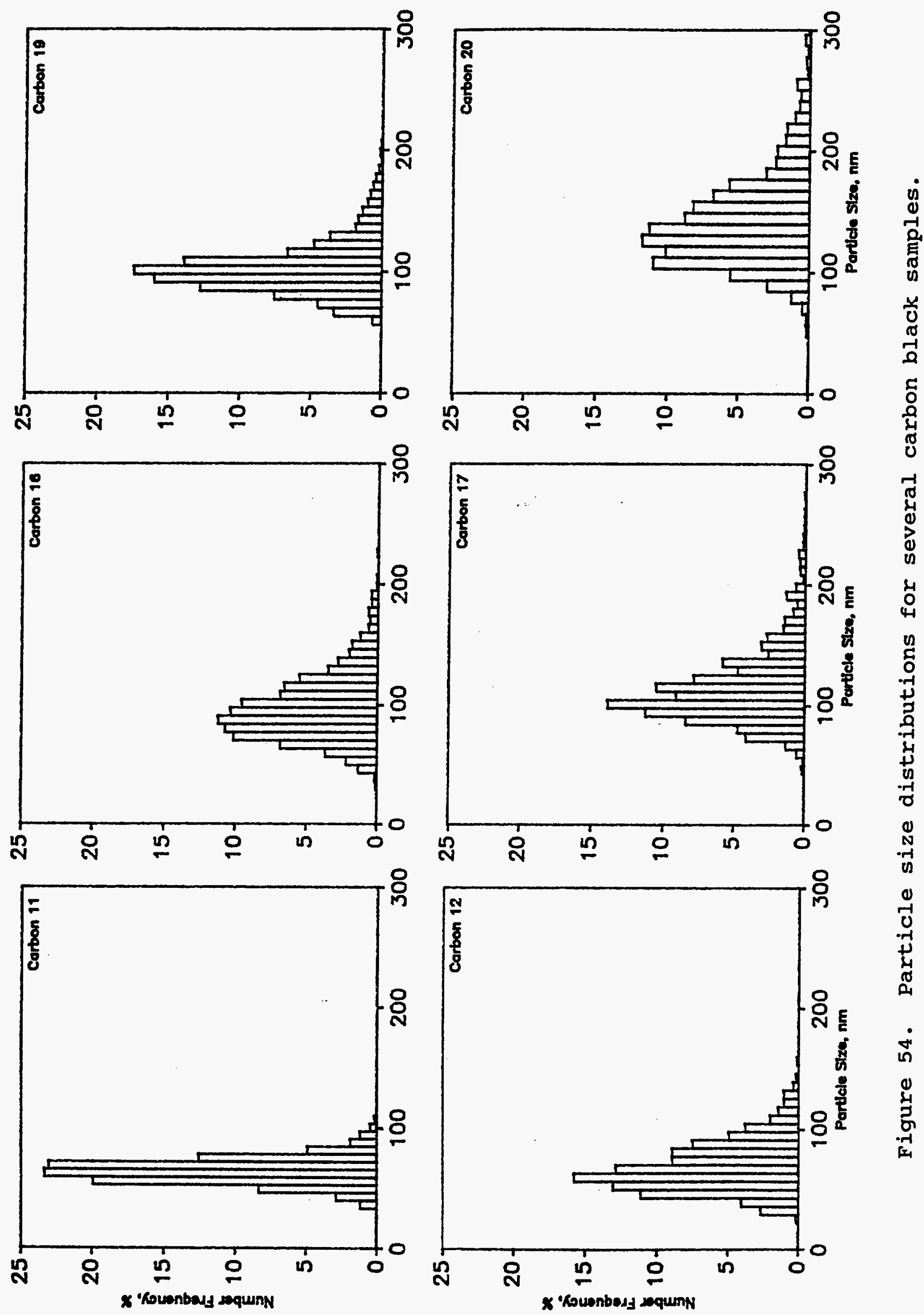
that process conditions can be manipulated to determine the surface area of the product.

\subsubsection{Carbon Particle and Agglomerate Morphology}

Figures 55 through 59 show SEM micrographs taken at 20,000X magnification for carbons produced in runs $7,10,12$, 13, and 17, respectively. These samples encompass the range of temperatures and residence times employed.

The primary particles are very nearly spherical in all samples. These micrographs contain information on primary particle shape and size but do not appear to illustrate the aggregate structure. The samples were not mechanically dispersed before imaging, and this is most probably responsible for the lack of structural information.

A comparison of micrographs for carbons 10,13 , and 17 illustrates the effect of temperature on particle size and primary particle agglomeration. These runs were made using a 50 percent hydrogen/50 percent methane gas mixture and a residence time of 0.6 to 0.7 second. In Run 10 , conducted at $1,200^{\circ} \mathrm{C}$, the primary particles are large $(300 \mathrm{~nm})$. The particles are also very tightly packed together and may actually be connected by bridges. The primary particles in the Run 17 sample $\left(1,300^{\circ} \mathrm{C}\right.$ ) are much smaller (about $100 \mathrm{~nm}$ ) and there is no evidence of bridging. In the Run 13 sample, the particles are smaller still ( 80 to $90 \mathrm{~nm}$ ) and are only loosely connected. It is apparent from these data that high temperatures favor the formation of small, non-agglomerated particles at the residence time and feed composition of these runs.

A comparison of micrographs from runs 7,12 , and 13 illustrates the effect of residence time at $1,400^{\circ} \mathrm{C}$ on particle size and agglomeration. In Run 12, which was made at the shortest residence time, particle size data reported above indicate an average size of $69 \mathrm{~nm}$. The particles in Figure 58 appear to be slightly larger than this because of the tungsten coating. Particles from Run 13, made at the next shortest residence time, are larger at about $90 \mathrm{~nm}$. Increasing the residence time further to more than 7 seconds, as in Run 7, produces much larger particles of at least $200 \mathrm{~nm}$ diameter. These data indicate that particle size can be controlled by controlling residence time. 


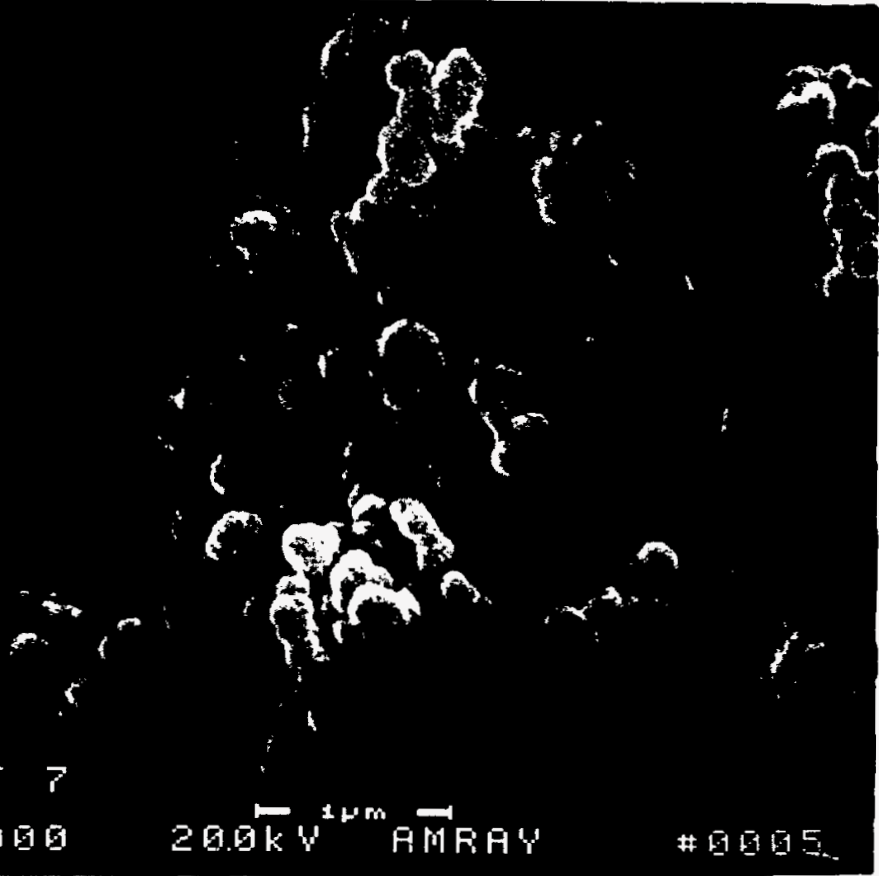

Figure 55. Scanning electron micrograph of carbon produced in Run 7.

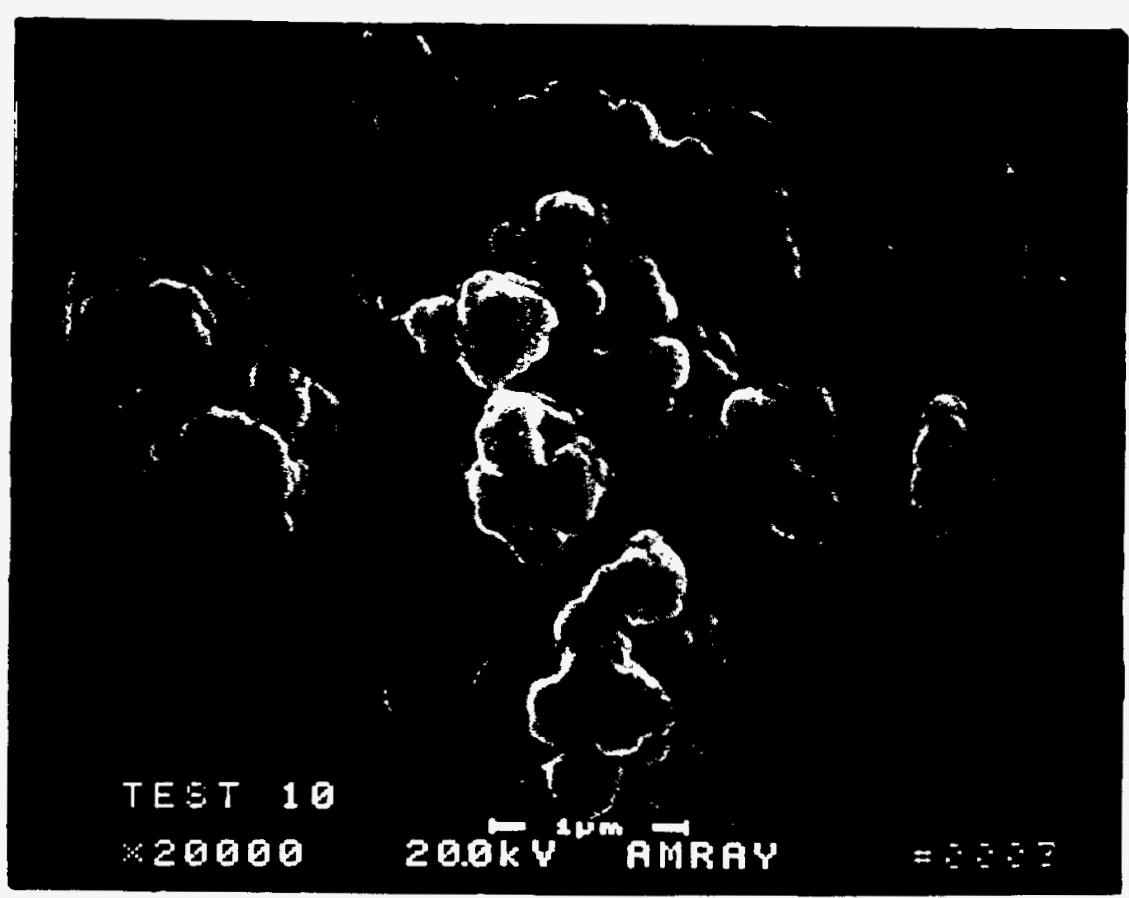

Figure 56. Scanning electron micrograph of carbon produced in Run 10. 


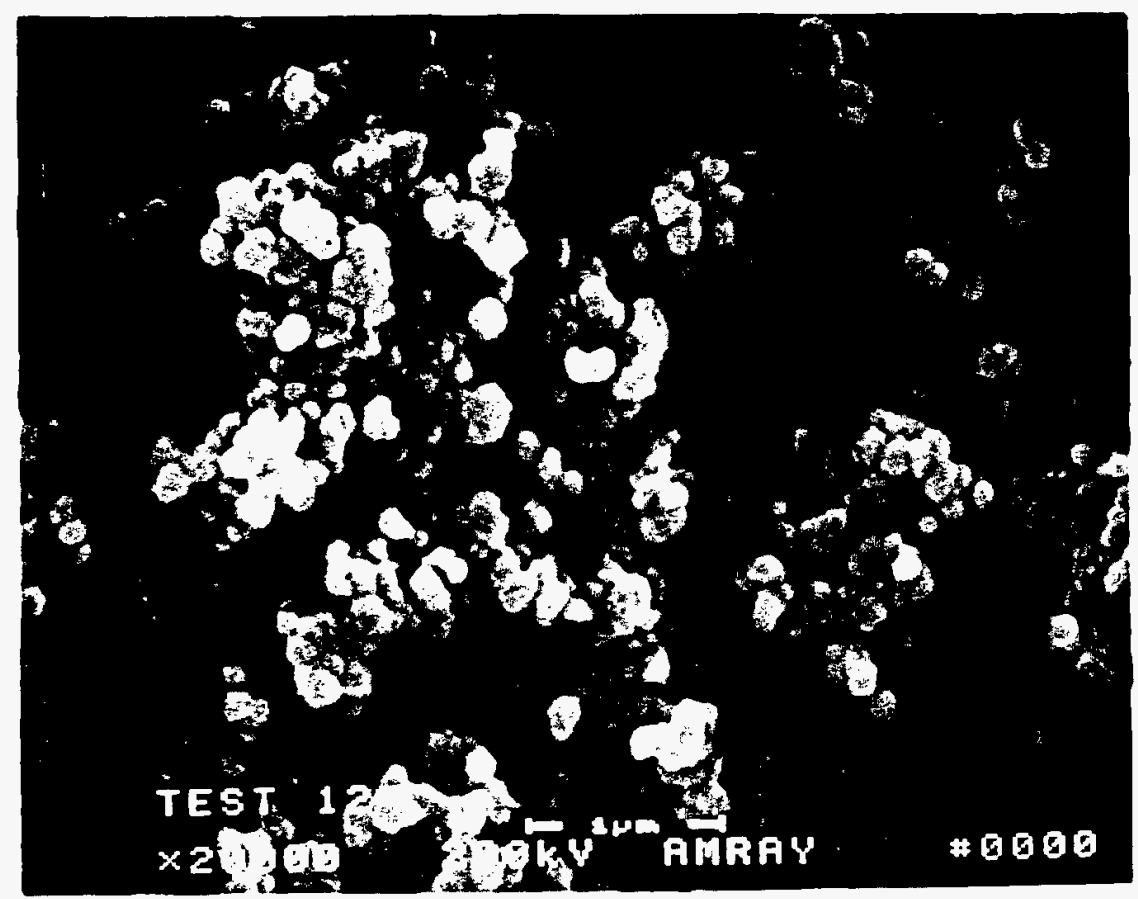

Figure 57. Scanning electron micrograph of carbon produced in Run 12 .

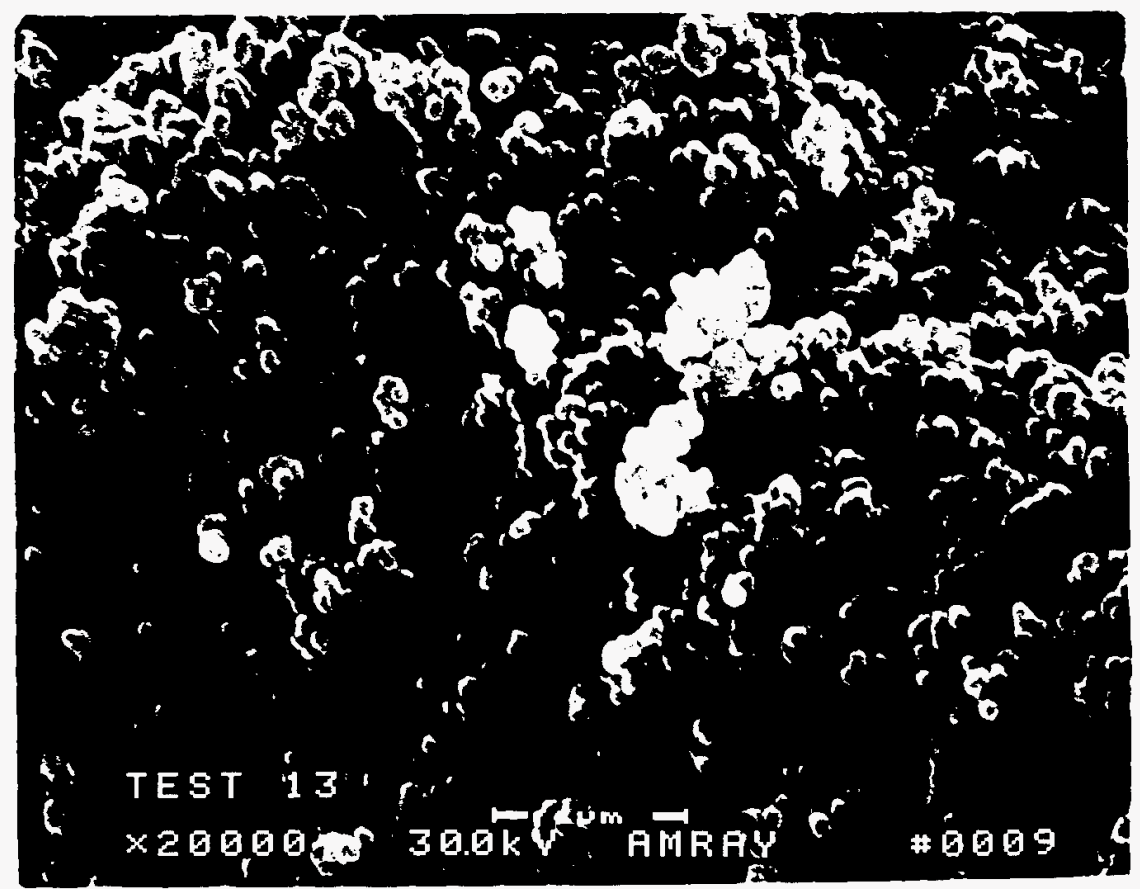

Figure 58. Scanning electron micrograph of carbon produced in Run 13. 


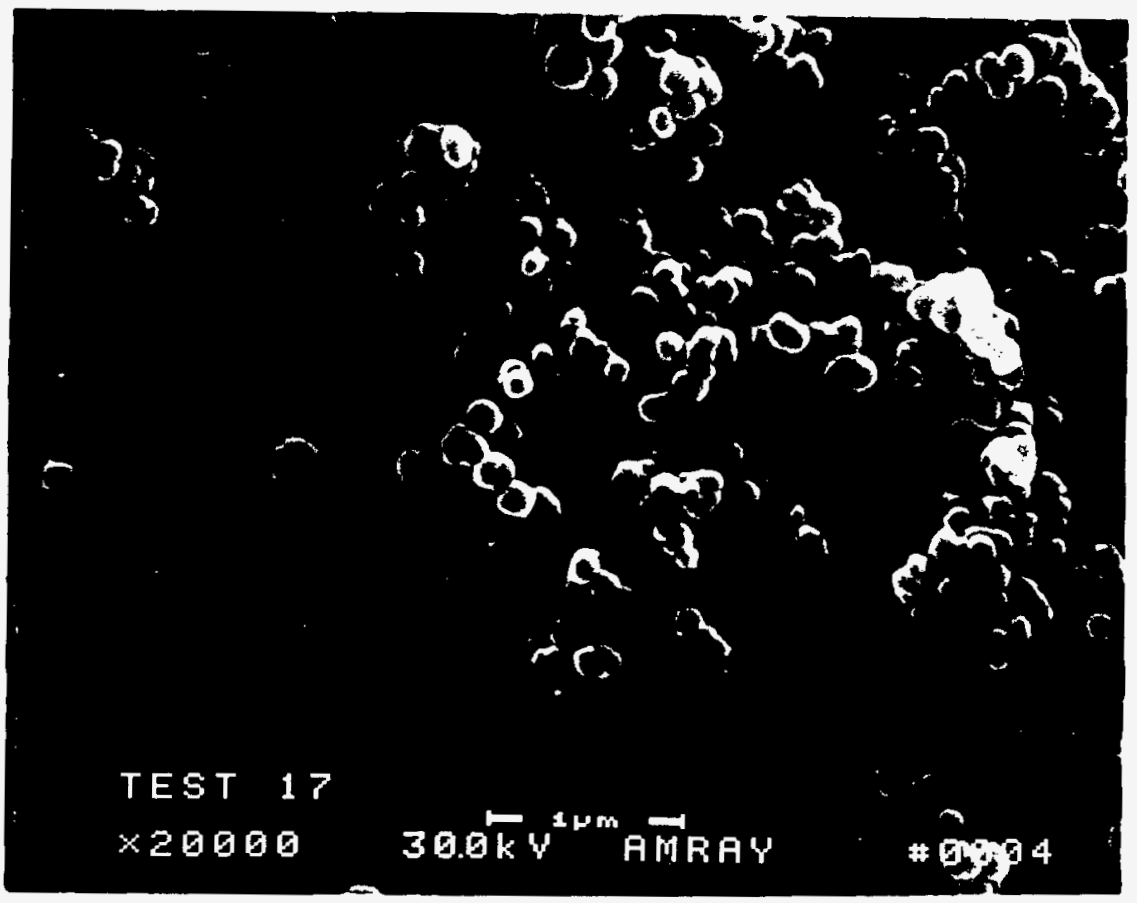

Figure 59. Scanning electron micrograph of carbon produced in Run 17.

\subsubsection{Comparison with Commercial Carbons}

Particle size distributions for the carbons studied are in between the sizes reported for fine thermal black (N880) and the coarser grades of furnace blacks (N550, for example). The same statement can be made for carbon surface areas. ${ }^{2}$ Also, the SEM micrographs indicate that AMAX carbons exhibit more structure than fine or medium thermal blacks but less than observed for furnace blacks. This conclusion is based on micrographs shown in References 2 and 30 . At this point, the AMAX carbon looks similar to products currently on the market but slightly different in some respects.

\subsection{SUMMARY OF CARBON PRODUCTION RESULTS}

The results presented in this section indicate that carbons similar to both thermal blacks and furnace blacks can be produced in an indirectly heated system. The type of carbon produced depends upon the conditions selected for the reactor. The physical properties of the carbon product can be controlled by varying residence time, temperature, and methane partial pressure. Also, the carbon and hydrogen content can be controlled by varying conditions. If sulfur is present in the feed gas as $\mathrm{H}_{2} \mathrm{~S}$, very little will become incorporated into the carbon. While this will be important in fuel and anode applications, the presence of low levels of sulfur does not significantly affect the performance of carbon black in elastomers. 2 


\subsection{SIGNIFICANCE OF RESULTS}

The experiments performed under Task 3 were designed to investigate the feasibility of the char upgrading process and to allow selection of appropriate reactor designs for the Task 4 PDU. The data will also be used to size the PDU reactors. Carbon product characterization will allow more detailed market studies to be performed. The significance of the reported results to these goals is discussed below.

\subsection{PROCESS FEASIBILITY}

The results presented in the preceding chapters indicate that the proposed AMAX process for upgrading mild gasification char is technically feasible. The production of methane from mild gasification char has been shown to be feasible at relatively moderate conditions of temperature and pressure. A residence time of less than 90 minutes is required. Conversions as high as 70 percent (maf) have been obtained. There is reason to believe that higher conversions could be obtained in a fluidized-bed reactor where gas-solid contacting is much more efficient than in a fixed bed.

The production of carbon from methane is a well known process. The process under development at AMAX R\&D is similar in some ways to conventional technology, but the carbon production reactor design is significantly different. While details of the reactor design are unique, the associated carbon collection and handling operations are practiced extensively throughout the energy and minerals industries. Carbon product characterization data indicate that the reactor under development at AMAX R\&D can produce a product similar in quality to carbon blacks marketed commercialiy today. These facts, and the results presented above, indicate that the production of high value carbon and a hydrogen rich recycle gas from methane is feasible.

\subsection{PROCESS ENGINEERING}

For process engineering, the goal of this development project have been two-fold: 1) to identify the unit operations which will be necessary in a larger scale plant and 2) to provide data which will allow the selection of appropriate reactor designs. The results presented here indicate that no new unit operations need to be added to the proposed process (as described in Chapter 2).

Char gasification data indicate that removal of heat from the reaction vessel is important. This can clearly be seen by examining the temperature profiles shown in Appendix $D$ for the fixed-bed runs. These data indicate that temperature control in a fixed-bed system is quite difficult. Much better 
temperature control could be obtained in a fluidized-bed or a moving-bed system. Here, the heat of reaction is more distributed throughout the bed in these types of reactors, and heat transfer tubes could be inserted into the bed. Better gas-solid contacting will be obtained because of the higher gas velocities used. The observation that high methane partial pressures do not have a great effect on the gasification rate suggests that a single-stage fluidized or moving bed might be adequate. However, this question will need to be addressed in more detail in the Task 4 process demonstration unit design.

Carbon formation results indicate that high quality carbon can be made in an indirectly heated reactor. This is

different from conventional indirectly heated systems where the reactor is filled with a silica brick checkerwork (thermal black process). Reactor design for the carbon formation step should concentrate on the development of a tubular ceramic system which is indirectly heated. 


\subsection{CONCLUSIONS}

The important conclusions that can be drawn from this work are:

- The mild gasification chars have a very open pore structure, relatively low volatile matter content, and maintain their reactivity when stored in an inert atmosphere.

- Methanation of these chars can be accomplished using hydrogen in the temperature range of 700 to $850^{\circ} \mathrm{C}$ and pressure range of 200 to $400 \mathrm{psig}$ with about 70 percent carbon conversion being obtained in less than 2 hours.

- Sulfur in the mild gasification chars is present in a very refractory form, so it is not gasified. The sulfur remains with the spent char or ash.

- The use of steam offers no advantage in mild gasification char methanation.

- The use of catalysts such as potassium carbonate or sodium carbonate did not increase reaction rates in char methanation and, therefore, offers no advantage.

- A fluidized-bed reactor is the most appropriate choice of reactor design for the char methanation reactor.

- The production of carbon from methane in indirectly heated, tubular reactors was proven to be feasible.

- The carbon produced in this type of reactor has properties which depend on the temperature, gas composition, and residence time employed.

- Carbon samples exhibited particle size distributions, surface areas, and structure similar to those observed for commercial grade thermal and furnace blacks.

- The overall process of conversion of char to high purity carbon is technically feasible and studies to integrate char gasification and carbon formation should proceed. 


\subsection{REFERENCES}

1. Cha, C. -Y., Merriam, N. W., Jha, M. C., and Breault, R. W., Topical Report for Task 1, Development of an Advanced, Continuous Mild Gasification Process for the Production of Coproducts, Contract No. DE-AC21-87MC24268, January 1988.

2. Dannenberg, E. M., "Carbon Black" in Kirk-othmer Encyclopedia of Chemical Technology, Volume 4, 3rd Edition, John Wiley and Sons, New York, 1980, pp. 631-666.

3. Smith, J. M. and Van Ness, H. C., Introduction to Chemical Engineering Thermodynamics, McGraw-Hill, New York, 1975.

4. Grohse, E. W. and Steinberg, M., "Economic Clean Carbon and Gaseous Fuels from Coal and other Carbonaceous Raw Materials", Brookhaven National Laboratory Informal Report, BNL 40485, November 1987.

5. Thiele, E. W., "Relation Between Catalytic Activity and Particle Size", Ind. Eng. Chem. 31, 916 (1939).

6. Johnson, J. L., "Fundamentals of Coal Gasification", in Chemistry of coal Utilization, second supplementary Volume, Martin A. Elliot, Editor, Wiley-Interscience, New York, 1981.

7. Wilke, C. R. and Lee, C. Y., "Estimation of Diffusion Coefficients for Gases and Vapors", Ind. Eng. Chem. 47, 1253 (1955).

8. Satterfield, C. N., Mass Transfer in Heterogeneous Catalysis, Krieger Publishing, Huntington, New York, 1981, pp. 157 .

9. Huttinger, K. J. and Schleicher, P., "Kinetics of Hydrogasification of coke Catalyzed by $\mathrm{Fe}, \mathrm{Co}$, and $\mathrm{Ni",}$ Fuel 60, 1005 (1981).

10. Zielke, C. W. and Gorin, E., "Kinetics of Carbon Gasification", Ind. Eng. Chem. 47, 820 (1955).

11. Cao, J.-R. and Back, M. H., "Kinetics of the Reaction of Hydrogen with Thin Films of Carbon", Carbon 20, 505 (1982).

12. Zoheidi, $\mathrm{H}$. and Miller, D. J., "Influence of $\mathrm{K}_{2} \mathrm{CO}_{3}$ Catalyst on Rate of Hydrogen Gasification of Carbon Black", Carbon 25, 265 (1987). 
13. Zoheidi, H. and Miller, D. J., "Role of oxygen Surface Groups in Catalysis of Hydrogasification of Carbon Black by Potassium Carbonate," Carbon 25, 809 (1987).

14. Liu, Z.-L. and Zhu, H.-H., "Steam Gasification of Coal Char Using Alkali and Alkaline-Earth Metal Catalysts", Fuel 65, 1334 (1986).

15. Walker, P. L., Matsumoto, S., Hanzawa, T., Muira, T., Ismial, I. M. K., "Catalysis of Gasification of CoalDerived Cokes and Chars", Fuel 62, 140 (1983).

16. Matsukata, M., Fujikawa, T., Kikuchi, E., Morita, Y., "Interaction Between Potassium Carbonate and Carbon substrate at Subgasification Temperatures. Migration of Potassium into the Carbon Matrix," Energy and Fuels $\underline{2}, 750$ (1988).

17. Huttinger, K. J. and Minges, R. "Catalytic water vapour Gasification of Carbon: Importance of Melting and Wetting Behaviour of the Catalyst", Fuel 64, 491 (1985).

18. Coates, D. J., Evans, J. W., Cabrera, A. L., Somorjai, G. A., Heinemann, H., "An Electron Microscopy Study of the Low Temperature Catalyzed Steam Gasification of Graphite", J. Catal. 80, 215 (1983).

19. Hebden, D. and Stroud, H. J. F., "Coal Gasification Processes" in Chemistry of Coal Utilization, Second Supplementary Volume, Martin A. Elliot, Editor, WileyInterscience, New York, 1981.

20. Van Heek, K. H., "Technical Status and New Developments of Coal Gasification Processes" in Coal and Carbon Gasification, NATO ASI Series E, Volume 5, Jose' L. Figueiredo and Jacob A. Moulijn, Editors, Martinus Nijhoff, Dordrecht, 1986.

21. Gregg, S. J. and Sing, K. S. W., Adsorption, Surface Area and Porosity, Academic Press, New York, 1967.

22. Wertz, D. L., "Amorphous X-Ray Scattering in Coals and Devolatilized Coal By-Products", Powder Diffraction $\underline{3}$, 153 (1988).

23. Huttinger, K. J., "Fundamental Problems in Iron-Catalyzed Coal Gasification - A Survey", Fuel 62, 166 (1983).

24. Nishiyama, Y., "Catalytic Behaviour of Iron and Nickel in Coal Gasification", Fuel 65, 1404 (1986). 
25. Haga, T. and Nishiyama, Y., "Promotion of Iron-Group Catalysts by a Calcium Salt in Hydrogasification of Carbons at Elevated Pressures", Ind. Eng. Chem. Res. 26, 1202 (1987).

26. Johnson, J. L., "Relationship Between the Gasification Reactivities of Coal Char and the Physical and Chemical Properties of Coal and Coal Char", ACS Div. Fuel Chem. Prepr. 20, (4) 85 (1975).

27. Johnson, J. L., "Kinetics of Initial coal Hydrogasification stages", ACS Div. Fuel Chem. Prepr. 22, 17 (1977).

28. Jha, M. C. and McCormick, R. L., Topical Report for Subtask 3.1, Bench-Scale Char Upgrading and Utilization Study: Experimental Test Plan, Contract No. DE-AC2187MC24268, September, 1988.

29. Huttinger, K. J., Masling, B., Minges, R., "Catalytic Activity of Carbon supported Potassium in the Carbon Monoxide Shift Reaction", Fuel 65, 932 (1986).

30. Donnet, J.-B. and Voet, A. Carbon Black, Marcel Dekker, New York, 1976.

31. Abrahamson, J., "Saturated Platelets Are New Intermediates in Hydrocarbon Pyrolysis and Carbon Formation", Nature $\underline{266}, 323(1977)$.

32. Khan, M. R., Chen, W. -Y., Suuberg, E., "Influence of Steam Pretreatment on Coal Composition and Devolatilization", Energy and Fuels, 3, 223 (1989). 
APPENDIX A

THERMAL GRAVIMETRIC ANALYSIS OF MILD GASIFICATION CHAR 
DEVELOPMENT OF AN ADVANCED

MILD GASIFICATION PROCESS

DOE DE-AC21-87MC24268

THERMAL GRAVIMETRIC ANALYSIS

OF MILD GASIFICATION CHAR

Prepared by:

Riley Research Center

RILEY STOKER CORPORATION

45 McKeon Road

Worcester, MA 01610

Project Manager:

Frank J. Zone, Jr.

Prepared for:

WESTERN RESEARCH INSTITUTE

University of Wyoming Research Corp.

P.0. Box 3395

Laramie, WY 82071

WRI Project Manager:

Chang-Yul Cha

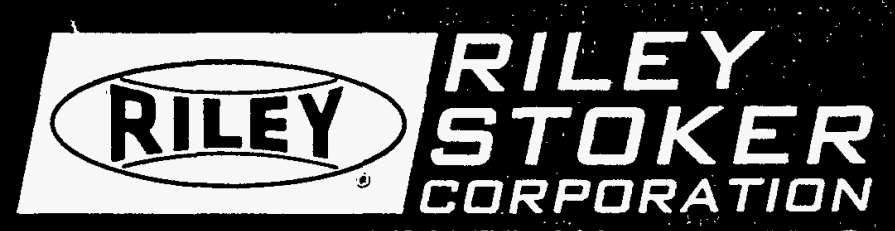

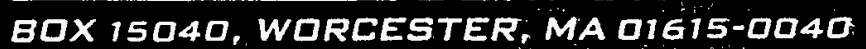


DEVELOPMENT OF AN ADVANCED

MILD GASIFICATION PROCESS

DOE DE-AC21-87MC24268

THERMAL GRAVIMETRIC ANALYSIS

OF MILO GASIFICATION CHAR

Prepared by:

Riley Research Center RILEY STOKER CORPORATION

45 Mckeon Road

Worcester, MA 01610

Project Manager:

Frank J. Zone, Jr.

Prepared for:

WESTERN RESEARCH INSTITUTE

University of Wyoming Research Corp.

P.0. Box 3395

Laramie, WY 82071

WRI Project Manager:

Chang-Yul Cha 
DEVELOPMENT OF AN ADVANCED

MILD GASIFICATION PROCESS

DOE CONTRACT DE-AC21-87MC24268

Ri 1ey Contract 88801

Internal Distribution:

R. A. Lisauskas

R. K. Mongeon.

Contract File 88801
External. Distribution:

Dr. Chang Yul Cha

Manager, Division of Process

Development

Western Research Institute

Mahesh C. Jha

Manager, Energy R\&D

AMAX

Approvals:

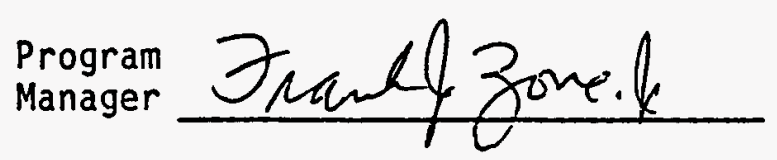

30 geme 1989 
THERMAL GRAVIMETRIC ANALYSIS

OF MIID GASIFICATION CHAR

\section{OBJECTIVE}

Thermal gravimetric analysis (TGA) is routinely used to determine burning profiles of fuels, that is, profiles of weight loss with increasing temperature in an oxidizing environment. The burning profiles of new fuels can be used for qualitative comparison with the profiles of fuels whose combustion characteristics are known. We attempted here to use the TGA instrument to determine quantitative rate constants for the combustion reaction of char with oxygen. The objective was to rank the chars in combustion reactivity, and to determine intrinsic reactivity quantitatively.

\section{SUMMARY OF RESULTS}

Five samples of mild gasification char (MGT-6 through MGT-10) were supplied to RSC by WRI. One sample was analyzed over a broad temperature range $(500-900 \mathrm{C})$, with variable sample size and oxygen concentration. While the TGA technique appeared promising on the basis of preliminary tests with a less reactive char, the reaction rate of the mild gasification chars appeared to be Iimited by the geometry of the apparatus rather than by intrinsic reactivity. Therefore, the tests completed to date provide only minimal information on absolute reaction rate. The remaining samples were analyzed over a lower temperature range (450-550 C) with a fixed sample size and oxygen content. The reactivities of all five char samples were similar, and all appeared to be much more reactive than a bituminous char (produced in our laboratory at about 800 C) tested for comparison. Samples MGT 6 and MGT-9 were the most reactive of the five MG samples, but the range was fairly narrow.

\section{TEST PROCEDURE}

The tests were performed using a Perkin-Elmer TGS-2 analyzer. All char samples were double-screened to $140 \times 120$ mesh, or about 115 micrometer average particle size. A sample of char was placed in the TGS-2 pan, and the furnace tube was purged with 400 $\mathrm{cm} 3 / \mathrm{m}$ nitrogen. The furnace was brought to the test temperature, and then the purge gas was switched over to an $02 / \mathrm{N} 2$ mixture. In the first series of tests, the 02 concentration was varied by adding oxygen to the purge nitrogen just upstream of the furnace, and the concentration was measured with a gas chromatograph. In a second series of tests at a fixed 02 concentration, the purge gas was switched from pure $N 2$ to a calibration gas mixture of $3 \%$ 02 in nitrogen. This technique, required because of problems with the GC, gave a slower response to the start of 02 flow since a larger portion of the instrument had to be purged of nitrogen. 
The TGS-2 data output is a plot of $\%$ weight (ie, $\%$ of initial sample weight) vs time. An example plot is attached as Figure 1 for run 82 with sample 38443 (Riley lab ID for MGT-6). Note that the abscissa is labeled as temperature only because the analyzer normally ramps up temperature linearly with time, and the plotter output cannot be relabeled. All tests herein were run at constant temperature. The ramp rate printed in the upper right hand corner can be used to convert the temperature scale into time. The initial decay from $100 \%$ is presumably residual volatile loss. The oxidizing gas flow is started after the weight reaches a steady value in nitrogen at temperature. When the premixed oxidizing gas was used (series 2 tests), the switch to oxidizer is evidenced by a bump in the curve as shown for run 82 .

\section{DATA REDUCTION}

Although the TGS-2 plotter output is fixed, the data is stored on floppy disk, and the instrument can be used to step through the plot and tabulate sample wt\% vs time. This was done for each test in the second series. The data was then plotted as rate vs time by taking rate = initial weight $\mathrm{x}$ (del $\% \mathrm{wt} / 100) /($ del time), in units of $\mathrm{g} / \mathrm{s}$. A rate vs time plot for the MG-6 char tests (lower temperature range, constant 02 , series 2) is attached as Figure 2 .

Most of the rate vs time plots are for a sample size of about 1.5 mg. Examination of these plots shows that the rate increases during the first four minutes of each test, remains fairly steady for three to four more minutes, and then decreases. The rate for each test was taken as the average during the constant rate period. The constant rate period corresponded to about 15-30\% weight loss at $450 \mathrm{C}$, and $25-50 \%$ weight loss at $550 \mathrm{C}$ for the MG chars. At higher temperatures, for smaller samples, or for the bituminous char, the weight loss either peaked and declined without a steady state, or was still increasing at the end of the test. The rate was taken as the maximum observed for these cases. In the first test series, the rate was estimated from the TGS-2 plotter output. Because of the different techniques used to switch to oxidizer, and the different methods used to estimate the rate, the two test series are not entirely consistent. However, there is reasonable agreement where temperature and sample size overlap.

The rate for each test was normalized for sample size and oxygen concentration. For consistency with data available in the literature, the rate was normalized on the basis of external surface area calculated from the initial sample weight, particle size, and density. Similarly, oxygen concentration was expressed in atmospheres to give a rate constant $\mathrm{k}$ in ( $\mathrm{mg}$ of $\mathrm{C}$ )/(cm2-satm). The test conditions and results are given in Tables 1 and 2 . 


\section{DISCUSSION}

Sample size effect. The rate of carbon combustion in $\mathrm{g} / \mathrm{s}$ at 700 $C$ is plotted as a function of sample size in Figure 3 . The rate appears to be linear with sample size up to about $1.5 \mathrm{mg}$. This is the expected behavior for the rate (in contrast to the rate constant, which is normalized to sample size). Rate is independent of sample size above $1.5 \mathrm{mg}$, indicating that oxygen availability may be limiting the combustion reaction. This is the crux of the problem discovered with using the existing TGA instrument for evaluating rate constants. In the TGS-2, the sample pan is suspended in a furnace consisting of a heated crucible which is open at the top, but closed at the bottom. The sweep gas cannot flow directly over the sample. The gas is directed toward the mouth of the crucible, and must then flow around the crucible to the exhaust port. Calculations made after completing the TGA tests showed that the flow is laminar over the furnace, and could not be expected to penetrate to the sample pan. Further, the furnace crucible was modeled as a cylinder with zero oxygen concentration at the sample pan level, and bulk sweep gas oxygen concentration at the crucible mouth. This simple model seems to explain the data in Figure 3, where the horizontal line shows the calculated rate of carbon combustion at the limit imposed by diffusion of oxygen through a stagnant volume between the crucible mouth and sample pan. As modeled, this limiting rate depends only on the furnace cross section and depth, oxygen concentration, and temperature. The limited data at other oxygen concentrations were consistent with the bulk diffusion limitation.

With the existing instrument, bulk diffusion limits should be less severe with either smaller samples or lower temperatures (chemical reaction rate decreasing much more rapidly than diffusion with decreasing temperature). Figure 4 shows the rate constant measured at temperatures of 450,500 , and $550 \mathrm{C}$ for nominally $1.5 \mathrm{mg}$ samples of MGT-6 char. Unfortunately, bulk diffusion is still limiting as shown by the larger value of the rate constant measured for a $0.3 \mathrm{mg}$ sample at $500 \mathrm{C}$. The nearly horizontal line in the figure is the calculated apparent rate constant for $1.5 \mathrm{mg}$ samples. (Note that the word apparent is emphasized since the rate in $\mathrm{g} / \mathrm{s}$ for the diffusion limit is fixed, whereas the apparent rate constant at that limit is inversely proportional to sample size.) In retrospect, smaller samples should have been used. However, without additional tests, it is not clear whether sample size can be reduced sufficiently to eliminate diffusion limits while maintaining weight loss resolution.

Mild gasification chars. The reaction rate constants measured for the mild gasification chars in the 450-550 C range are shown in Figure 5. The decreasing slope with increasing temperature is 
typical for a regime in which control is changing from chemical to diffusion rate. The range of reactivity is narrow, 0.079 to 0.104 at $450 \mathrm{C}$, and 0.146 to 0.187 at $550 \mathrm{C}$, ie, all are within $+/-15 \%$ of the mean. Previous tests by WRI (described in WRI's october-December 1988 Technical Progress Report) of reactivity at $900 \mathrm{C}$ in a $3 \%$ water/balance hydrogen stream showed a similar relative ranking as the present tests in $02 / \mathrm{N} 2$ :

$\begin{array}{lcc}\text { type } & \begin{array}{c}\mathrm{k}, \mathrm{mg} /(\mathrm{cm} 2-\mathrm{s}-\mathrm{atm}) \\ \text { in } 02 / \mathrm{N2} \text { at } 450 \mathrm{C}\end{array} & \begin{array}{c}\mathrm{R}, \% \text { loss } \\ \text { at } 900 \mathrm{C}\end{array} \\ \text { MGT-6 } & 0.104 & \\ \text { MGT-7 } & 0.090 & 10.8 \\ \text { MGT-8 } & 0.079 & 7.2 \\ \text { MGT-9 } & 0.102 & 6.5 \\ \text { MGT-10 } & 0.093 & 13.1\end{array}$

The differences between samples were more pronounced in the reducing environment.

Comparison to bituminous char. A $120 \times 140$ mesh bituminous char (made by exposing a -60 mesh bituminous coal sample to nitrogen flow at 800 c) was tested in the TGA for comparison to the mila gasification chars. Results of tests with $1.5 \mathrm{mg}$ samples over the range 500-800 C are shown in Figure 6. Also shown is a single test of a $0.3 \mathrm{mg}$ sample of bituminous char at $550 \mathrm{C}$. Note the reduction of sample size effect with this material:

MG $(500 \mathrm{C}) \quad$ bituminous $(550 \mathrm{C})$
$1.5 \mathrm{mg}$ sample
0.16
0.033
$0.3 \mathrm{mg}$ sample
0.285
0.040
ratio
1.78
1.21

The MGT-6 data shown previously in Figure 5 are shown again in Figure 6 , as is the calculated diffusion-limited apparent rate for $1.5 \mathrm{mg}$ sample size. In addition, the higher-temperature MGT6 data from the first test series is shown. Both the mild gasification and bituminous chars appear to approach the diffusion limit at higher temperature. While the bituminous char reactivity drops well below the diffusion limit of the apparatus at lower temperatures, the MG char reactivity remains relatively close to the diffusion limit. 
Comparison to published values. Published values for char reactivity span a wide range. Field (1), in a 1969 review of the literature, attempted to eliminate results showing an effect of mass transfer, and to fit the best correlation for the surface reaction rate coefficient. He concluded that the available data were best fit by $\mathrm{In}(\mathrm{k})=15.98$ - 35,700/RT (for units consistent with this discussion), independent of the carbon type. The data reviewed were for temperatures of 950-1700 K. Field suggested that differences would emerge as data became available for other coals, since "the presence of impurities can increase the rate by orders of magnitude". Indeed, rates for brown coal chars in another study by Field (2), as presented by Smith (3) were correlated by

$\ln (\mathrm{k})=11.23-21,050 / \mathrm{RT}$ over a similar temperature range. Smith concluded that this data indicated pore diffusion to be the limiting rate. These two correlations, extrapolated to $500 \mathrm{C}$, compare with the present results as follows:

\section{Source}

\author{
Field (1) correlation \\ Smith (3) correlation
}

MGT-6, TGA measurement $(1.5 \mathrm{mg})$

$(0.3 \mathrm{mg})$
Bituminous char $(1.5 \mathrm{mg})$
0.010

Selected measured data are replotted in Figure 7 with the two published correlations. Although the absolute values are much different, the slope of the line fitting the three lowesttemperature points for the bituminous char is similar to that of the first correlation, suggesting that this data reflects a property of the char rather than the apparatus. The MG char data for $1.5 \mathrm{mg}$ samples has a much lower activation energy than either of the two correlations. However, a line connecting the $500 \mathrm{C}$ point for $0.3 \mathrm{mg}$ sample and the $450 \mathrm{C}$ point (smaller sample size, lower temperature being less limited by diffusion) does nearly parallel the second correlation. This suggests that with modification to the instrument and test procedure, the TGA might $\cdot$ be able to determine reactivity of MG char, at least at low temperature. However, most of the MG data appear to be compromised by instrument Iimitations. 


\section{CONCLUSIONS}

1. A simple model of the analyzer and the apparent activation energy of the MG char both suggest that most of the data for the MG char is seriously compromised by instrument limitations.

2. A bituminous char, being less reactive, was not as instrument limited at 450-550 c. However, at higher temperatures, the bituminous char reactivity was also limited by the apparatus.

3. Not withstanding the MG reactivity limitation, the MG char was clearly much more reactive than the bituminous char. At $500 \mathrm{C}$, the reaction rate coefficient for $M G$ char was at least 4-7 times higher than for the bituminous char.

4. The reactivities with oxygen among the five MG char samples were less variable than the reactivities determined previously by WRI for steam/H2. However, the ordering among the samples was similar, with MGT-6 and MGT-9 showing somewhat higher reactivity.

\section{REFERENCES}

1. Field, M.A., D.W. Gill, B.B. Morgan, and P.G.W. Hawksley, Combustion of Pulverised coal, p.329-345, British Coal Utilisation Research Association, Leatherhead, 1967.

2. Field, M.A., Combustion and Flame, 13, 237 (1969).

3. Smith, I.W., Nineteenth Symposium (International) on

Combustion, p. 1045, The Combustion Institute, Pittsburgh, 1982. 
TABLE 1

CHAR TGA, FIRST SERIES

\begin{tabular}{|c|c|c|c|c|c|c|}
\hline $\begin{array}{l}\text { CHAR } \\
\text { TYPE }\end{array}$ & $\begin{array}{l}\text { RUN } \\
\text { NO. }\end{array}$ & $\begin{array}{l}\text { TEMP } \\
\mathrm{C}\end{array}$ & $\begin{array}{l}\text { SIZE } \\
\text { mg }\end{array}$ & $\begin{array}{l}02 \\
8\end{array}$ & $\begin{array}{l}\text { RATE } \\
\mathrm{mg} / \mathrm{s}\end{array}$ & $\begin{array}{l}\mathrm{k}, \mathrm{mg} / \\
(\mathrm{cm} 2-\mathrm{s}-\mathrm{atm})\end{array}$ \\
\hline $\begin{array}{l}\text { Bitum } \\
\text { (38391) }\end{array}$ & $\begin{array}{l}49 \\
51 \\
47 \\
48 \\
49\end{array}$ & $\begin{array}{l}500 \\
550 \\
600 \\
700 \\
800\end{array}$ & $\begin{array}{l}1.416 \\
1.432 \\
1.388 \\
1.446 \\
1.427\end{array}$ & $\begin{array}{l}2.9 \\
2.7 \\
2.9 \\
2.9 \\
2.9\end{array}$ & $\begin{array}{l}0.00014 \\
0.00043 \\
0.00111 \\
0.00212 \\
0.00270\end{array}$ & $\begin{array}{l}0.010 \\
0.033 \\
0.083 \\
0.152 \\
0.197\end{array}$ \\
\hline MGT- 6 & $\begin{array}{l}41 \\
40 \\
34 \\
37 \\
38 \\
36 \\
15 \\
16 \\
24 \\
10 \\
25 \\
23 \\
17 \\
14 \\
7 \\
28 \\
27 \\
20 \\
21\end{array}$ & $\begin{array}{l}500 \\
500 \\
600 \\
700 \\
700 \\
700 \\
700 \\
700 \\
700 \\
700 \\
700 \\
700 \\
700 \\
700 \\
700 \\
800 \\
800 \\
800 \\
900\end{array}$ & $\begin{array}{l}0.206 \\
1.369 \\
1.395 \\
0.197 \\
0.244 \\
0.351 \\
0.787 \\
1.257 \\
1.362 \\
1.457 \\
1.474 \\
1.497 \\
1.539 \\
2.062 \\
2.534 \\
1.425 \\
1.495 \\
1.496 \\
1.451\end{array}$ & $\begin{array}{l}2.7 \\
2.8 \\
2.8 \\
2.6 \\
2.8 \\
2.6 \\
2.8 \\
2.9 \\
2.8 \\
2.8 \\
1.4 \\
2.8 \\
2.9 \\
2.7 \\
2.0 \\
5.8 \\
1.5 \\
2.8 \\
2.9\end{array}$ & $\begin{array}{l}0.00058 \\
0.00143 \\
0.00170 \\
0.00071 \\
0.00073 \\
0.00092 \\
0.00275 \\
0.00362 \\
0.00300 \\
0.00347 \\
0.00168 \\
0.00377 \\
0.00373 \\
0.00383 \\
0.00345 \\
0.00816 \\
0.00204 \\
0.00385 \\
0.00434\end{array}$ & $\begin{array}{l}0.314 \\
0.112 \\
0.131 \\
0.421 \\
0.321 \\
0.237 \\
0.376 \\
0.299 \\
0.237 \\
0.256 \\
0.245 \\
0.271 \\
0.251 \\
0.207 \\
0.137 \\
0.297 \\
0.274 \\
0.276 \\
0.310\end{array}$ \\
\hline
\end{tabular}

-All tests 115 micron particles except No. 36 with 90 micron particles.

-All tests with $400 \mathrm{~cm} 3 / \mathrm{min}$ sweep gas except Nos. 10 and 11 with 600 and $800 \mathrm{~cm} 3 / \mathrm{m}$ respectively. 
TABLE 2

CHAR TGA, SECOND SERIES

\begin{tabular}{|c|c|c|c|c|c|c|}
\hline $\begin{array}{l}\text { CHAR } \\
\text { TYPE }\end{array}$ & $\begin{array}{l}\text { RUN } \\
\text { NO. }\end{array}$ & $\begin{array}{l}\text { TEMP } \\
\mathrm{C}\end{array}$ & $\begin{array}{c}\text { SIZE } \\
\mathrm{mg}\end{array}$ & $\begin{array}{l}02 \\
8\end{array}$ & $\begin{array}{l}\mathrm{RATE} \\
\mathrm{mg} / \mathrm{s}\end{array}$ & $\begin{array}{l}\mathrm{k}, \mathrm{mg} / \\
(\mathrm{cm} 2-\mathrm{s}-\mathrm{atm})\end{array}$ \\
\hline MGT-6 & $\begin{array}{l}81 \\
82 \\
83 \\
98\end{array}$ & $\begin{array}{l}450 \\
500 \\
550 \\
500\end{array}$ & $\begin{array}{l}1.498 \\
1.350 \\
1.374 \\
0.295\end{array}$ & $\begin{array}{l}3.0 \\
3.0 \\
3.0 \\
3.0\end{array}$ & $\begin{array}{l}0.00156 \\
0.00215 \\
0.00247 \\
0.00084\end{array}$ & $\begin{array}{l}0.104 \\
0.160 \\
0.182 \\
0.285\end{array}$ \\
\hline MGT -7 & $\begin{array}{l}84 \\
85 \\
86\end{array}$ & $\begin{array}{l}450 \\
500 \\
550\end{array}$ & $\begin{array}{l}1.532 \\
1.479 \\
1.461\end{array}$ & $\begin{array}{l}3.0 \\
3.0 \\
3.0\end{array}$ & $\begin{array}{l}0.00137 \\
0.00214 \\
0.00213\end{array}$ & $\begin{array}{l}0.090 \\
0.145 \\
0.146\end{array}$ \\
\hline MGT-8 & $\begin{array}{l}87 \\
88 \\
89\end{array}$ & $\begin{array}{l}450 \\
500 \\
550\end{array}$ & $\begin{array}{l}1.503 \\
1.513 \\
1.467\end{array}$ & $\begin{array}{l}3.0 \\
3.0 \\
3.0\end{array}$ & $\begin{array}{l}0.00118 \\
0.00228 \\
0.00253\end{array}$ & $\begin{array}{l}0.079 \\
0.151 \\
0.173\end{array}$ \\
\hline MGT-9 & $\begin{array}{l}90 \\
91 \\
92\end{array}$ & $\begin{array}{l}450 \\
500 \\
550\end{array}$ & $\begin{array}{l}1.575 \\
1.571 \\
1.546\end{array}$ & $\begin{array}{l}3.0 \\
3.0 \\
3.0\end{array}$ & $\begin{array}{l}0.00161 \\
0.00259 \\
0.00284\end{array}$ & $\begin{array}{l}0.102 \\
0.165 \\
0.185\end{array}$ \\
\hline MGT-10 & $\begin{array}{l}93 \\
94 \\
95\end{array}$ & $\begin{array}{l}450 \\
500 \\
550\end{array}$ & $\begin{array}{l}1.586 \\
1.606 \\
1.574\end{array}$ & $\begin{array}{l}3.0 \\
3.0 \\
3.0\end{array}$ & $\begin{array}{l}0.00147 \\
0.00228 \\
0.00294\end{array}$ & $\begin{array}{l}0.093 \\
0.142 \\
0.187\end{array}$ \\
\hline $\begin{array}{l}\text { Bitum } \\
\text { (38391) }\end{array}$ & 97 & 550 & 0.271 & 3.0 & 0.00011 & 0.040 \\
\hline
\end{tabular}

-All tests with 115 micron particles, $400 \mathrm{~cm} 3 / \mathrm{min}$ sweep gas. 


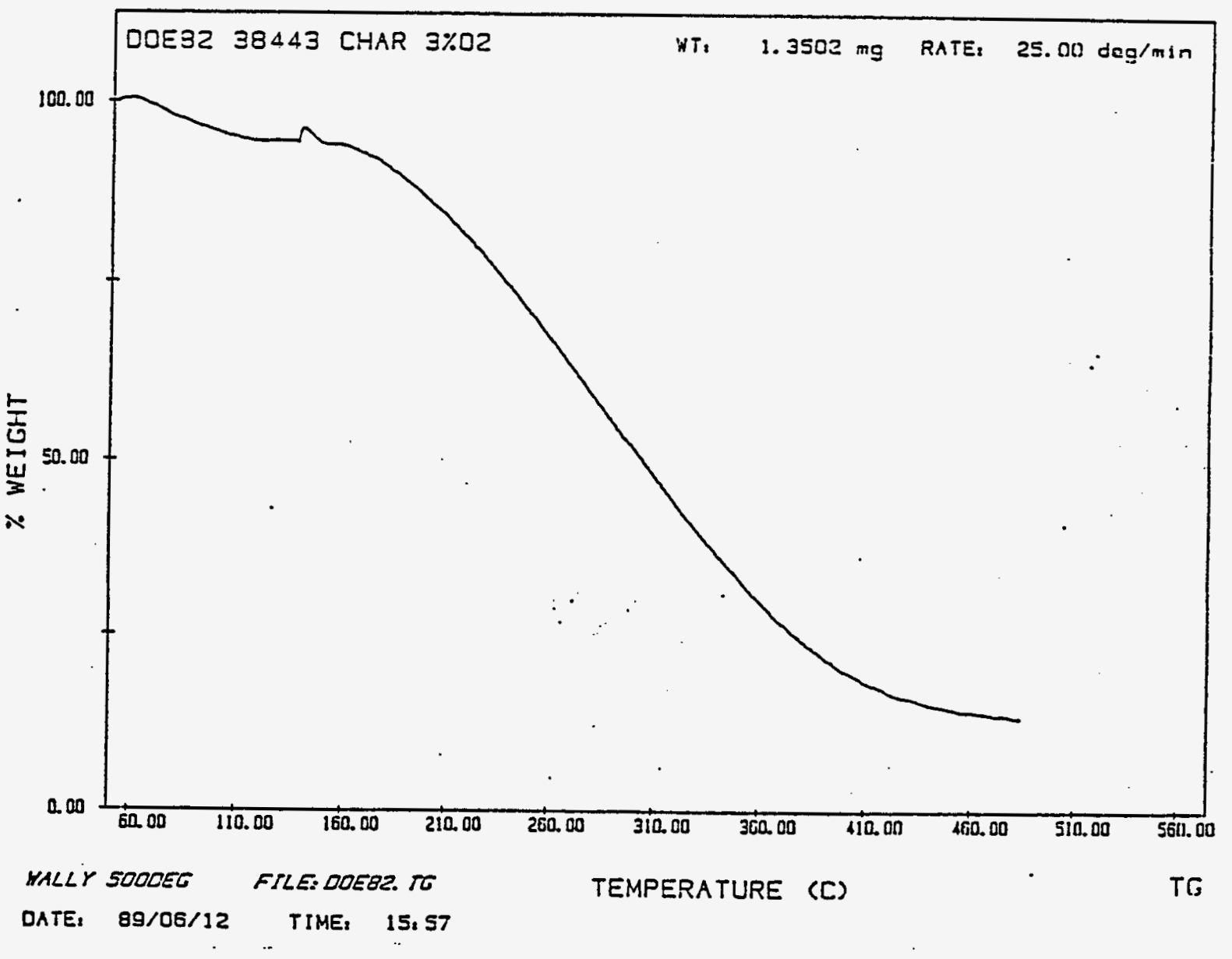

Figure 1. TGA plotter output for run 82. Test is isothermal, see text for explanation of abscissa units. 


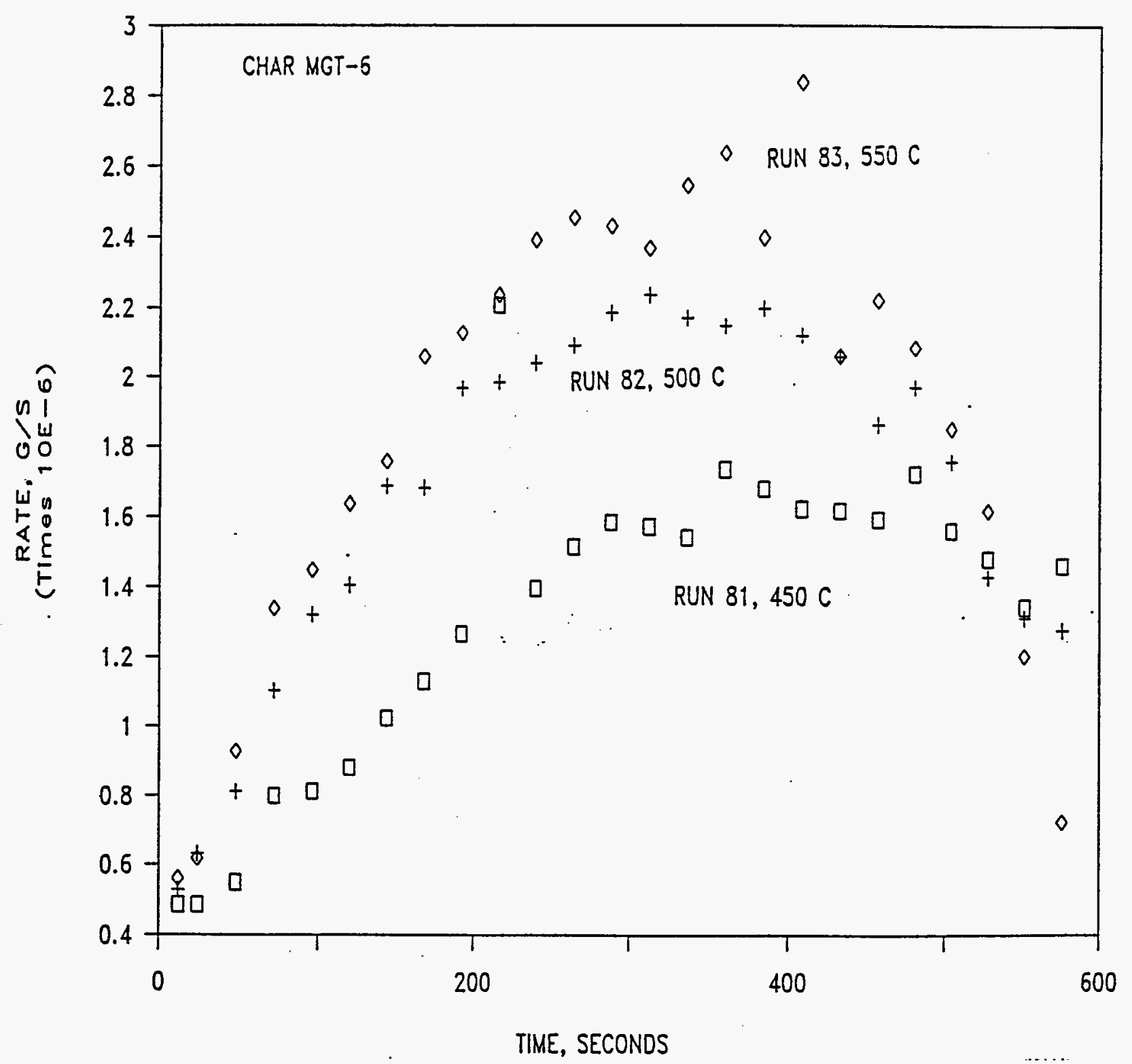

Figure 2. Rate vs time plot for series 2, MGT-6 runs. 


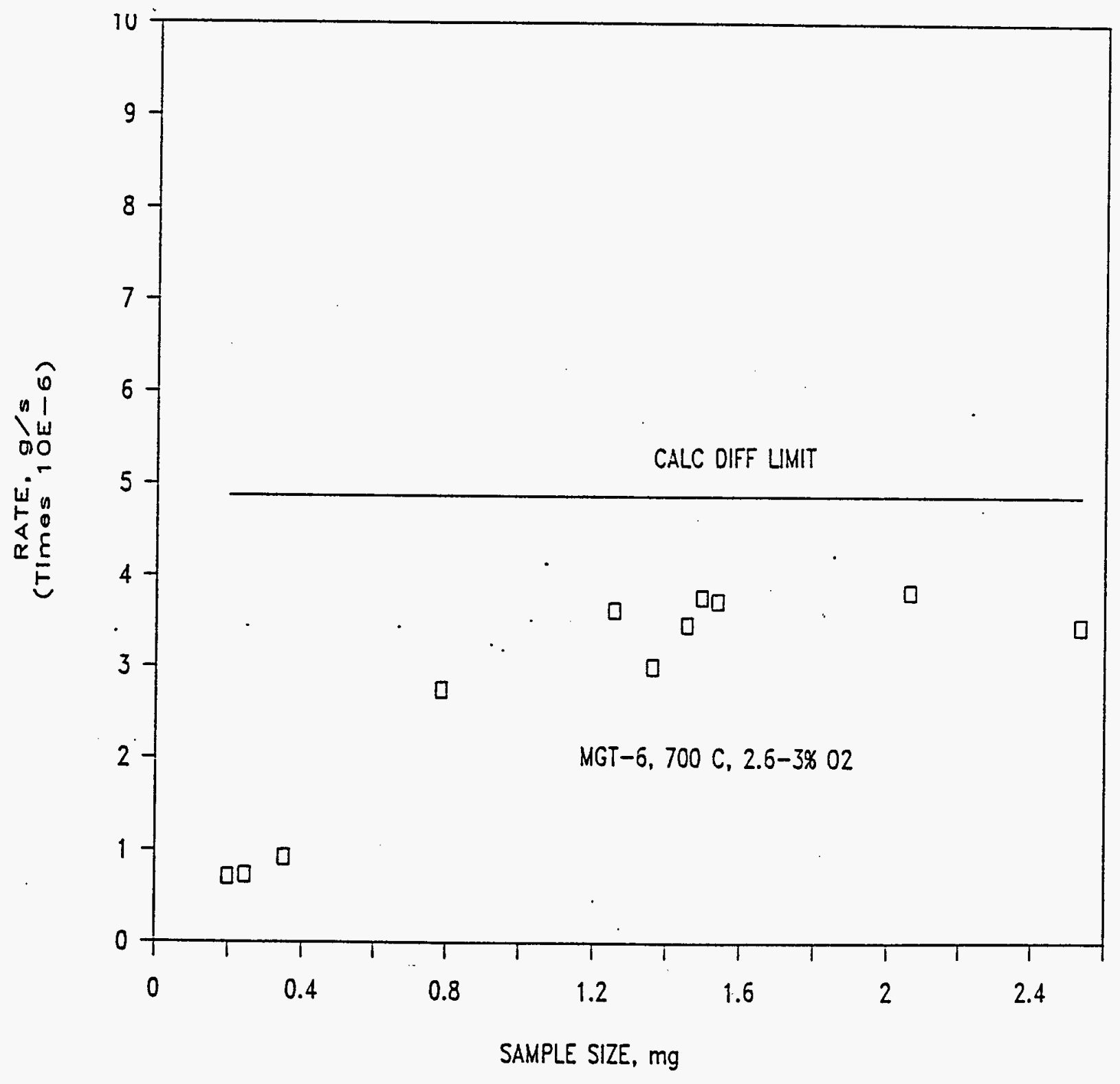

Figure 3. Dependence of combustion rate on sample size. 


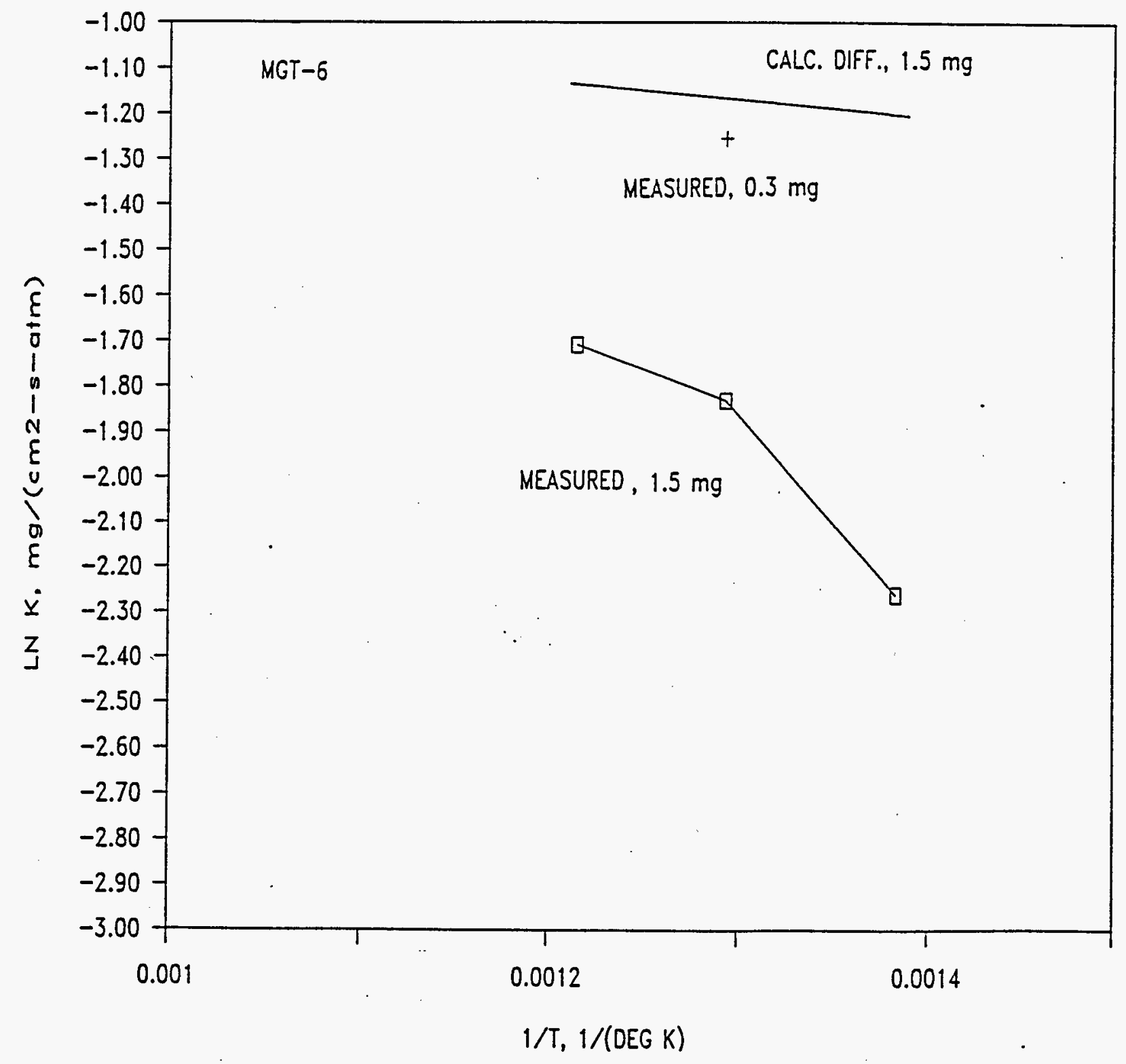

Figure 4. Rate constants for Series 2, MGT-6 runs. 


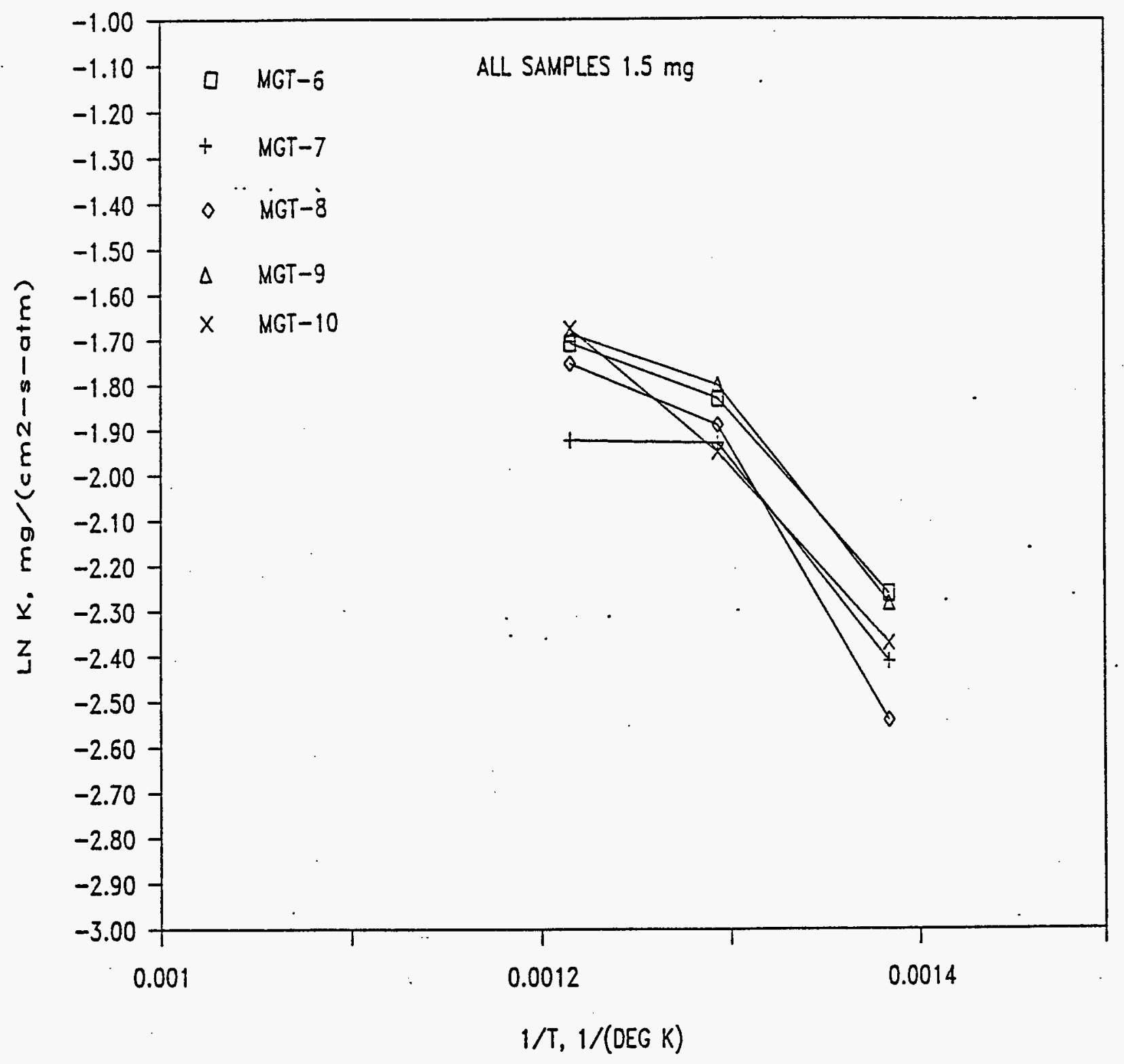

Figure 5. Rate constants for five mild gasification chars, Series 2 runs. 


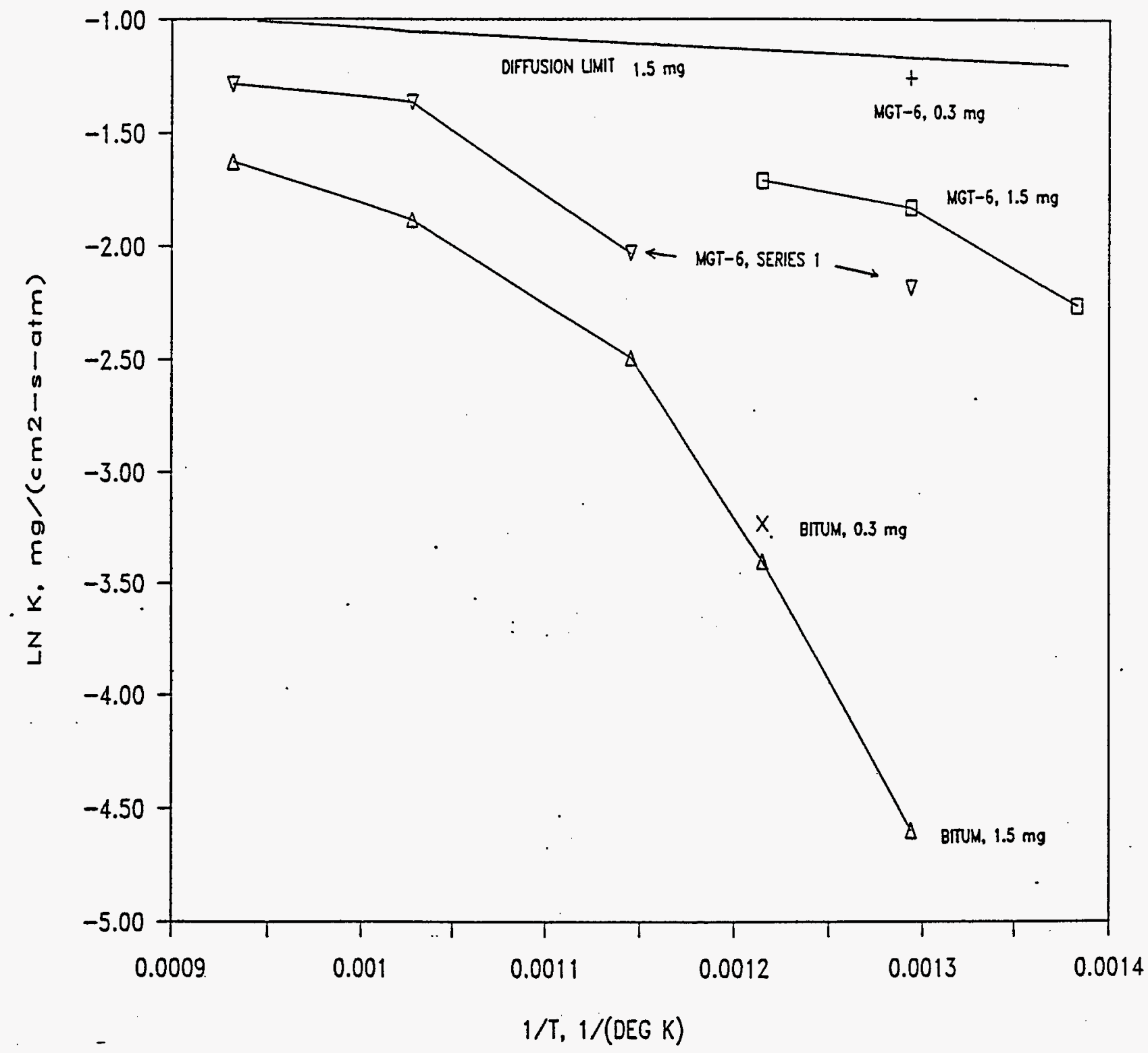

Figure 6. Rate constants for MGT-6 and a bituminous char. 


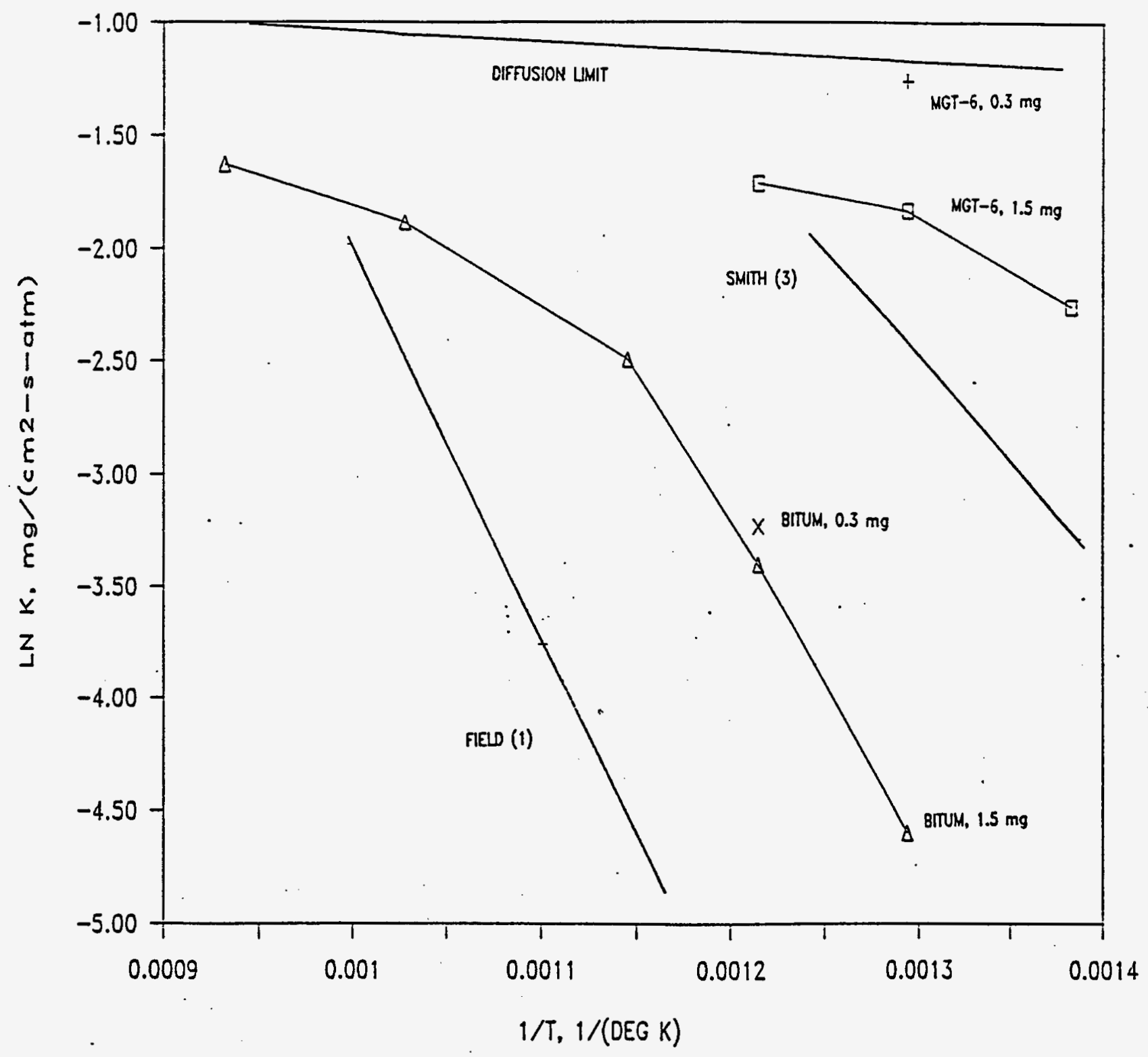

Figure 7. Measured rate constants compared to published correlations. 
APPENDIX B

PORE SIZE DISTRIBUTIONS FOR MILD GASIFICATION CHARS

131 
CUMULATIVE \% POROSITY Vs. PORE DIAMETER (UM)

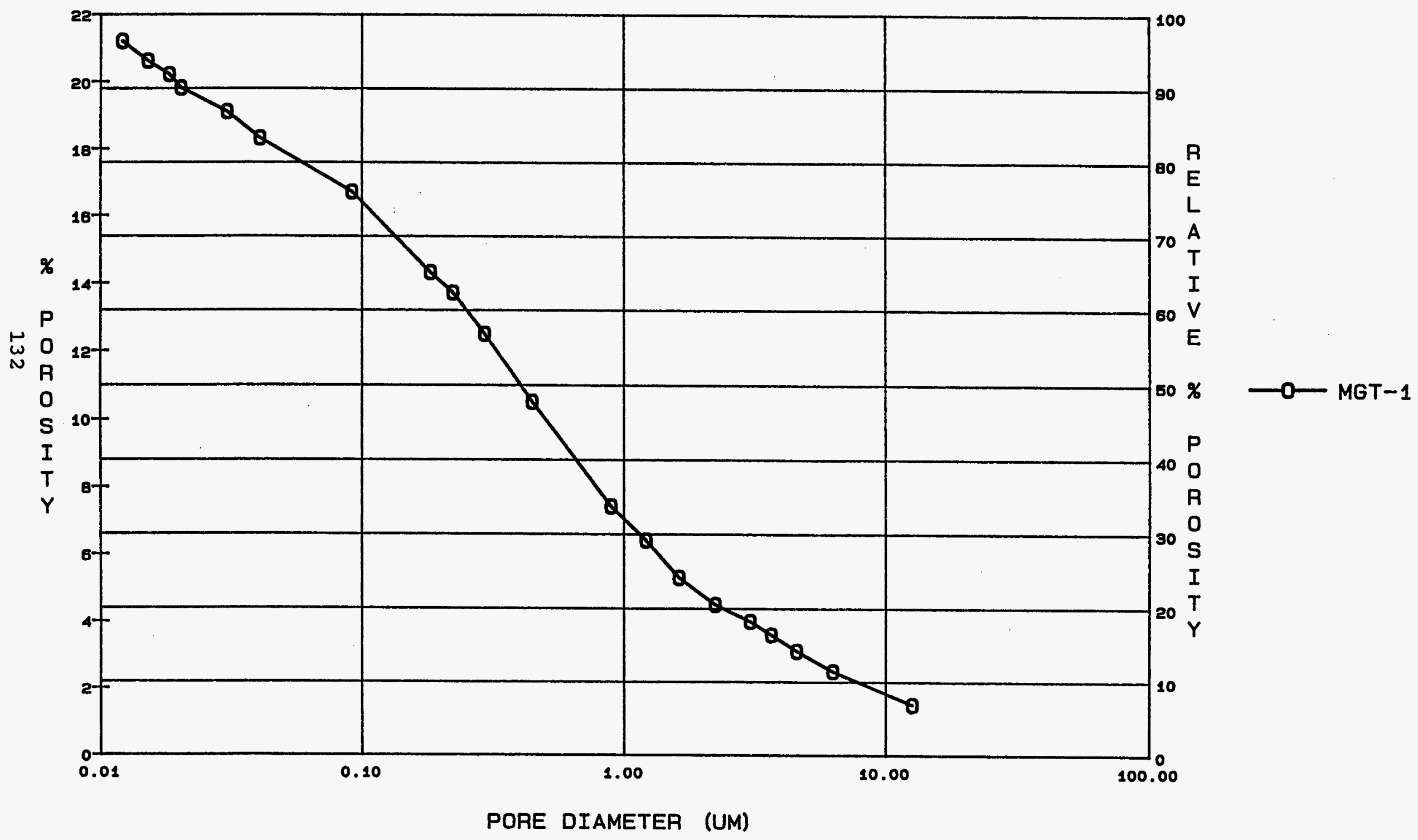




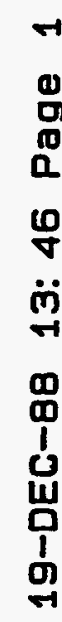

0
1
$\frac{1}{2}$
1

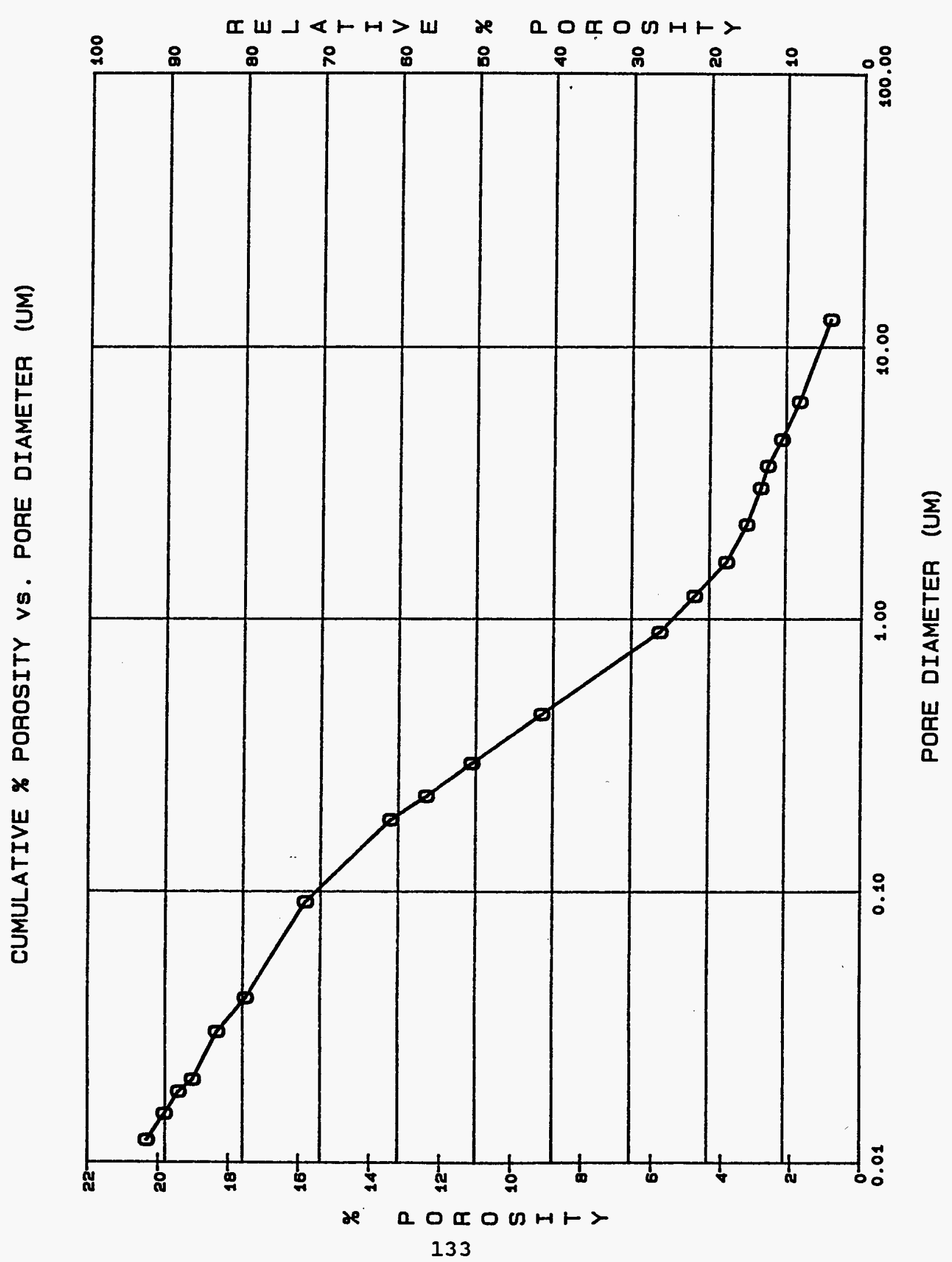


CUMULATIVE $\%$ POROSITY Vs. PORE DIAMETER (UM)

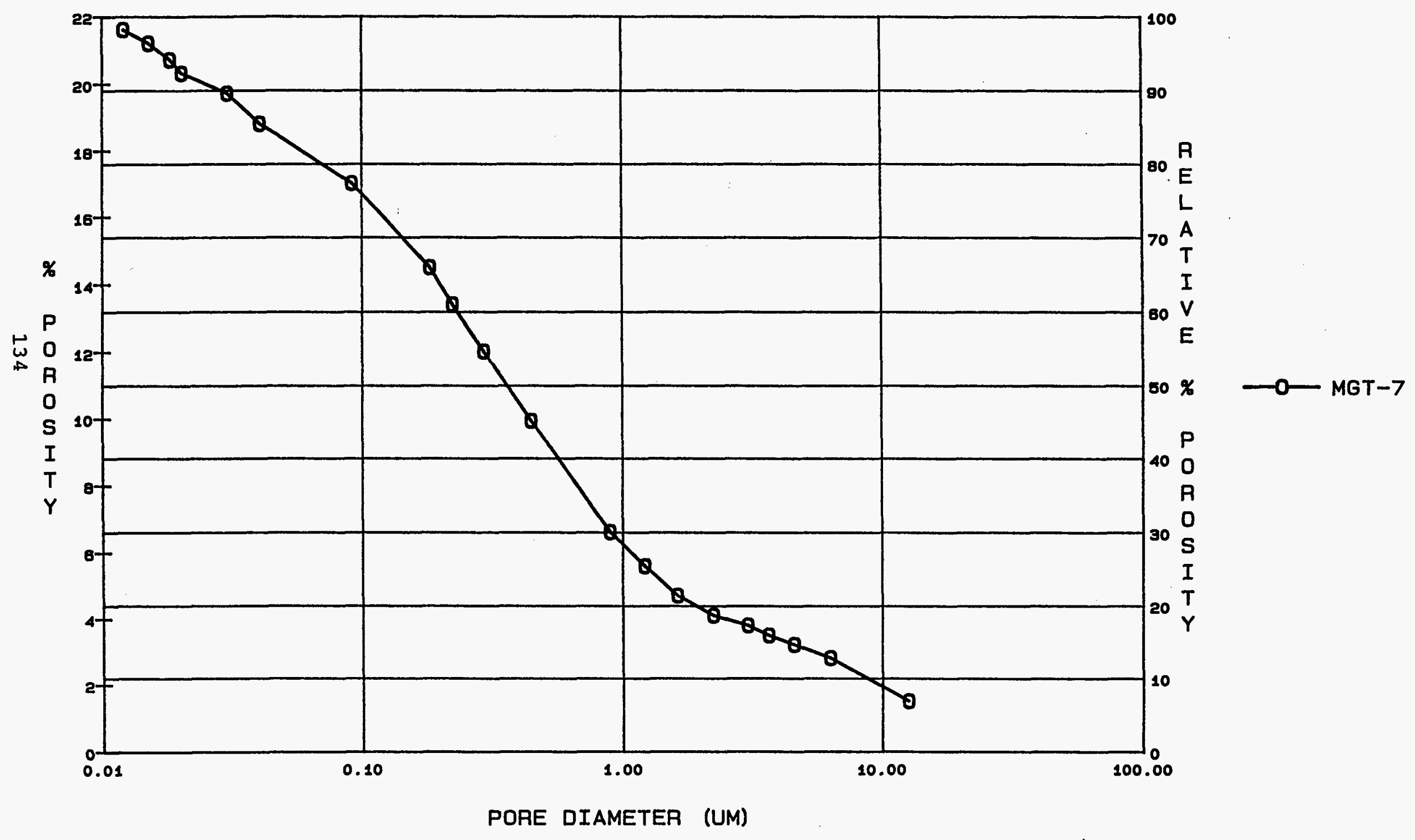


CUMULATIVE * POROSITY vs. PORE DIAMETER (UM)

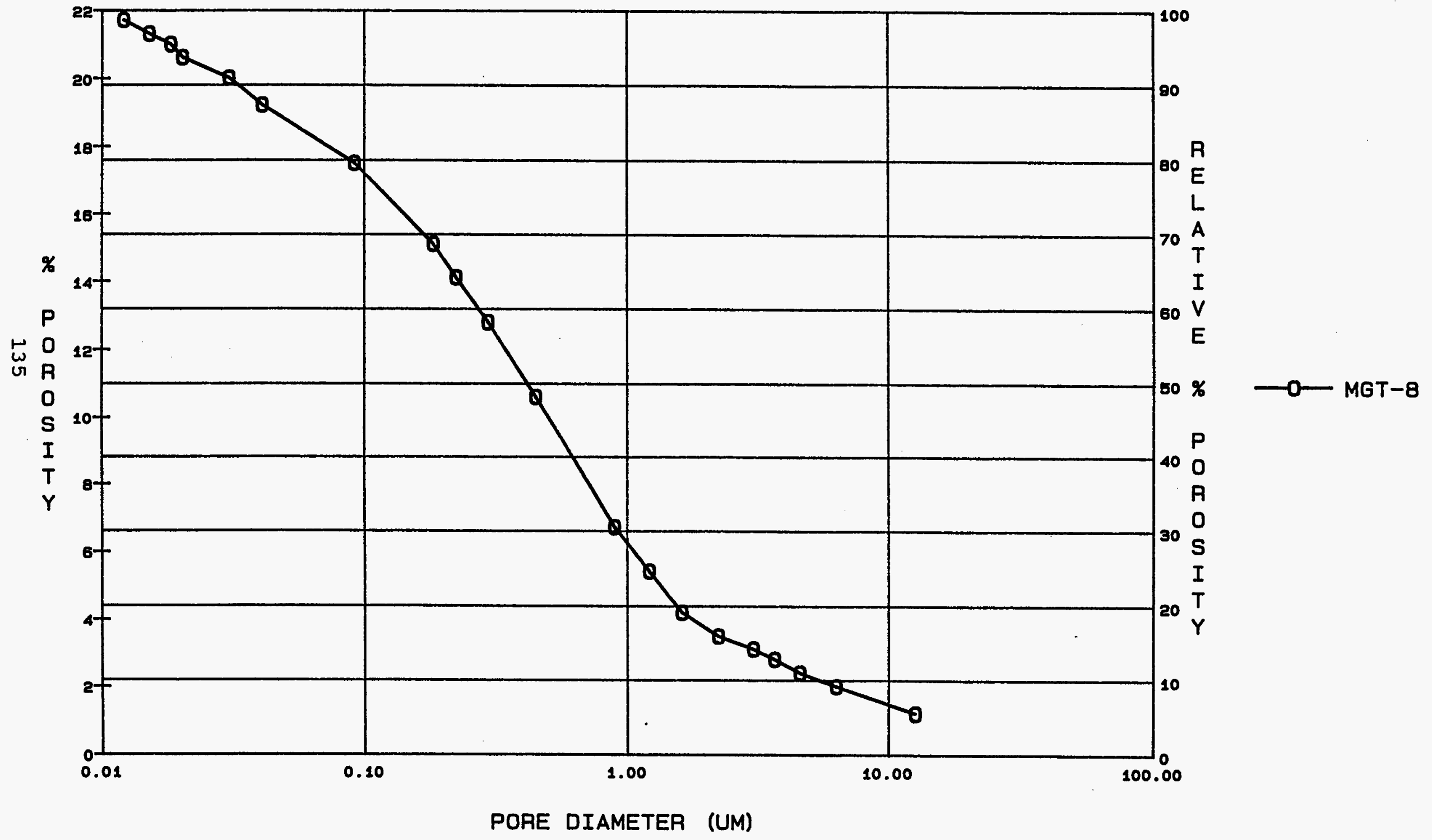


CUMULATIVE \% POROSITY VS. PORE DIAMETER (UM)

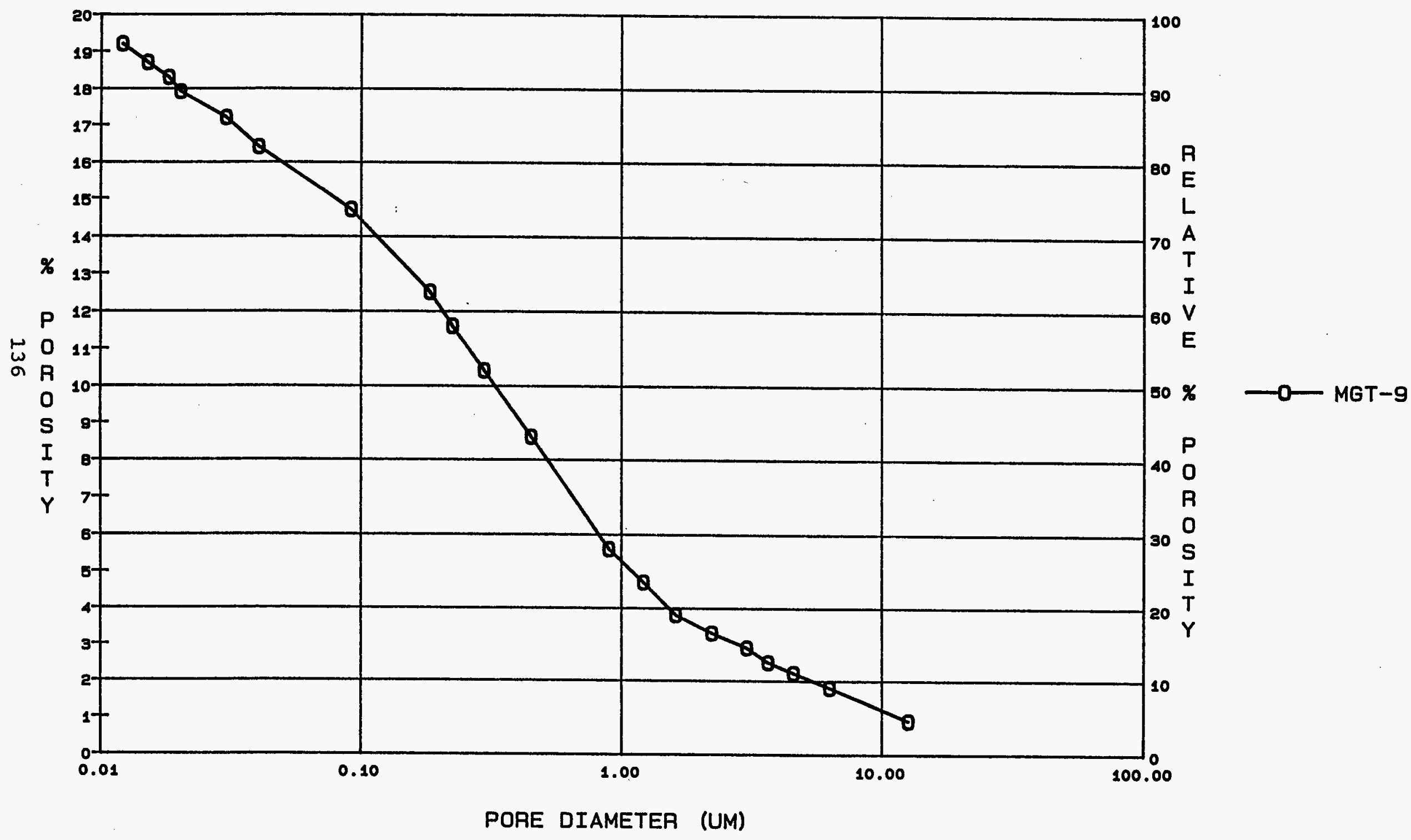


$r$
0
0
0
0
0
0
00
0
0
0
0
1
0
$u$
0
1
0
-1

$\frac{0}{1}$

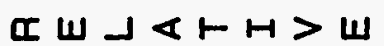

x 0 O

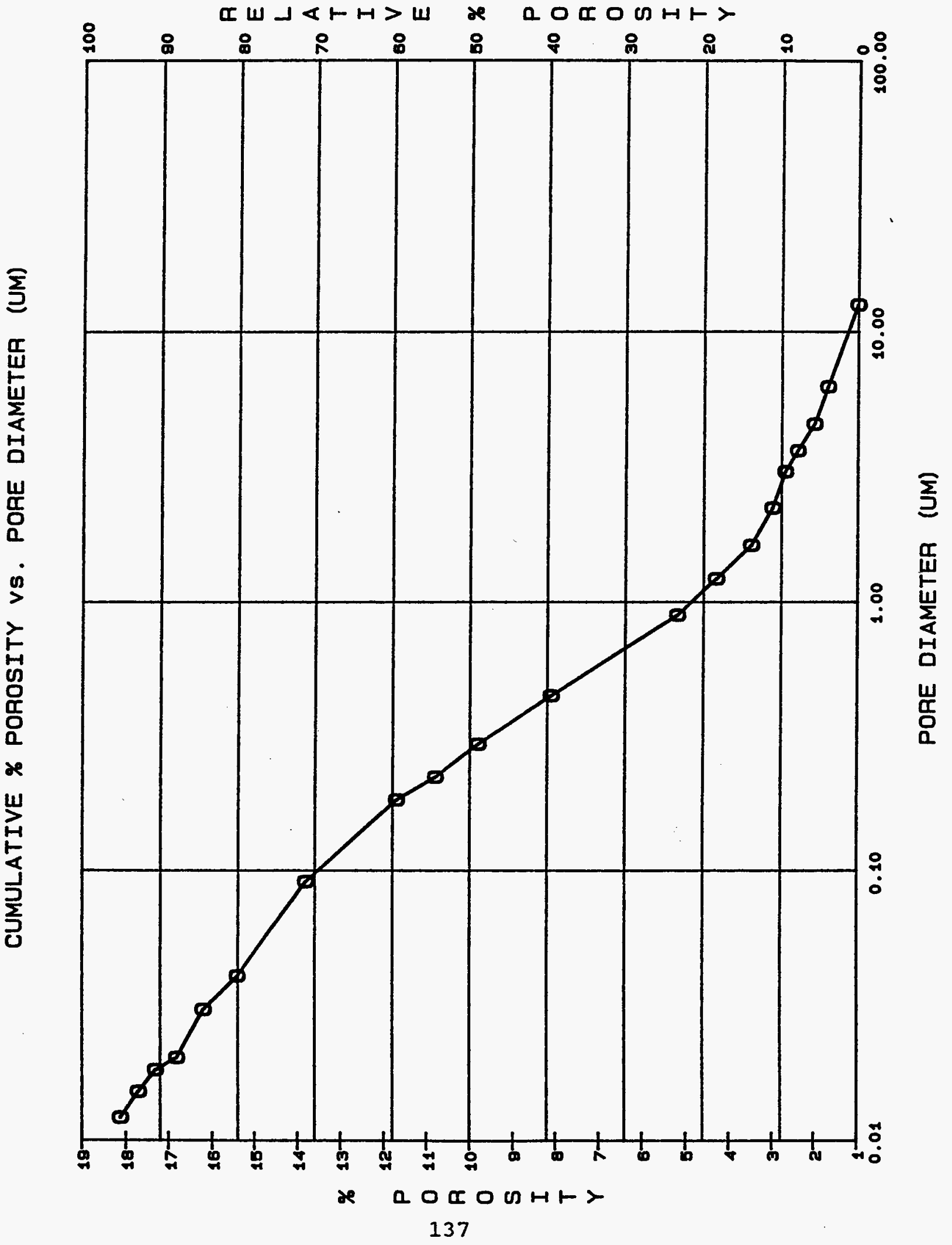


CUMULATIVE $\%$ POROSITY vs. PORE DIAMETER (UM)

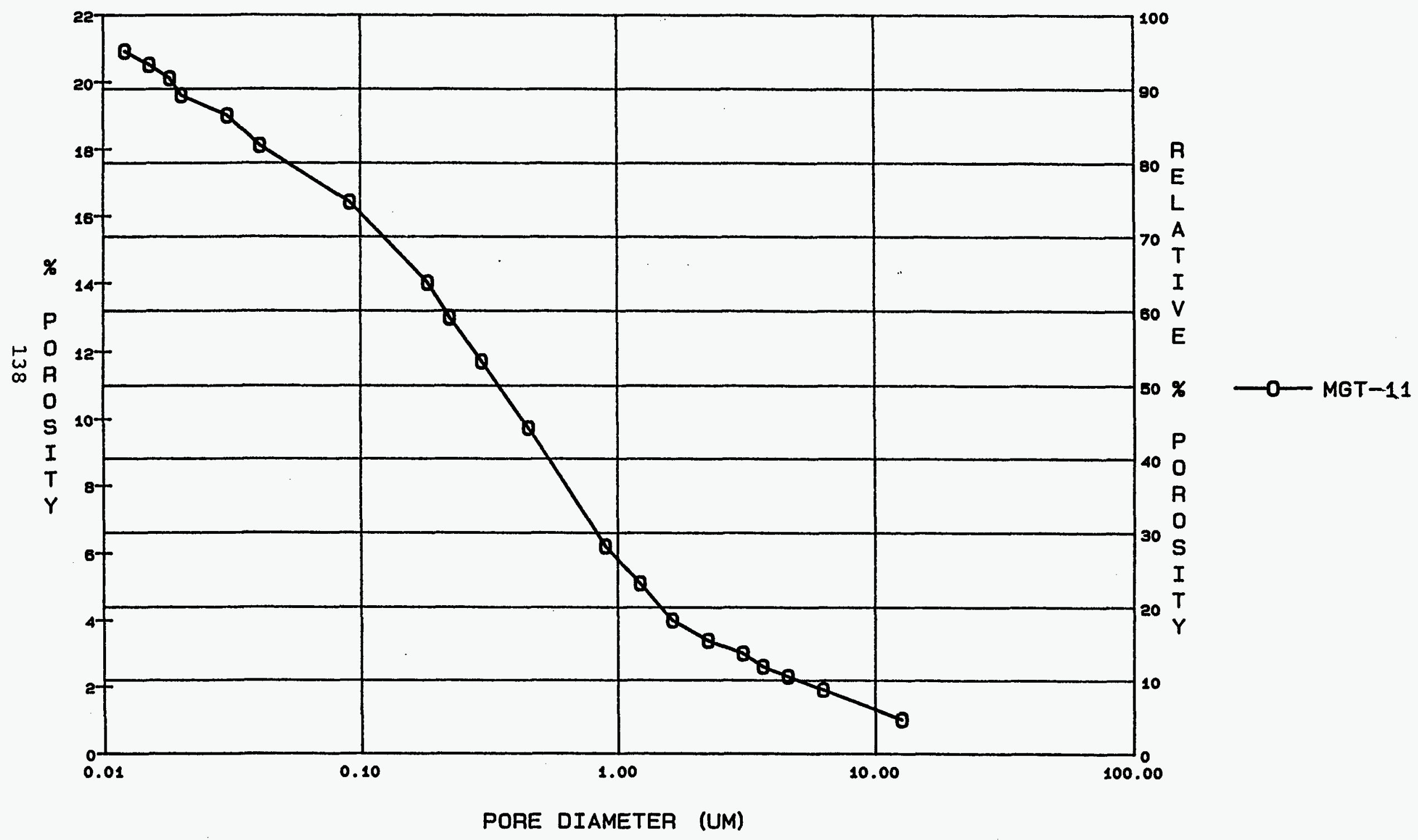




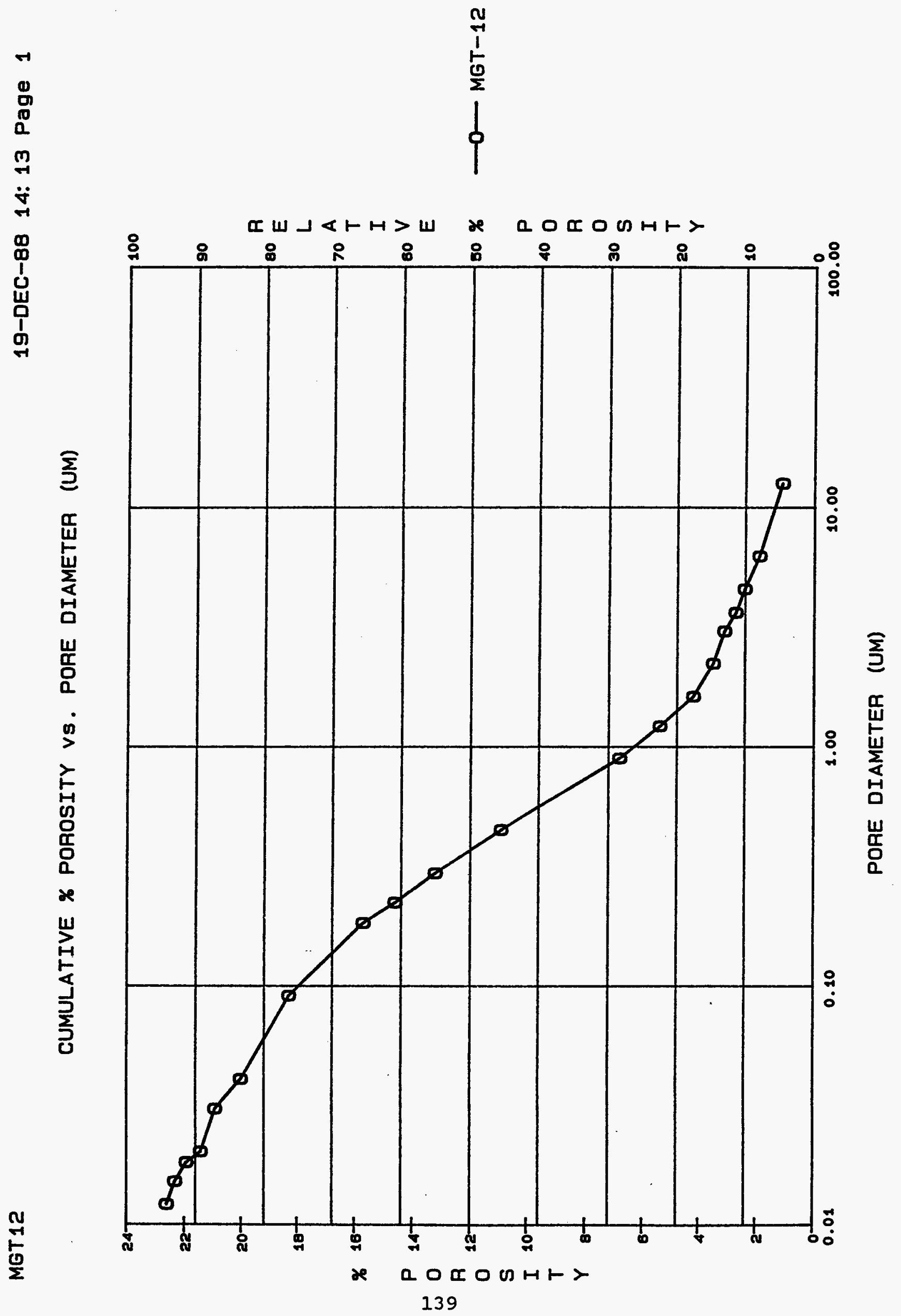


$r$
0
0
0
0
0
$N$
-1
$\ddot{ \pm}$
-1
0
0
1
0
$u$
$u$
0
1
0
-1

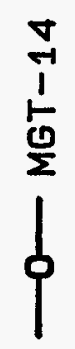

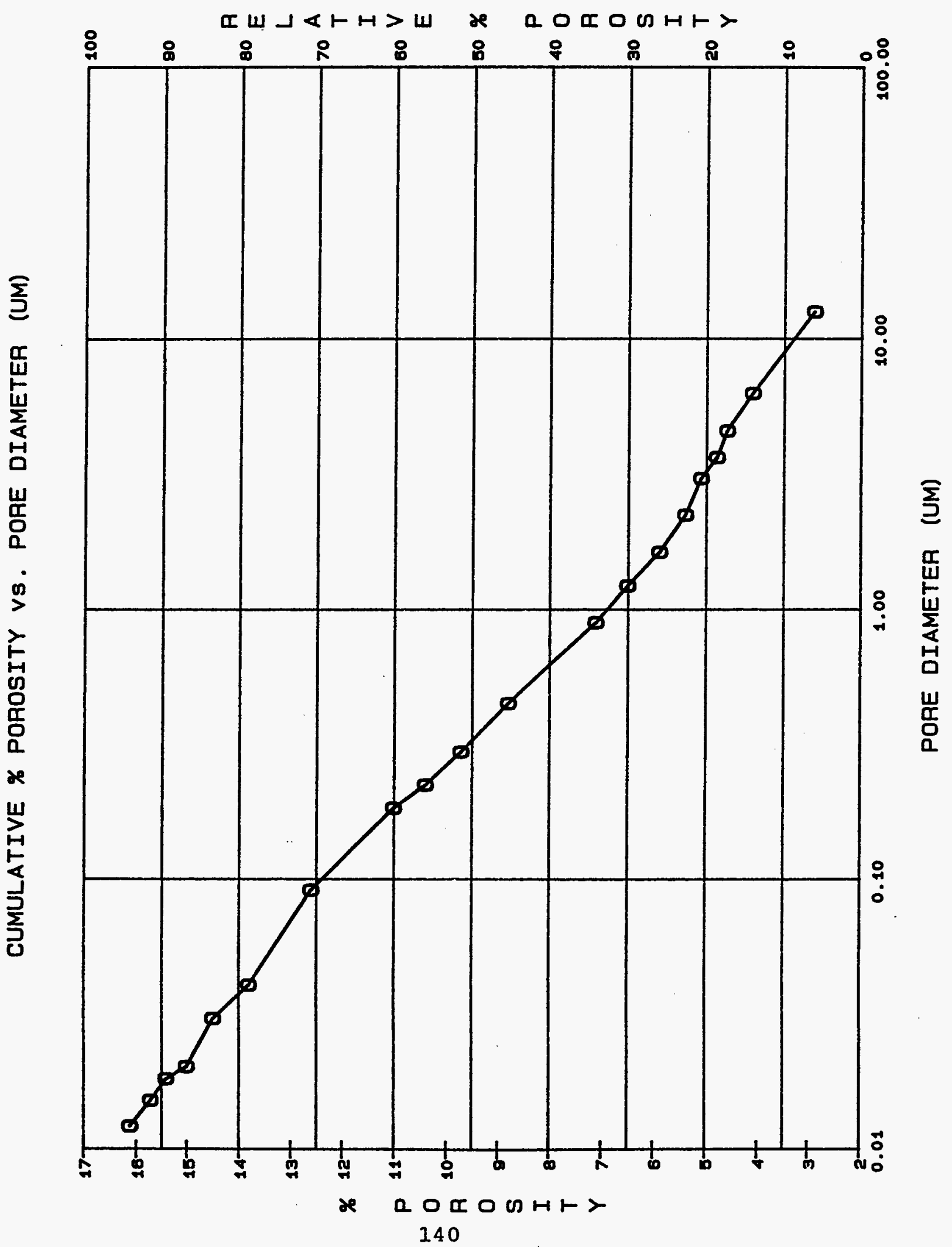




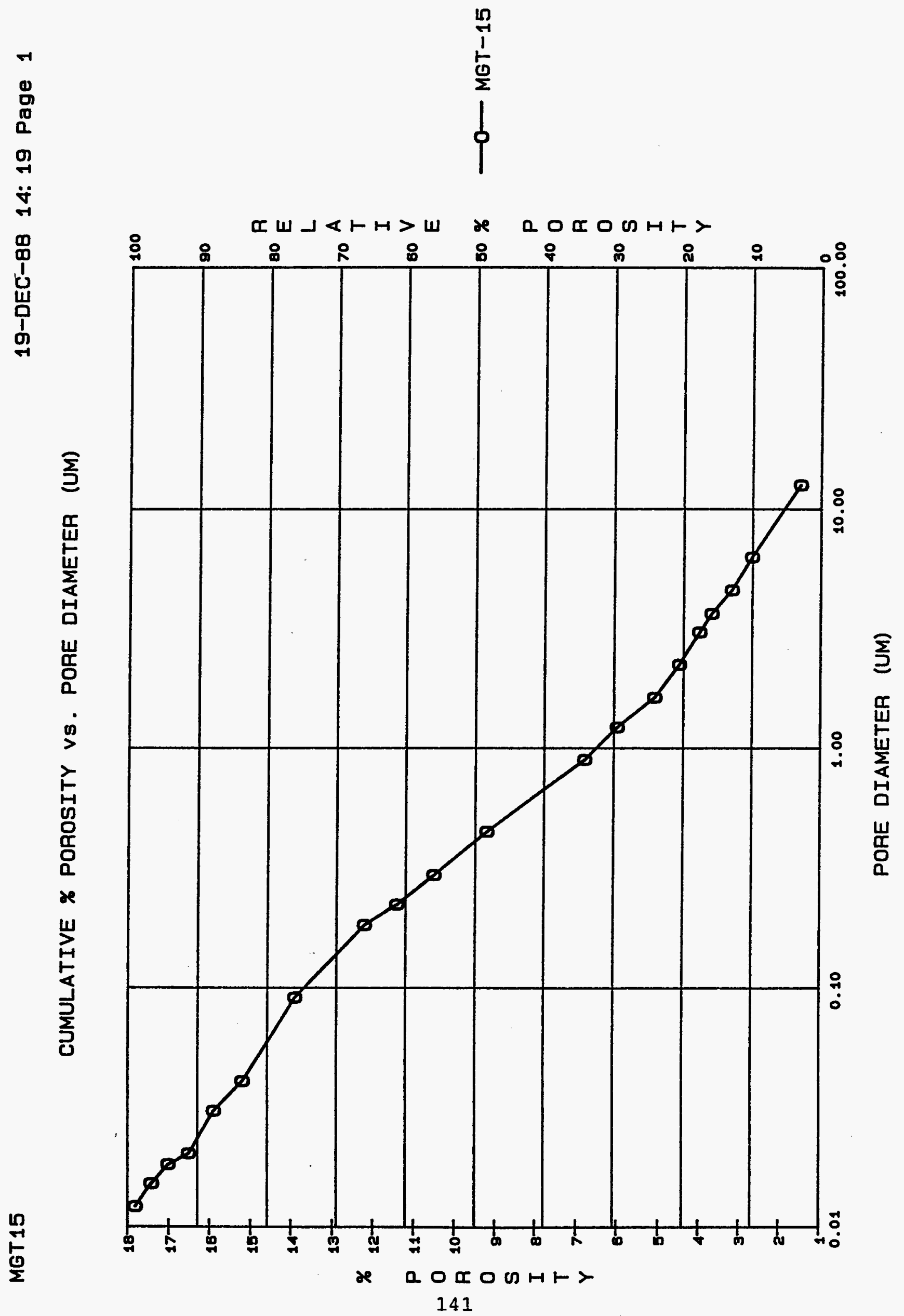


CUMULATIVE \% POROSITY vs. PORE DIAMETER (UM)

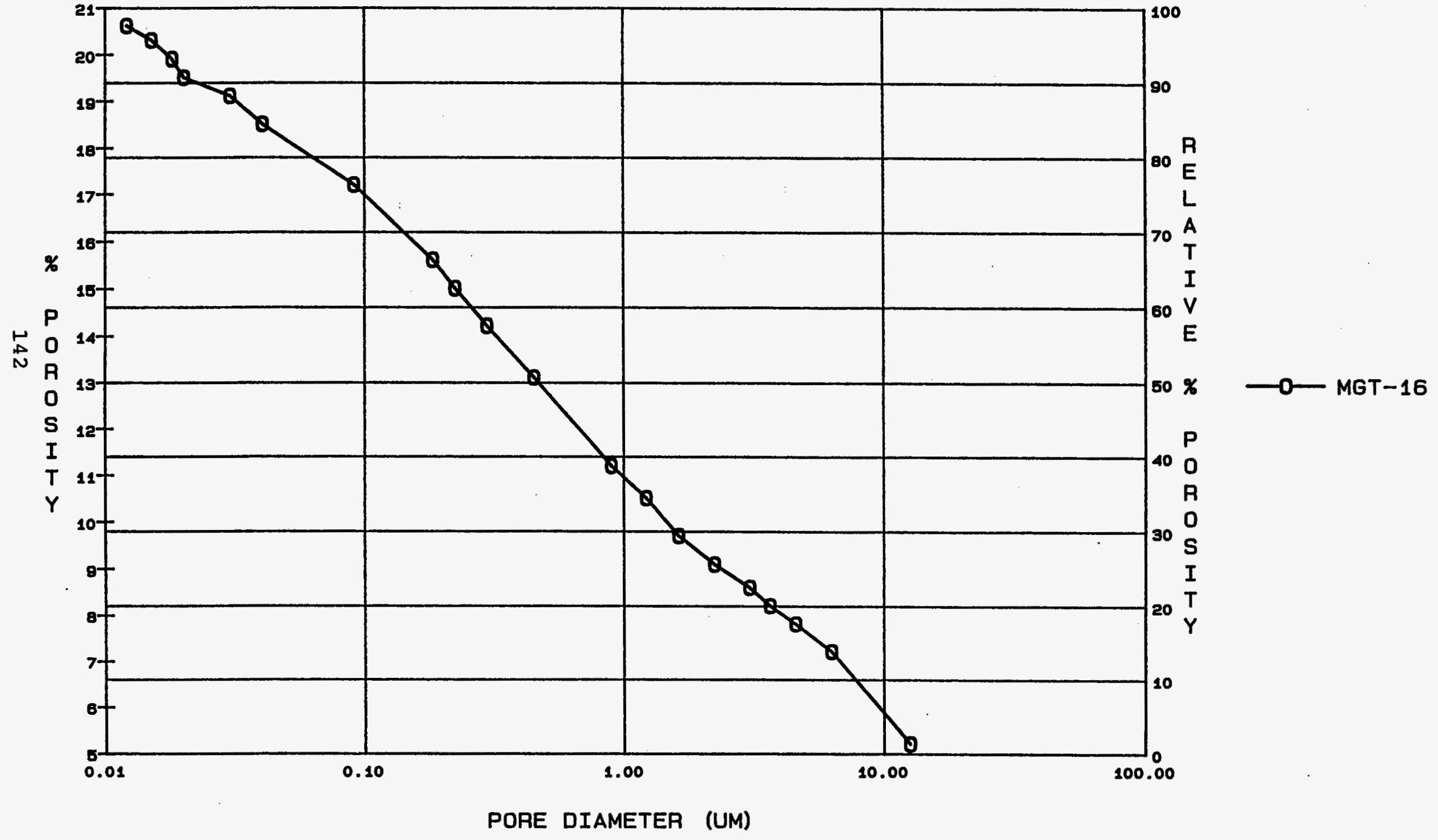


CUMULATIVE $x$ POROSITY vs PORE DIAMETER

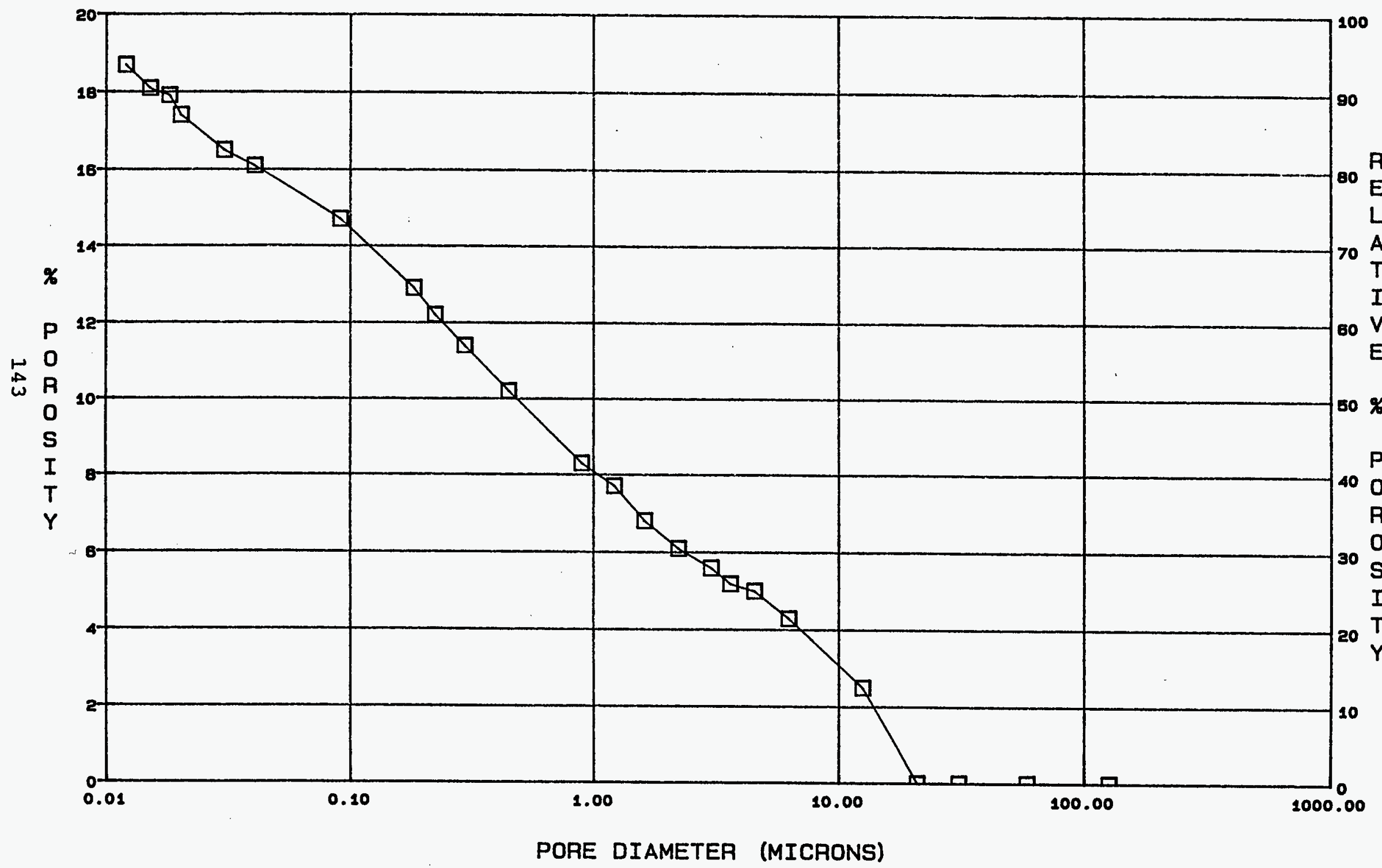




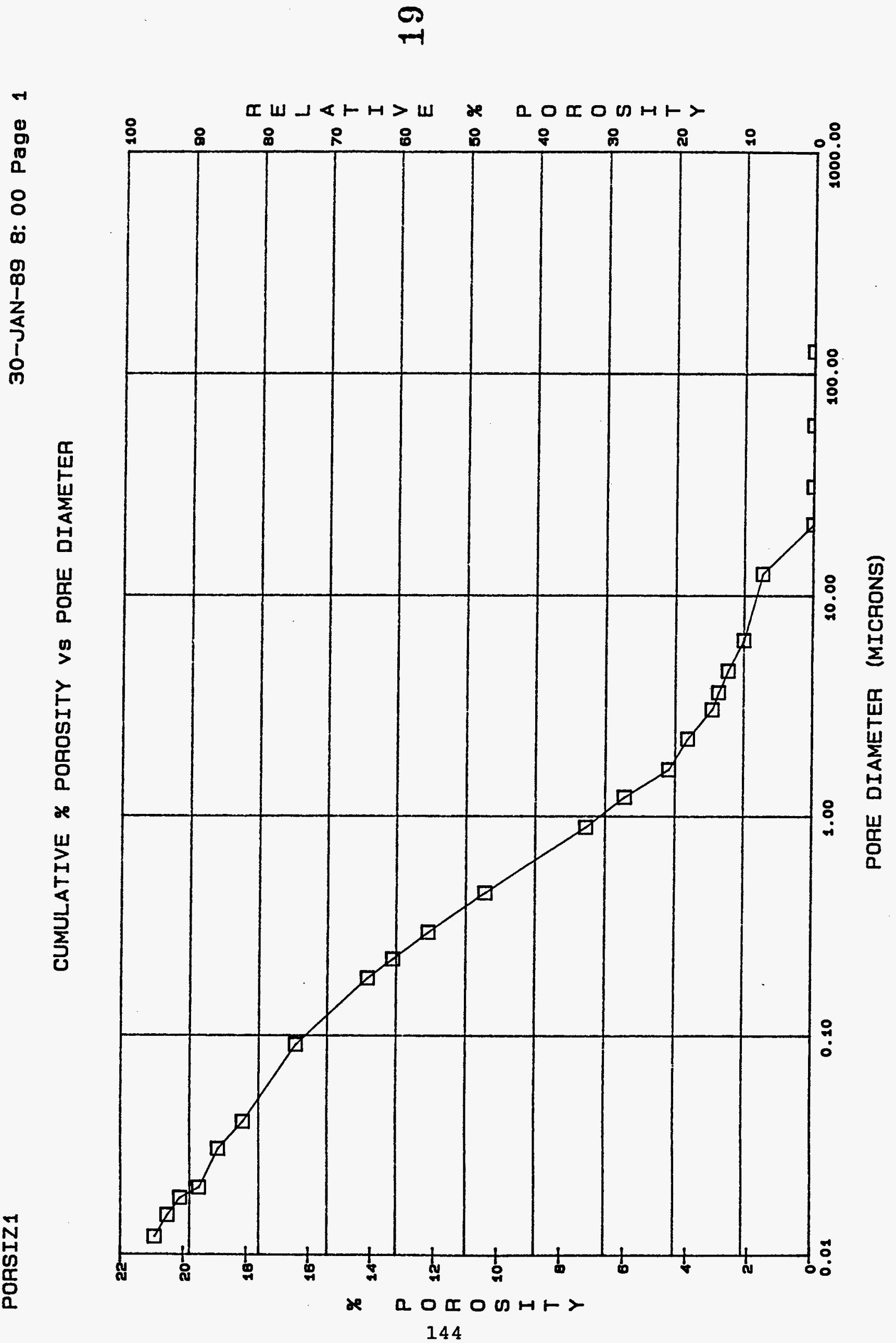


CUMULATIVE $\%$ POROSITY VS PORE DIAMETER

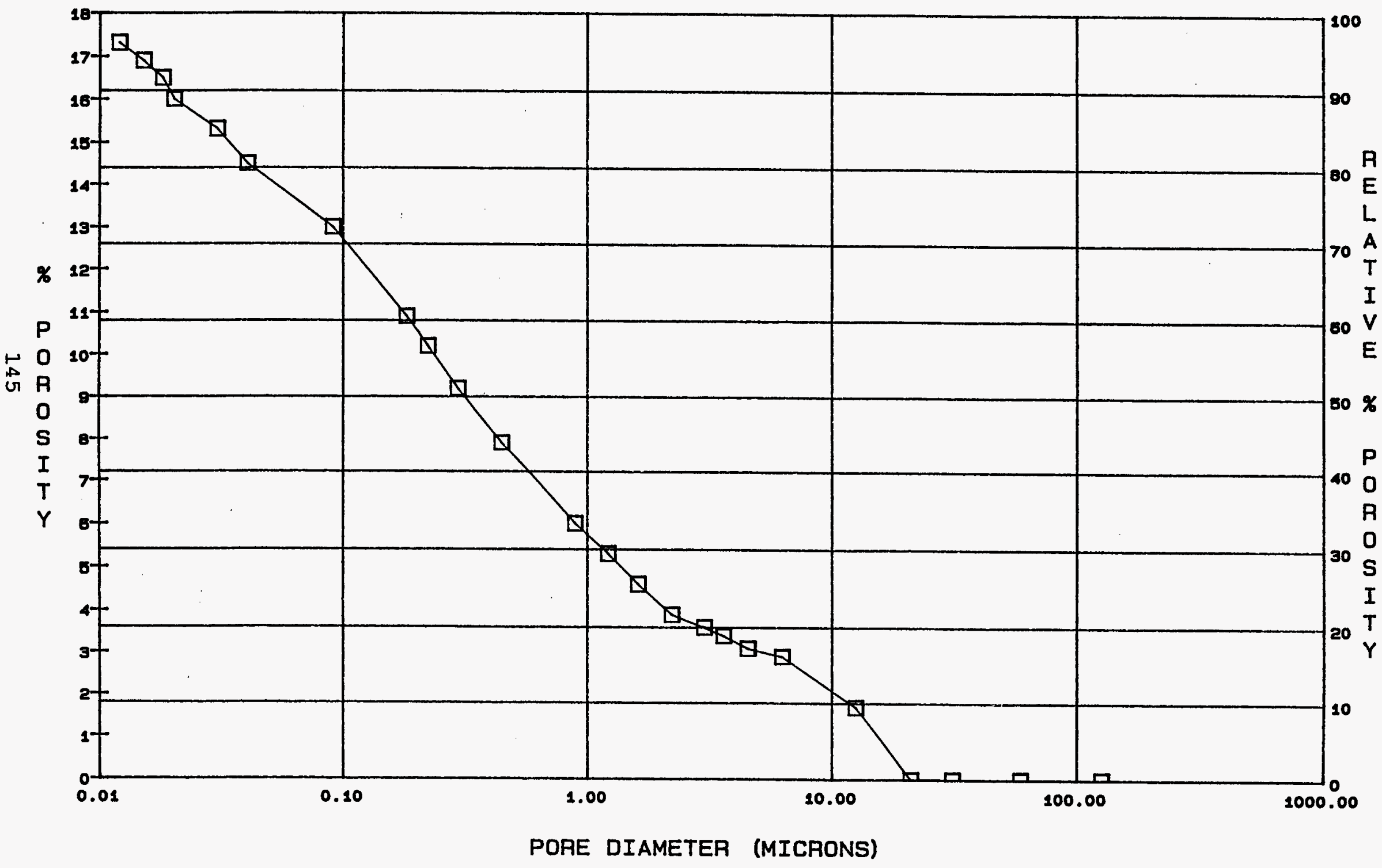


CUMULATIVE \% POROSITY Vs PORE DIAMETER

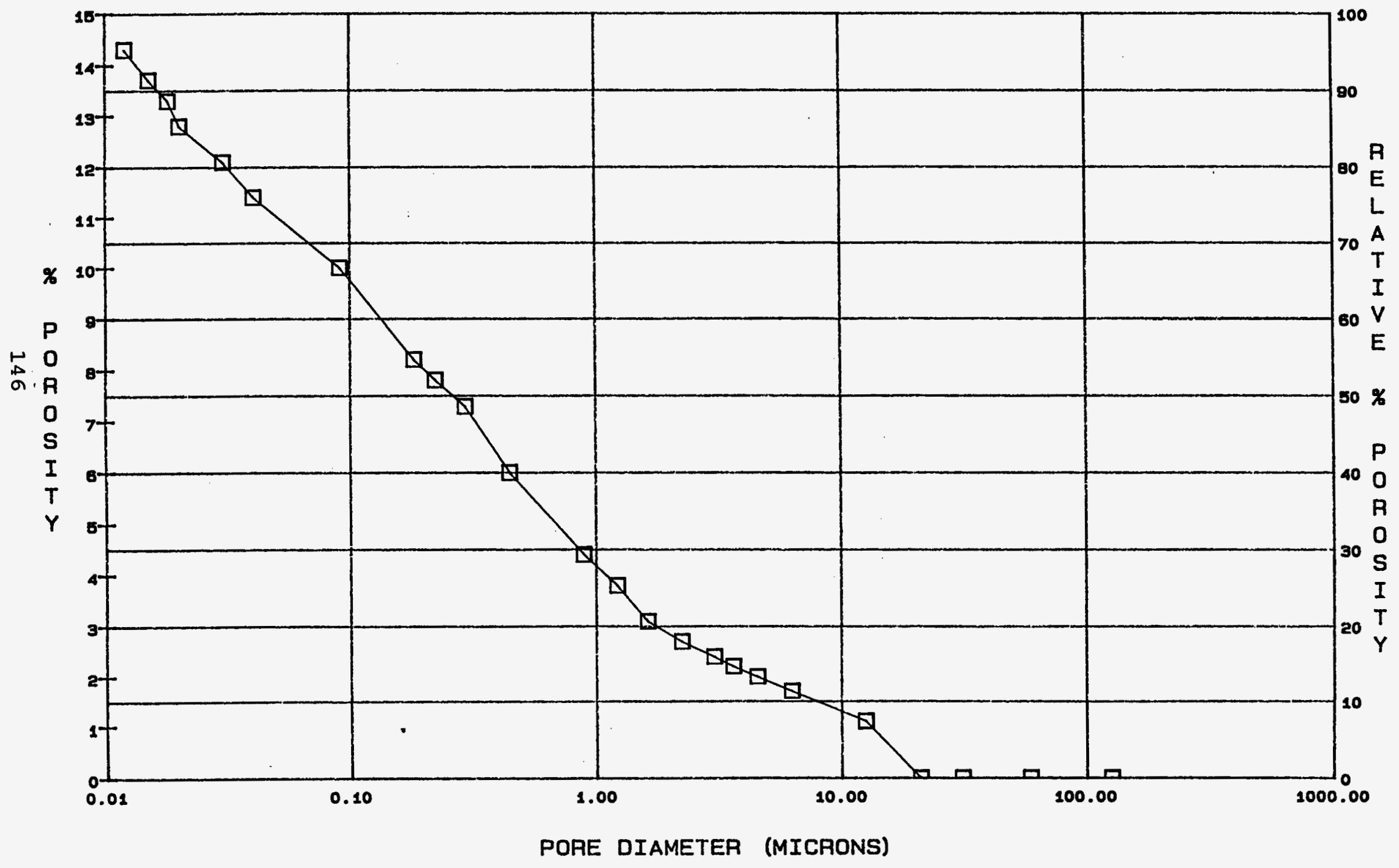




\section{APPENDIX C}

RESULTS OF MICRO-FIXED-BED GASIFICATION TESTS 


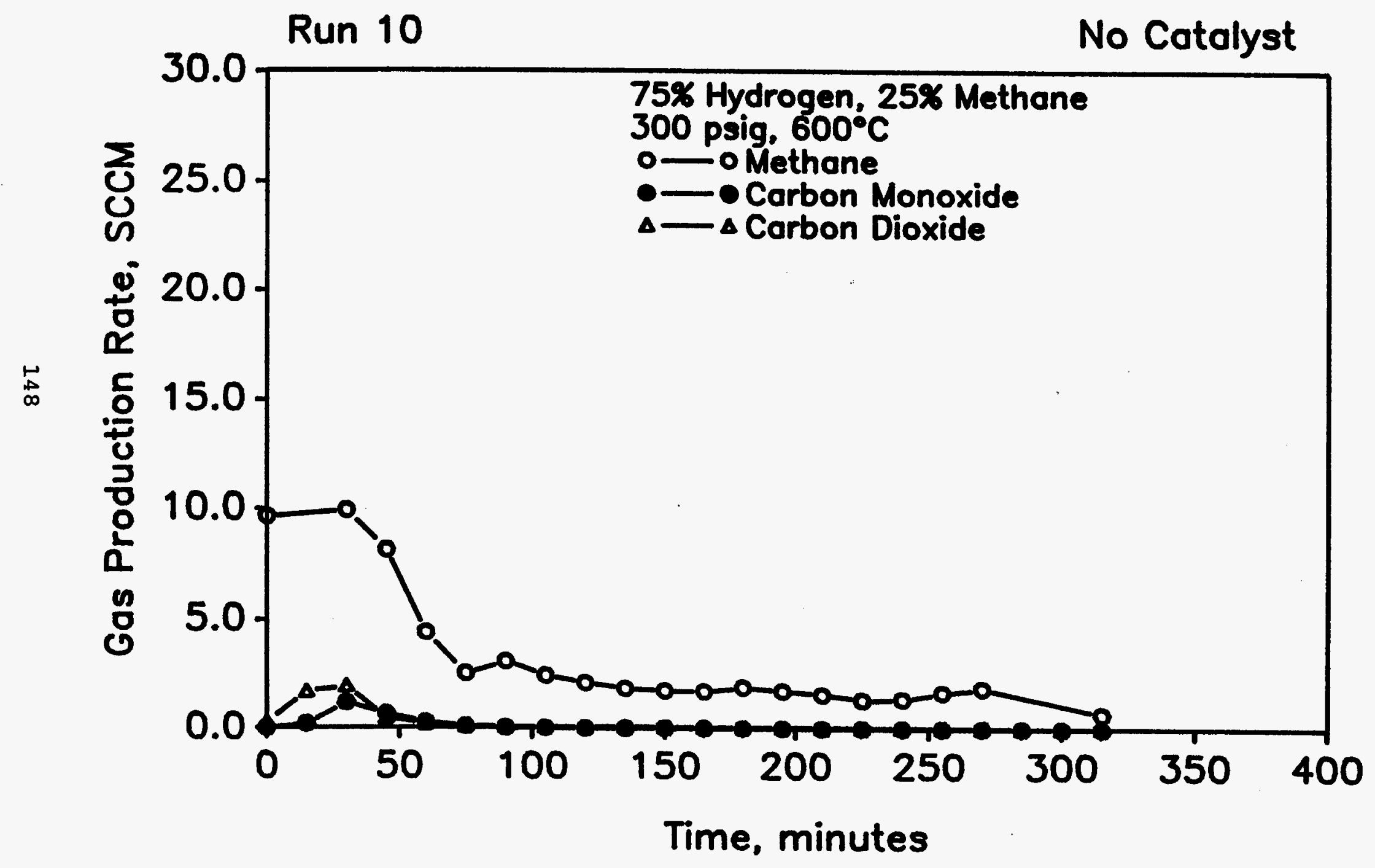




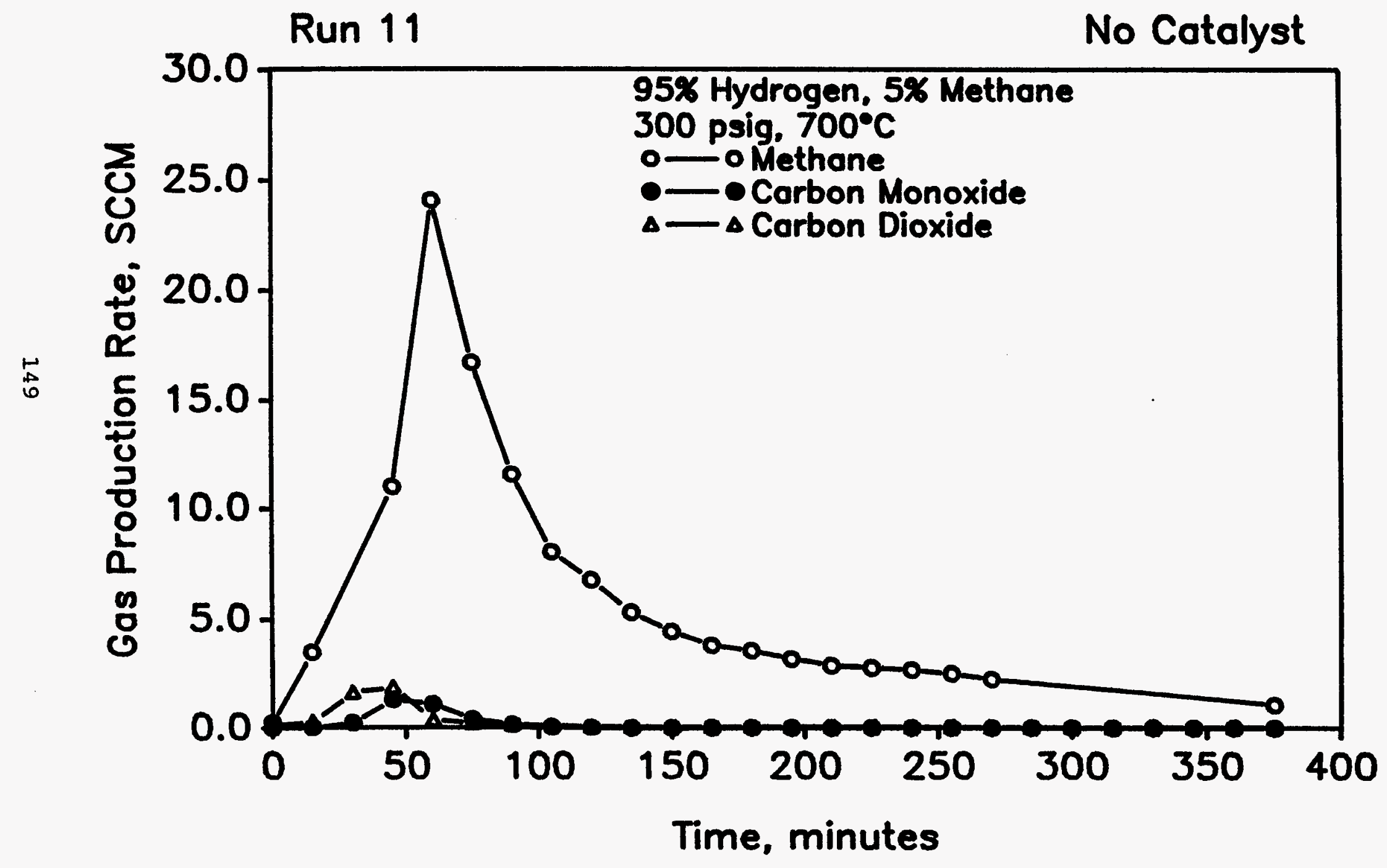




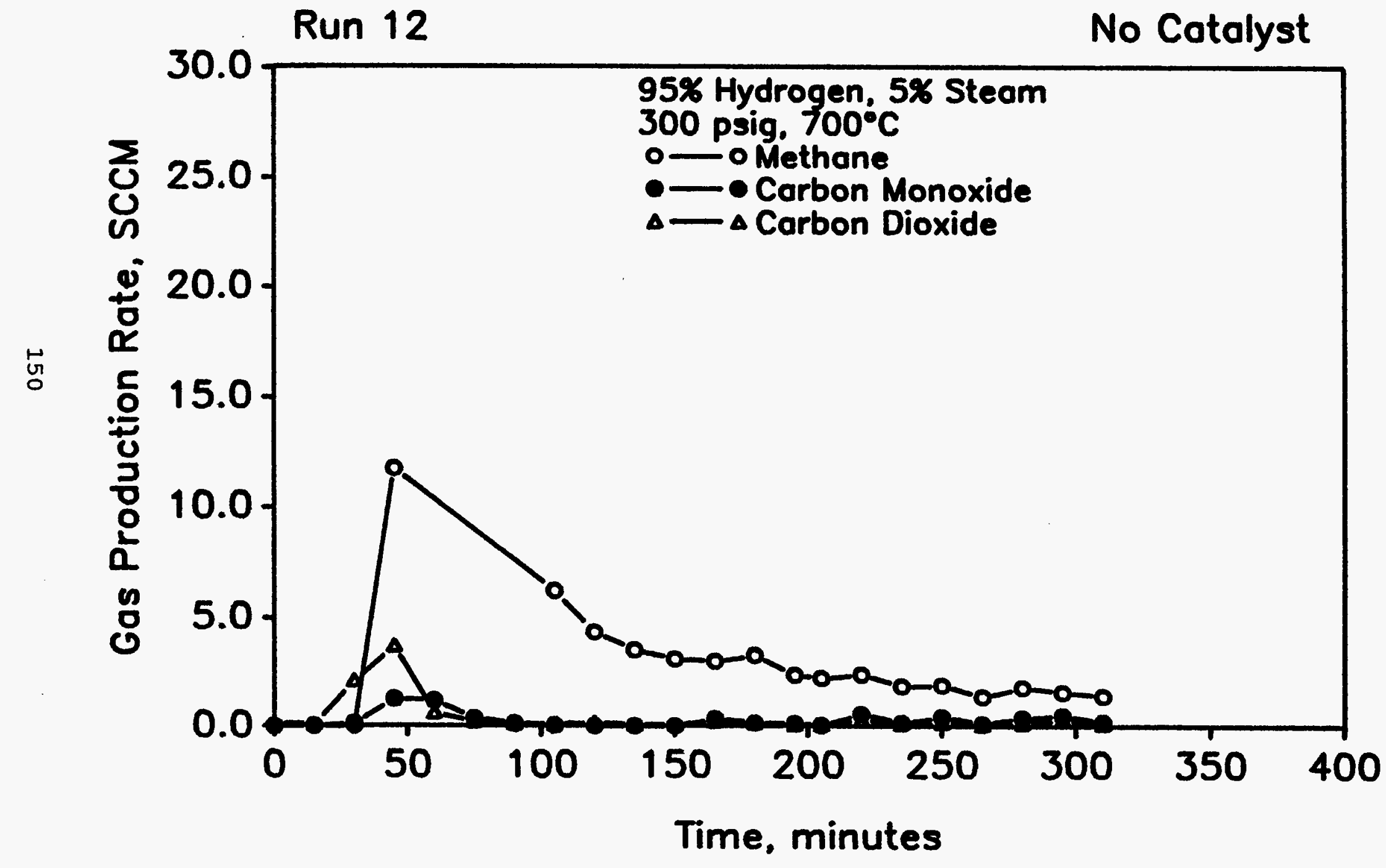




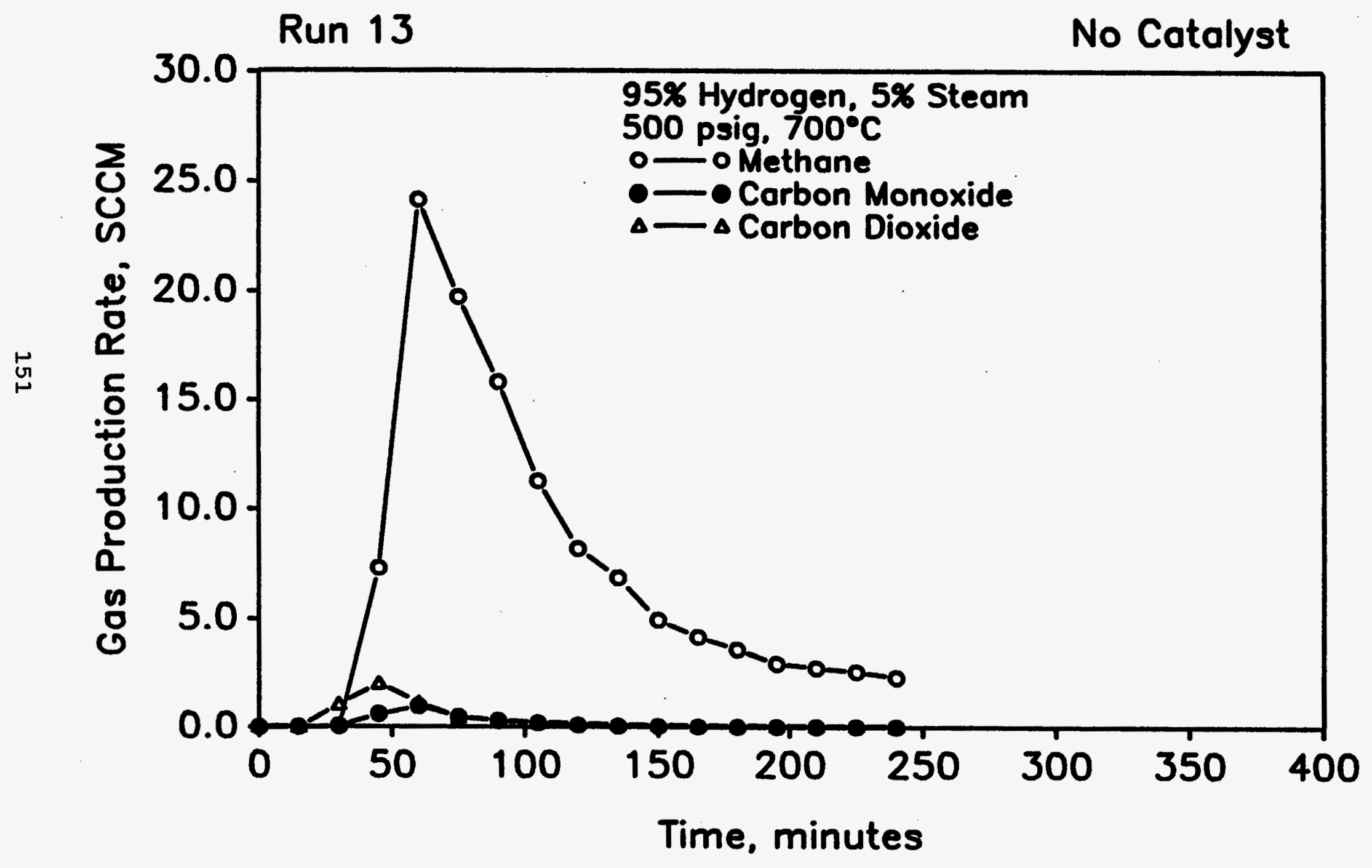




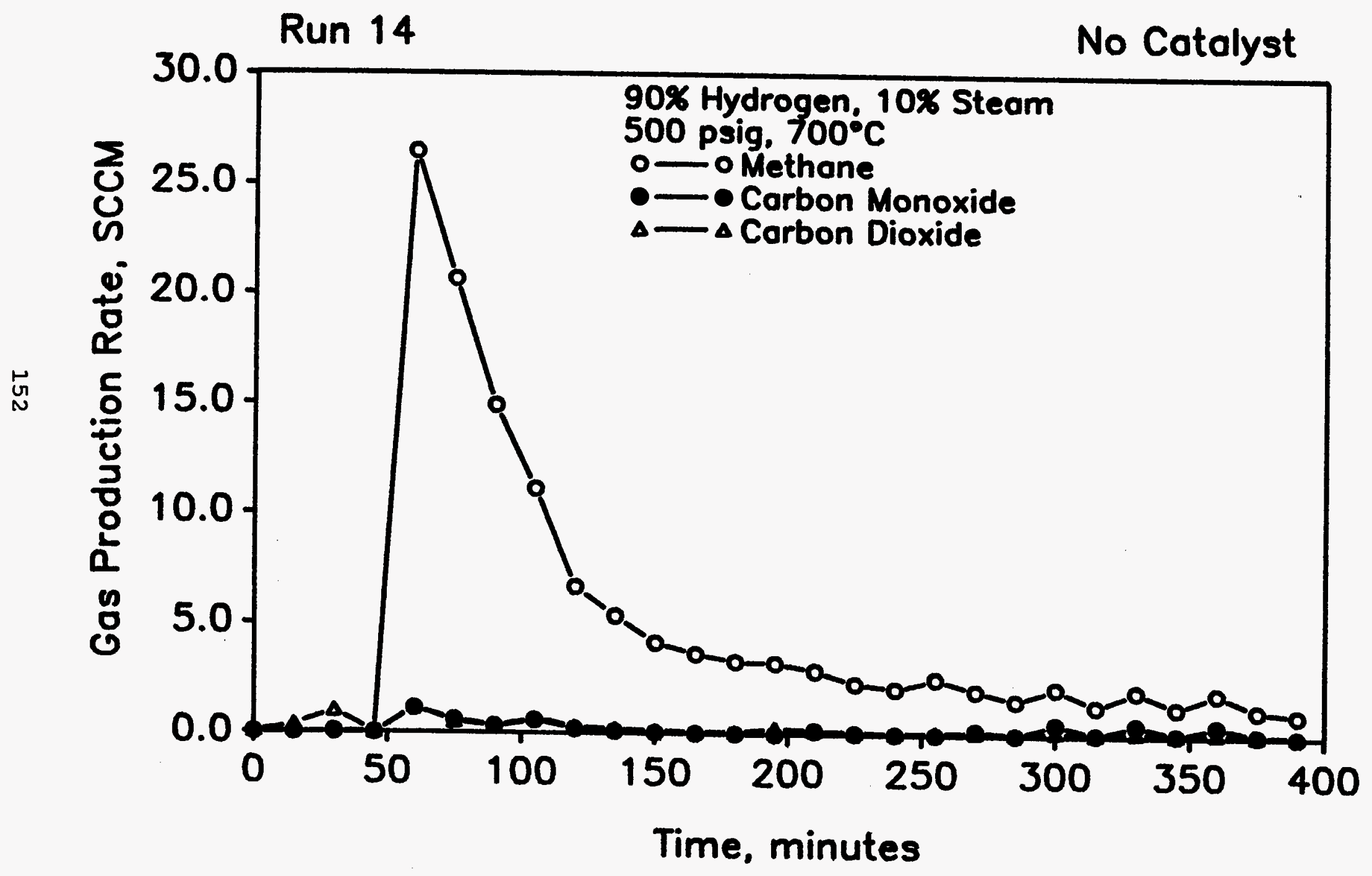




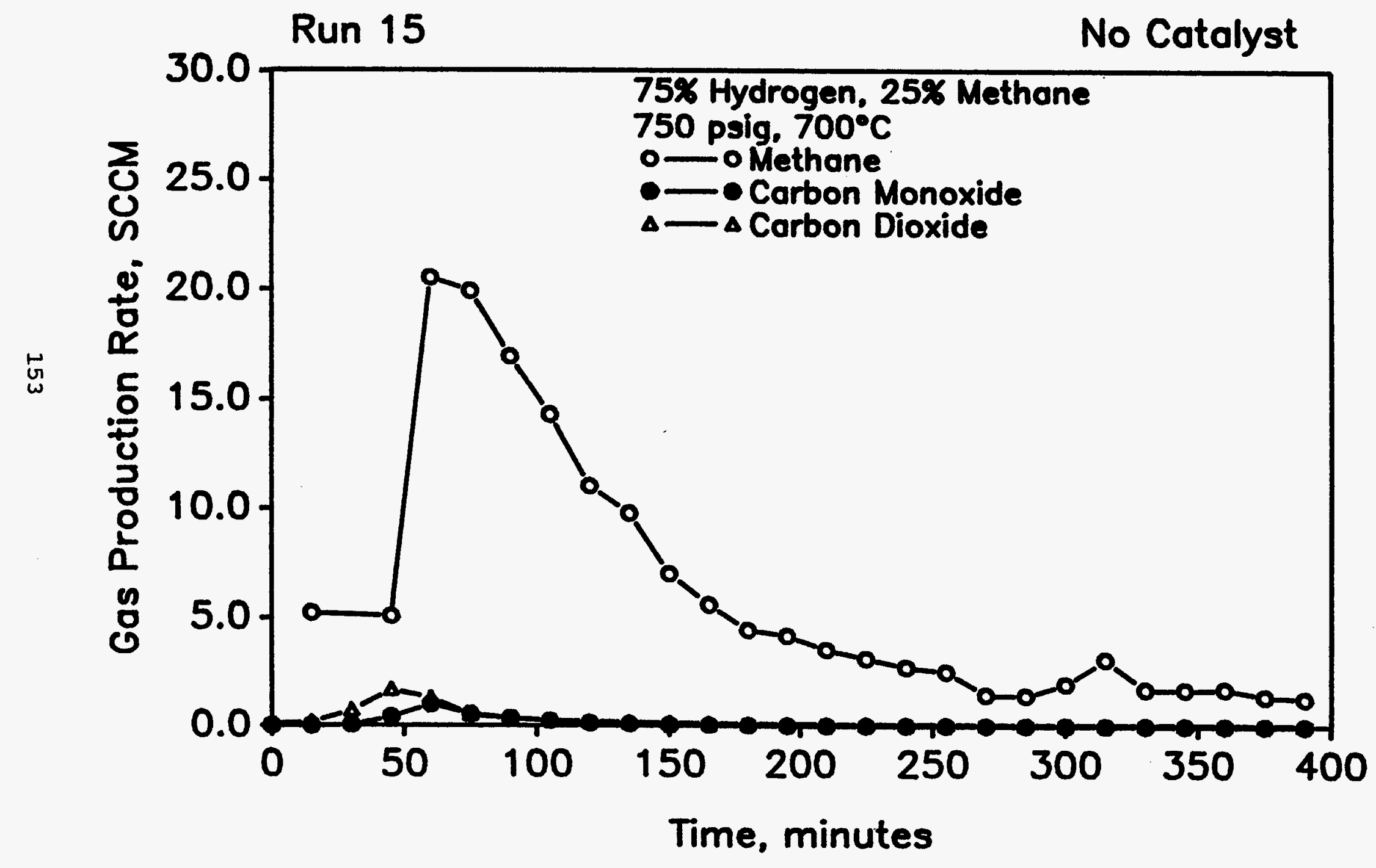




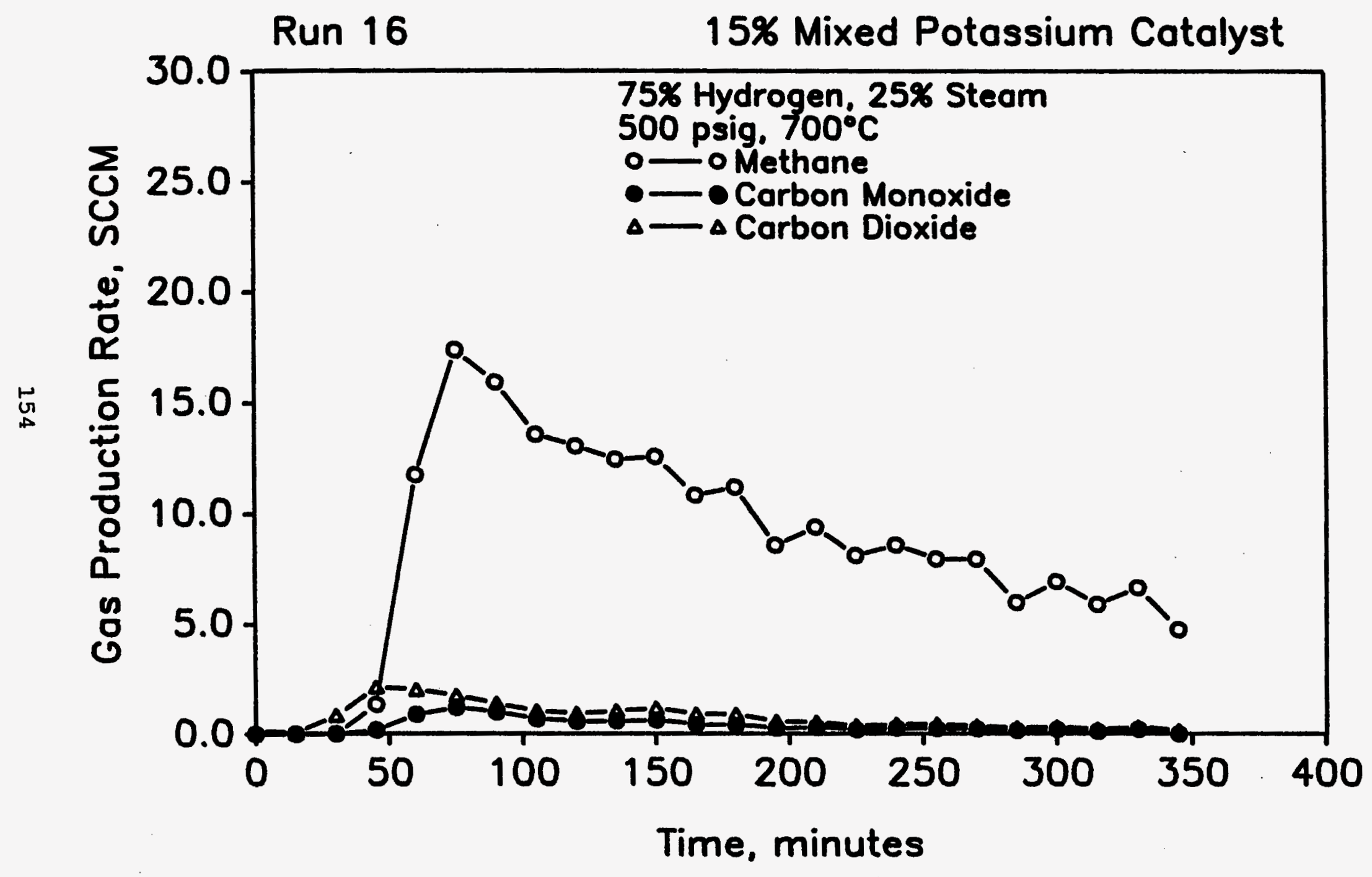




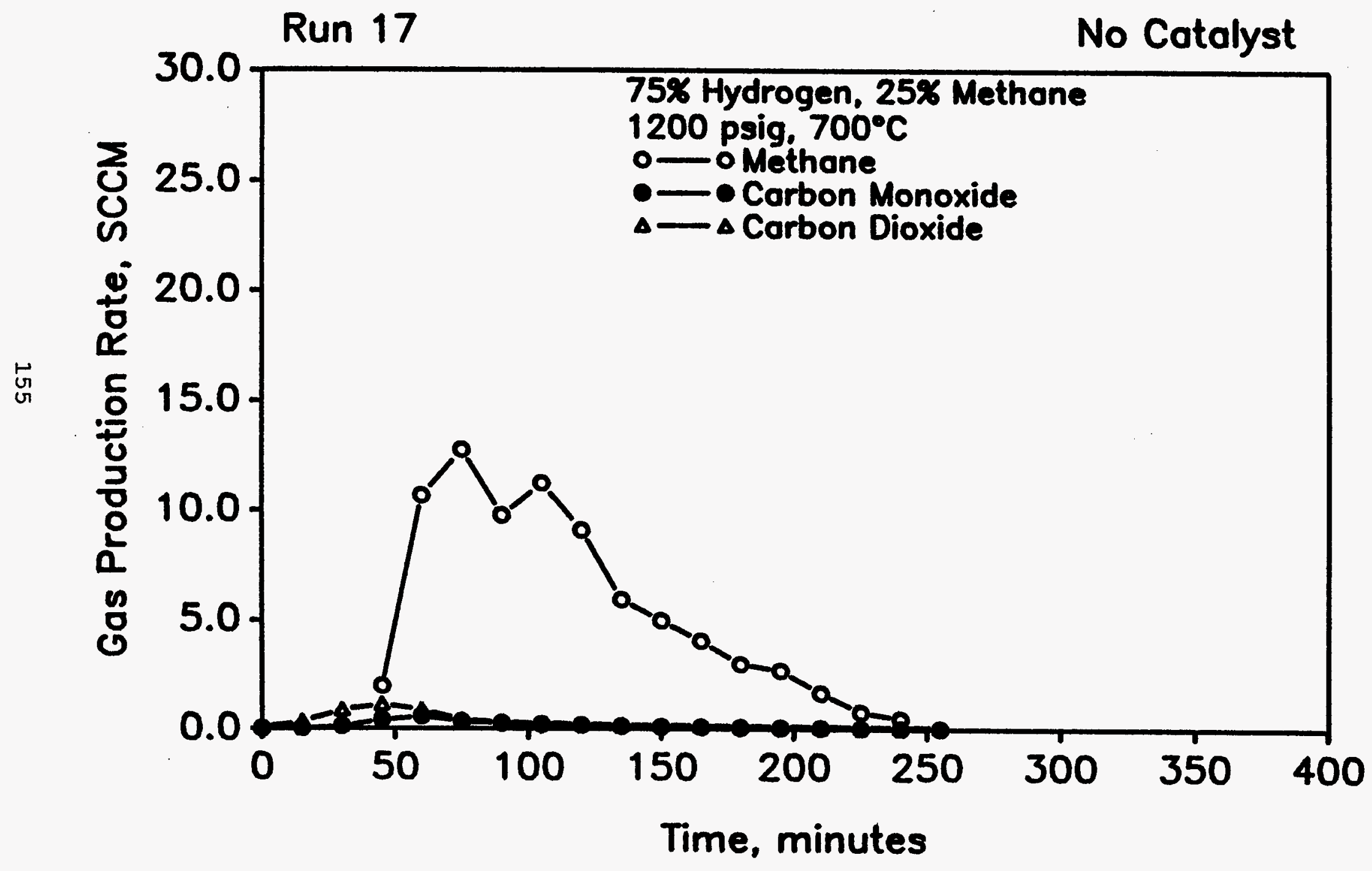




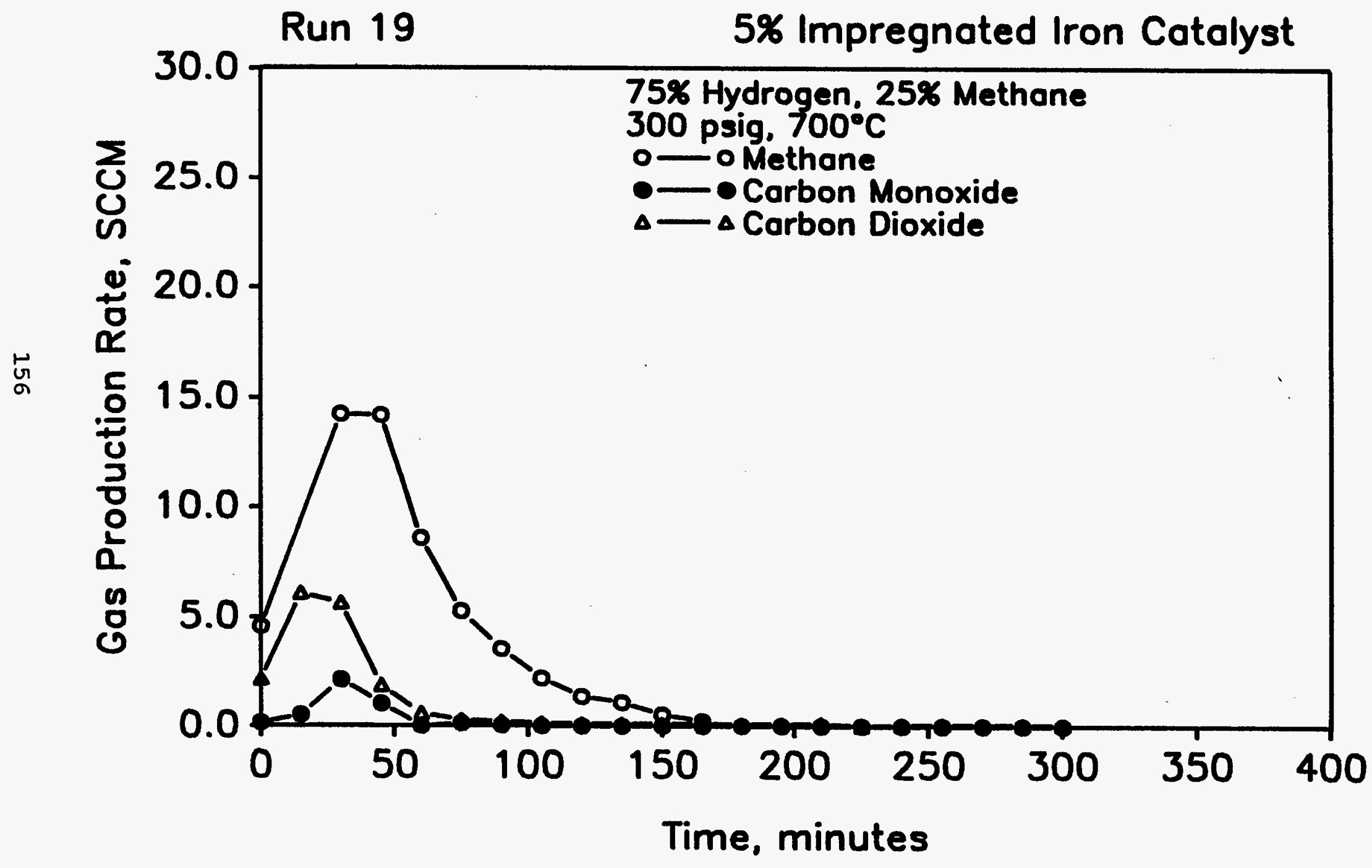




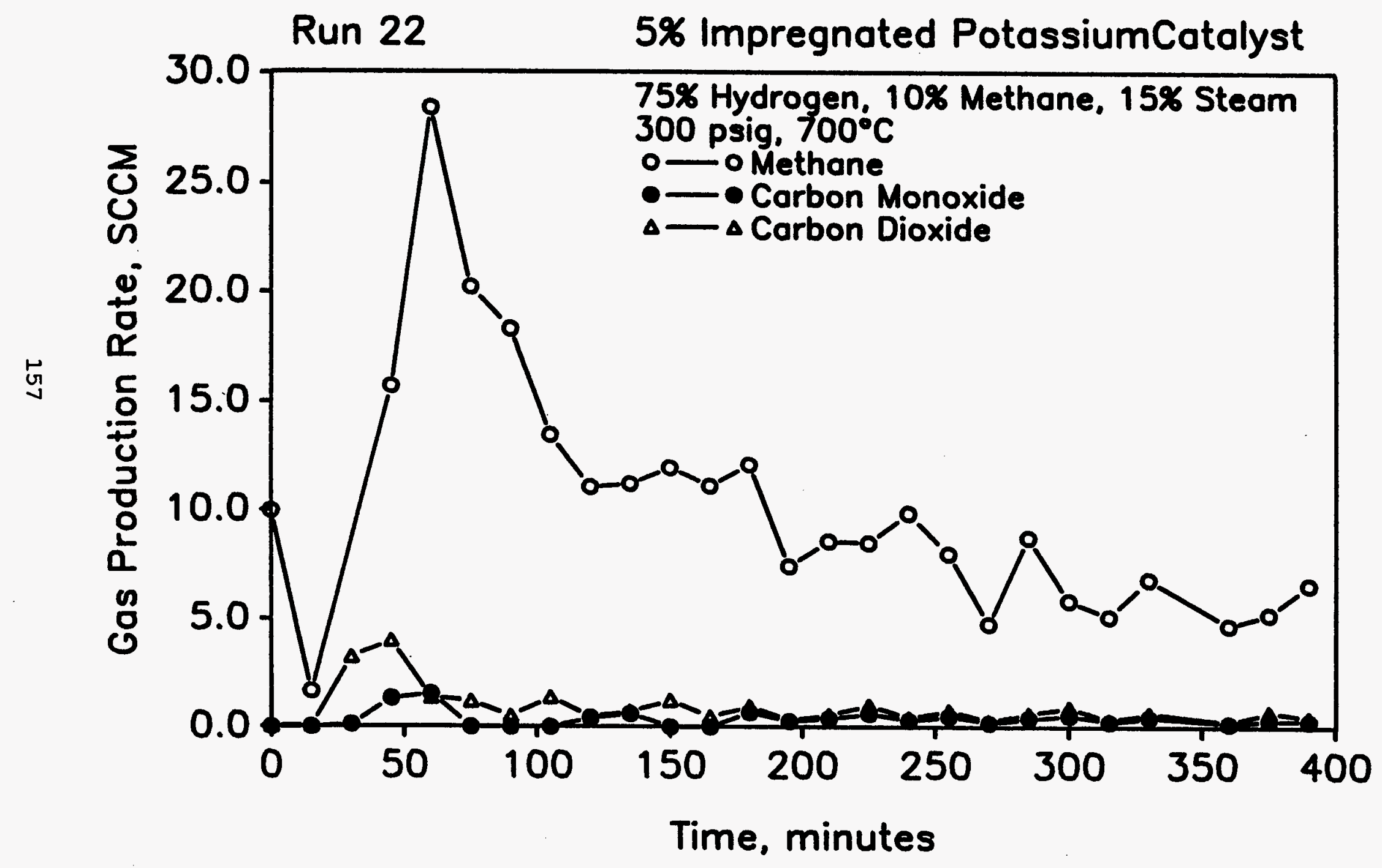




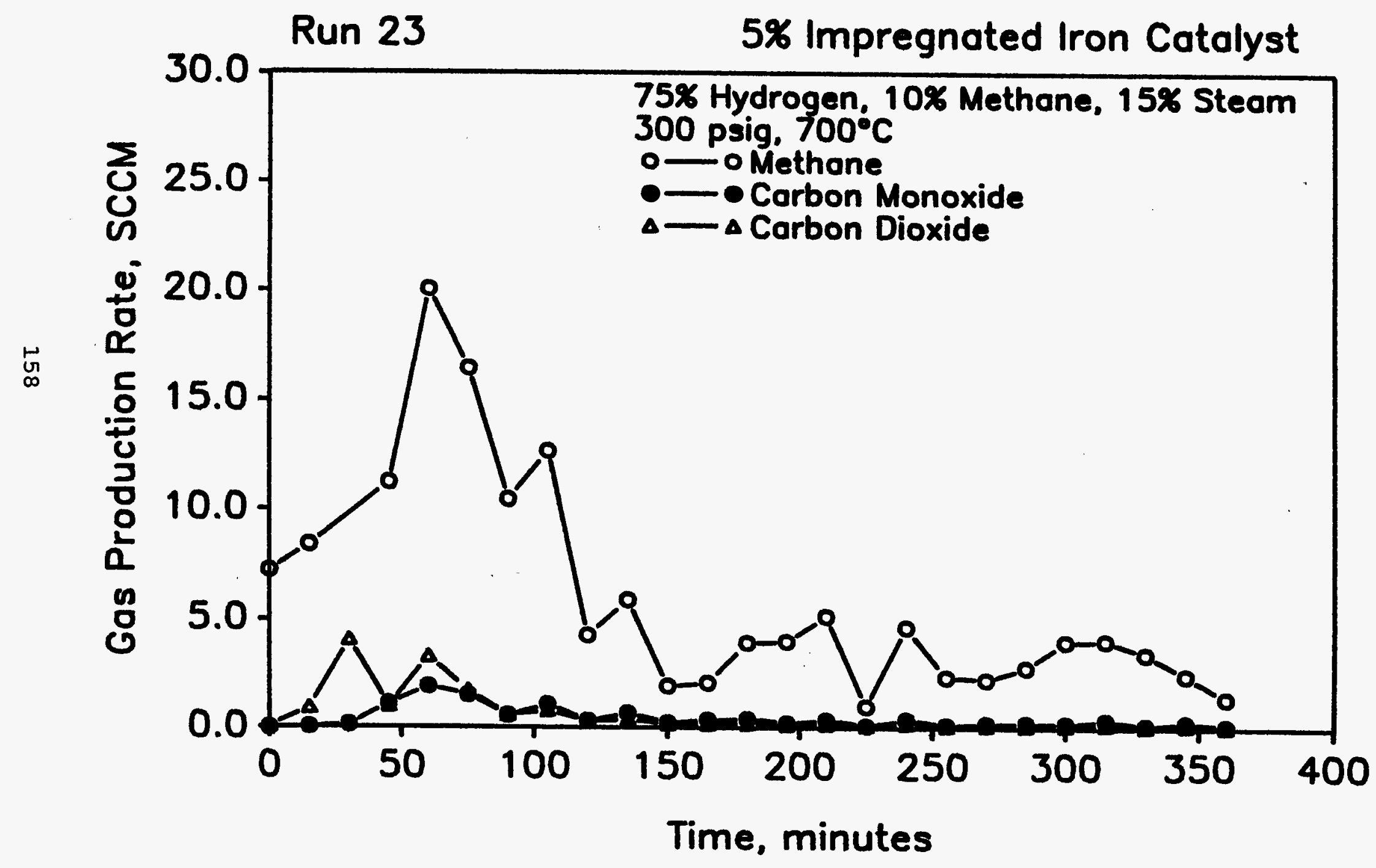




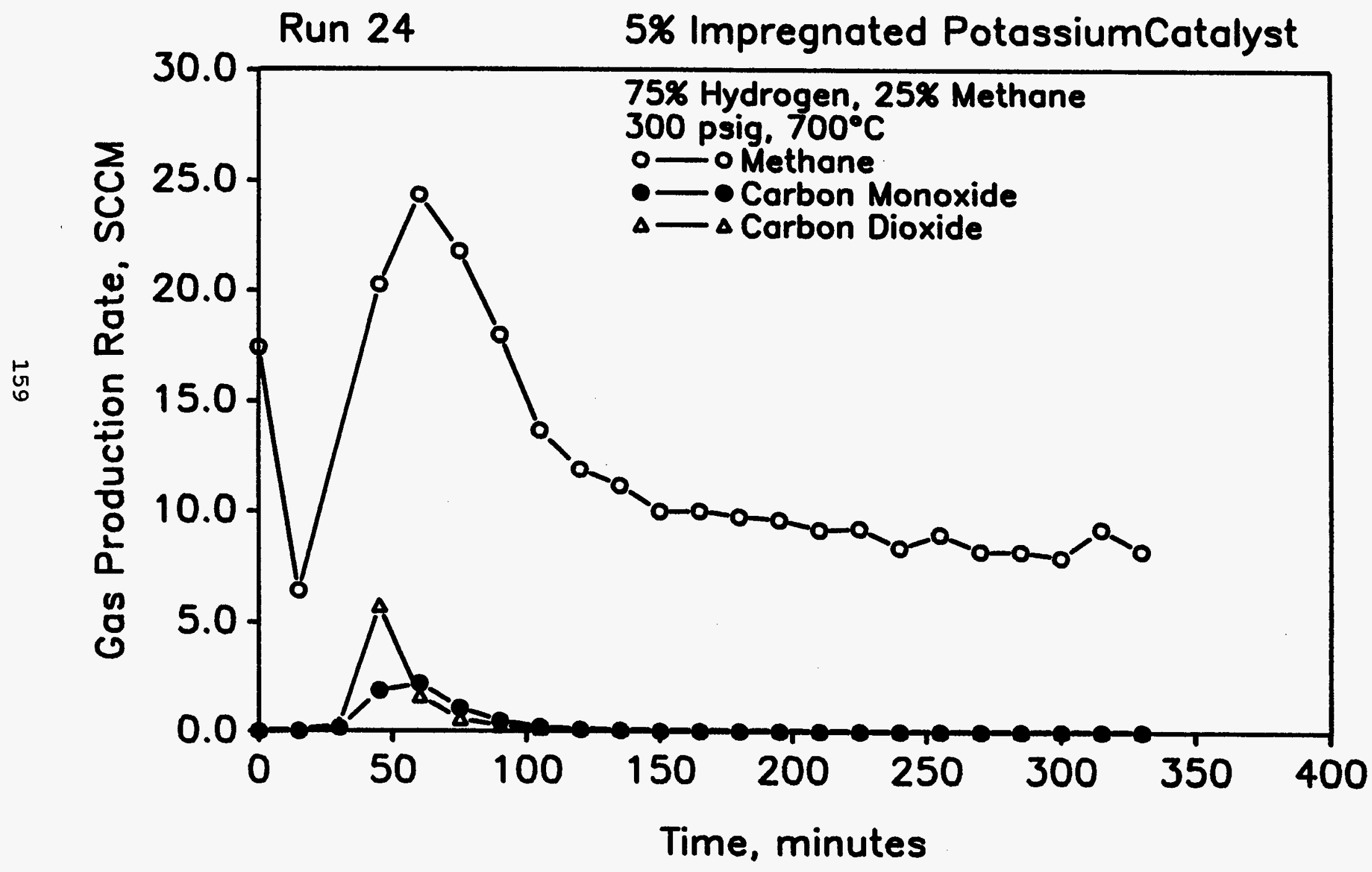




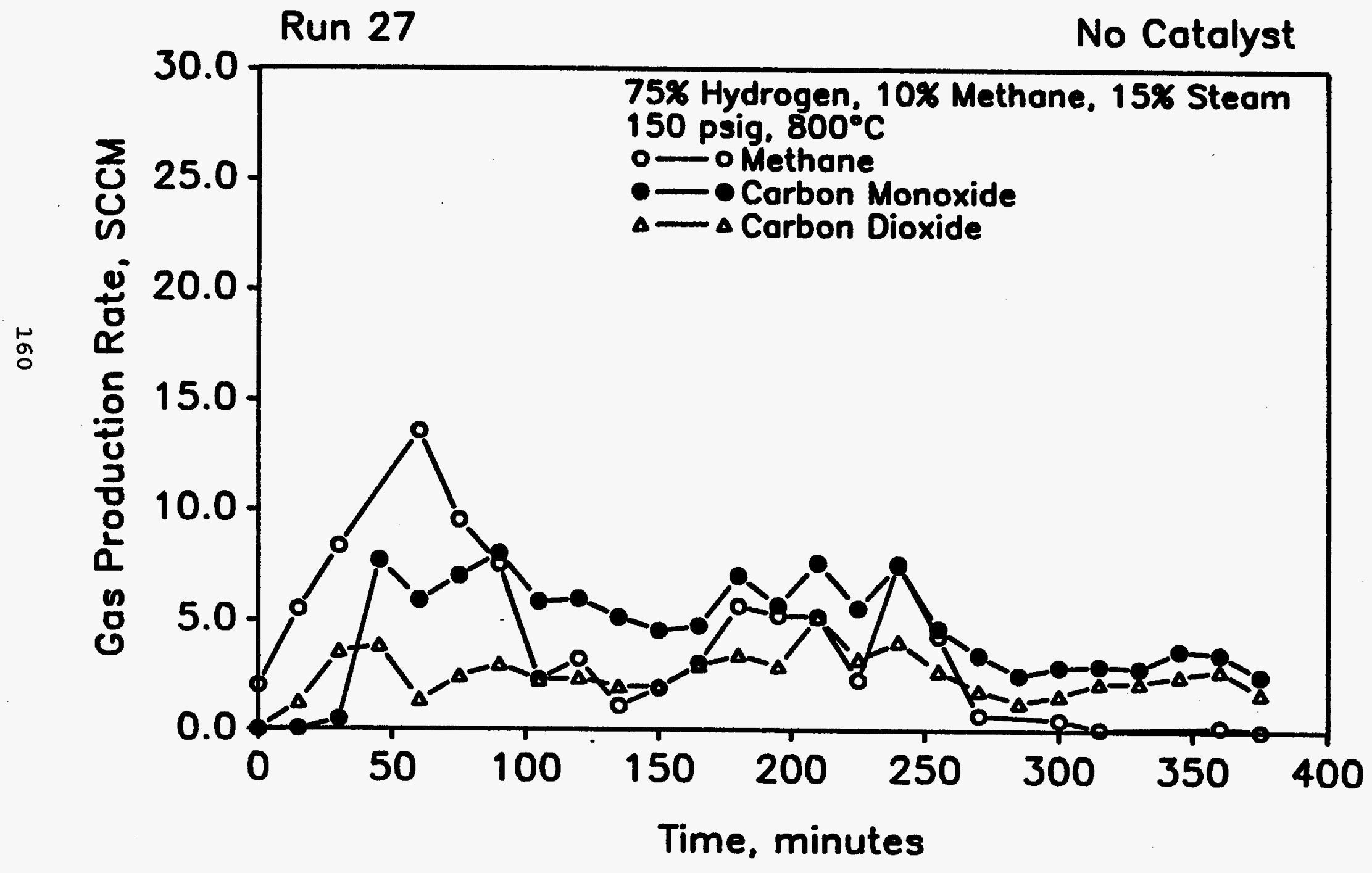




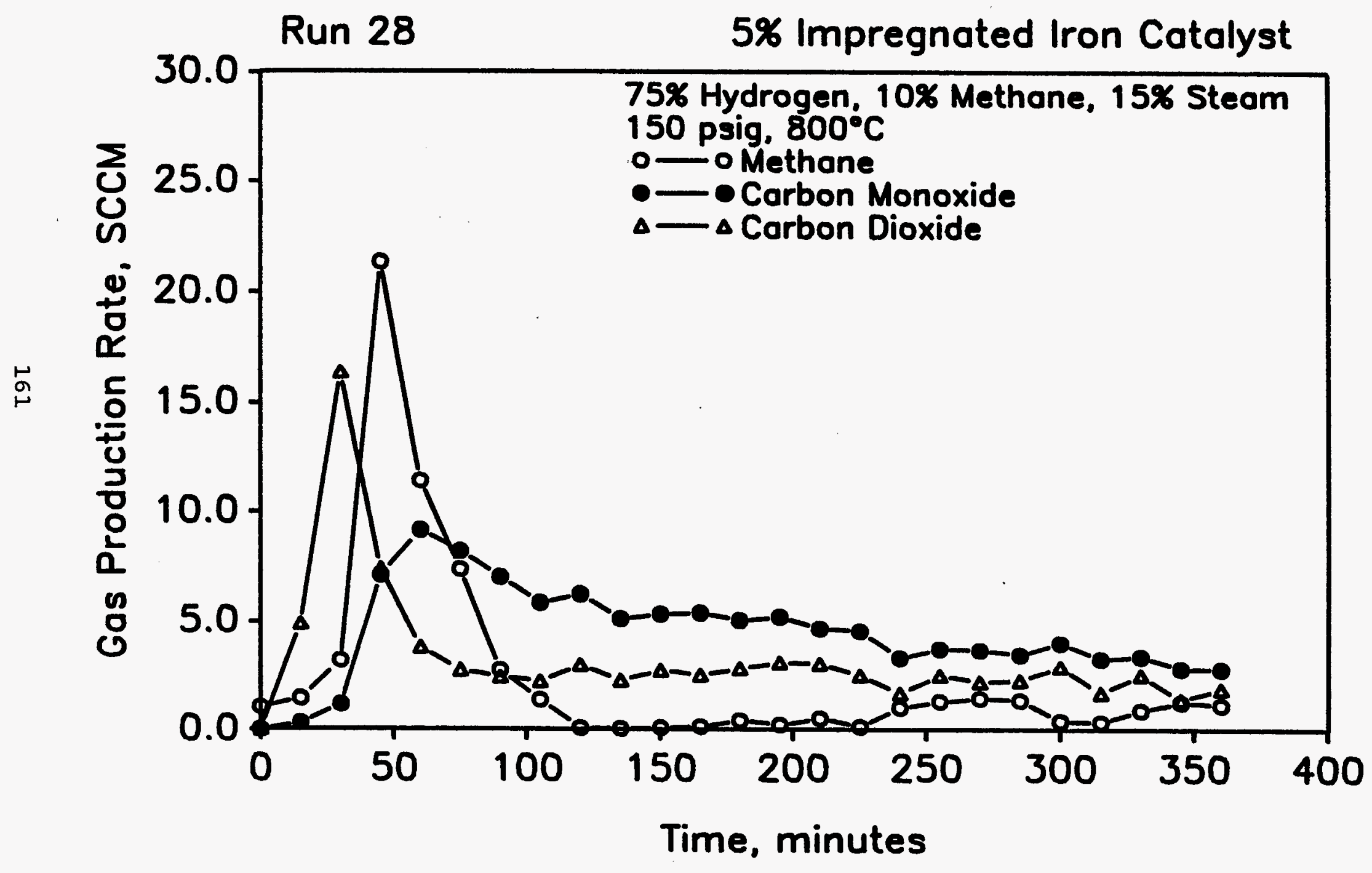




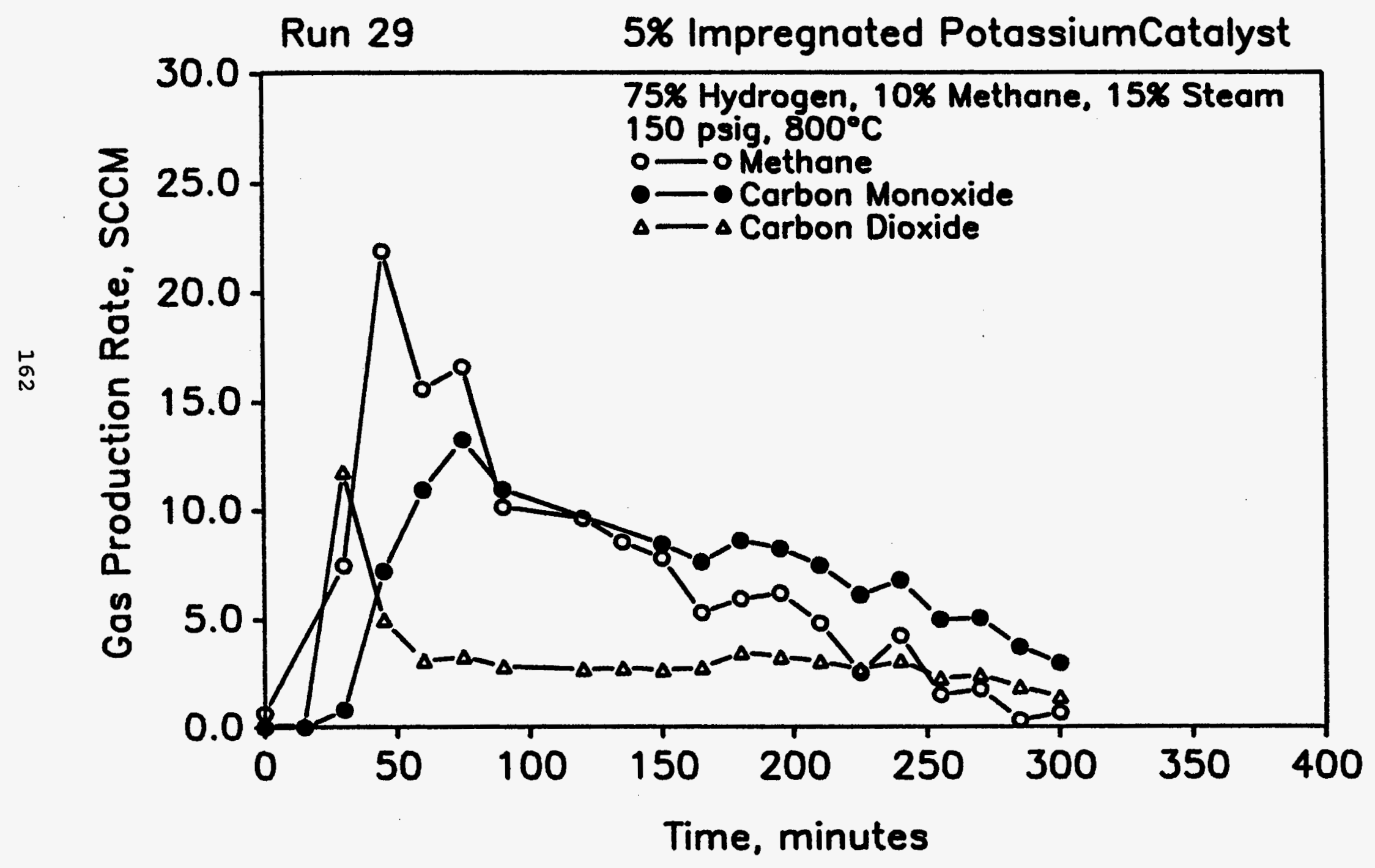




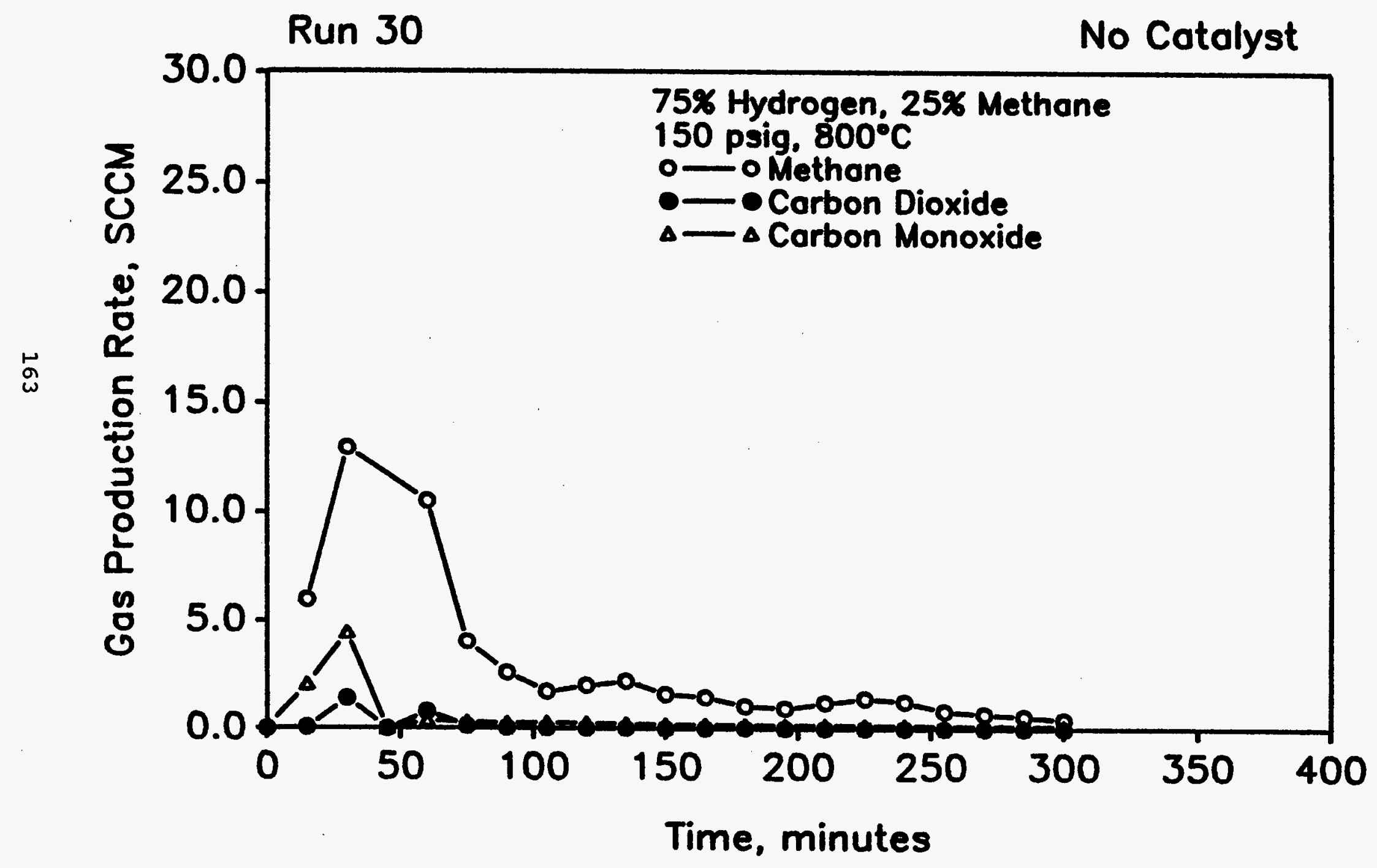




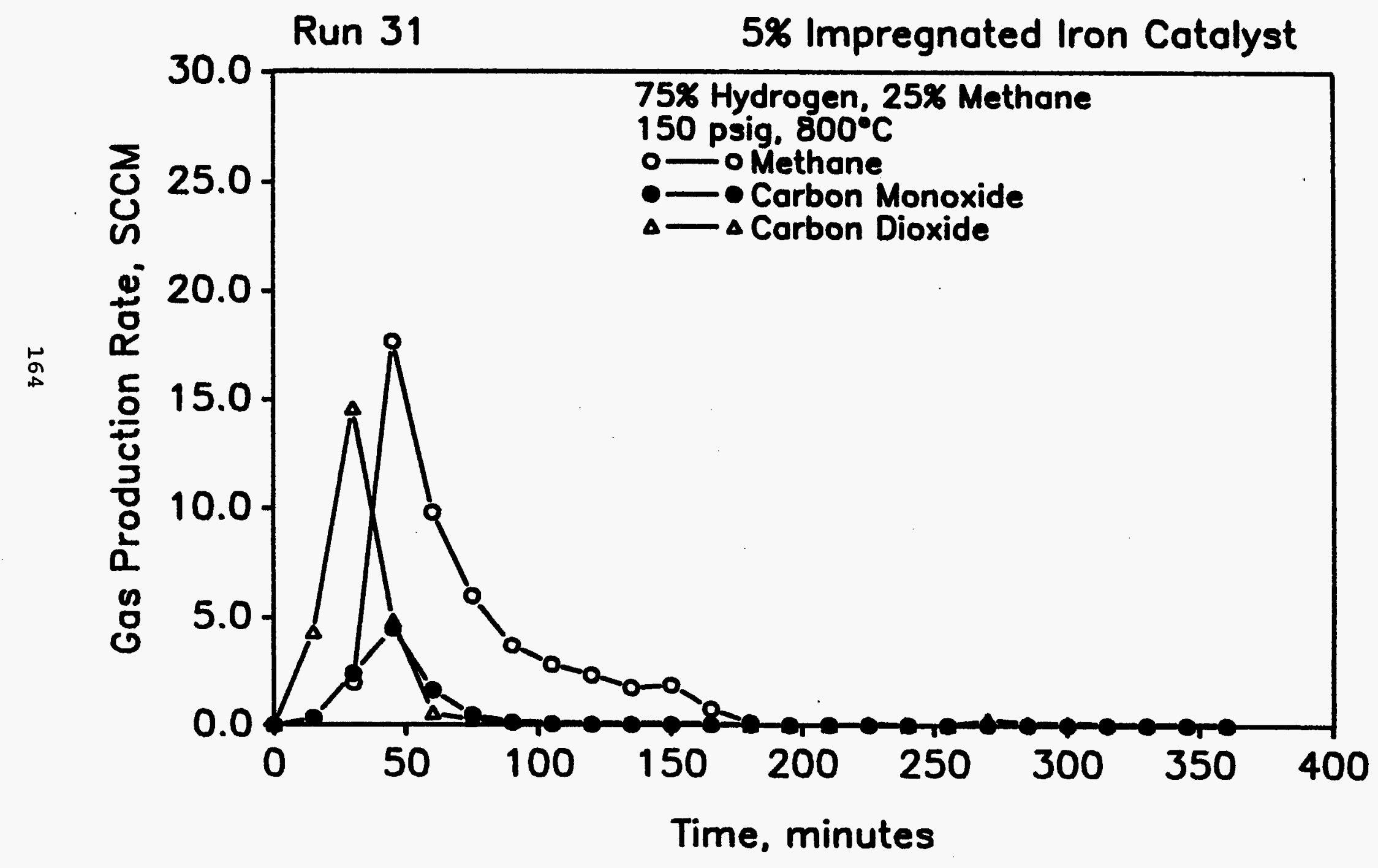




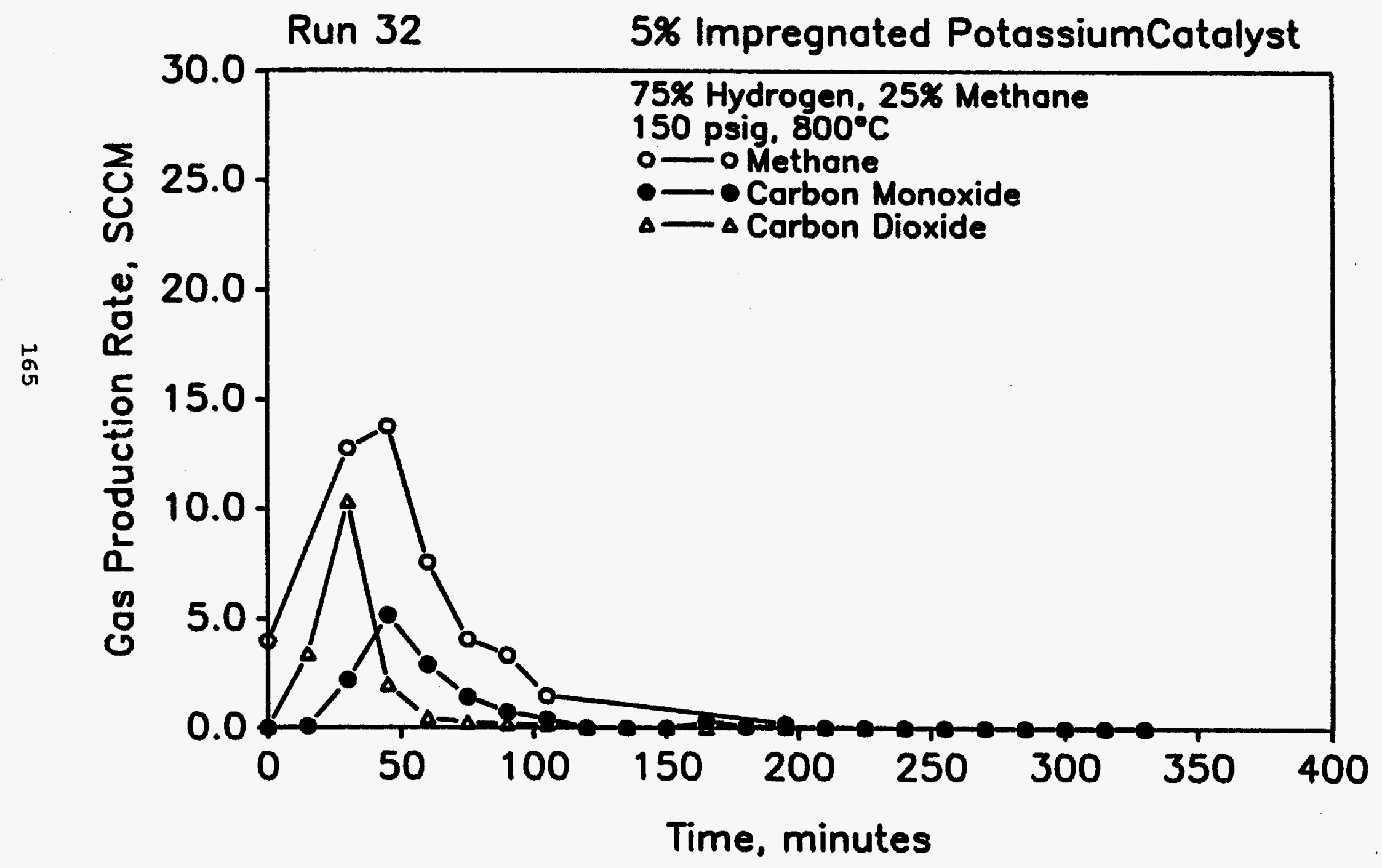




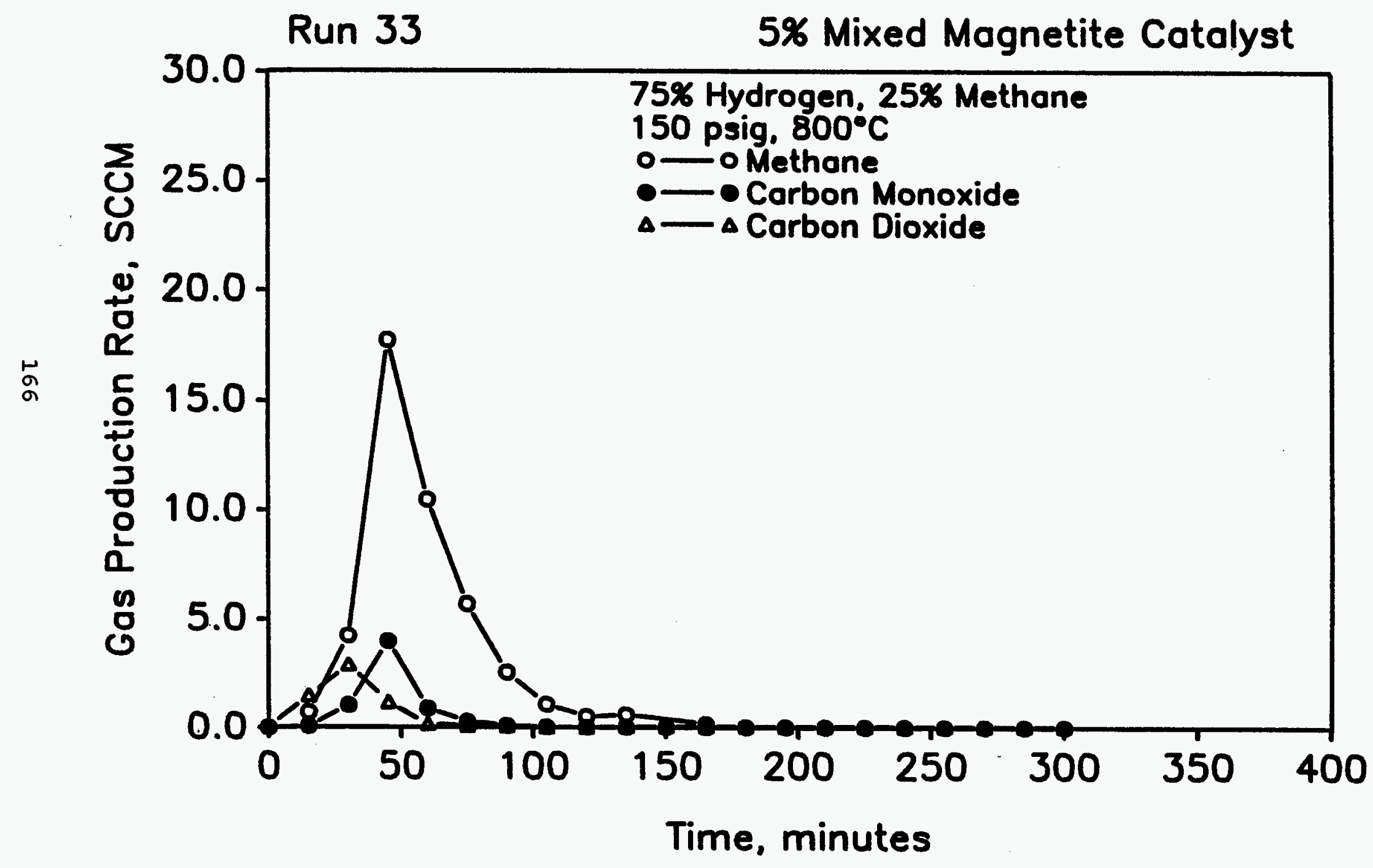




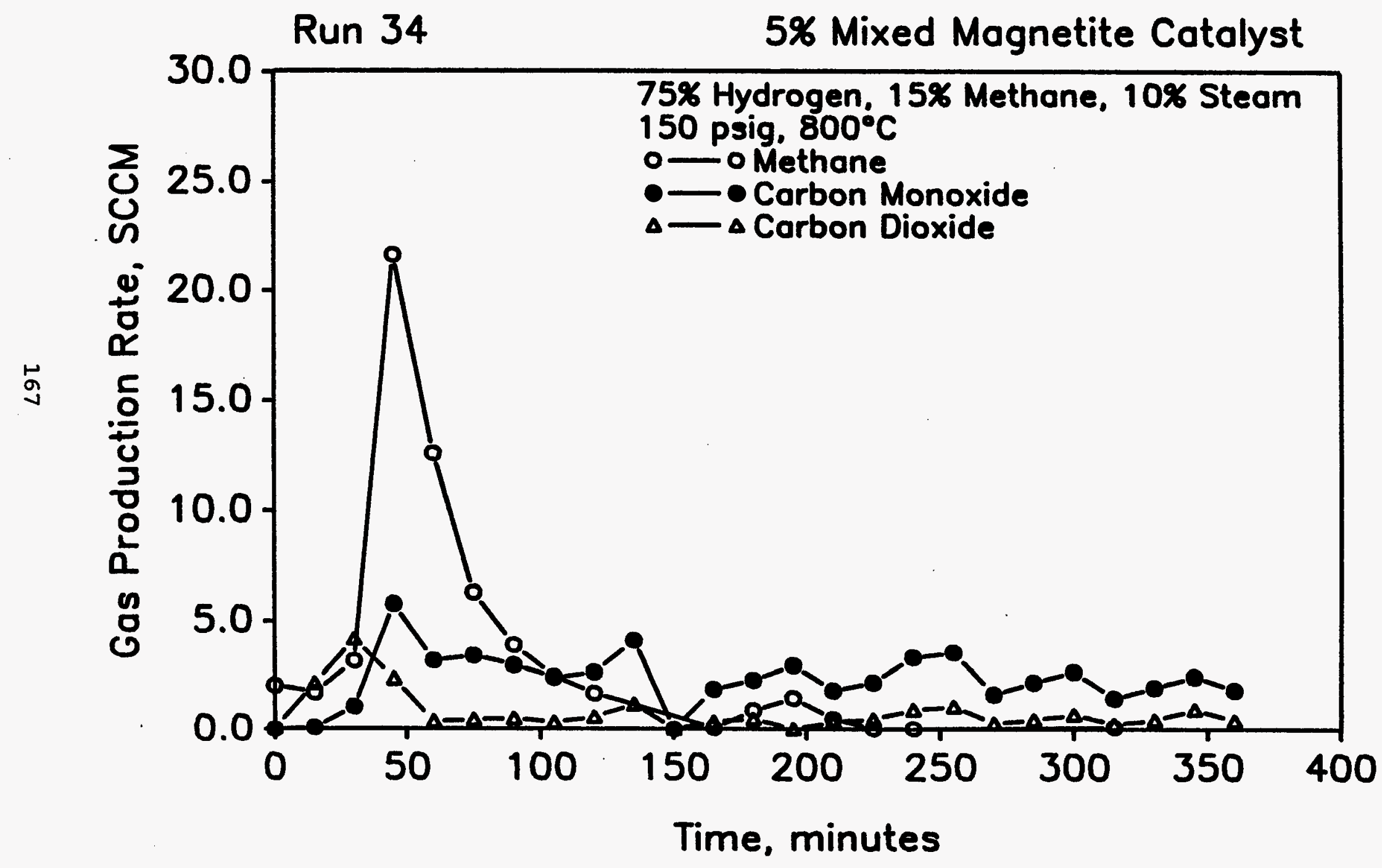


APPENDIX D

RESULTS OF BENCH-SCALE CHAR GASIFICATION TESTS 

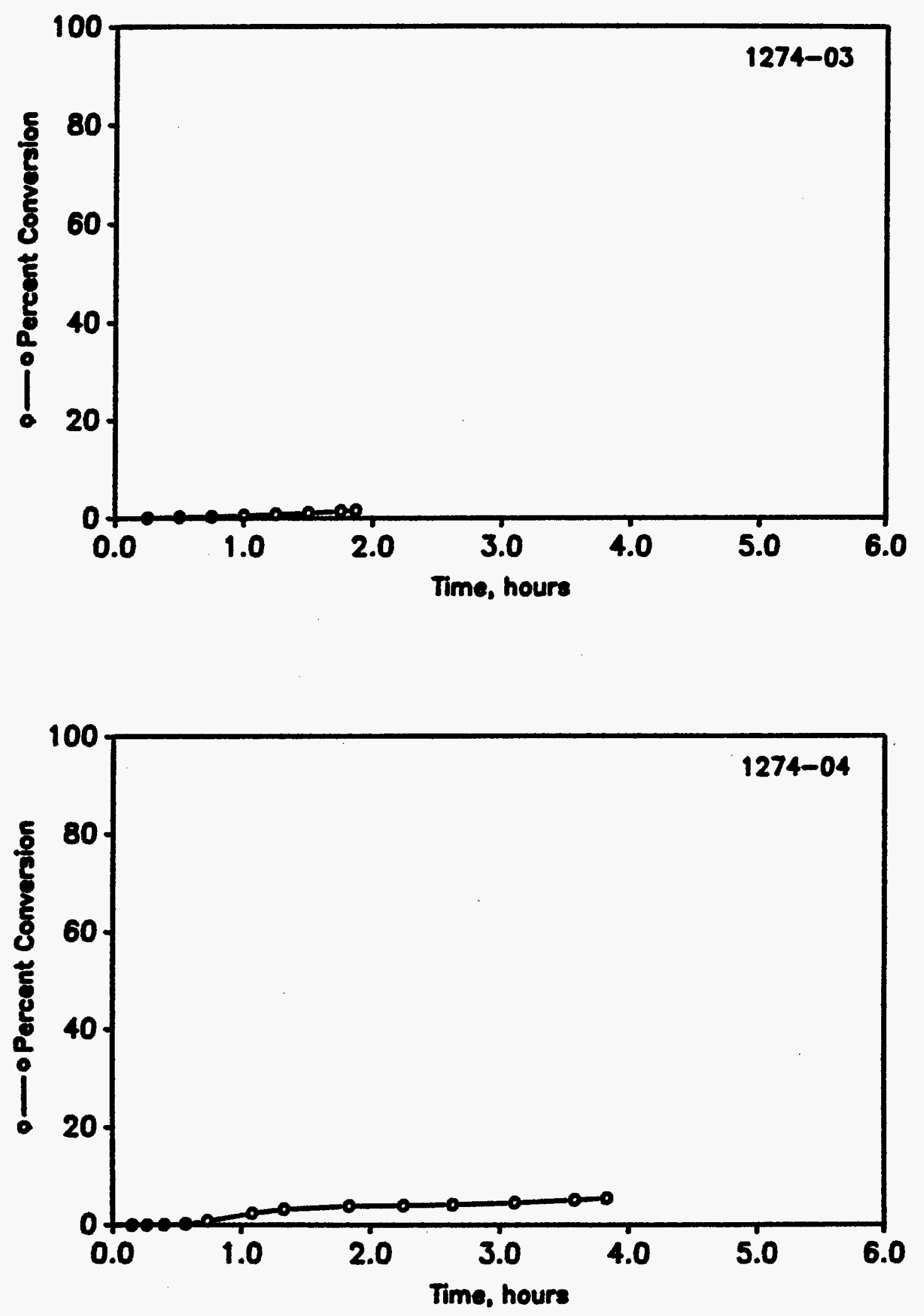

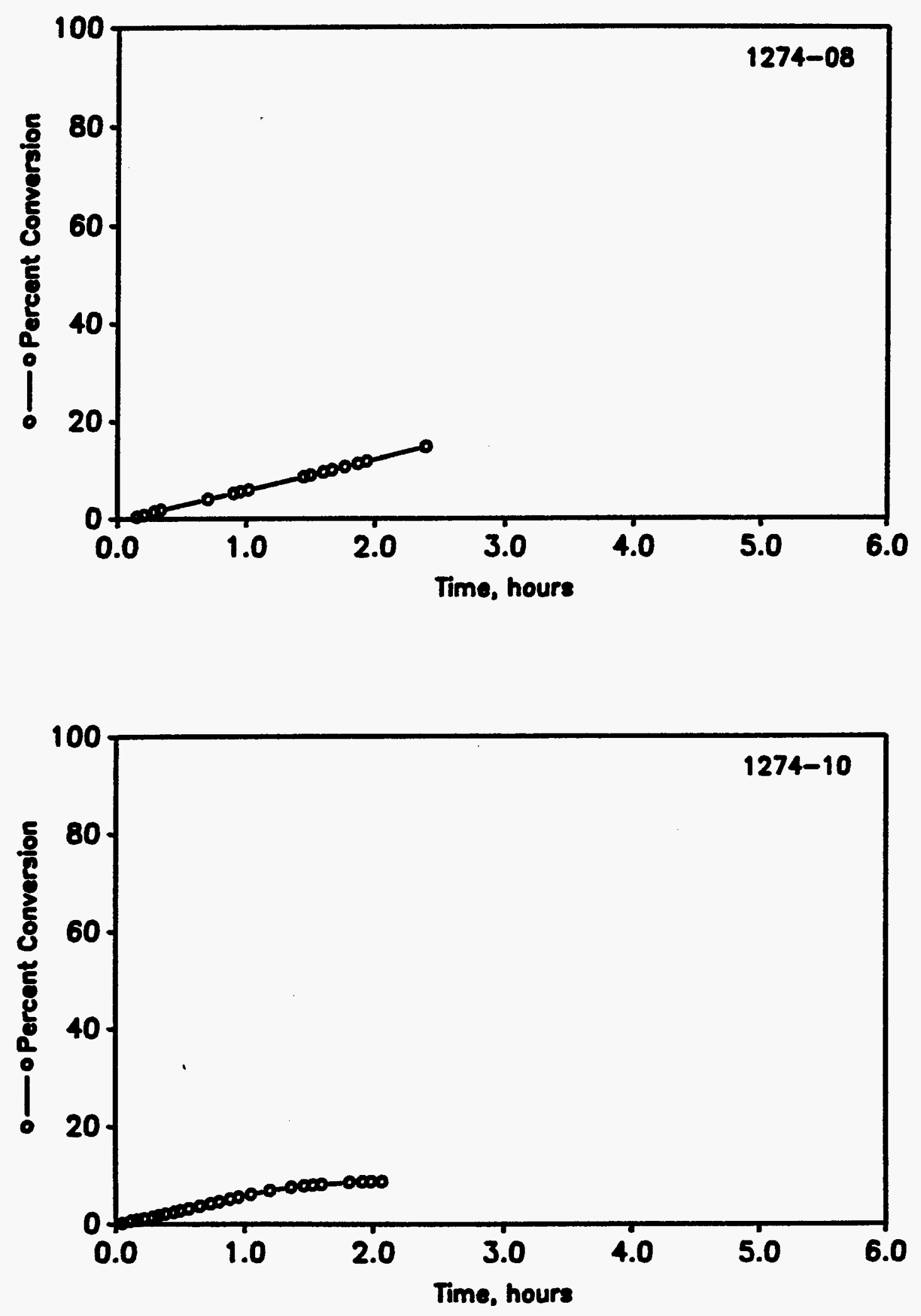

170 

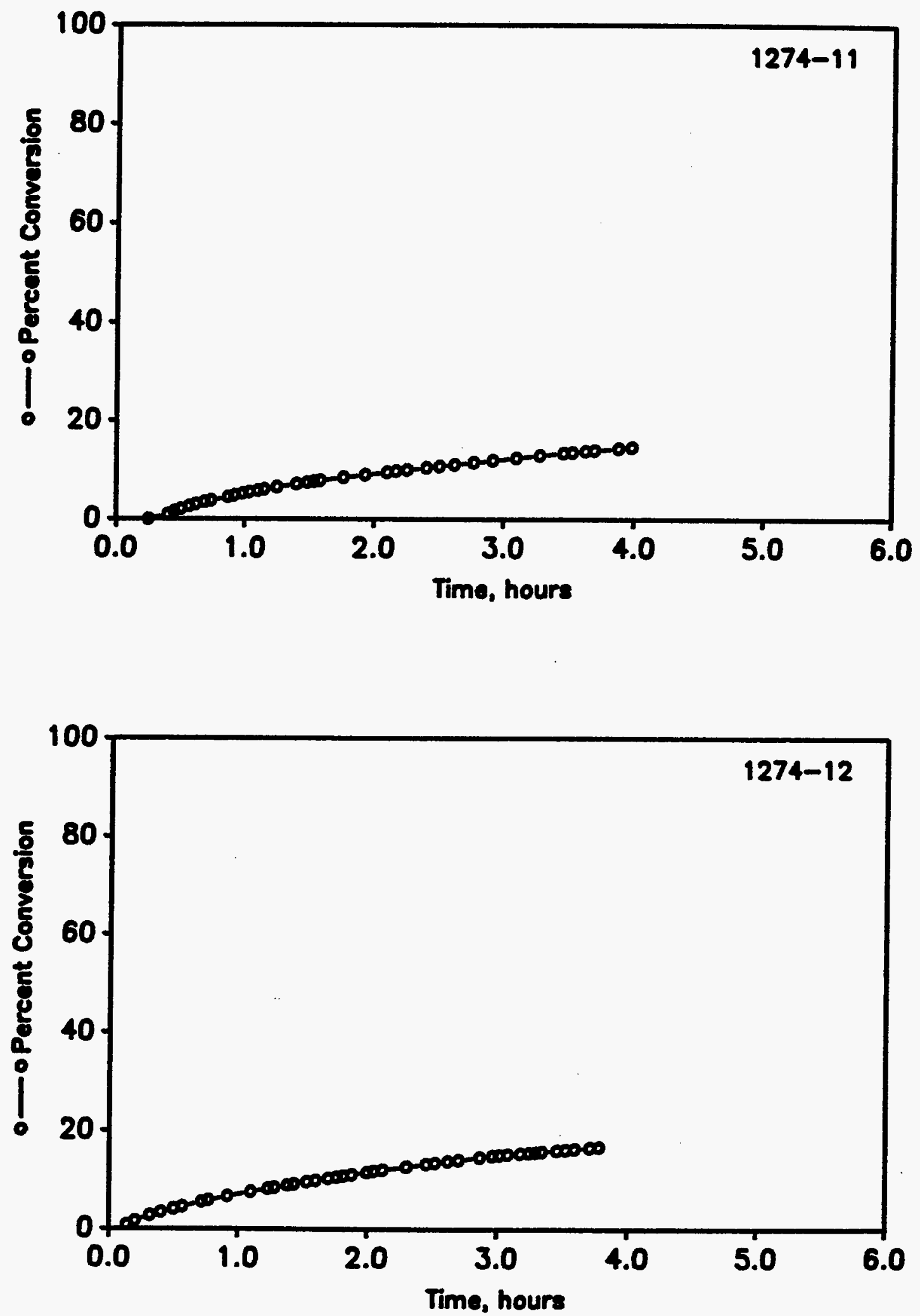

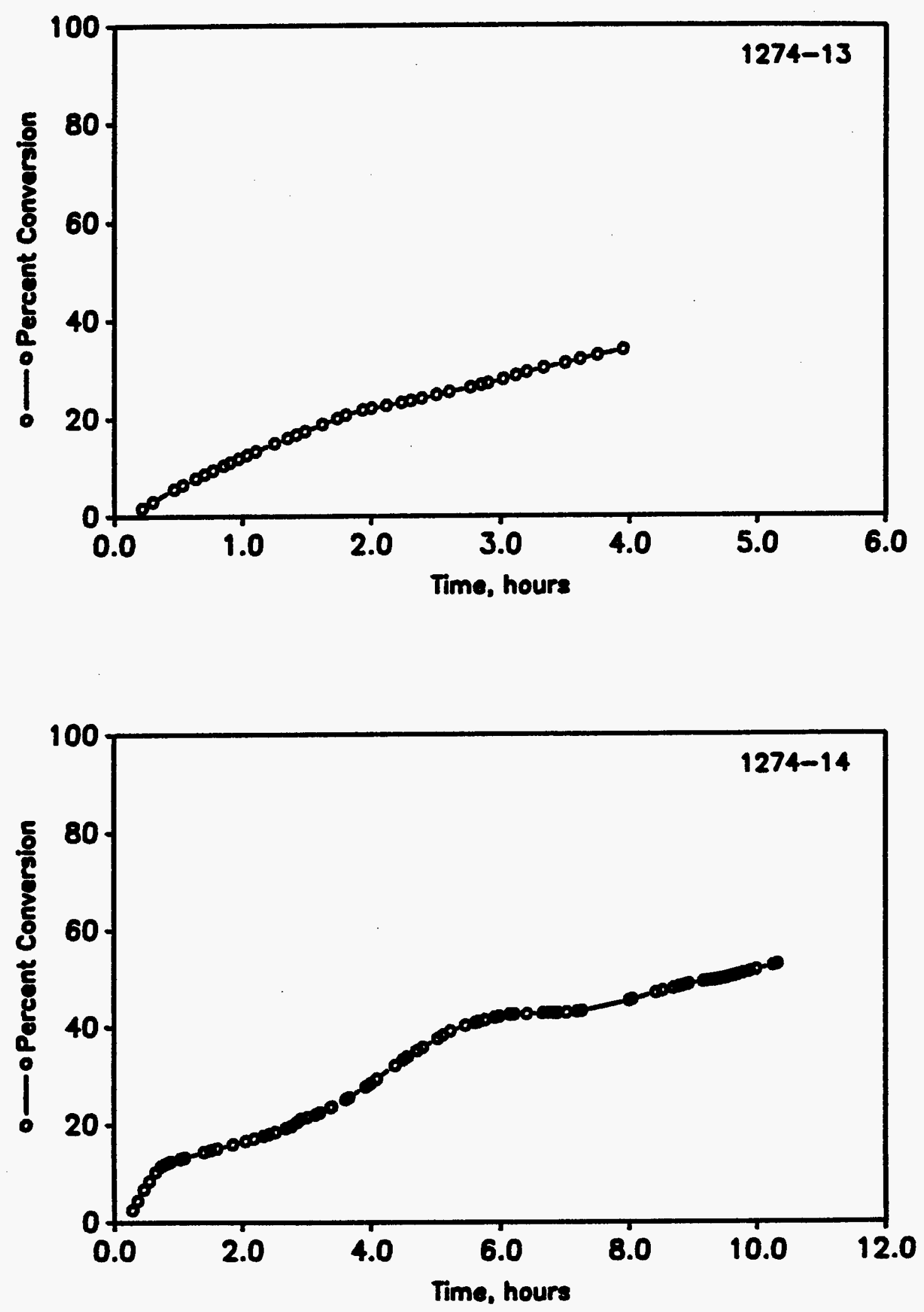

172 

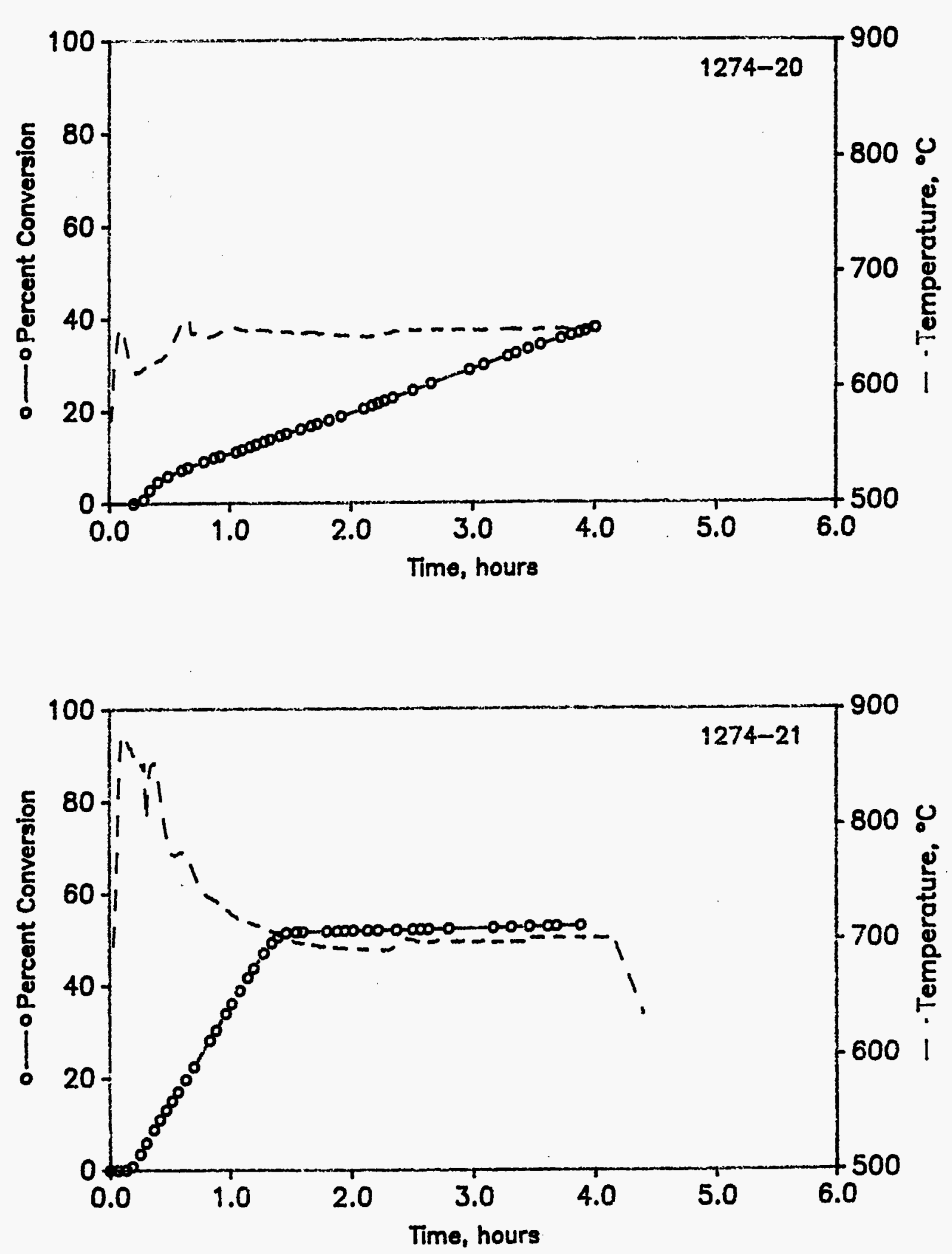

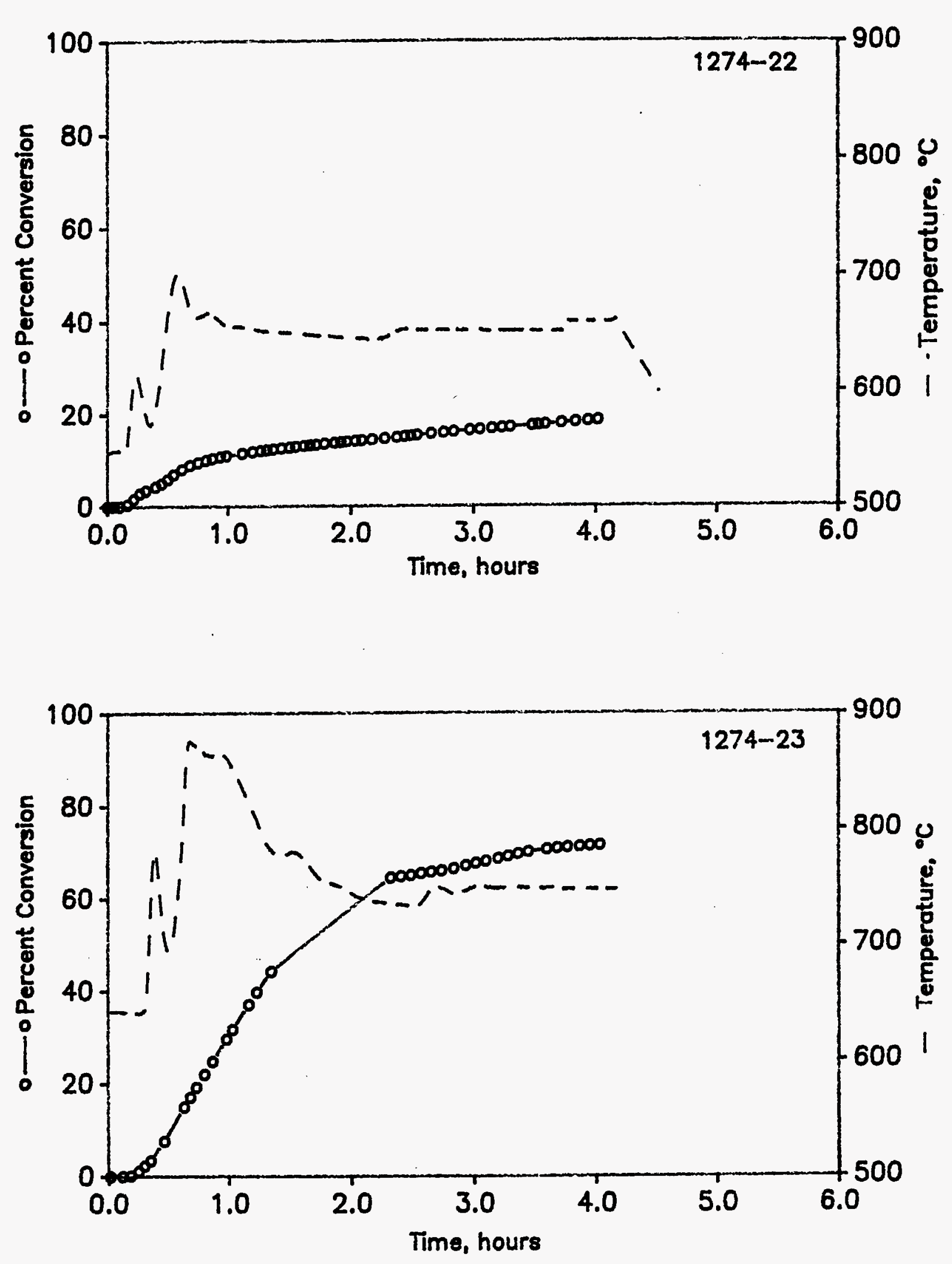

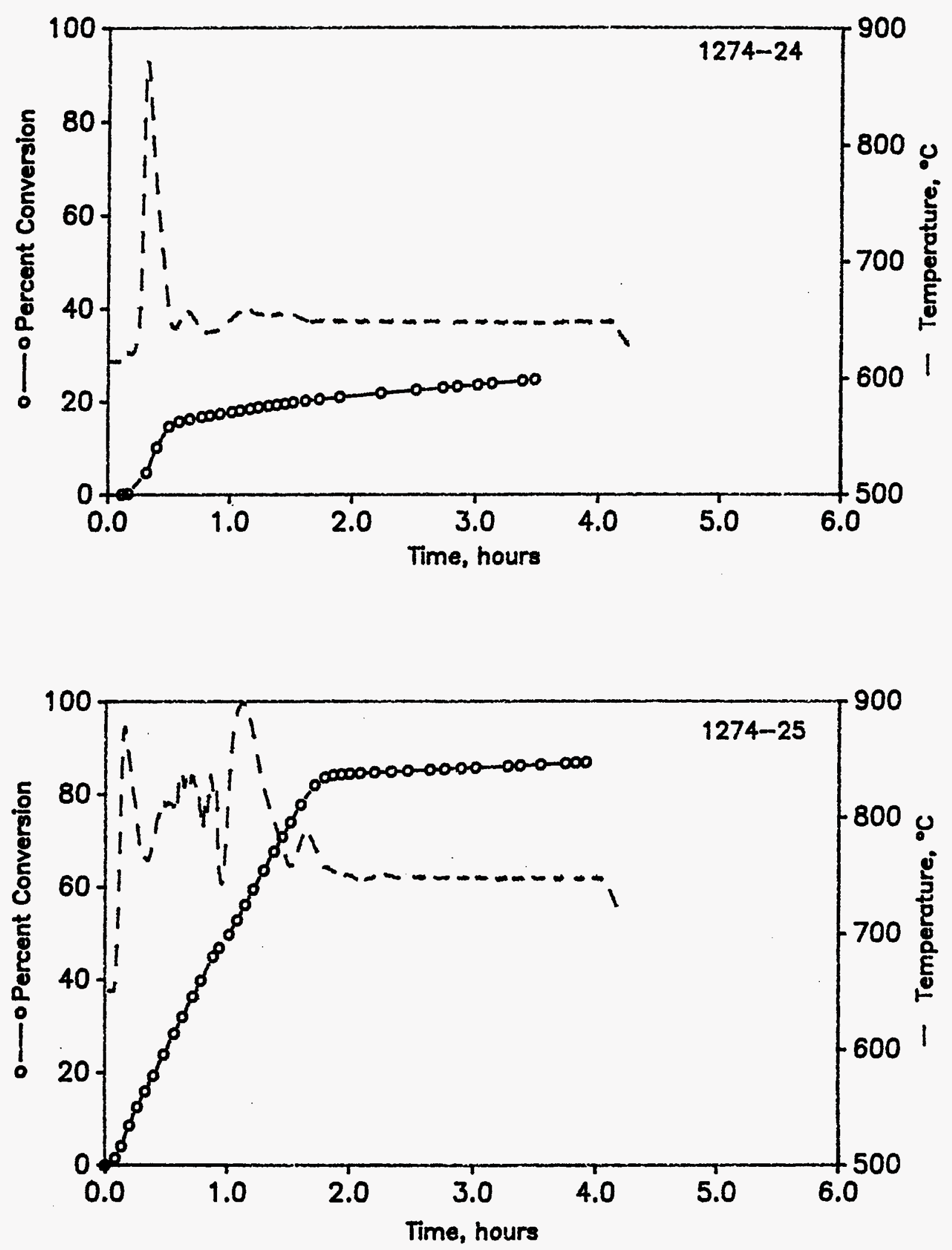

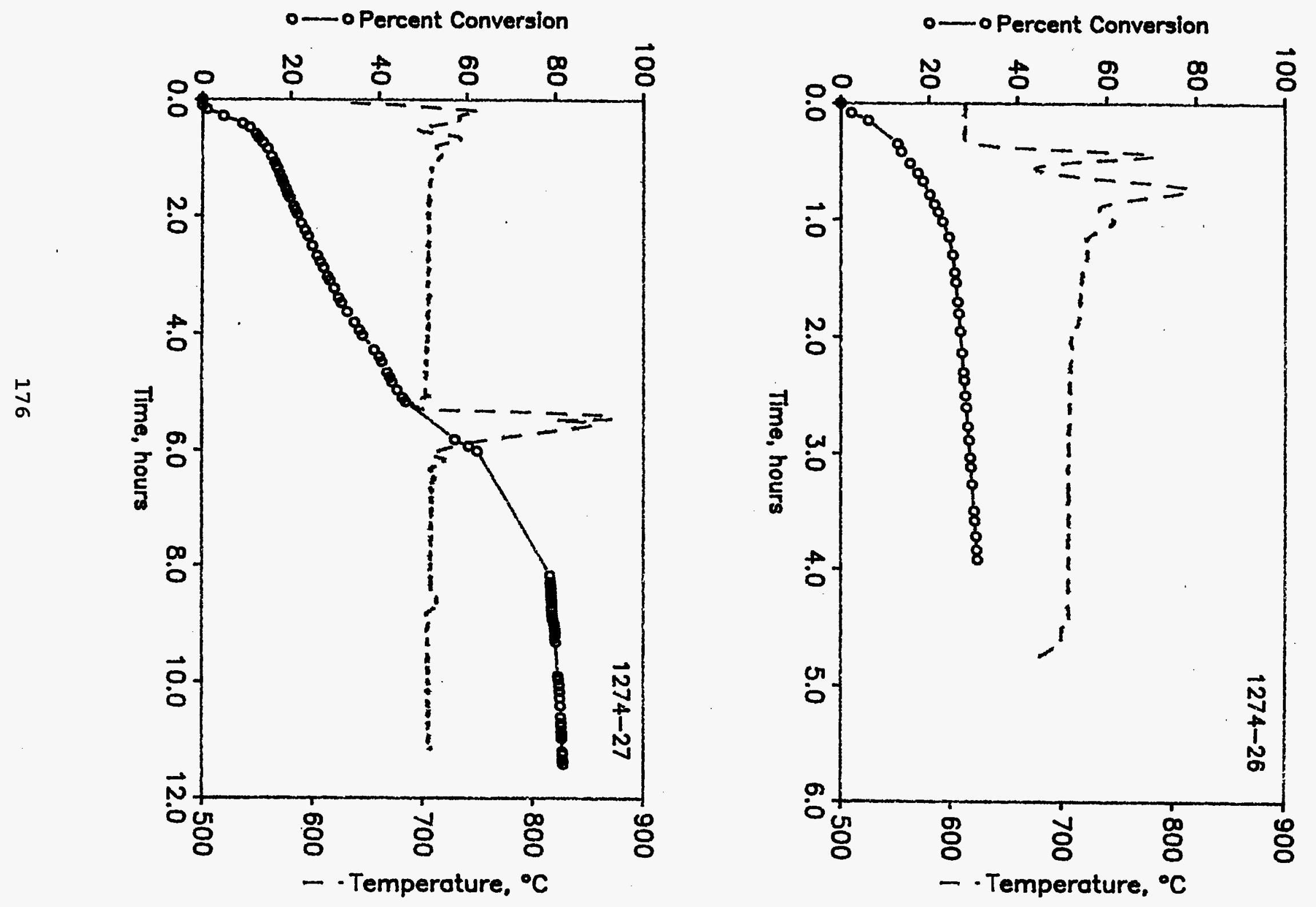

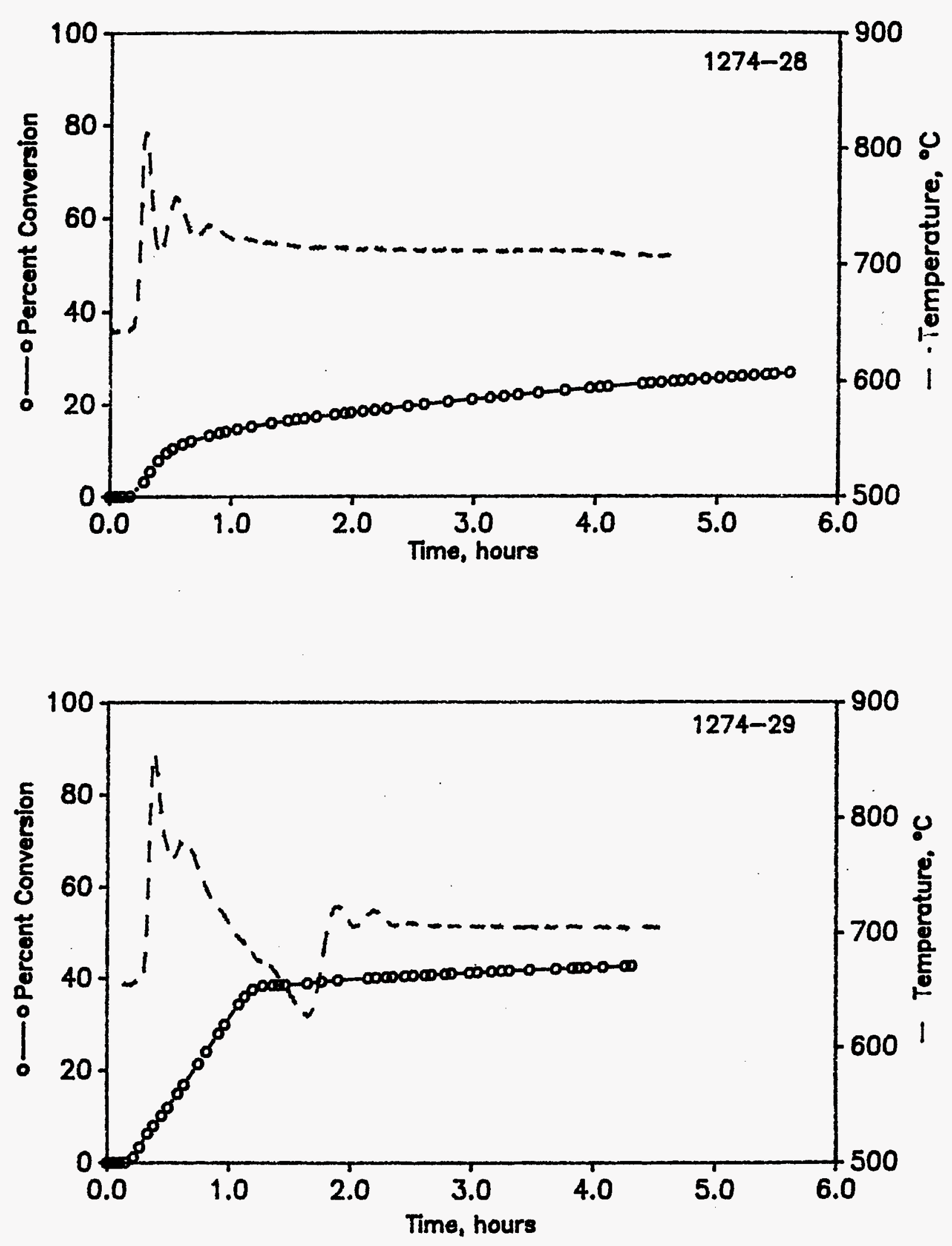

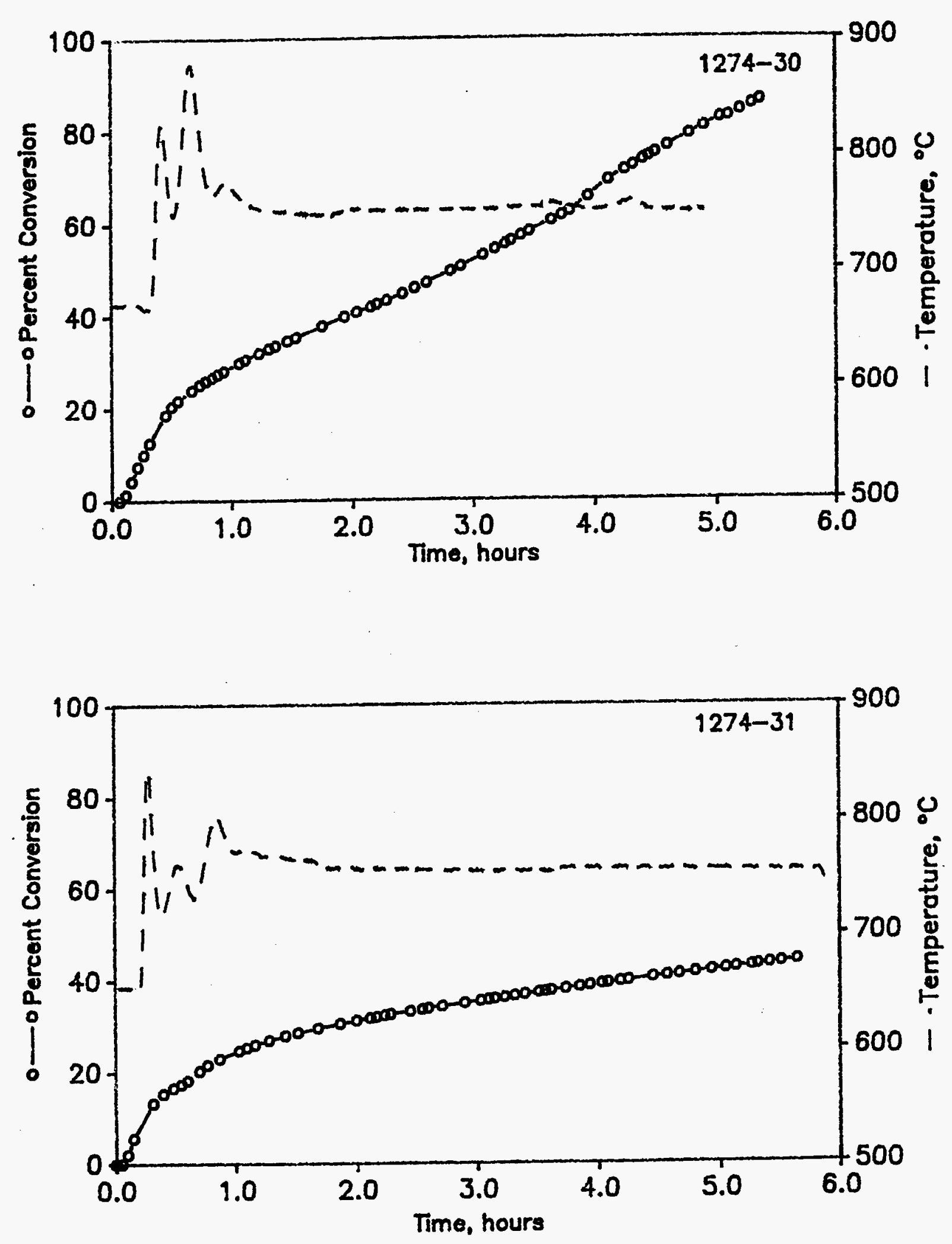

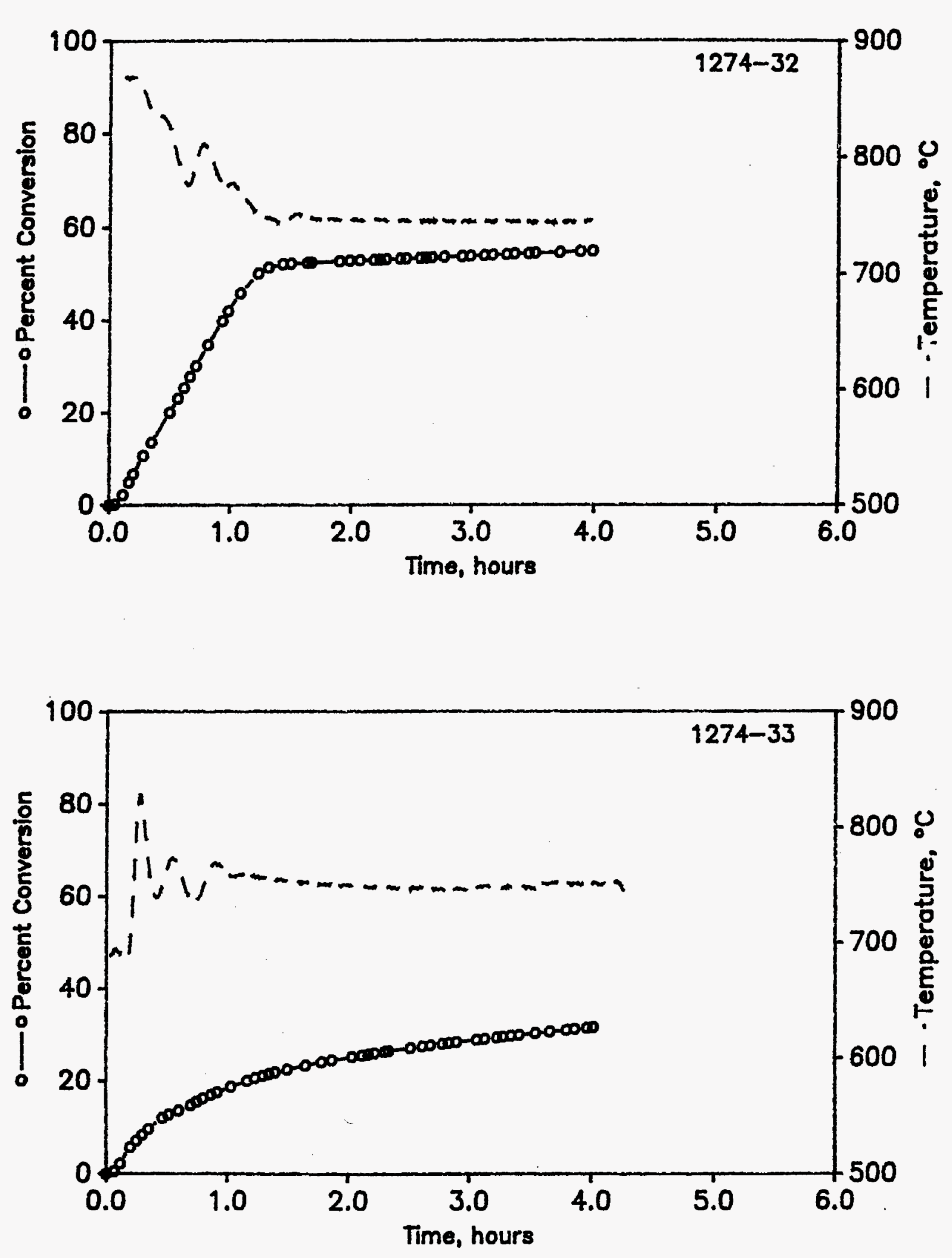

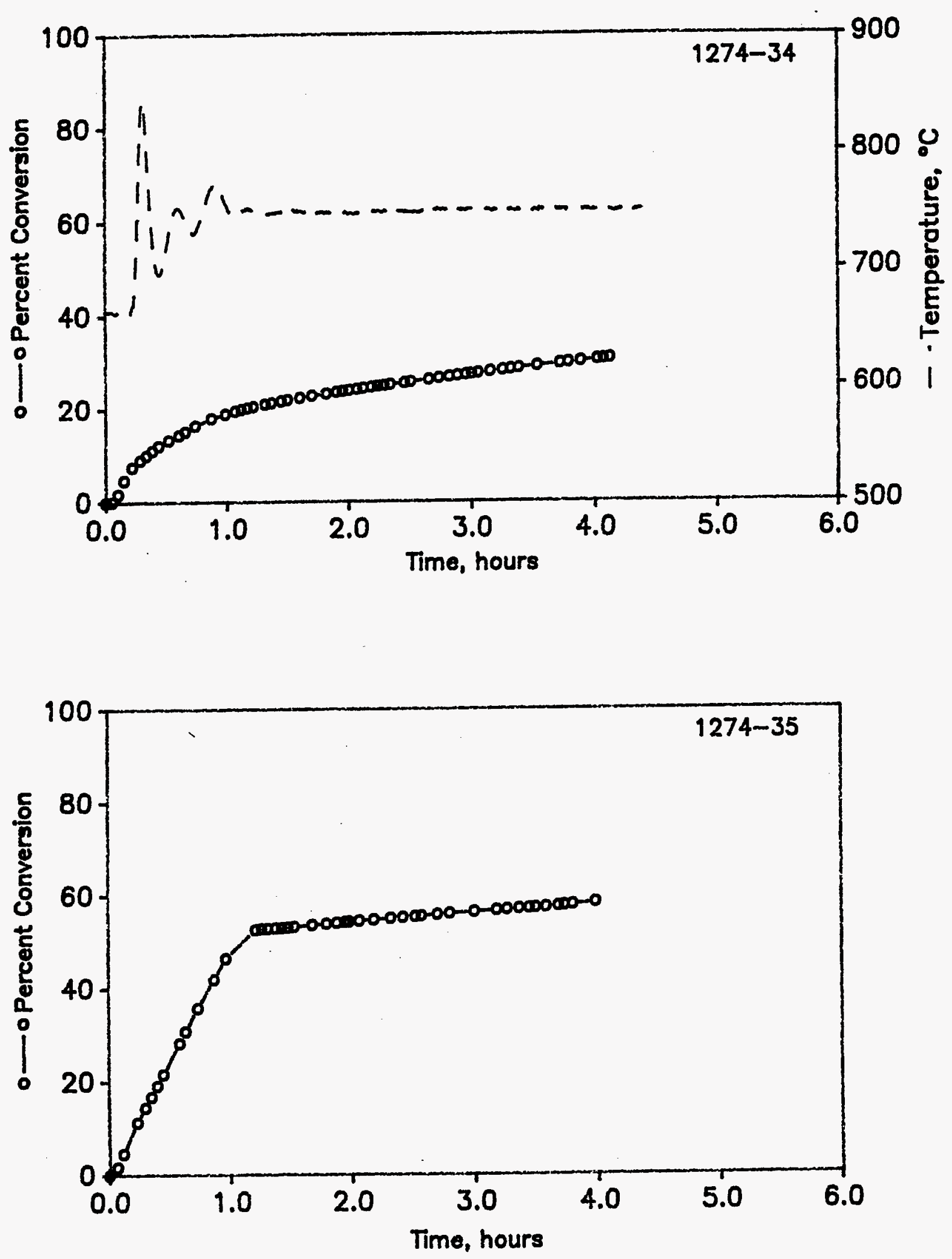

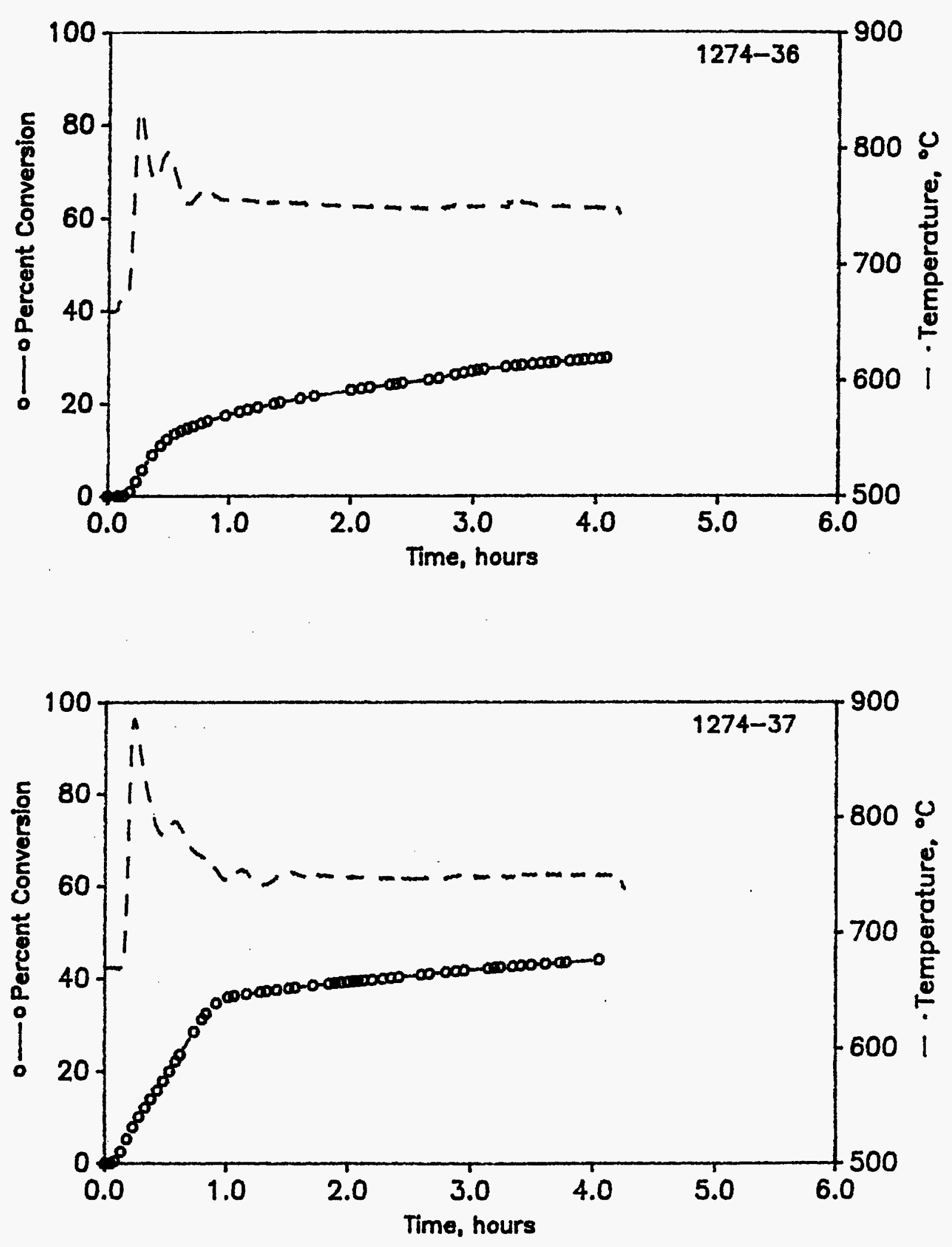

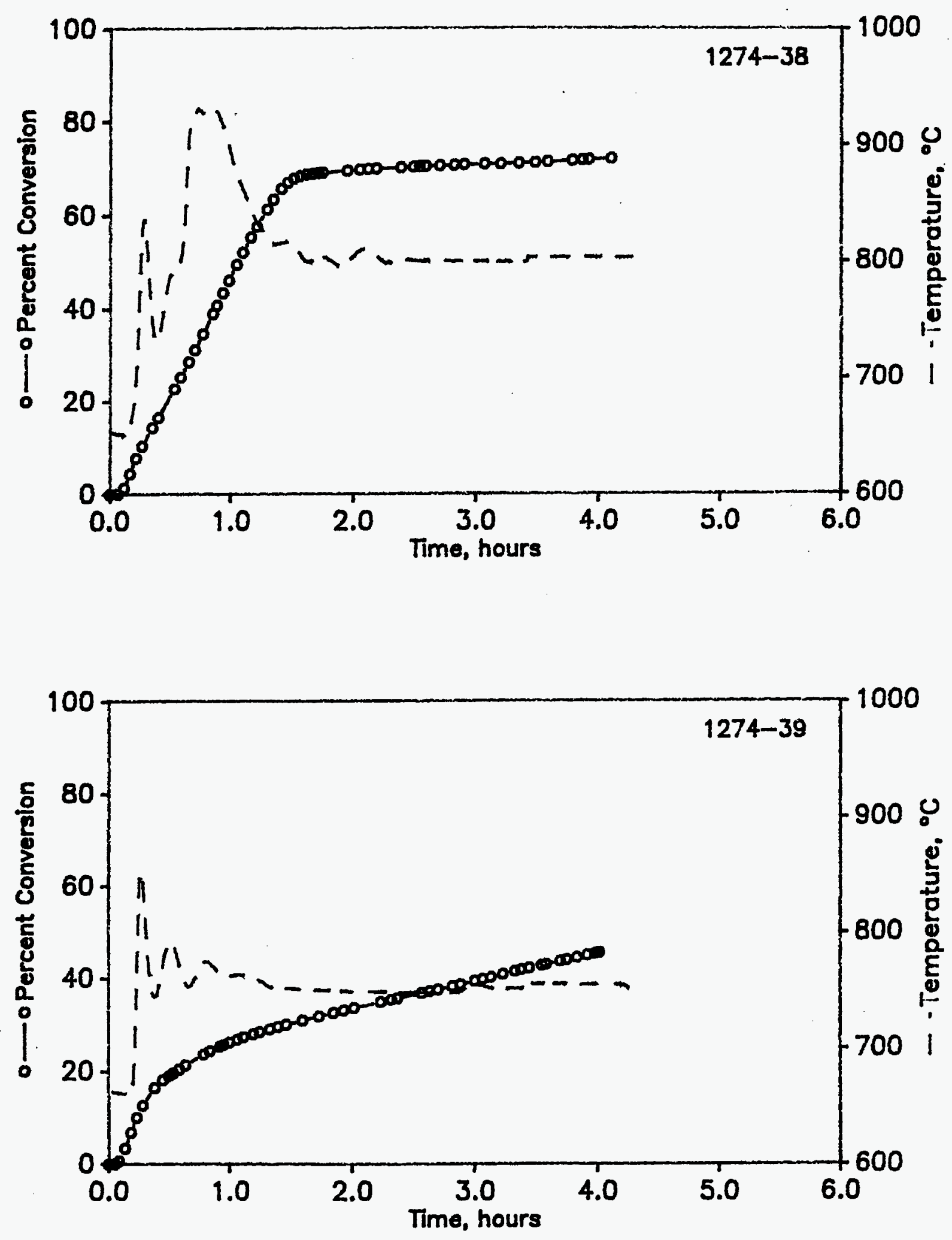

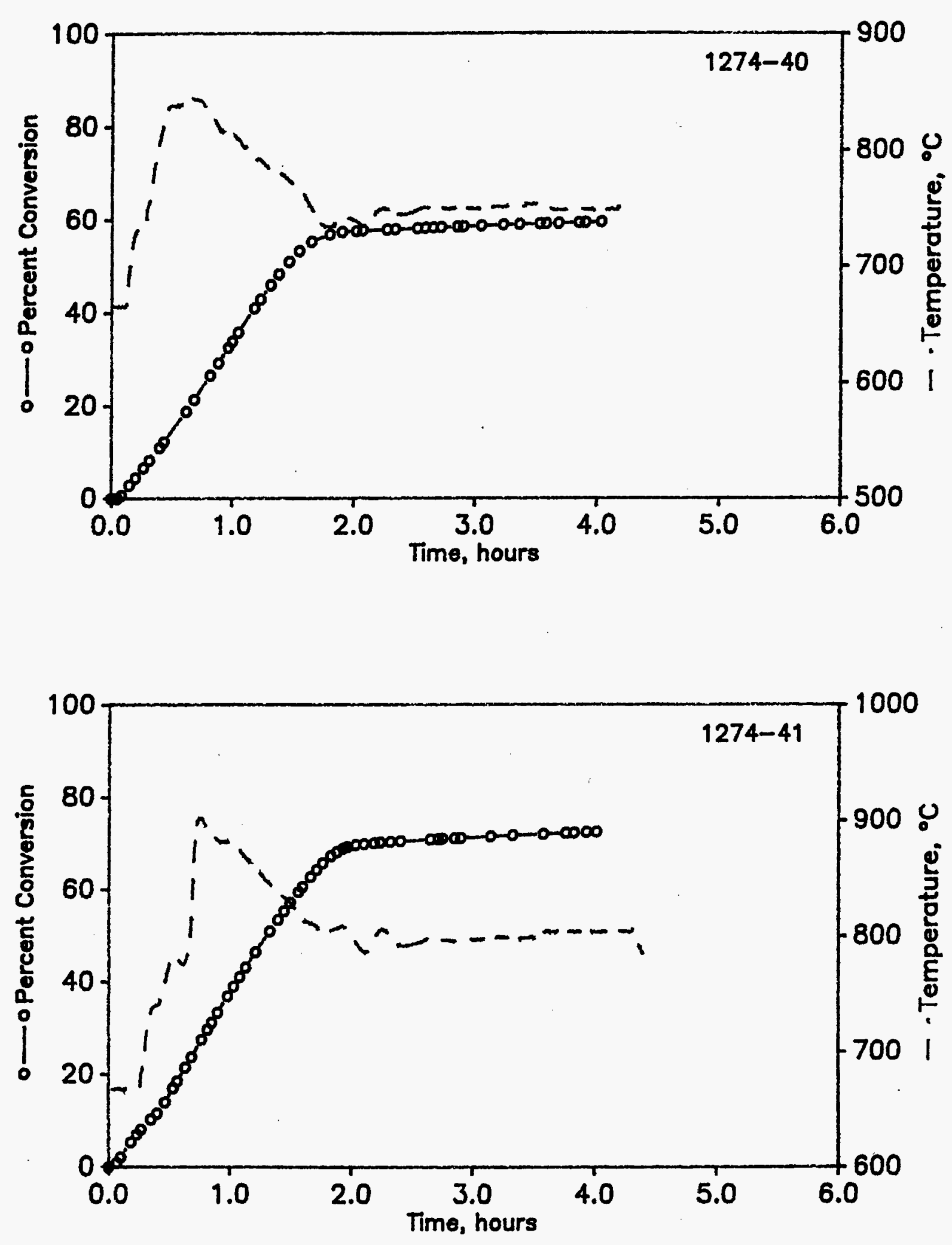

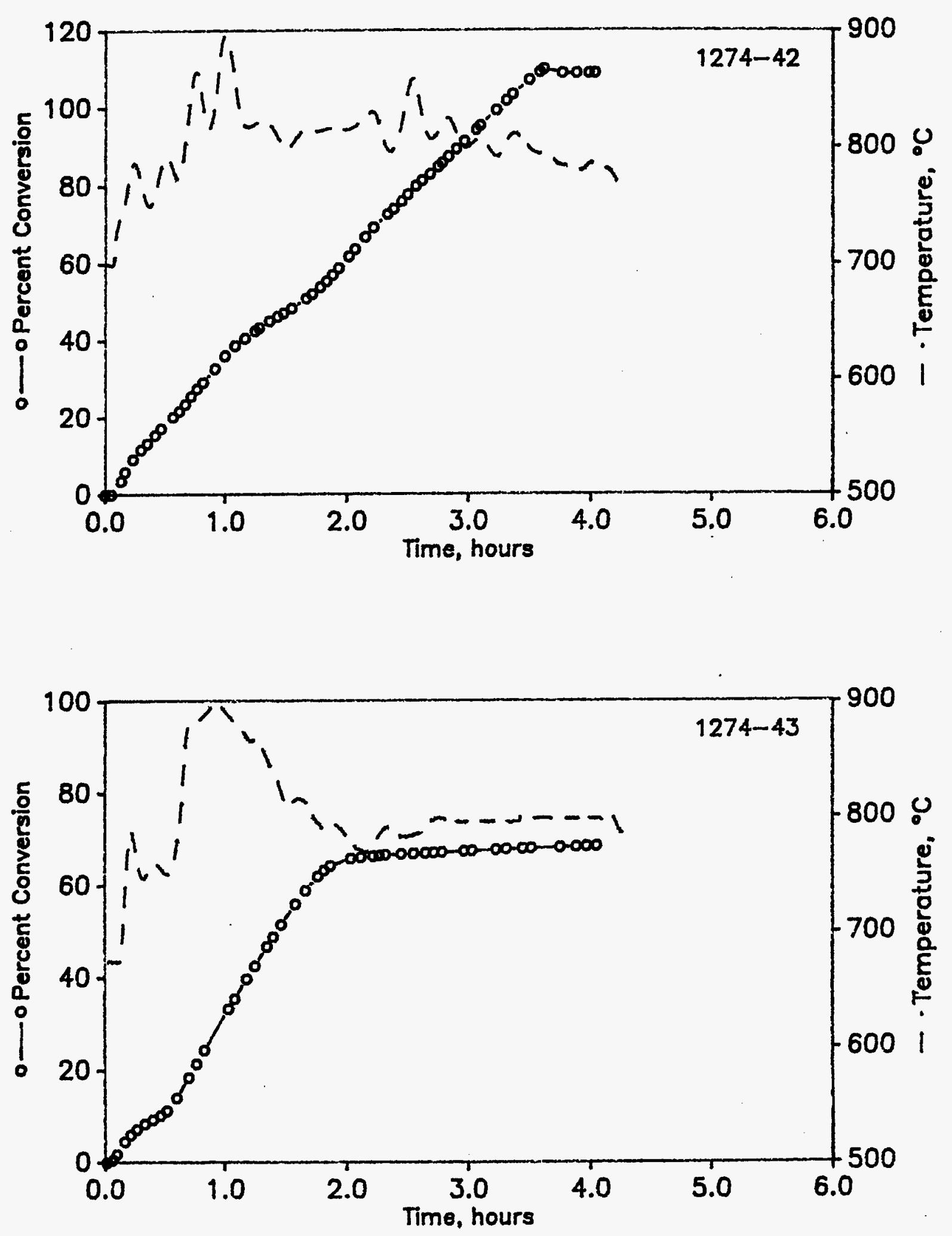

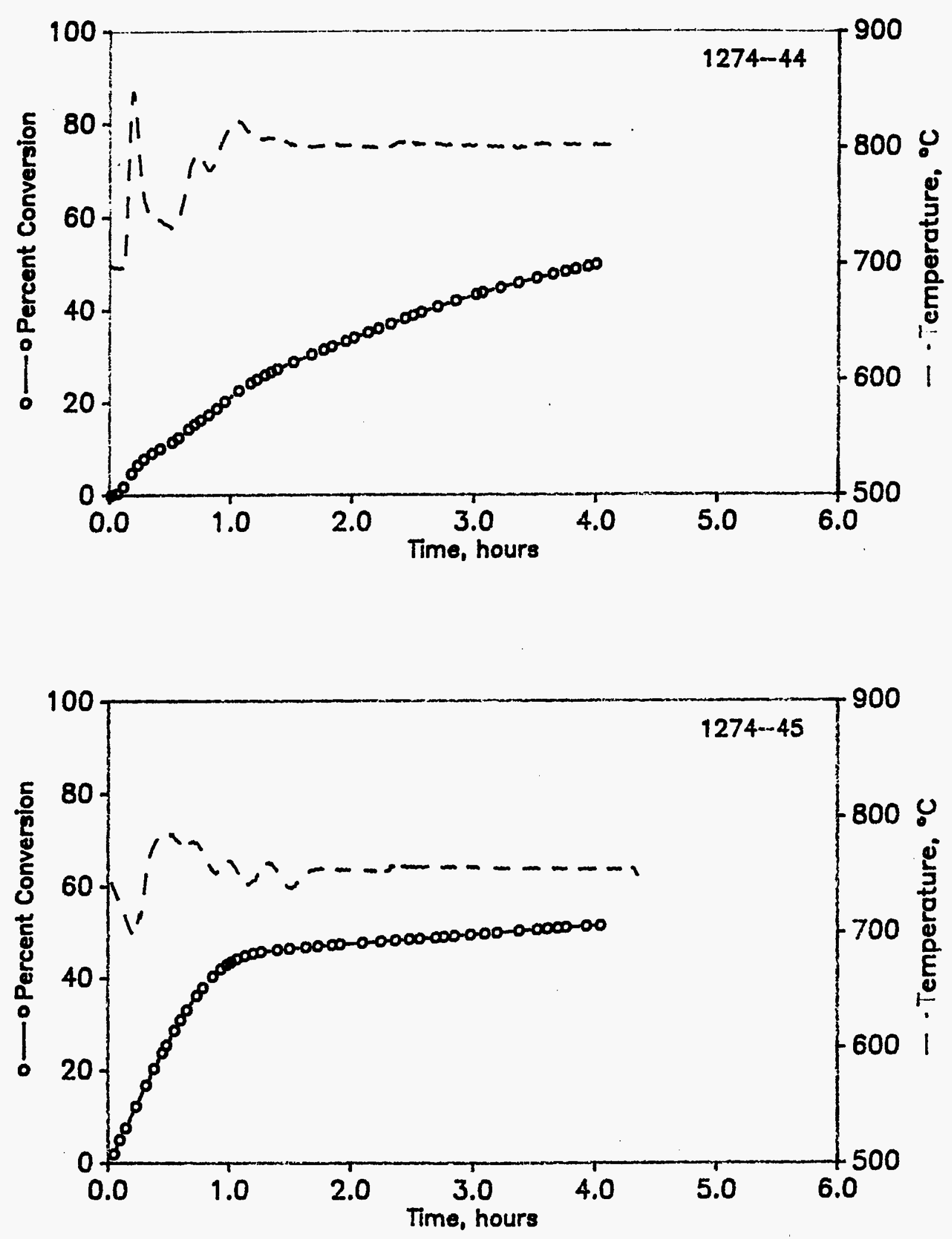

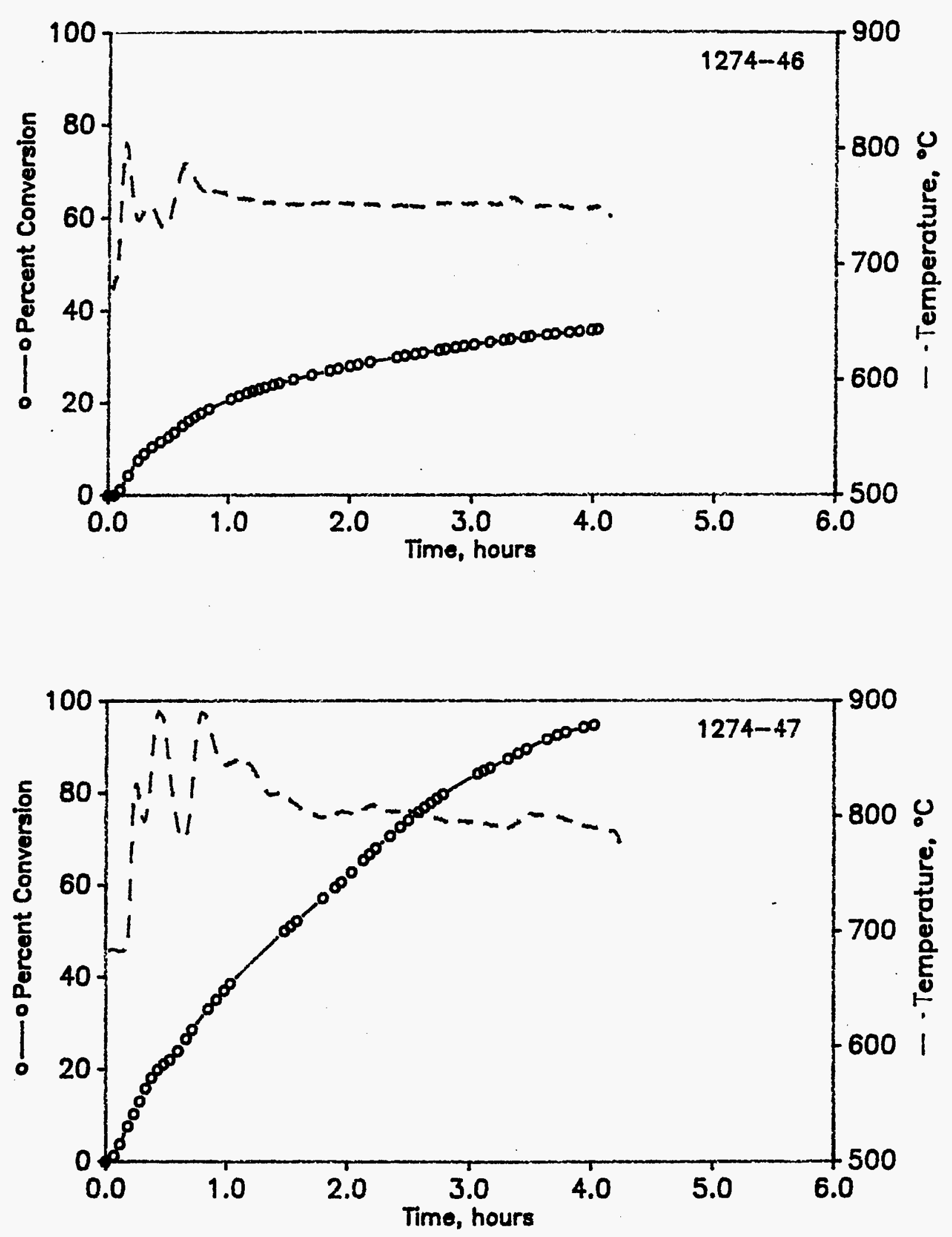

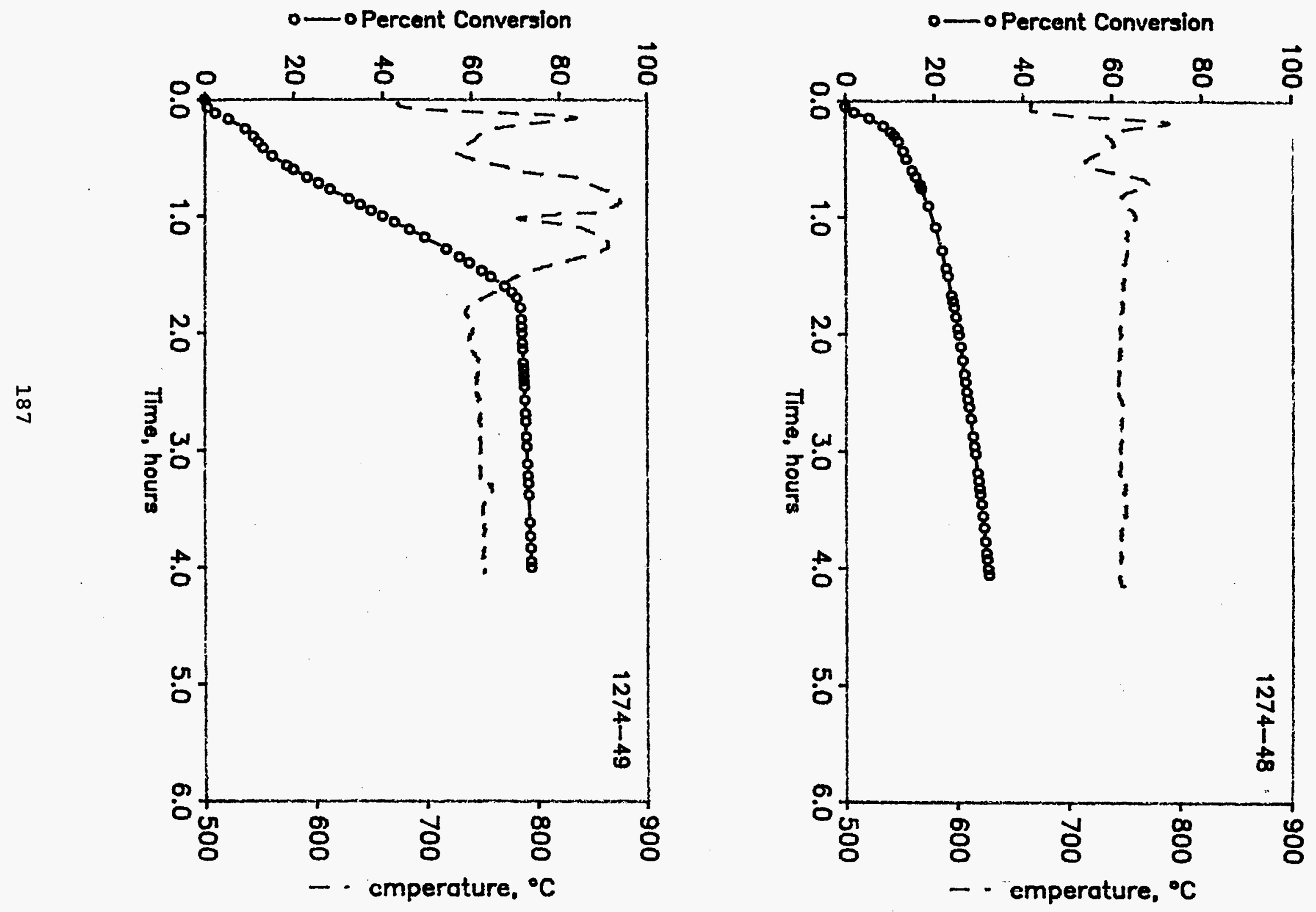

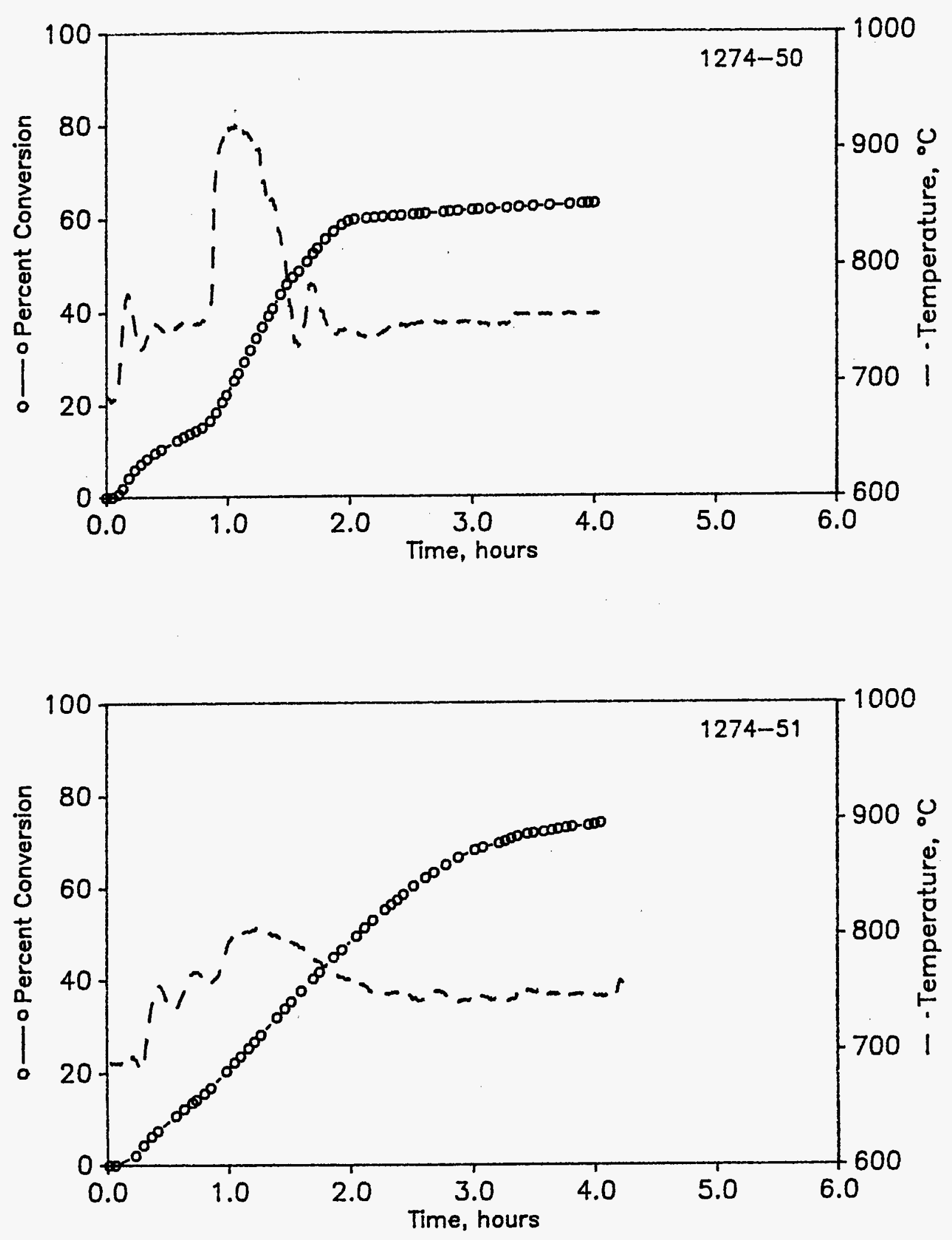

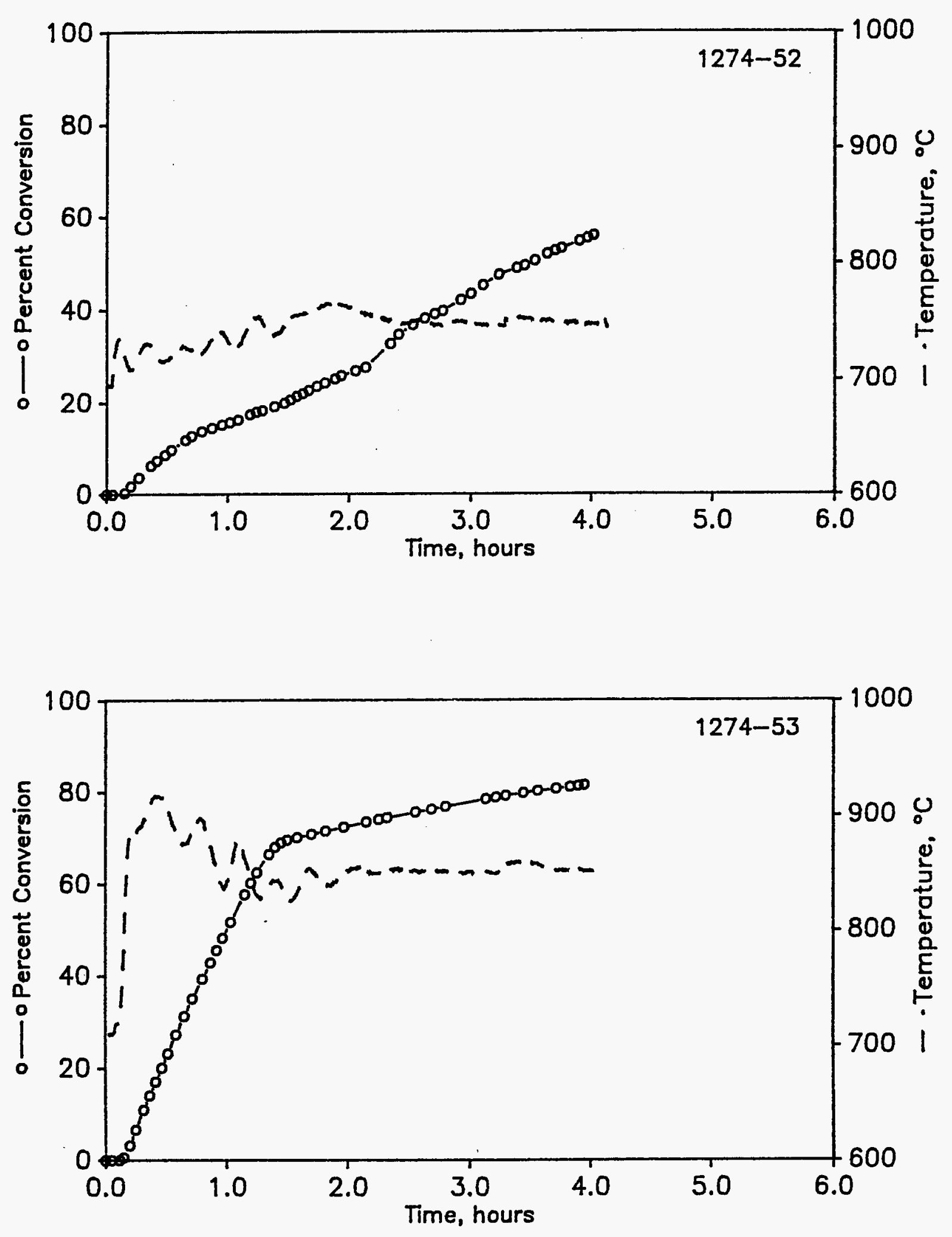

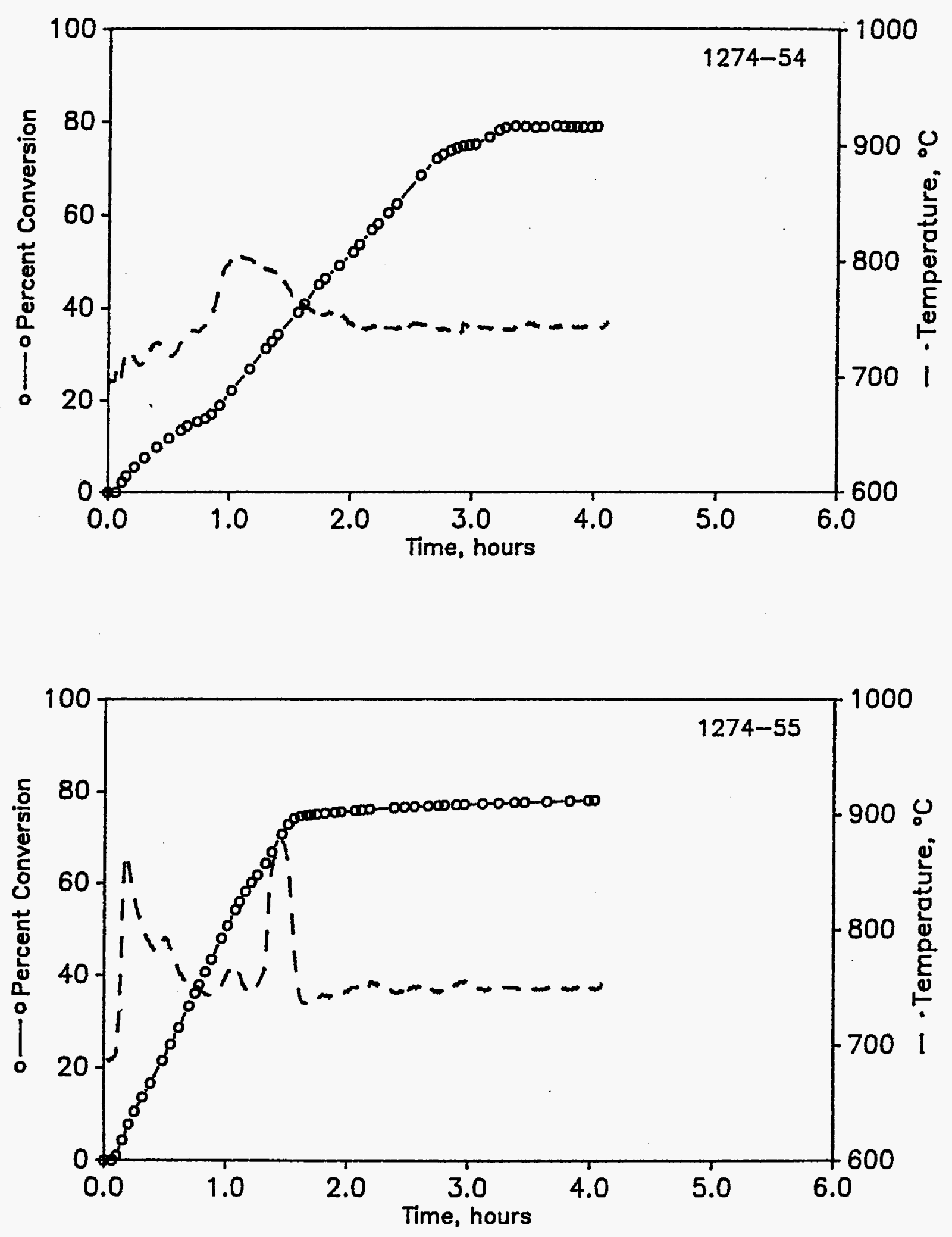

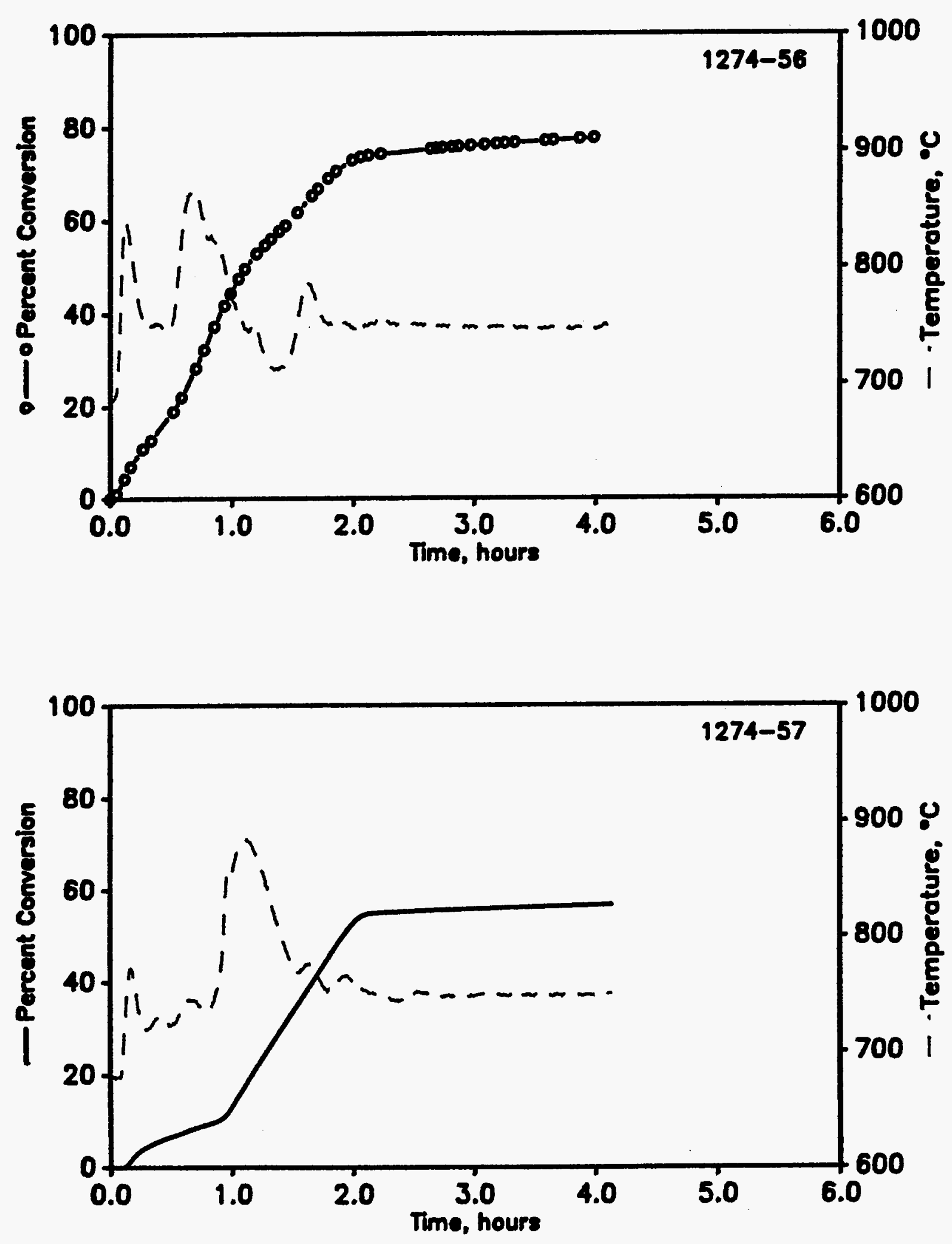

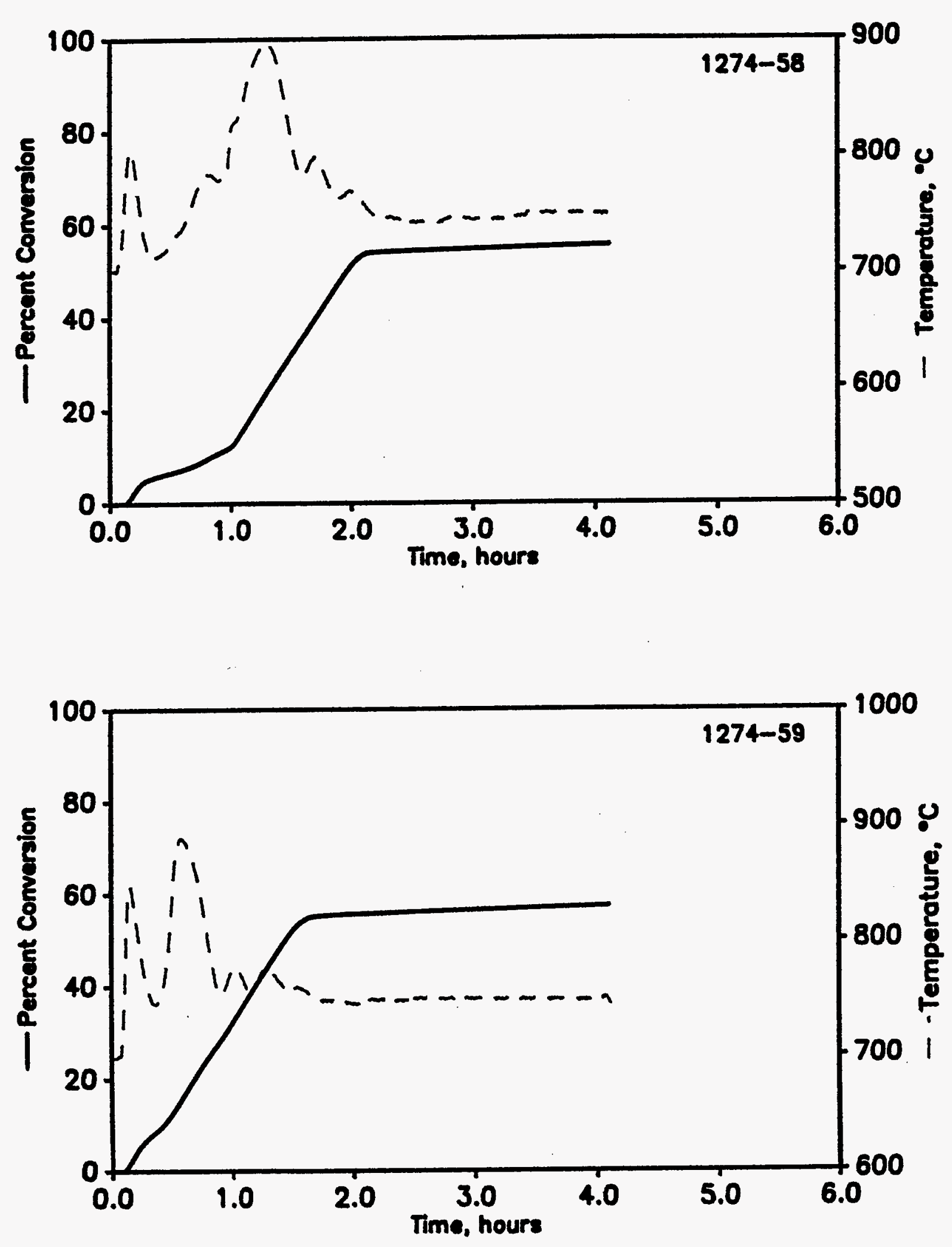

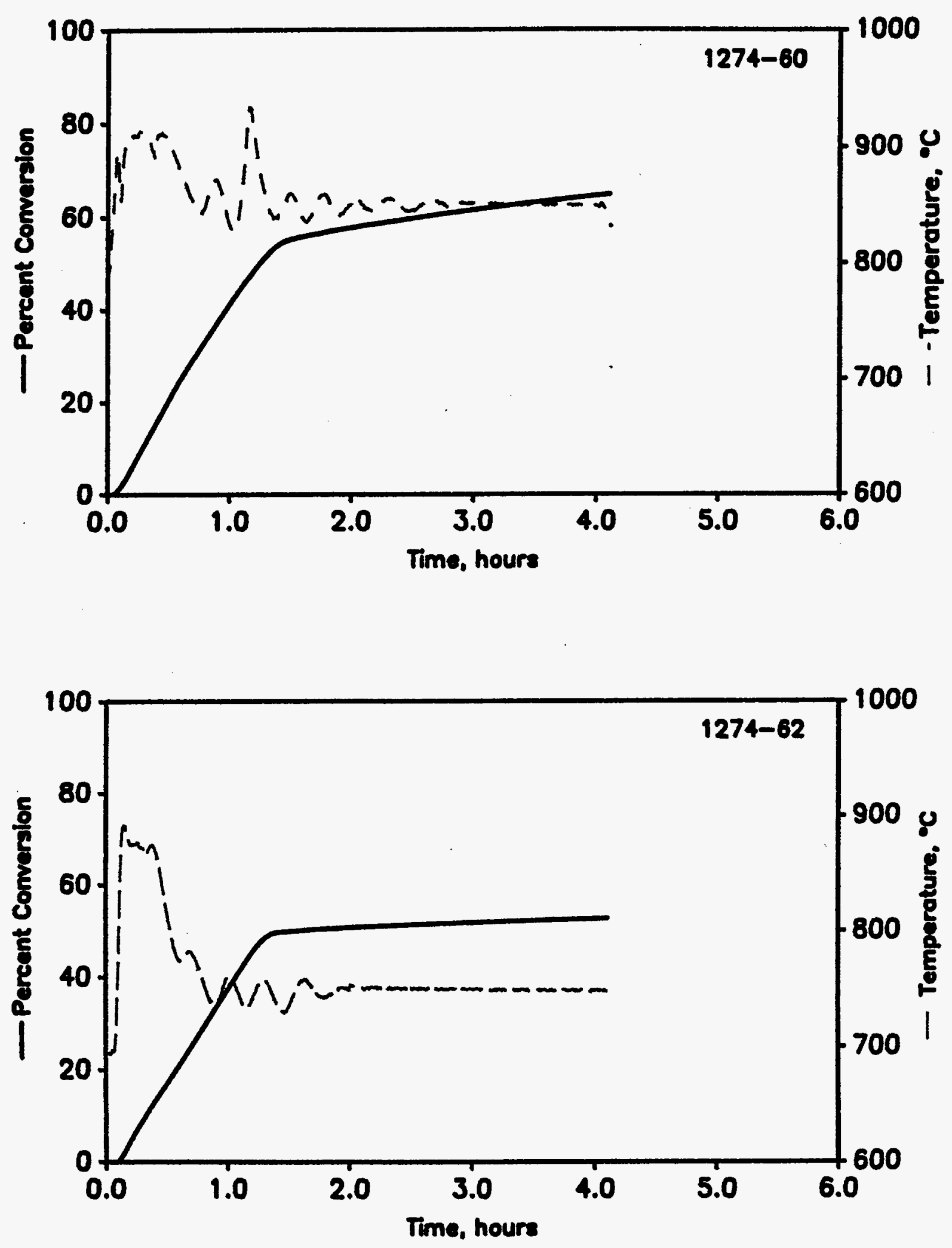

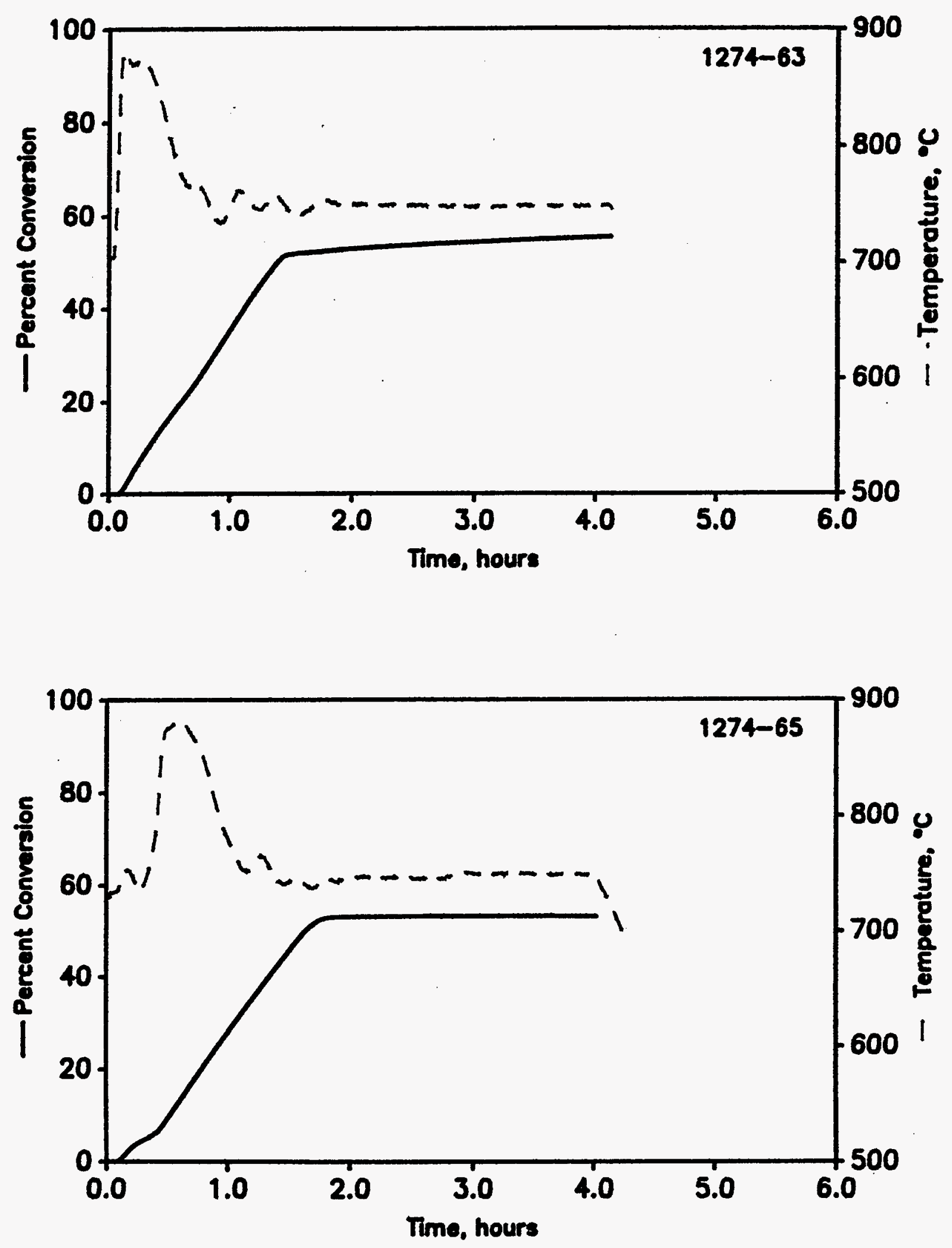


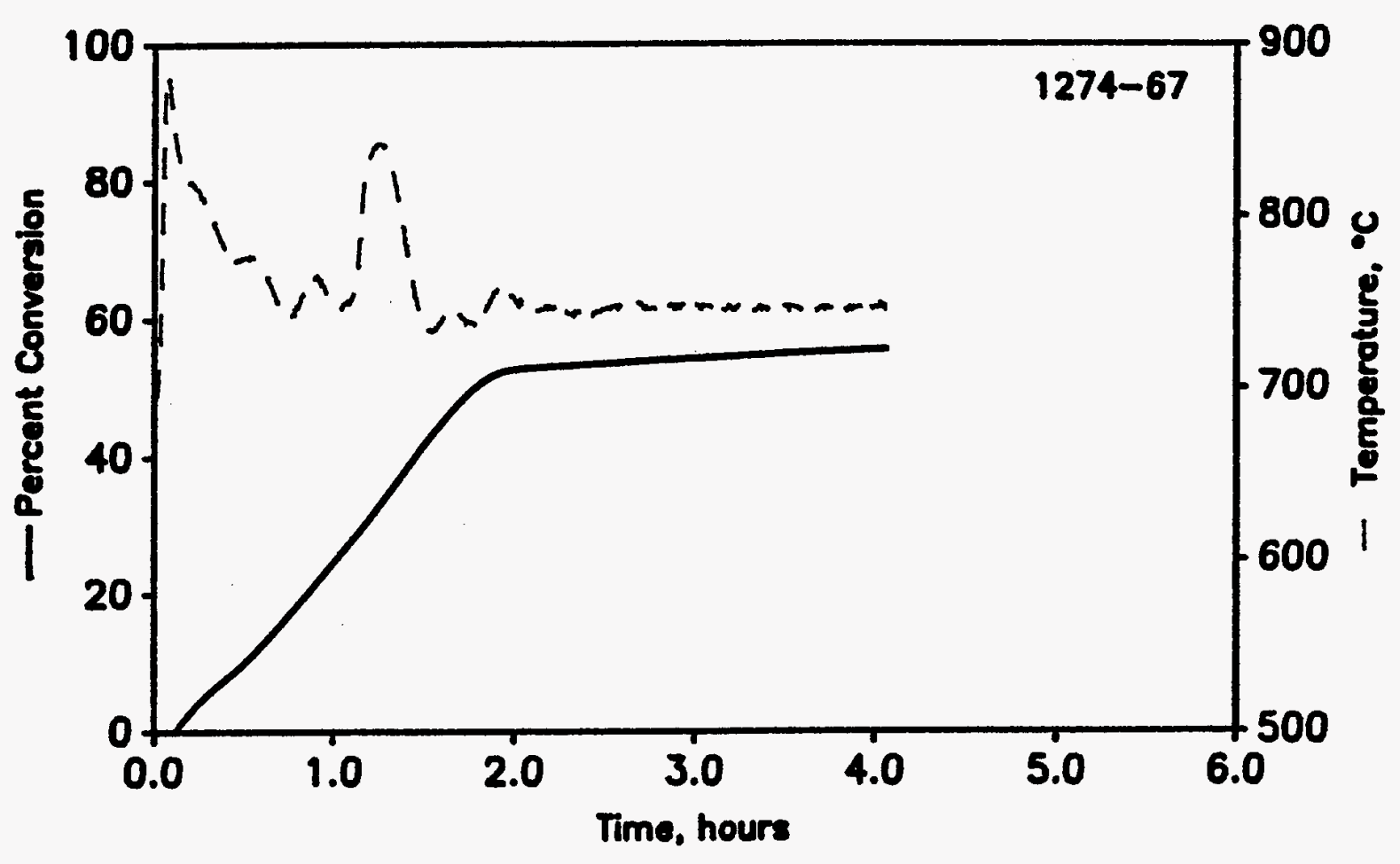


APPENDIX E

PORE SIZE DISTRIBUTIONS FOR SPENT CHARS 


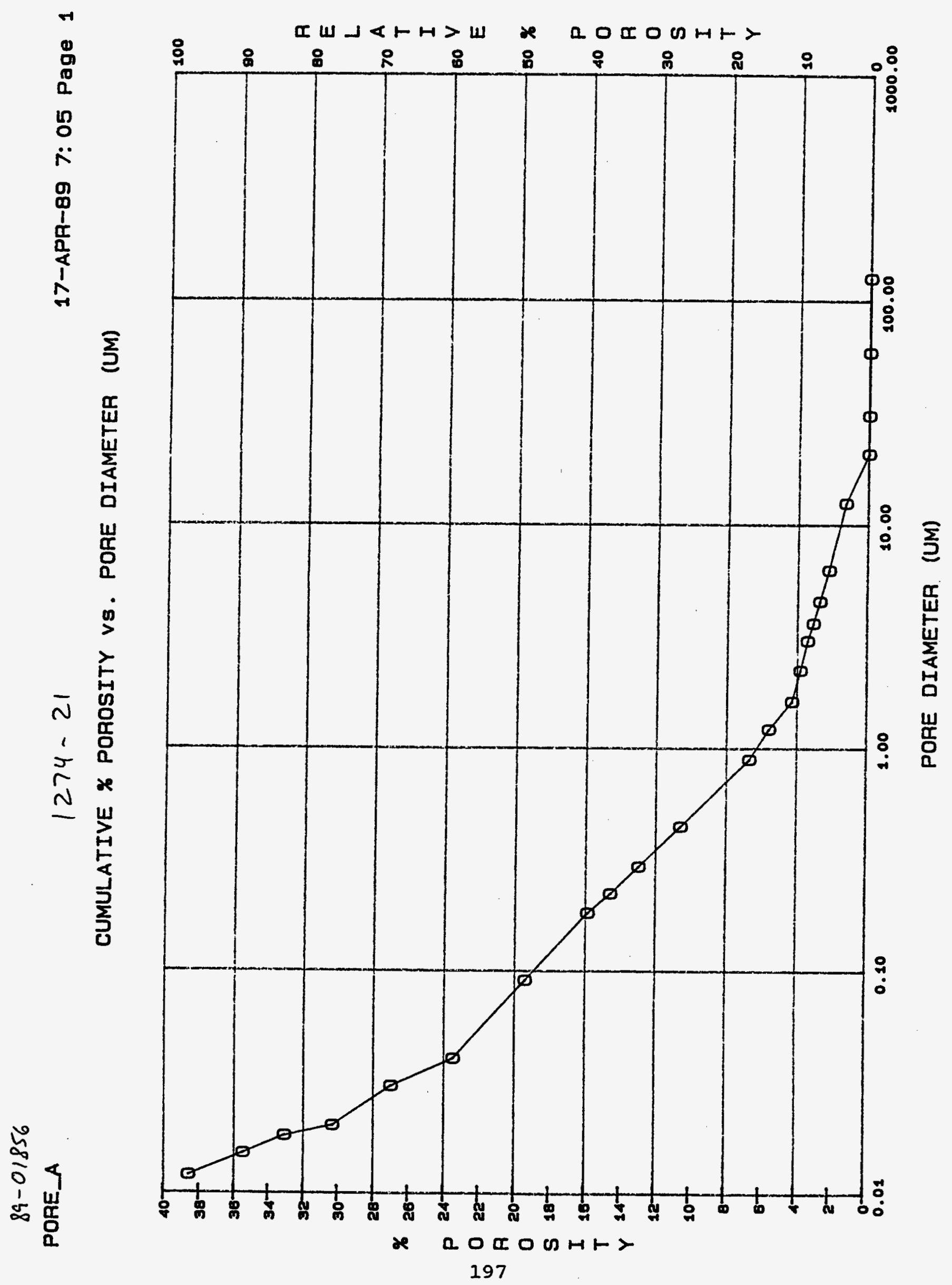




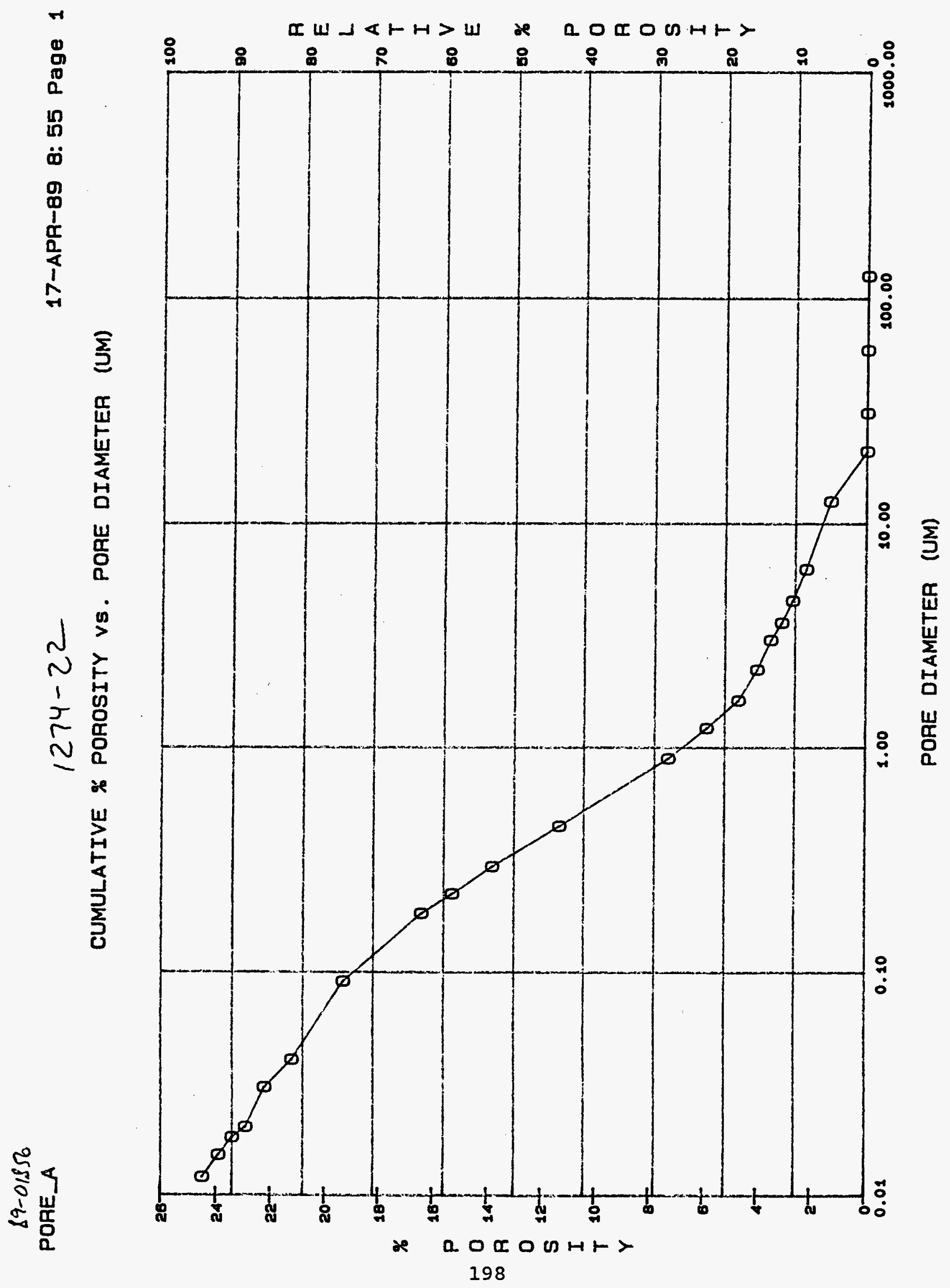




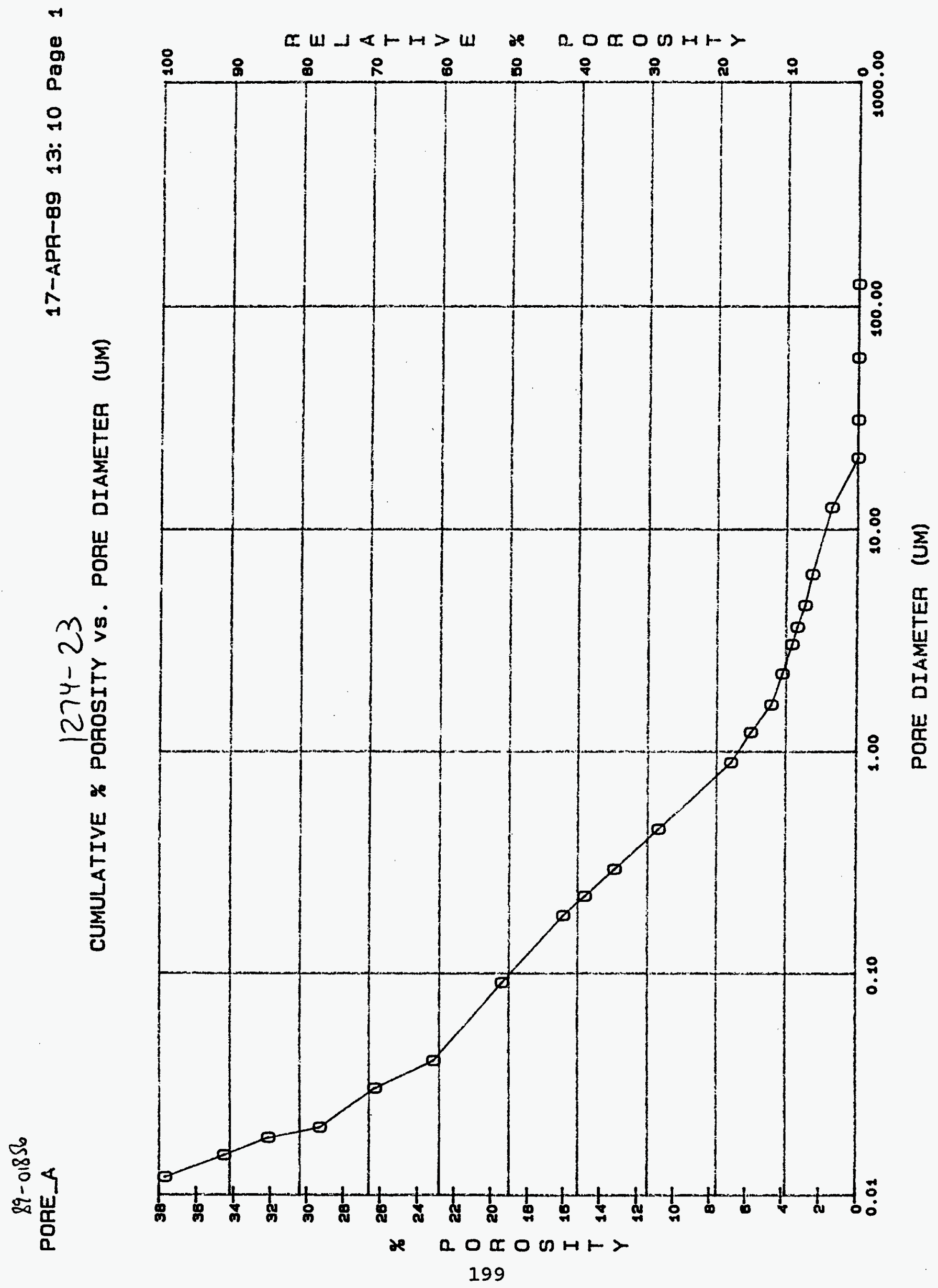


$89-018 \Omega 6$

PORE_A

$$
1274-24
$$

17-APR-B9 13: 24 Page 1

CUMULATIVE $\%$ POROSITY Vs. PORE DIAMETER (UM)

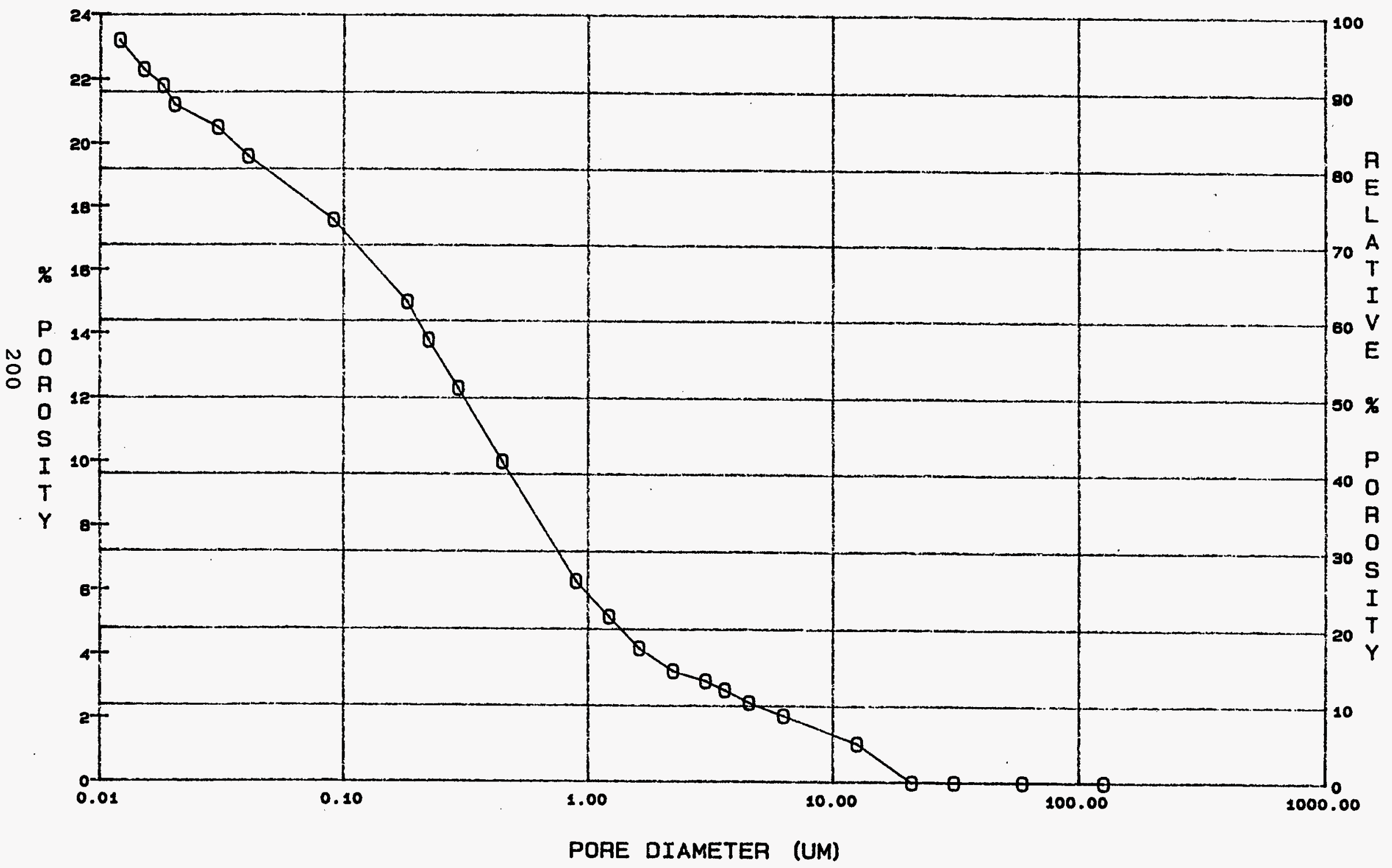




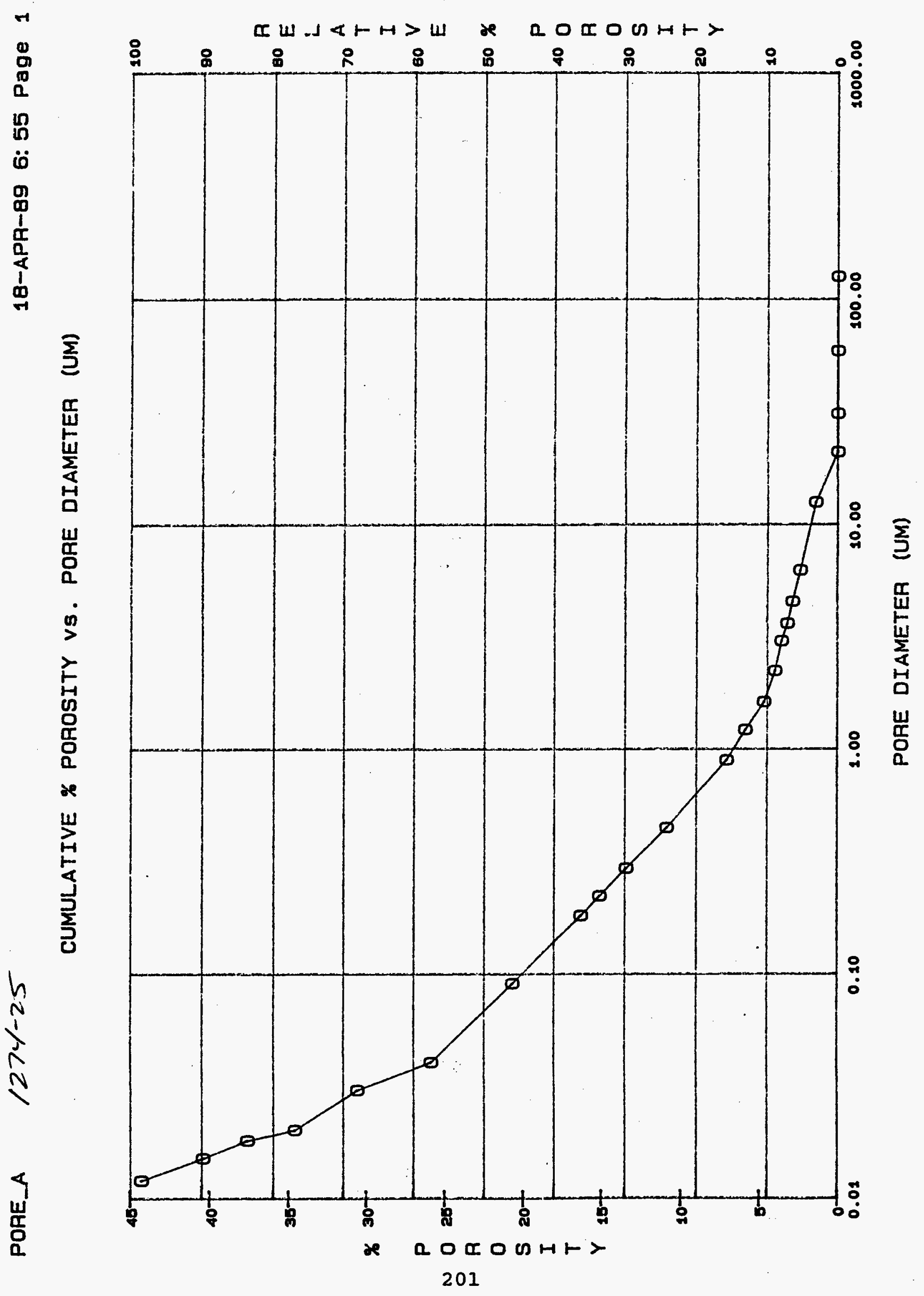




\section{M98002008

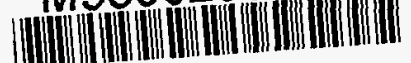

Report Number (14) DOE/MC/24268-5799

Publ. Date (11)

Sponsor Code (18)

19890802

UC Category (19)

$\frac{E E+X F}{U C-102, D O E / E R}$

